\title{
$(4)$
}

UNIVERSIDAD PERUANA DE CIENCIAS APLICADAS

FACULTAD DE ARQUITECTURA

PROGRAMA ACADÉMICO DE ARQUITECTURA

\section{HOSPITAL II EN CAMANÁ}

\author{
TESIS \\ Para optar el título profesional de: \\ Arquitecto
}

AUTOR

Uyén Gomero, Alejandra Tabata (0000-0002-5604-7030)

\begin{abstract}
ASESOR
Mercado Neumann, María Del Pilar (0000-0003-2983-1046)
\end{abstract}

Lima, 19 de Noviembre de 2018 
Dedicatoria

A la memoria de Gonzalo Uyén donde quiera que estés.. 
Agradecimientos

A Carmela de Uyén por su apoyo incondicional.

A Renzo Gallardo por su infinita paciencia. 


\section{RESUMEN}

El presente proyecto mediante una simbiosis entre la arquitectura y el paisaje natural busca conceder al usuario una estancia agradable desde la atención ambulatoria hasta la hospitalización en el Hospital II en Camaná. La integración entre la arquitectura curativa, el paisaje natural, los espacios integradores y los jardines terapéuticos se logra mediante la aplicación de ciertos patrones arquitectónicos estudiados que ayudan al bienestar del usuario tales como el color, texturas, luz y la conexión directa en indirecta con el paisaje antes mencionado, logrando una cercanía con la realidad, produciendo el efecto inside out estar dentro del hospital pero teniendo la sensación de estar en el exterior. Por otro lado el proyecto muestra énfasis en los espacios de reunión entre; el paciente y sus familiares para afianzar el vínculo familiar lo cual es vital para la mejoría emocional del paciente y por ende la recuperación de la salud.

Lo que se busca plasmar en el diseño del Hospital II en Camaná es aminorar el tiempo de permanencia en el hospital y para lograrlo se necesita de un diseño con calidad espacial que cuente con los conceptos arriba mencionados y que a su vez no interfiera en el correcto funcionamiento del nosocomio.

Hospital, Salud, Paisaje, Integración, Recuperación. 


\section{ABSTRACT}

The present Project trough a symbiosis between the architecture and the natural landscape seeks to grant the user a pleasant stay from ambulatory care to hospitalization in the Hospital II in Camaná. The integration between the curative architecture, the natural landscape, the integrating spaces and the therapeutic gardens is achieved through the application of certain studied architectural patterns tha help the user's well-being such as color, textures, natural light and direct indirect connection with the landscape mentioned above, achieving a closeness to reality, producing the effect inside out to be inside the hospital but having the feeling of being on the outside. On the other hand, the project shows an emphasis on meeting spaces between; the patient and his relatives to strengthen the family bond, wich is vital for the emotional improvement of the patient and therefor the recovery of health.

What is sought to translate into the design of Hospital II in Camaná is to reduce the time in the hospital and to achieve this, a design with spatial quality that has the above mentioned concepts and that in turn does not interfere with the correct operation of the hospital.

Hospital, Health, Landscape, Integration, Recovery 


\section{TABLA DE CONTENIDO}

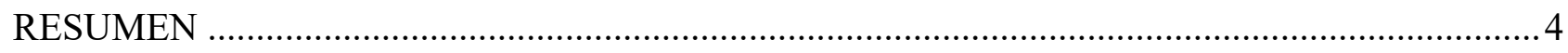

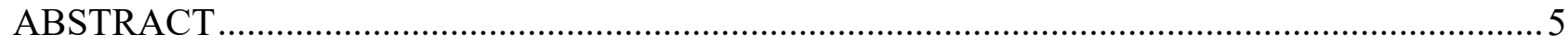

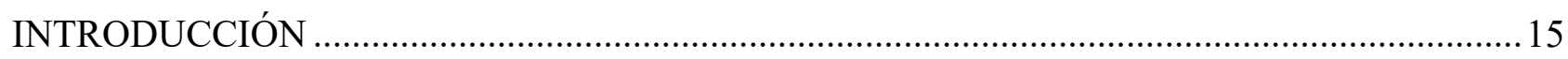

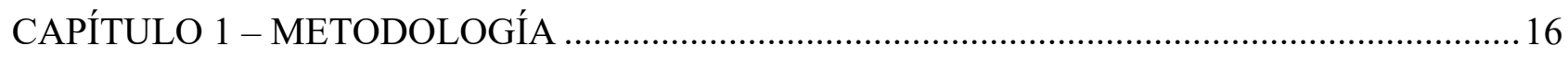

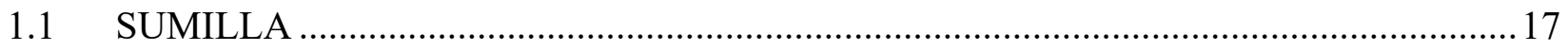

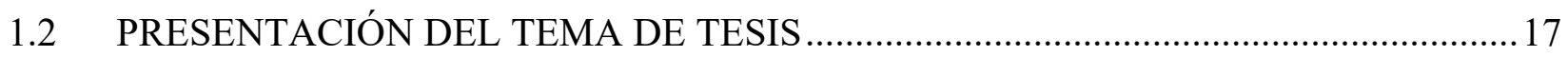

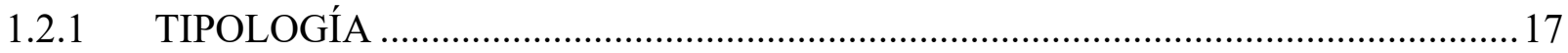

1.2.2 ÉNFASIS: INTEGRACIÓN DE LA ARQUITECTURA Y EL PAISAJE ...................18

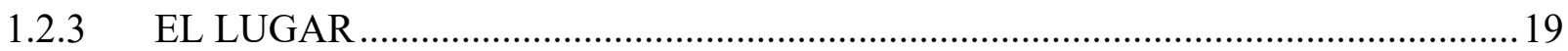

1.2.4 USUARIO

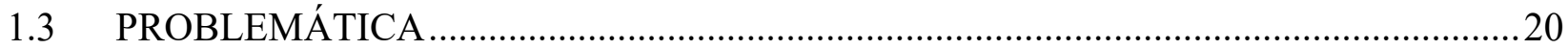

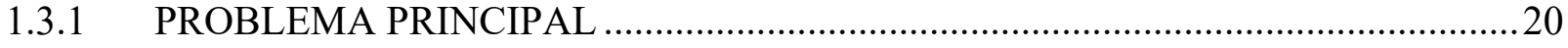

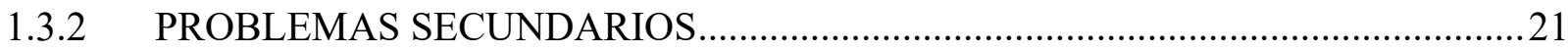

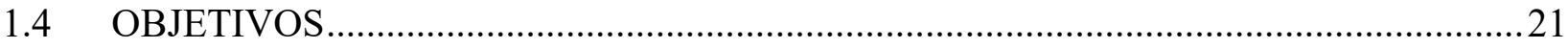

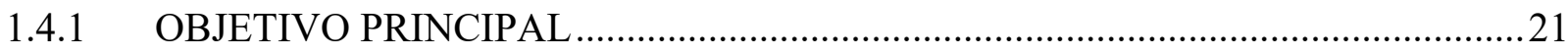

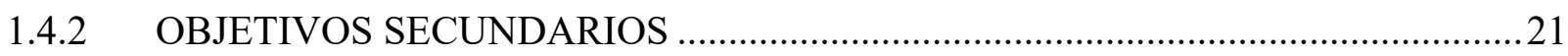

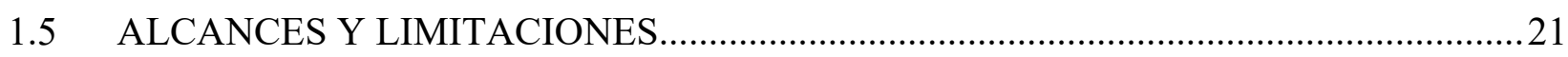

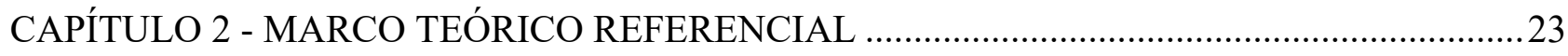

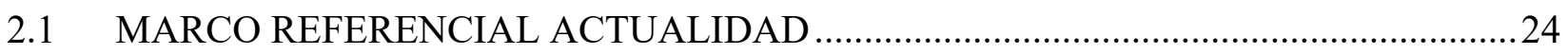

2.1.1 SITUACIÓN ACTUAL DE LA SALUD EN LA PROVINCIA DE CAMANÁ ........24

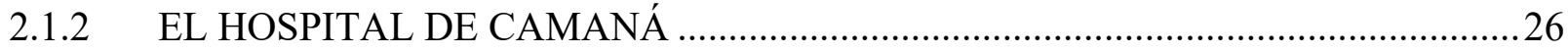

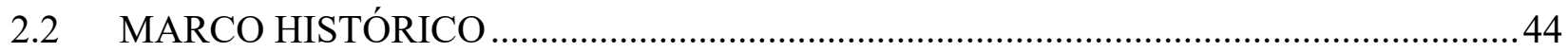

2.2.1 ARQUITECTURA HOSPITALARIA EN EL PERÚ ....................................................4

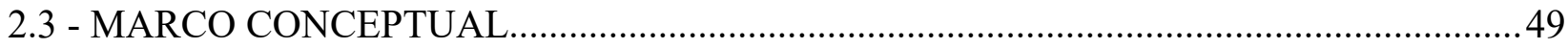

2.3.1 DEFINICIONES ………………………………............................................ 
2.3.2 CLASIFICACIÓN DE HOSPITALES .............................................................. 49

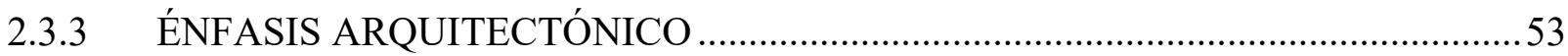

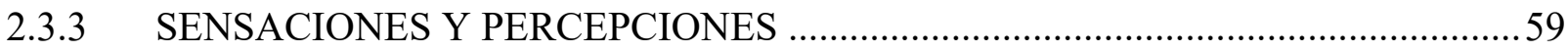

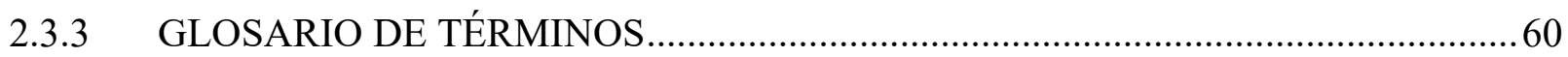

CAPÍTULO 3 ANÁLISIS DE PROYECTOS REFERENCIALES ...............................................62

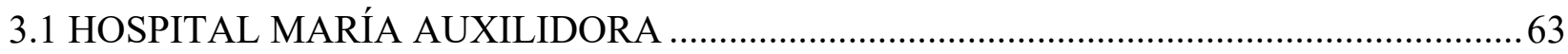

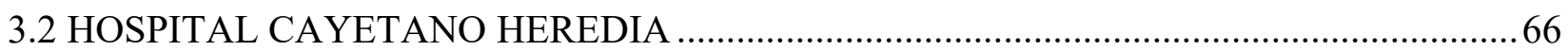

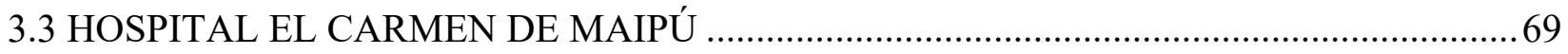

3.4 HOSPITAL CLEMENTE ÁLVAREZ ........................................................................ 72

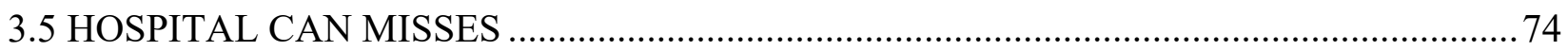

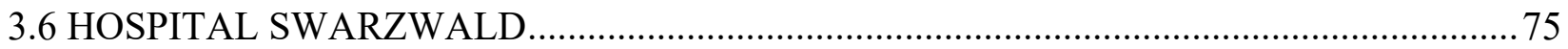

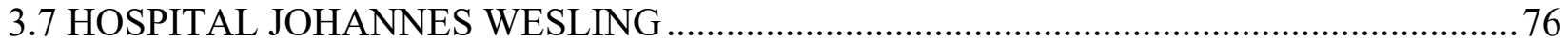

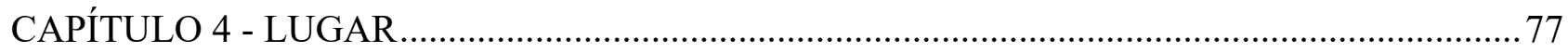

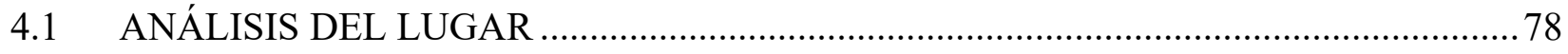

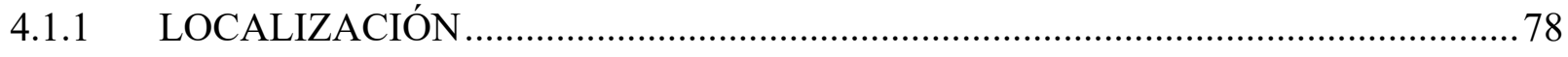

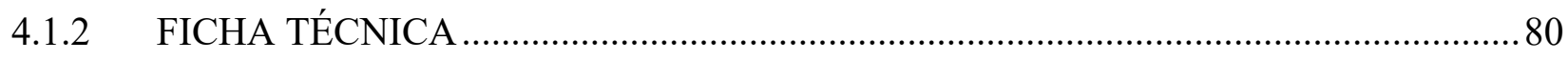

4.1.3 EVOLUCIÓN Y CRECIMIENTO DE CAMANÁ ...................................................81

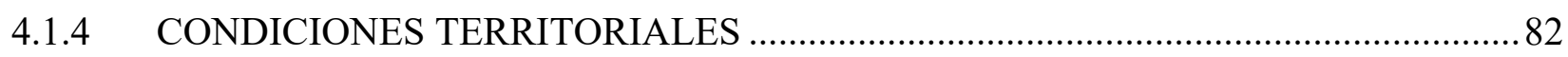

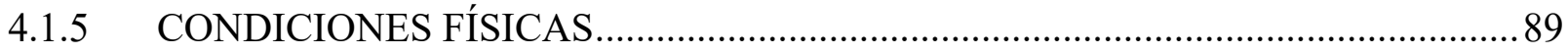

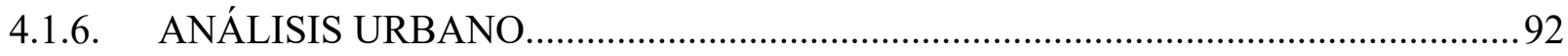

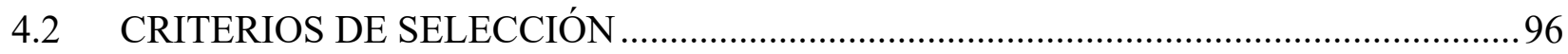

4.2.1 RELACIONADO A LA DISPONIBILIDAD DE SERVICIOS BÁSICOS ..............96

4.2.2 RELACIONADO A LA LOCALIZACIÓN ACCESIBILIDAD ................................96

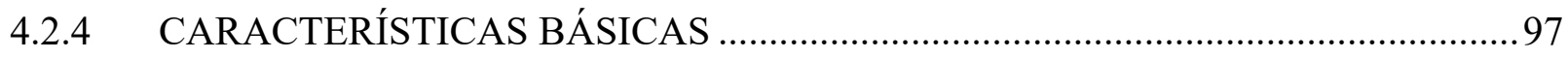

4.2.5 DISPONIBILIDAD DE LAS ÁREAS DE TERRENO ...........................................97

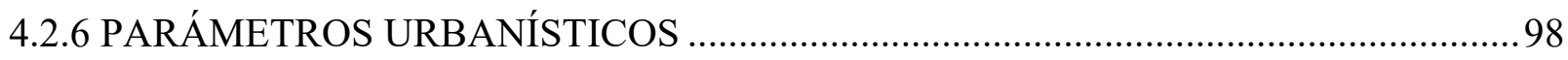




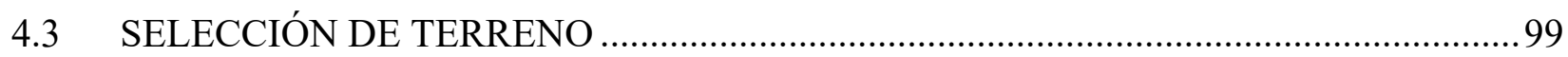

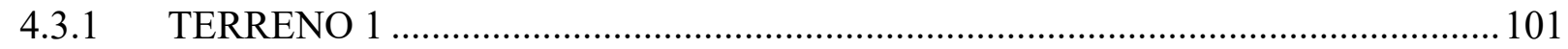

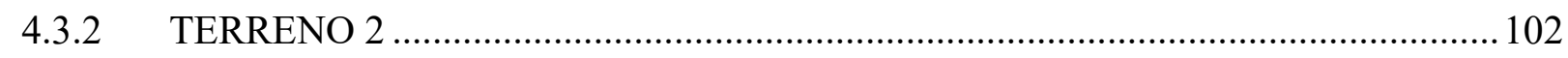

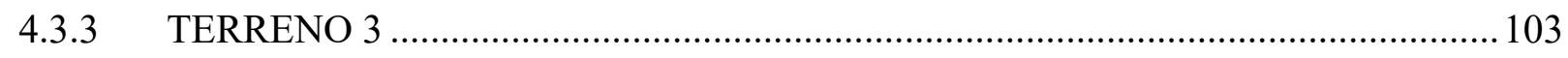

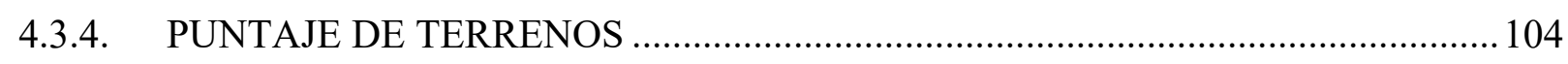

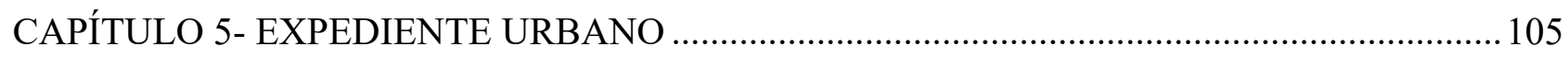

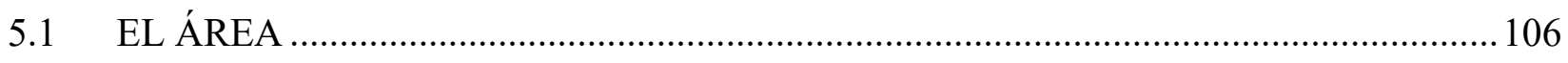

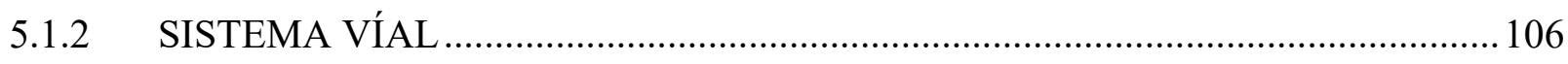

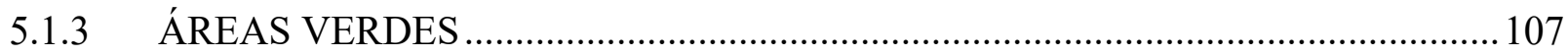

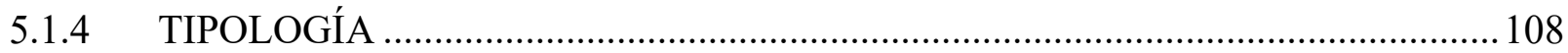

5.1.5 ZONIFICACIÓN- USO DE SUELO- ALTURAS ......................................................109

5.1.6 SENDAS-BORDES-NODOS-HITOS .................................................................. 110

5.1.8 ANEXOS NORMAS LEGALES ………………..........................................112

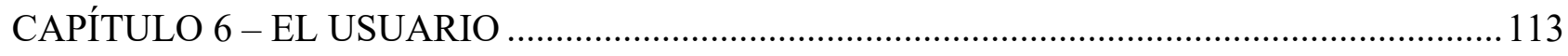

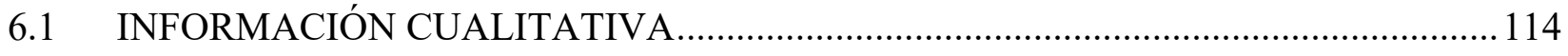

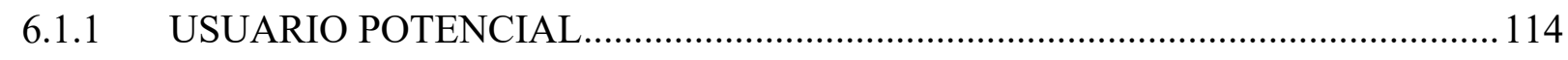

6.1.2 USUARIO DIRECTO E INDIRECTO ………………………………………..... 123

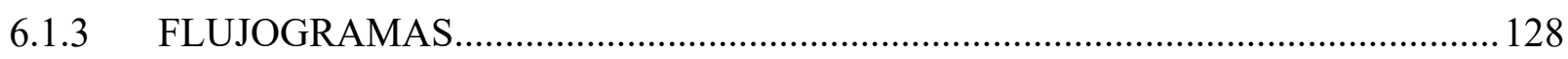

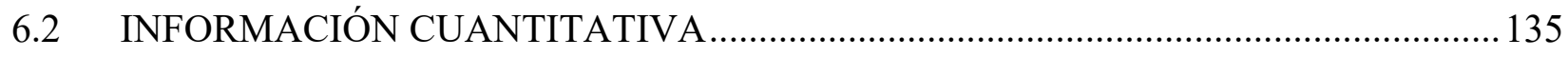

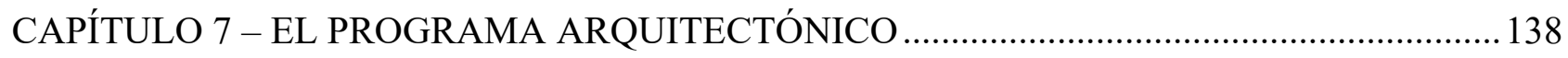

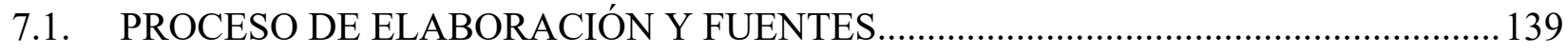

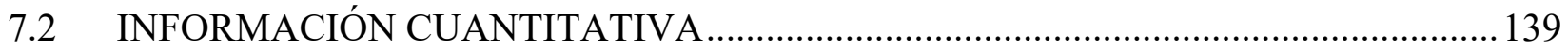

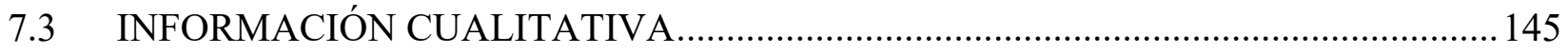

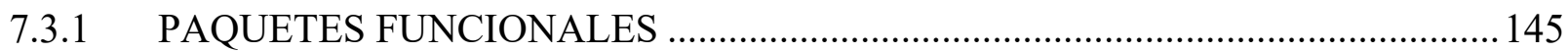

7.4 DIAGRAMAS ORGANIZACIONALES Y FUNCIONALES ……………………........149

7.4.1 ORGANIGRAMA GENERAL INSTITUCIONAL .................................................. 149 


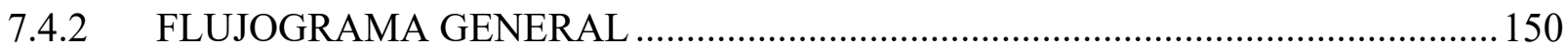

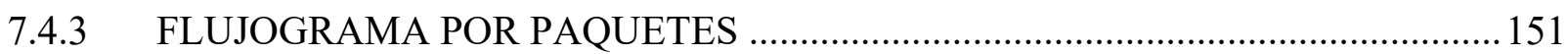

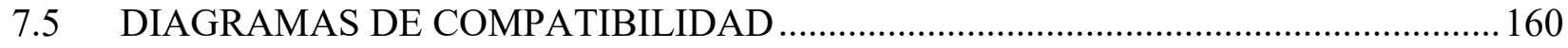

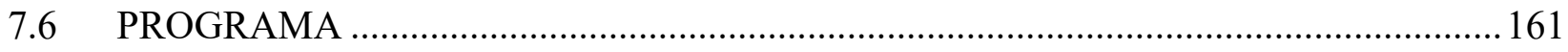

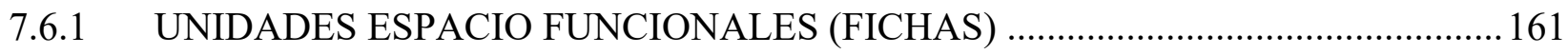

7.6.2 COMPARATIVO DE PROGRAMA ARQUITECTÓNICO...........................................166

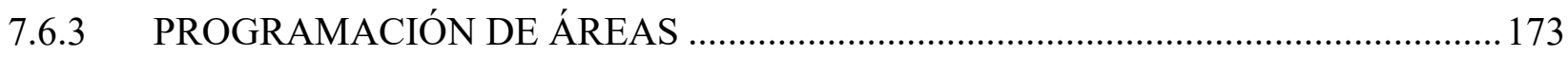

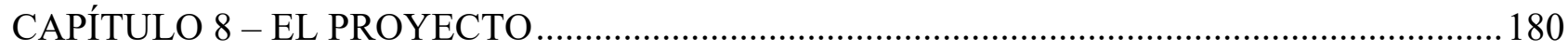

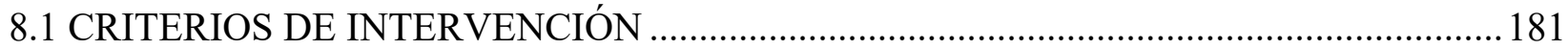

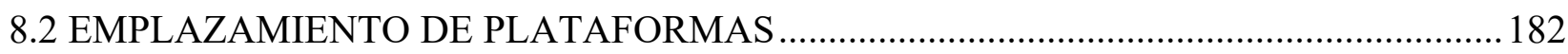

8.3 EMPLAZAMIENTO DE PAQUETES FUNCIONALES …………………………............. 183

8.4 CIRCULACIONES HORIZONTALES Y VERTICALES …………………………........... 185

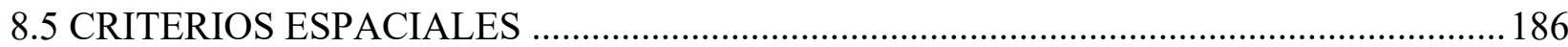

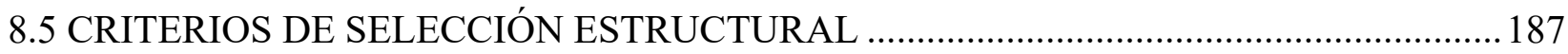

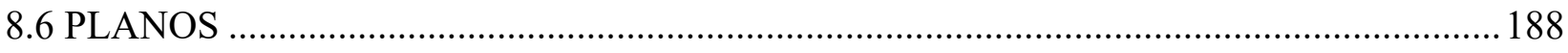

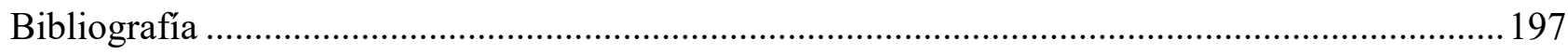




\section{ÍNDICE DE TABLAS}

Tabla 1: Organigrama de la Red de Salud de Camaná ...............................................................24

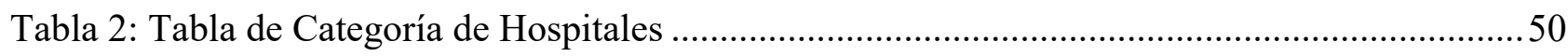

Tabla 3: Tabla de profesionales de un Hospital ........................................................................ 51

Tabla 4: Cuadro comparativo de las UPS según las diferentes categorías. ....................................52

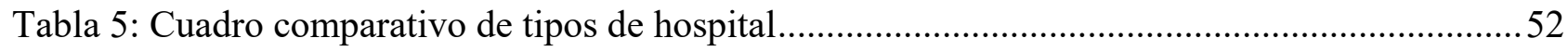

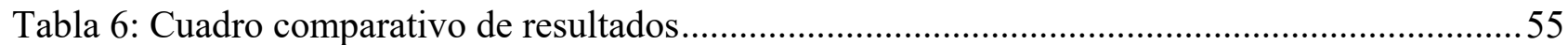

Tabla 7: Tabla de recomendaciones para el aumento de la seguridad ..........................................56

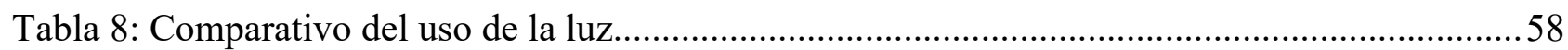

Tabla 9: Cuadro comparativo de Población en Arequipa ............................................................ 114

Tabla 10: cuadro comparativo de tasa de crecimiento poblacional ............................................ 114

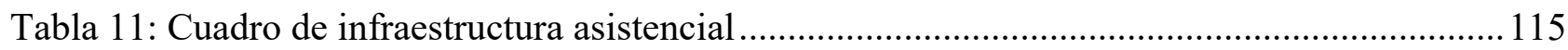

Tabla 12: Tabla de atendidos y atenciones del 01 de enero al 31 de marzo del 2015 ................... 116

Tabla 13: Tabla de número de trabajadores en la Red de Salud 2015 ........................................... 116

Tabla 14: Tabla de profesionales de la salud en el hospital de Camaná 2015 ...............................116

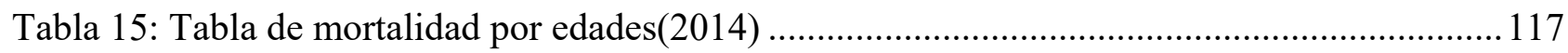

Tabla 16: Tabla de causas principales de mortalidad ..................................................................... 118

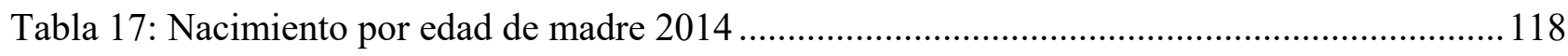

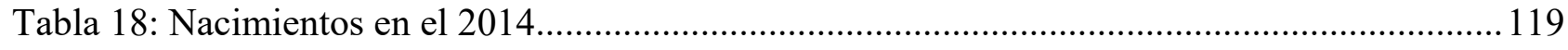

Tabla 19:Indice de desarrollo Humano según provincias 2007 .................................................... 120

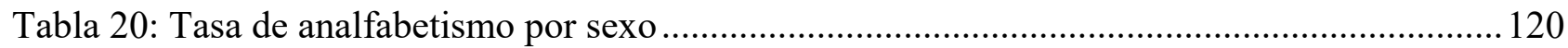

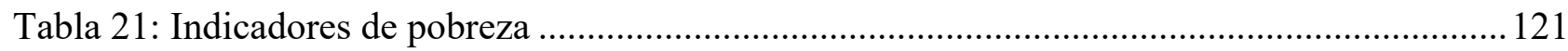

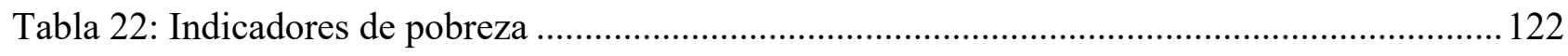

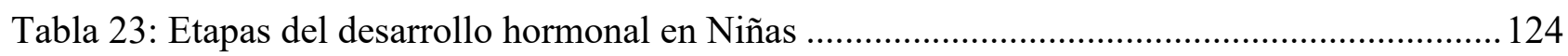

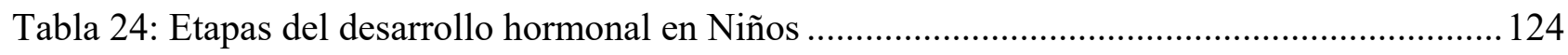

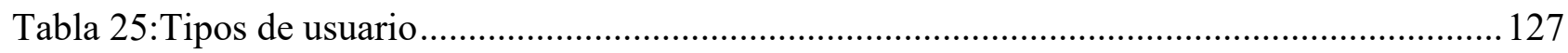

Tabla 26: Cuadro de relación de nro de atendidos en tres hospitales .............................................. 135

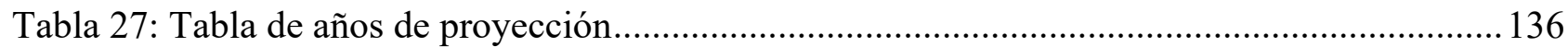

Tabla 28: cuadro de grupo ocupacional en comparativo con tres Hospitales ................................. 137

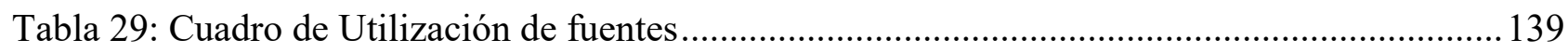

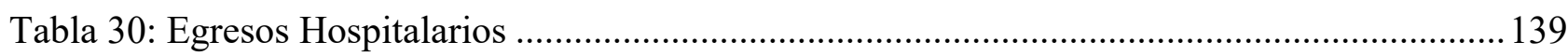


Tabla 31: Proyecciones de atenciones y atendidos; Consultas al año; Horas médicos, Nro de camas 140

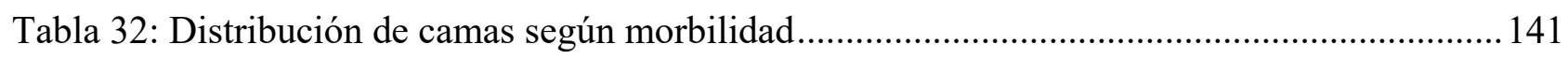

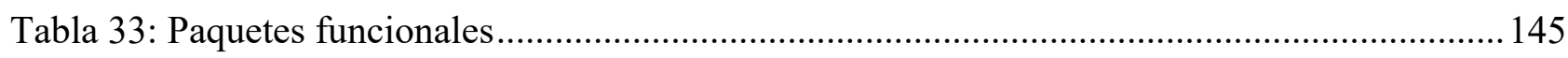

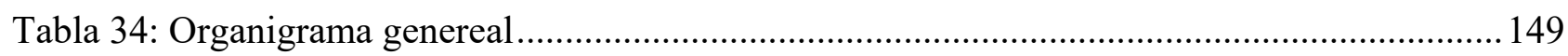

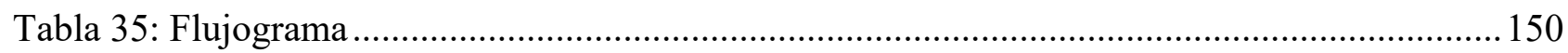

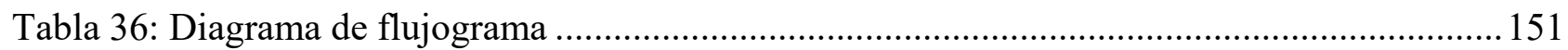

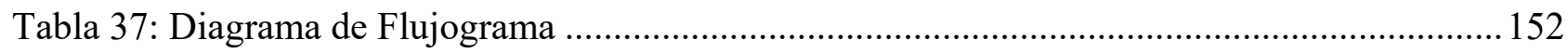

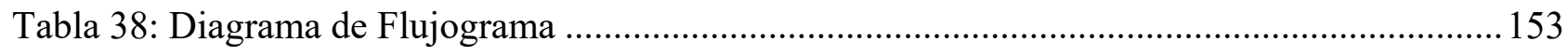

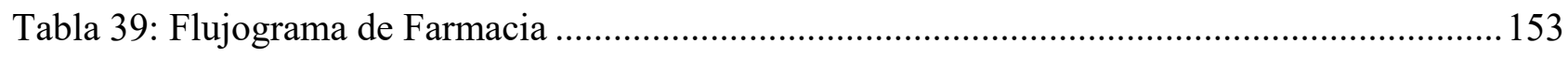

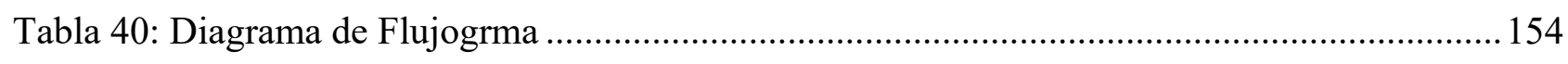

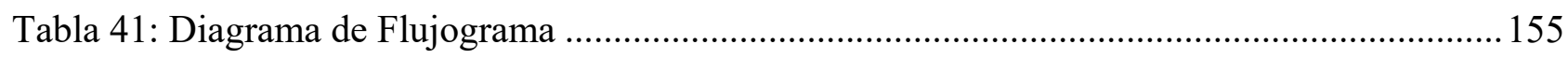

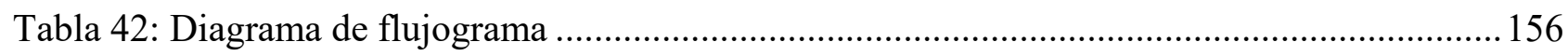

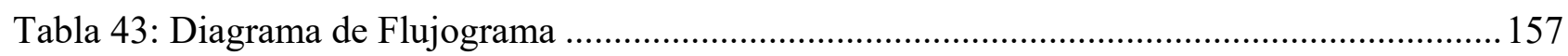

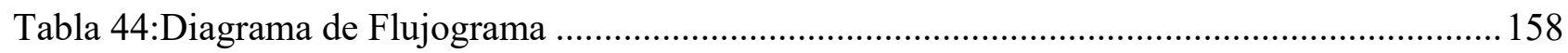

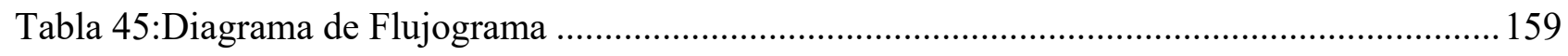

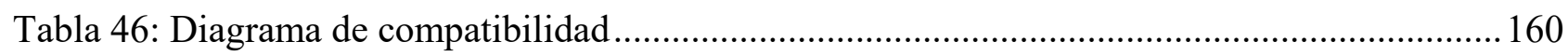




\section{ÍNDICE DE FIGURAS}

Figura 1: Ubicación de los Hospitales del Departamento de Arequipa .......................................20

Figura 2: Mapa del Departamento de Arequipa..........................................................................27

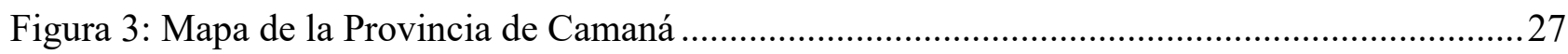

Figura 4: Mapa de Zonificación de la Provincia de Camaná............................................................22

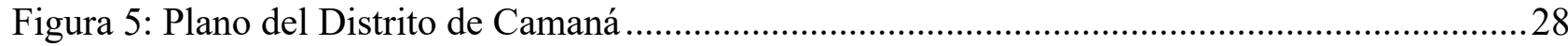

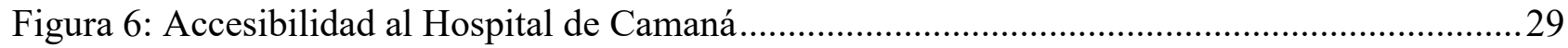

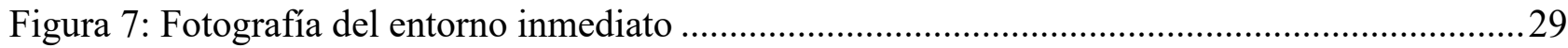

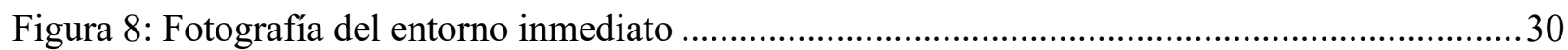

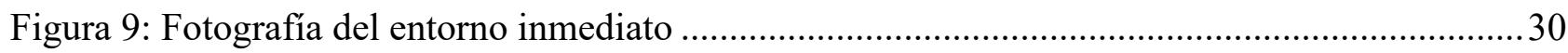

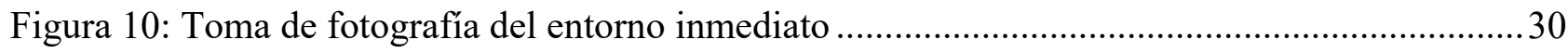

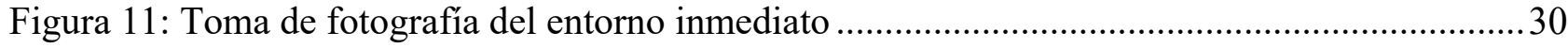

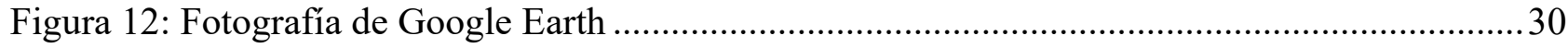

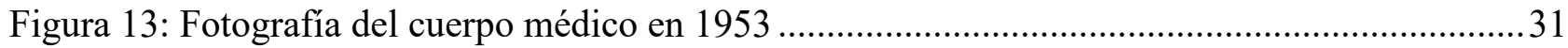

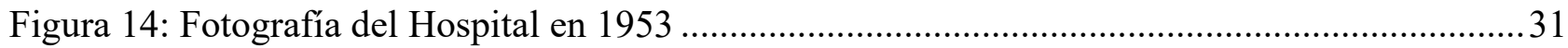

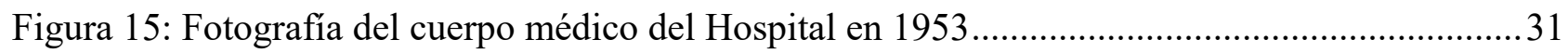

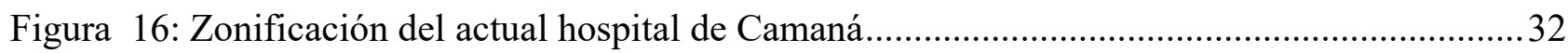

Figura 17: Vista de la Zonificación del Hospital de Apoyo ........................................................ 32

Figura 18: Zonificación del Hospital de Apoyo de Camaná................................................................33

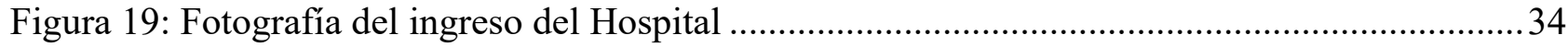

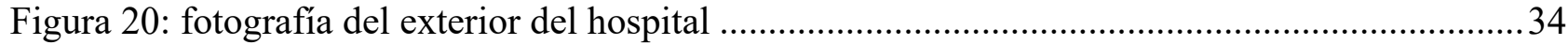

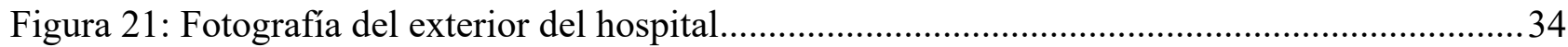

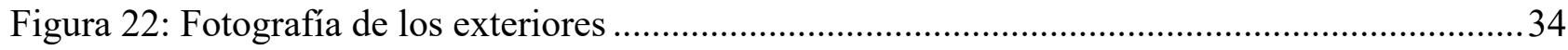

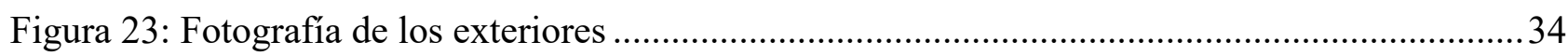

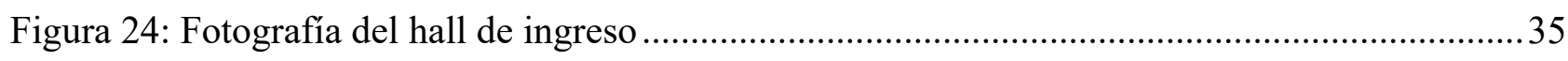

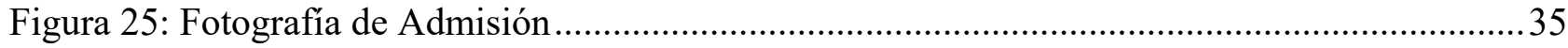

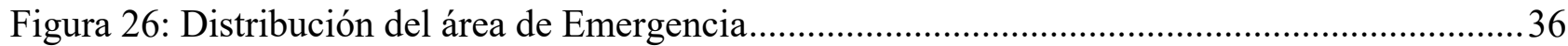

Figura 27: Fotografía del hall de ingreso a Emergencia.................................................................. 36

Figura 28: Fotografía de hall de ingreso de Emergencia y consulta externa ..................................37

Figura 29: Fotografía de caja y Triaje de Emergencia.................................................................... 37

Figura 30: Fotografía de la Farmacia del Hospital ........................................................................... 38

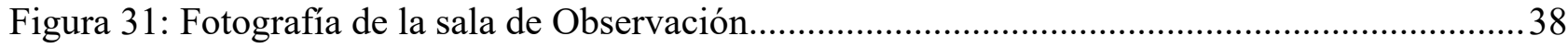




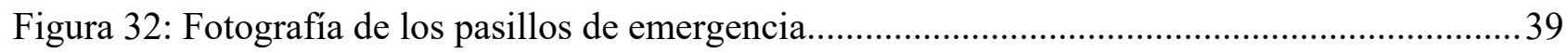

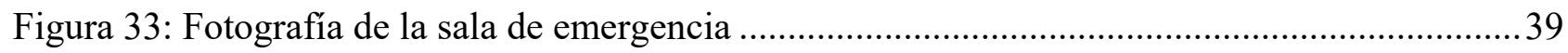

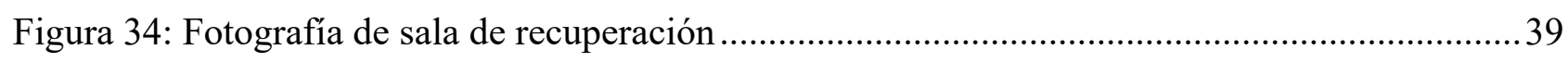

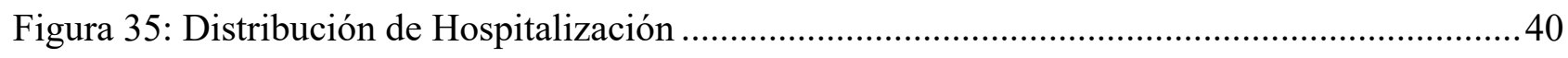

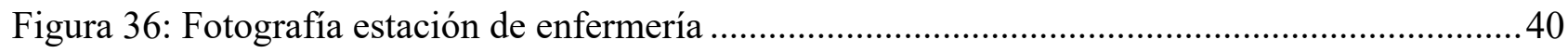

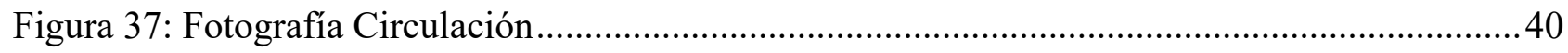

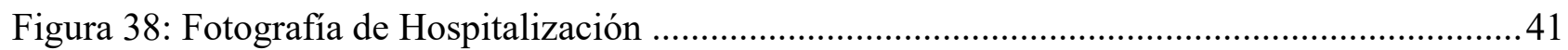

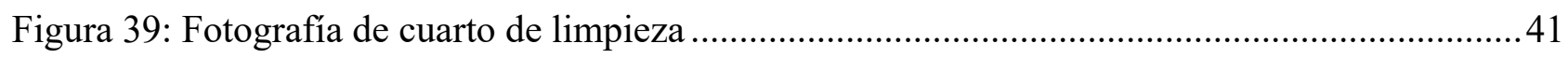

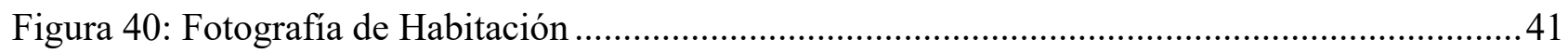

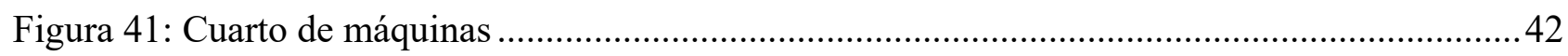

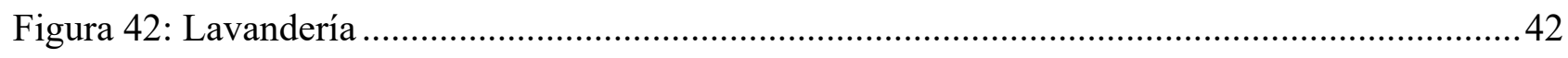

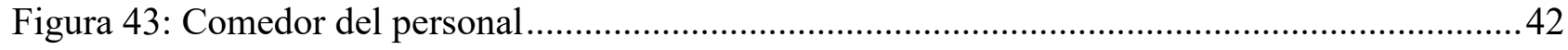

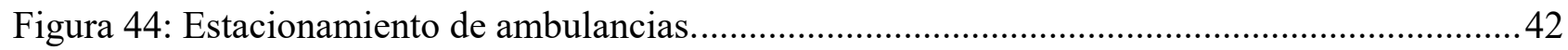

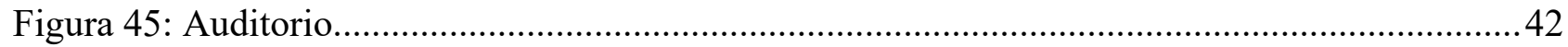

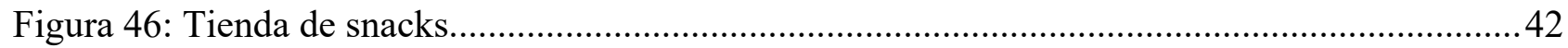

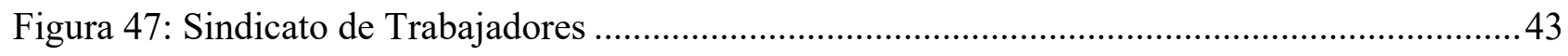

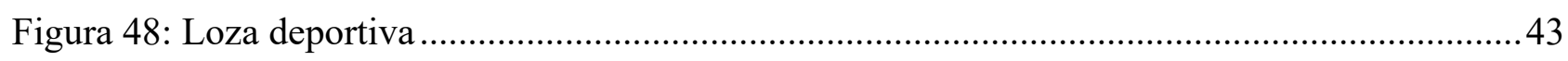

Figura 49: Bosquejo del Hospital Real de San Andrés ............................................................. 44

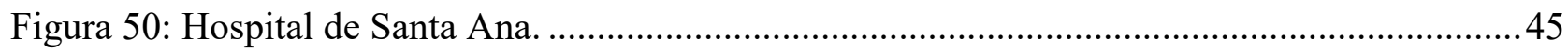

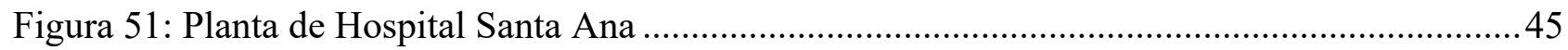

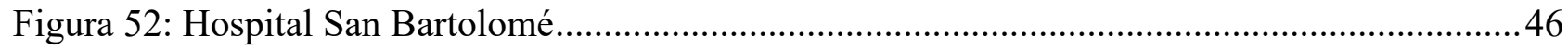

Figura 53: Planta y Fotografía del Hospital Arzobispo Loayza.....................................................46

Figura 54: Planta Hospital Dos de Mayo ............................................................................ 47

Figura 55: Fotografia Hospital Edgardo Rebagliati 1958 .......................................................... 47

Figura 56: Ejemplo de integración de la Arquitectura y el paisaje Hospital John Klinikum Minden

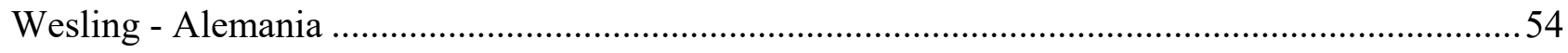

Figura 57: lámina de análisis del hospital María Auxiliadora en Lima .......................................63

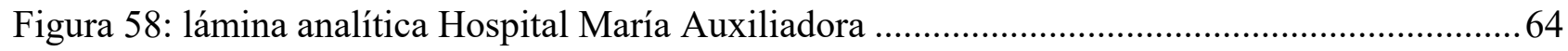

Figura 59: Lámina analítica Hospital María Auxiliadora ..........................................................65

Figura 60: Lámina analítica Hospital Cayetano Heredia ........................................................... 66

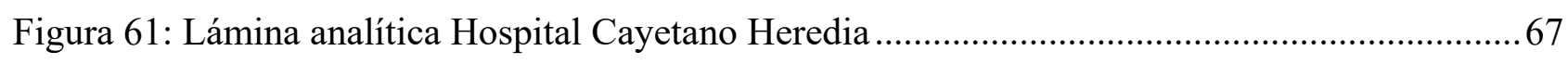

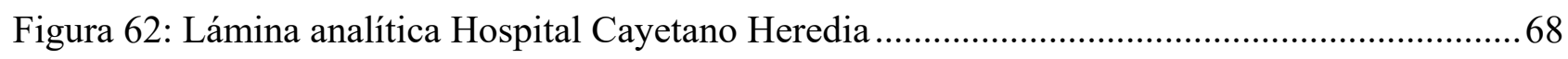


Figura 63: Lámina analítica Hospital El Carmen de Maipú ............................................................69

Figura 64: Lámina analítica Hospital El Carmen de Maipú ......................................................... 70

Figura 65: Lámina analítica Hospital El Carmen de Maipú ......................................................... 71

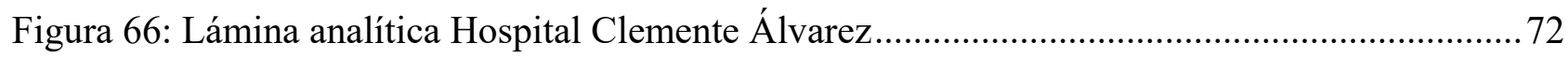

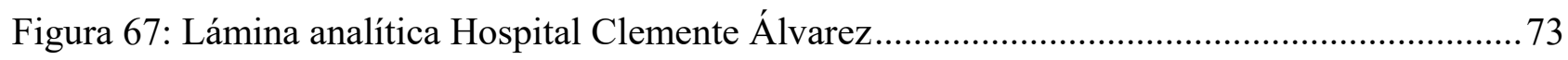

Figura 68 : Lámina analítica Hospital Can Misses ........................................................................ 74

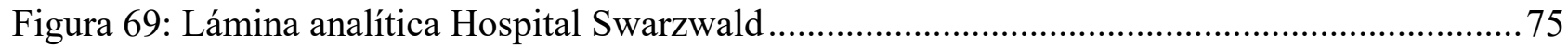

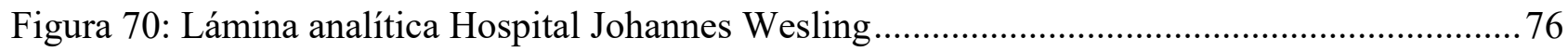

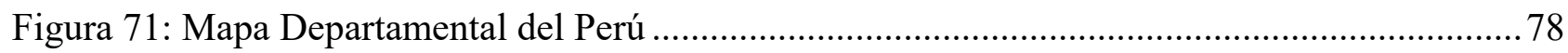

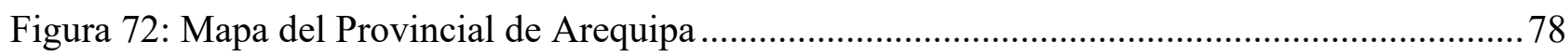

Figura 73: Mapa de Sectorización de la Red de Salud de Arequipa.............................................79

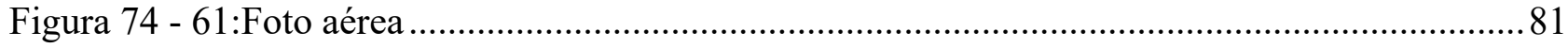

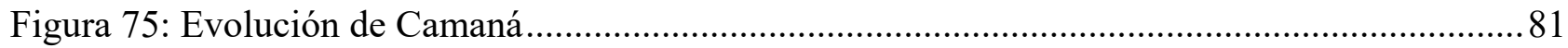

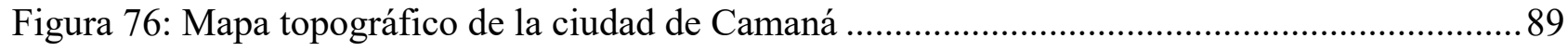

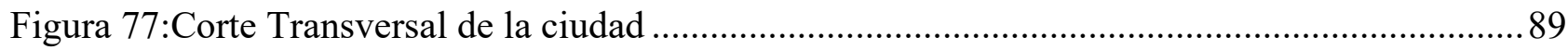

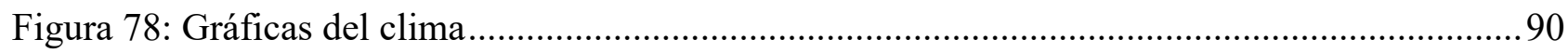

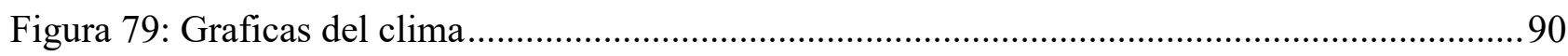

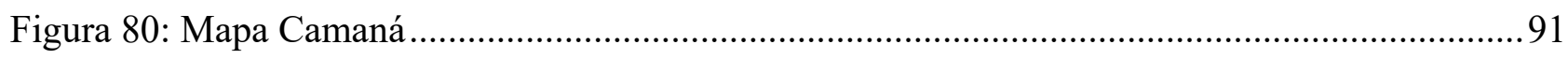

Figura 81: Mapa de recorrido solar en Camaná ..............................................................................91

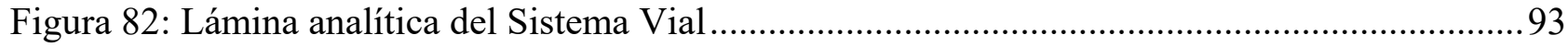

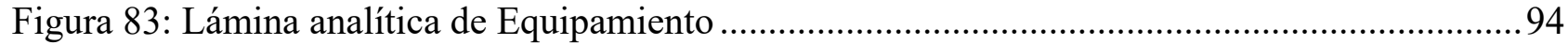

Figura 84: Lámina analítica de Áreas verdes.................................................................................95

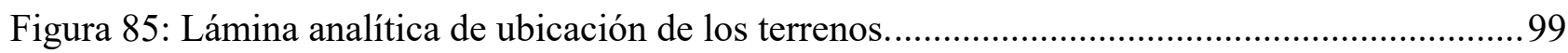

Figura 86: Lámina analítica de Equipamiento ........................................................................... 100

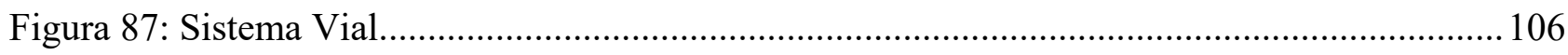

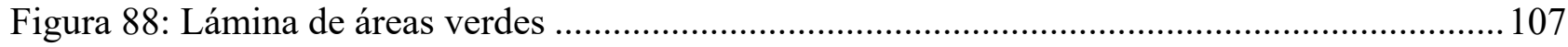

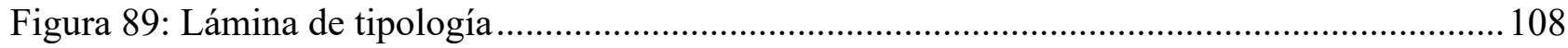

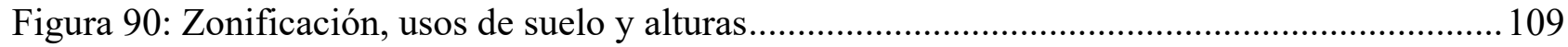

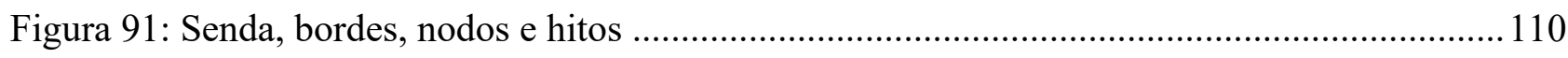

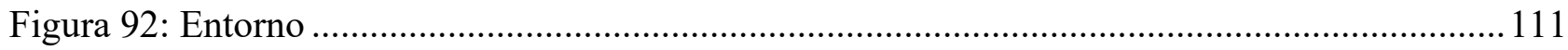




\section{INTRODUCCIÓN}

El aumento de la demanda del sector salud en el país ha ido creciendo cada año a una tasa aproximada del 18\% anual, ocasionando como consecuencia una urgencia de ampliación o construcción de nuevos establecimientos de salud, los cuales no se dan de la forma correcta sino mediante remodelaciones, o reciclaje de edificios lo cual no lleva a un óptimo funcionamiento del establecimiento ocasionando como resultado, confusión, desorden, y mala atención.

En esta tesis planteo presentar la investigación necesaria para diseñar un Hospital II de Categoría II en Camaná - Arequipa, la cual necesita de un nuevo hospital que abastezca a la población. En la actualidad el Hospital de Apoyo de la provincia de Camaná se encuentra en estado de emergencia y no abastece a la población, esto sustentado por una inspección del Estado Peruano a cargo del congresista Gustavo Rondón en enero del 2015.

La arquitectura hospitalaria en el Perú no ha evolucionado al ritmo del crecimiento de la población, dando como resultado problemas en la funcionalidad y atención. En el mundo se están creando una nueva tendencia de concepción de hospitales, en la que el enfoque principal es el confort del usuario, es decir la humanización de los espacios a través de la arquitectura y el paisaje.

La humanización de los espacios puede darse mediante la integración de la arquitectura y el paisaje, haciendo de estos los actores principales en todo el diseño arquitectónico, esta integración no sólo servirá para el confort de los usuarios, sino también para ayudar a una pronta recuperación de los pacientes y a un mejor desarrollo de actividades al staff médico, de esta manera se consigue familiarizar entre los usuarios (médico-estudiante-paciente-familiar) y hacer que la estadía sea menos estresante ya que estudios realizados por el Center Health Design que es una organización estadounidense la que se dedica a promover e investigar el diseño de establecimientos de salud "Healthcare Design" revelan que el ambiente hospitalario afecta al staff médico, los pacientes y familiares. 
CAPÍTULO 1 - METODOLOGÍA 


\subsection{SUMILLA}

El proyecto consiste en un Hospital II de categoría II que pertenece al MINSA del sector público con administración regional GERESA (Gerencia Regional de Salud de Arequipa), en la provincia de Camaná - Arequipa.

Este planteamiento tiene la finalidad de consolidar el sistema de salud en la provincia de Camaná y Caravelí, la cual se encuentra desabastecida y declarada en estado de emergencia

Mediante la propuesta arquitectónica se busca poner en confort a los usuarios (médicos- pacientes familiares- estudiantes) mediante la integración de la arquitectura y el paisaje, además de la utilización del color, la luz natural y la ventilación natural.

\subsection{PRESENTACIÓN DEL TEMA DE TESIS}

La motivación por la cual planteo como proyecto de tesis un hospital de emergencia y urgencia se basa en la necesidad que requiere la provincia de Camaná - Arequipa, mi ciudad natal, la cual tiene un hospital de apoyo que se encuentra en estado de emergencia. Además de no abastecer a la población debido a una insuficiencia de infraestructura, viéndose obligados a recurrir a consultorios externos, informales y que en muchos casos no cuentan con la salubridad que deberían tener, ocasionando como resultado una mala praxis, diagnóstico y hasta una infección en el paciente que puede causarles la muerte. En otros casos el paciente viaja hasta la ciudad de Arequipa porque el hospital no cuenta con médicos o equipos necesarios para poder atenderlo pudiendo morir en el camino debido a la emergencia de su estado.

\subsubsection{TIPOLOGÍA}

\section{Hospital}

Latín: Hospes, huésped. Casa que sirve para recoger pobres y peregrinos por tiempo limitado. "Establecimiento destinado al diagnóstico y tratamiento de enfermos donde se practican también la investigación y la enseñanza” (RAE, 2015)

"Los hospitales son un componente importante del sistema de atención de salud. Son instituciones sanitarias que disponen de personal médico y otros profesionales organizados y de instalaciones para el ingreso de pacientes, y que ofrecen servicios médicos y de enfermería y otros servicios relacionados durante las 24 horas del día, los 7 días de la semana.” (OMS, 2015) 
El hospital es una edificación que en un principio fue albergue para las personas más pobres de una determinada región, luego fue cambiando con el pasar de los años llegando a ser un edificio destinado a la salud que puede ser público o privado y que tiene como funcionalidad cuidar del bienestar médico de una población determinada. ${ }^{1}$

Según A. Plazola los hospitales se sitúan dentro de las edificaciones más complejas en cuanto a diseño y construcción, debido a los avances de la tecnología médica. El problema principal en su diseño es la organización funcional de la estructura y los espacios.

Un hospital es un establecimiento destinado al tratamiento de la salud de una determinada población, es una edificación compleja en su diseño y funcionalidad por las múltiples actividades que se realizan además de los diferentes usuarios que la ocupan, sin embargo esta debe ser clara y concisa para todo público.

\subsection{2 ÉNFASIS: INTEGRACIÓN DE LA ARQUITECTURA Y EL PAISAJE}

En este proyecto nos enfocaremos en dos temas la arquitectura y el entorno estos son importantes para la concepción del proyecto, los temas se escogieron después de haber analizado los principales problemas en la actual arquitectura hospitalaria en el Perú.

En este proyecto, se busca la calidad arquitectónica de todos los espacios del edificio desde las habitaciones hasta las oficinas de los médicos y que estos espacios sean funcionales y confortables donde no solo se ayudará a la recuperación de la salud sino también a un buen desempeño laboral. El confort de estos espacios se plasma en la integración de la arquitectura y el entorno natural por medio de la iluminación, ventilación, color, acústica, buena organización de espacios entre otros, gracias a esta integración se puede generar sensaciones que son percibidas por el usuario para estimularlos positivamente.

En síntesis el énfasis se centra en la integración de la arquitectura con el paisaje como estimulador positivo del usuario en un entorno hospitalario.

Los entornos curativos en los establecimientos de salud es un tema que se está abordando con mayor frecuencia en la arquitectura hospitalaria en el mundo, en el Perú la arquitectura hospitalaria no ha evolucionado quedándose con los problemas de tipologías que no responden a la funcionalidad de un hospital del siglo XXI, esto lo comprobaremos mediante un análisis sobre la evolución de las tipologías de hospitales.

\footnotetext{
${ }^{1}$ (Plazola Cisneros, 1995-2001)
} 
Hay estudios hechos por el Center Health Design que ratifican las mejorías de los pacientes gracias a la humanización de los espacios, que se refiere a que los ambientes sean más humanos es decir que cumplan con las medidas mínimas reglamentarias para el desplazamiento del usuario en el espacio sin tener que obstaculizar o invadir el espacio de otro. ${ }^{2}$

En el Perú existe un programa médico Arquitectónico para el diseño de hospitales seguros donde explica la importancia del confort de los espacios en un hospital, esto es un gran avance que aún se está quedando como teoría.

Según Bambarén en los últimos años, se han profundizado un gran número de cambios en el campo de la atención sanitaria creando nuevos escenarios, estos escenarios tienen como una de sus principales características la mayor participación y el empoderamiento de los ciudadanos y usuarios de los servicios, ante lo cual la gestión hospitalaria debería haber respondido ampliando sus fronteras a nuevas relaciones con la sociedad y a ser flexibles en la organización.

A pesar del crecimiento y empoderamiento poblacional los hospitales no han evolucionado en tipología y organización teniendo como consecuencia la debilitación de la relación de confianza y fidelidad de la población hacia los servicios que presta el estado. ${ }^{3}$

En conclusión el énfasis del proyecto está abocado a la arquitectura y al entorno natural relacionado con el confort del usuario.

\subsubsection{EL LUGAR}

El proyecto se desarrollará en la provincia de Camaná, Arequipa-Perú. En la actualidad existe un hospital de apoyo en la provincia de Camaná el cual atiende a 9 provincias del departamento de Arequipa este se encuentra en estado de emergencia y no abastece a toda la población, pues fue construido en el año 1953 cuando la población era de 10000 personas hoy la población asciende a más de 50000.

He considerado utilizar un terreno que está destinado al sector salud del Ministerio de Salud, por su accesibilidad y entorno inmediato.

\footnotetext{
2 "Entorno de curación” Huisman, Morales, Van Hoof y Kort 2012

3 "Programa Médico Arquitectónico para el Diseño de Hospitales Seguros" Bambarén y Alatrista 2008
} 
Figura 1: Ubicación de los Hospitales del Departamento de Arequipa

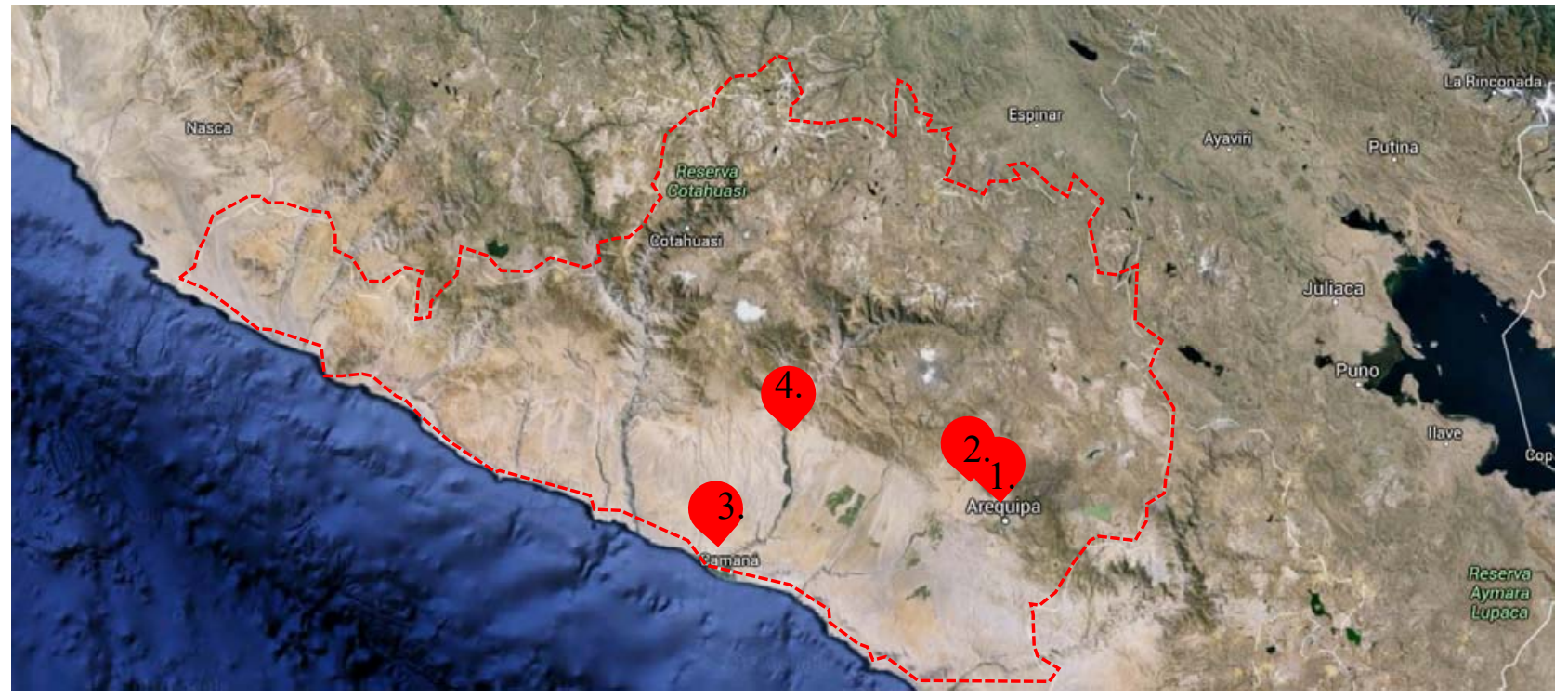

.Fuente: Google Earth. Edición propia.

1. Hospital Regional Honorio Delgado Espinoza. (120km)

2. Hospital Goyeneche. (120km)

3. Hospital de Apoyo Camaná

4. Hospital de Apoyo Aplao. (80km)

\subsubsection{USUARIO}

En un hospital hay diversidad de usuarios tales como los pacientes, médicos, enfermeros, personal administrativo, personal de servicios, y visitantes. Estos se pueden dividir en usuarios permanentes y temporales con grado de intensidad. Este tema lo desarrollaremos a fondo en el capítulo 5.

\subsection{PROBLEMÁTICA}

\subsubsection{PROBLEMA PRINCIPAL}

Los hospitales en el Perú se han quedado en el pasado, no han evolucionado arquitectónicamente, pues se han preocupado por dar soluciones a problemas puntuales como la "capacidad" o “modernización”, generando como resultado un ineficiente funcionamiento de los establecimientos. Este problema es el punto de partida para el crecimiento descontrolado de nuevos centros de salud privados desorganizados y sin ningún control o planeamiento. 


\subsubsection{PROBLEMAS SECUNDARIOS}

El actual hospital de Camaná, fue diseñado para una población de 10000 personas, hoy la población asciende a 102000 personas, con lo cual:

Hacen falta consultorios de todas las especialidades, los consultorios más cercanos están en la ciudad de Arequipa, a $120 \mathrm{~km}$ de Camaná, los consultorios actuales no cuentan con las medidas reglamentarias normadas por el MINSA.

Hacen falta espacios para los pacientes, las salas de esperan se traducen en bancas dentro de una circulación, o salas de espera compartidas entre las unidades de emergencia y consulta externa, además de espacios para los familiares, estudiantes y médicos, hacer que el hospital sea el segundo hogar.

Generar un ambiente confiable a través de la arquitectura, para atraer a la población que va a otros centros de salud (privados).

\subsection{OBJETIVOS}

\subsubsection{OBJETIVO PRINCIPAL}

La integración de la arquitectura con el paisaje de Camaná debe lograr una simbiosis que se refleje en todos los espacios del hospital sin dejar de ser funcional y confortable.

\subsubsection{OBJETIVOS SECUNDARIOS}

- Aplicar la integración de la arquitectura con el entorno paisajístico de Camaná, que logré como resultado una simbiosis entre la arquitectura y el paisaje.

- Aplicar en el diseño las recomendaciones del Center Health Design que guardan relación con los entornos curativos que generen sensaciones y percepciones que estimulen positivamente al usuario (staff médico- paciente - familiar).

\subsection{ALCANCES Y LIMITACIONES}

Se propone que el Hospital se encuentre en un punto accesible y además sea un referente para la arquitectura hospitalaria en el país, el alcance del proyecto es a nivel interprovincial, porque abastecería a 2 provincias Camaná y Caravelí. 
El programa del Hospital tendrá una unidad de apoyo a las enfermedades tropicales y brotes típicos de la zona como el mal de Chagas producido por un animal llamado Chirimacha, esta plaga se produce con mayor frecuencia en los asentamientos humanos, sin embargo cada vez que hay brote de la enfermedad se acude a una fumigación de la zona, el hospital intervendrá en charlas de prevención para evitar que este animal se reproduzca en la zona así como también cualquier otra enfermedad. 
CAPÍTULO 2 - MARCO TEÓRICO REFERENCIAL 


\subsection{MARCO REFERENCIAL ACTUALIDAD}

\subsubsection{SITUACIÓN ACTUAL DE LA SALUd EN LA PROVINCIA DE CAMANÁ}

La provincia de Camaná se encuentra en el Departamento de Arequipa al sur del Perú, el departamento de Arequipa tiene una Red de Salud llamada GERESA "Gerencia Regional de Salud Arequipa", dentro de esta Red Departamental, existen cuatro redes:

-Red de Salud Arequipa - Caylloma.

-Red de Salud Camaná - Caravelí.

-Red de Salud Castilla - Condesuyos - La Unión.

-Red de Salud Islay.

La provincia de Camaná es atendida por la Red de Salud Camaná - Caravelí la cual se organiza de

Tabla 1: Organigrama de la Red de Salud de Camaná

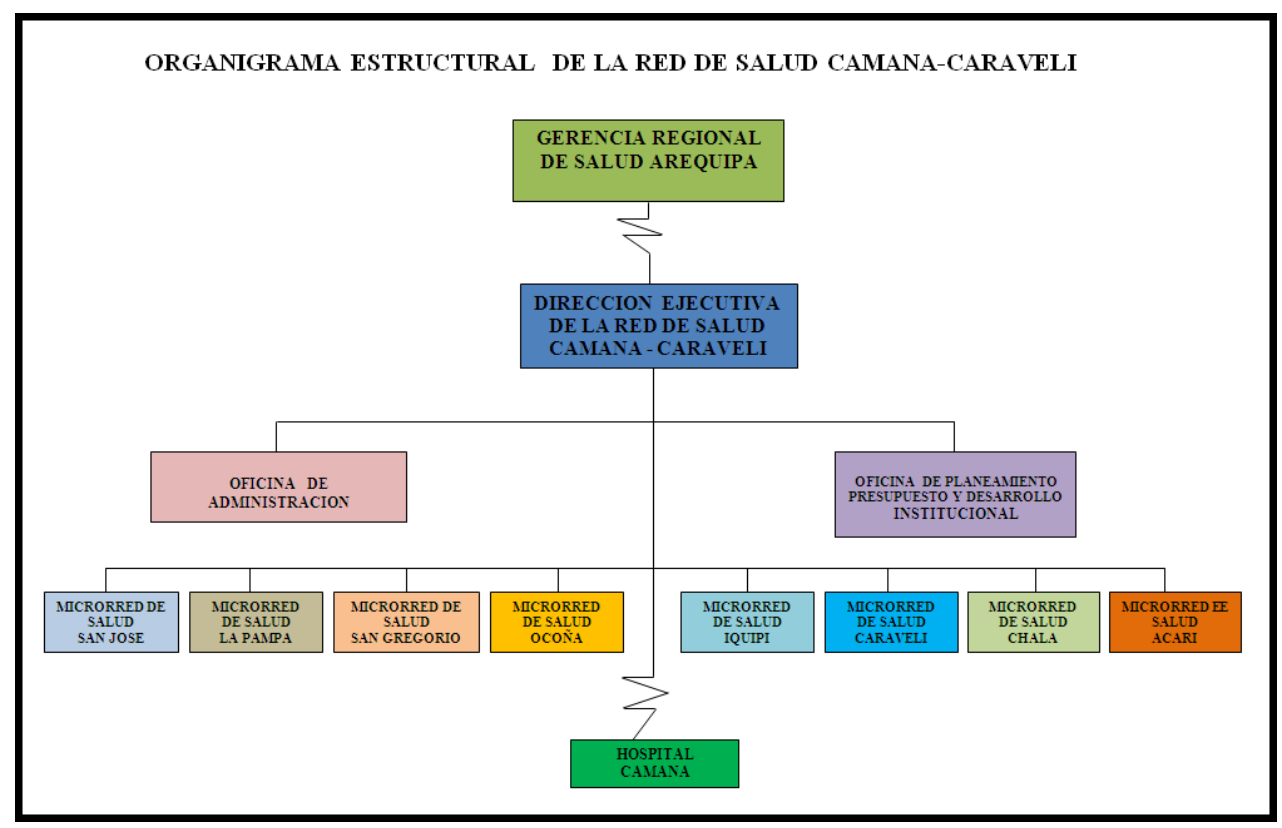

la siguiente manera:

Fuente: http://www.saludarequipa.gob.pe/camana/resena.html 
En el organigrama de la Red de Salud, el Hospital de Camaná es el único Hospital de toda la Región Camaná - Caravelí el cual tiene que abastecer a la población que el día de hoy asciende a 120 mil personas, cabe resaltar que el nosocomio fue construido en el año 1953 para la población que en ese entonces era de 10 mil personas.

Las otras 8 micro redes cuentan con centros de salud donde sólo cuentan con un médico por cada centro.

“Todo luce deteriorado al interior del hospital del Ministerio de Salud en la provincia de Camaná. Hay pacientes hospitalizados en reducidos ambientes divididos por telas, otros son atendidos en los pasillos y hay pocos médicos para tratarlos.” Extracto del Informe del congresista Gustavo Rondón Fudinaga

De las 5() plazas de médicos que debería de tener hay 7 que están sin ocupar y un último informe del 05 de septiembre del 2015 nos dice que sólo se encuentran laborando 20 médicos porque no hay profesionales que se animen a trabajar en este nosocomio. No solo los alejan las malas condiciones en que se encuentra el hospital sino también la baja remuneración económica.

El jefe de emergencia del hospital, el doctor Manuel García, explica que a diario el área de emergencia atiende un promedio de 25 pacientes graves cuando su capacidad es para 10 y en temporada de verano la demanda se duplica.

El hospital no cuenta con unidad de rayos x, laboratorio de análisis y banco de sangre.

El director del nosocomio, Ricardo Ruiz Rosas en enero del 2015, detalla que en hospitalización solo cuentan con 96 camas cuando la demanda es el doble.

La presidenta regional Yamila Osorio Delgado, natural de Camaná, prometió en su campaña electoral edificar un nuevo nosocomio en su provincia. Para ello se cuenta con un terreno de $25 \mathrm{mil}$ $\mathrm{m} 2$, en el sector de La Pampa a cinco minutos de la ciudad, este terreno ha sido donado para el Ministerio de Salud y está registrado en la sunarp con número de partida 12006764.

El congresista Gustavo Rondón Fudinaga declaró en estado de emergencia al hospital de Camaná en enero del 2015.

El 05 de septiembre de 2015 se ha dado la renuncia de cuatro médicos entre ellos del área de Medicina General, Pediatría y el Director del Nosocomio Dr. Óscar Caso del Carpio. 


\subsubsection{EL HOSPITAL DE CAMANÁ}

\subsubsection{HISTORIA}

El hospital de Camaná fue creado por causa de una epidemia de Paludismo, y por la falta de un nosocomio en la ciudad, sólo había un centro de salud llamado "Las Mercedes", el cual era sostenido por la Beneficencia pública y al tener demanda de la enfermedad antes mencionada por lo cual morían muchos ciudadanos; es así que durante el gobierno del Presidente Prado, se compra el terreno valorizado en 21,847.00 Soles y su ampliación en 54,015.20 es ahí donde funciona actualmente este añejo Hospital como primer nosocomio desde 15 de noviembre del año 1944.

Es así que se dan inicio a los trabajos de construcción en el terreno ubicado en la Av. Lima 550 y Jr. Martínez; concluyendo la obra en el año 1953; siendo inaugurada durante el Gobierno del General Manuel A. Odría un 27 de octubre del mismo año.

La Salubridad del Hospital no era la ideal; especialmente el agua, no contaba con este elemento fundamental; lo cual generaba serios problemas en Camaná, abasteciéndonos de agua de la acequia; fue creciendo la población y todo se fue agravando.

Han transcurrido 62 años y el Hospital cuenta con 230 trabajadores entre Profesionales Médicos, Enfermeras, Obstétricos, Asistentas Sociales, Nutricionistas. Odontólogos, Químicos Farmacéuticos, Técnicos en Enfermería, Administrativos y brinda servicios en especialidades como Medicina Interna, Otorrinolaringología, Oftalmología, Traumatología, Cirugía, Ginecología, Anestesiología, entre otros.

Actualmente cuenta con una capacidad de 95 camas distribuidas en los servicios de Observación, Gineco Obstetricia, Sala de Partos, Puerperio, Pediatría, Neonatología, Medicina, Neumología, Cirugía, Traumatología. Odonto - estomatología; Programas Especiales, Servicio Social, Consejería y Orientación, Planificación Familiar, Capacitación, Estadística e Informática, Personal, Logística, Administración, Economía, Bienestar de Personal, Laboratorio, Crecimiento y Desarrollo. ${ }^{4}$

\subsubsection{RED DE SALUD}

El hospital de Camaná pertenece a La Red de Salud No1 Camaná Caravelí, fué creado según Resolución Directoral Regional No 041402 CTAR/PE-DRSA/DG, con fecha 17 de Mayo del 2002, actualmente está a cargo del Dr. LELIS ENRIQUE NEYRA CASTRO, Director Ejecutivo. Esta

\footnotetext{
${ }^{4}$ http://www.saludarequipa.gob.pe/camana/resena.html 2015
} 
constituido por 8 Micro redes; Mr. Pampa, Mr. San José, Mr. San Gregorio, Mr. Ocoña, Mr. Caravelí, Mr. Chala, Mr. Acarí, Mr. Iquipi, 9 Centros de Salud y 29 Puestos de Salud.

\section{UBICACIÓN}

El hospital de apoyo de Camaná se encuentra en la provincia de Camaná, en el departamento de Arequipa,

El Hospital de Camaná se encuentra ubicado en la Av. Lima, la cual es la continuación de la Panamericana Sur.

Figura 2: Mapa del Departamento de Arequipa

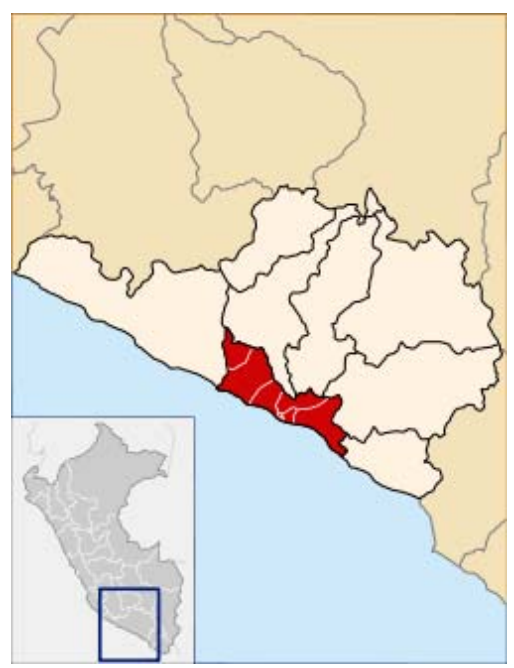

Fuente : Plan Camaná 2015 Edición propia.
Figura 3: Mapa de la Provincia de Camaná

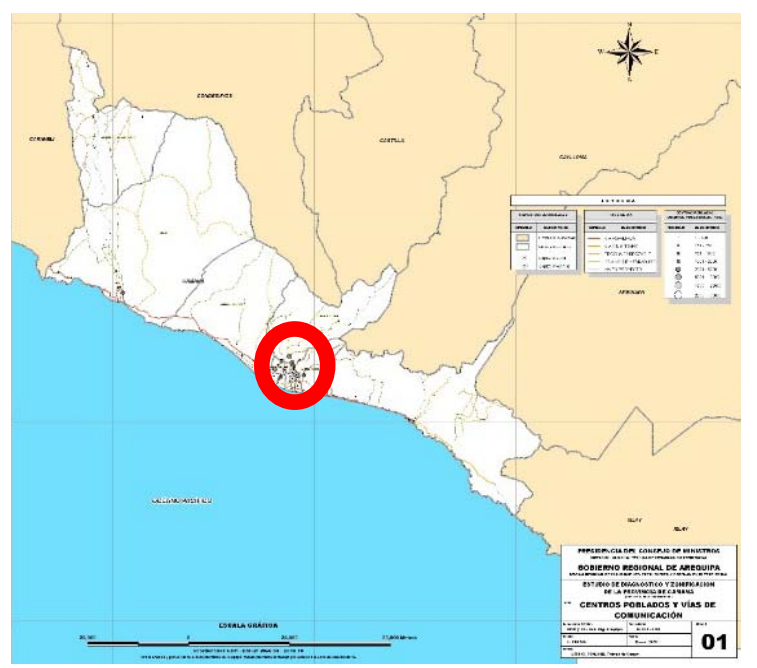

Fuente : Plan Camaná 2015 Edición propia.

Figura 4: Mapa de Zonificación de la Provincia de Camaná

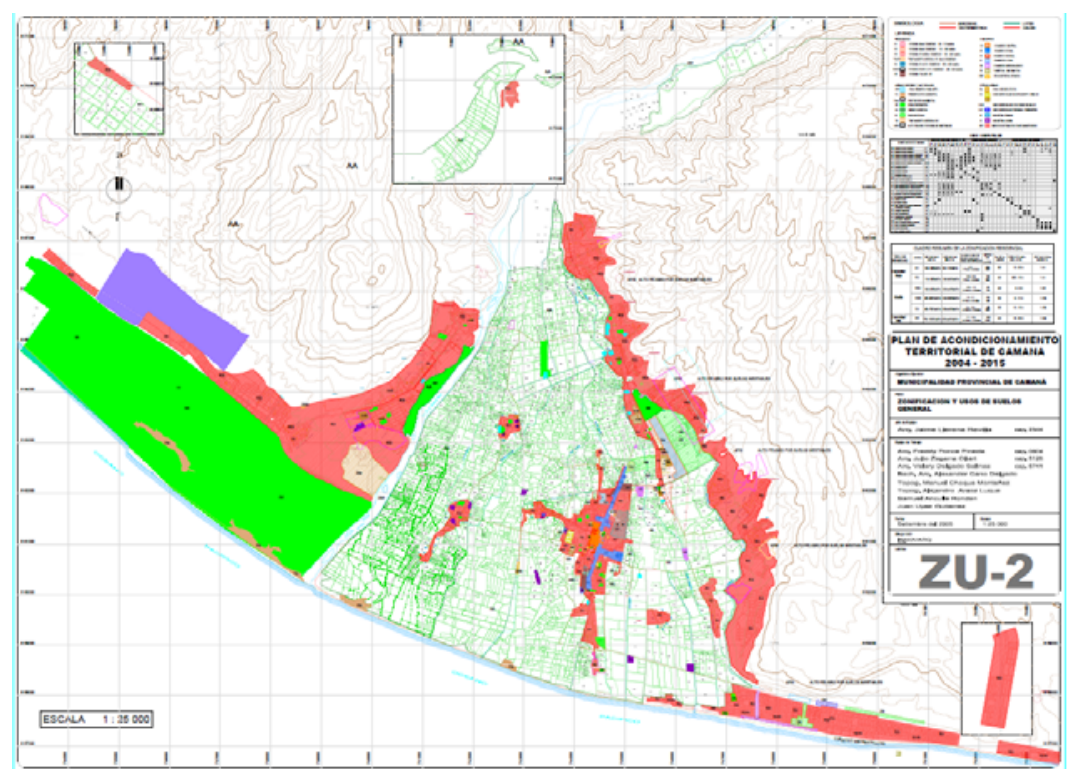

Fuente: Plan Camaná 2015 
Figura 5: Plano del Distrito de Camaná

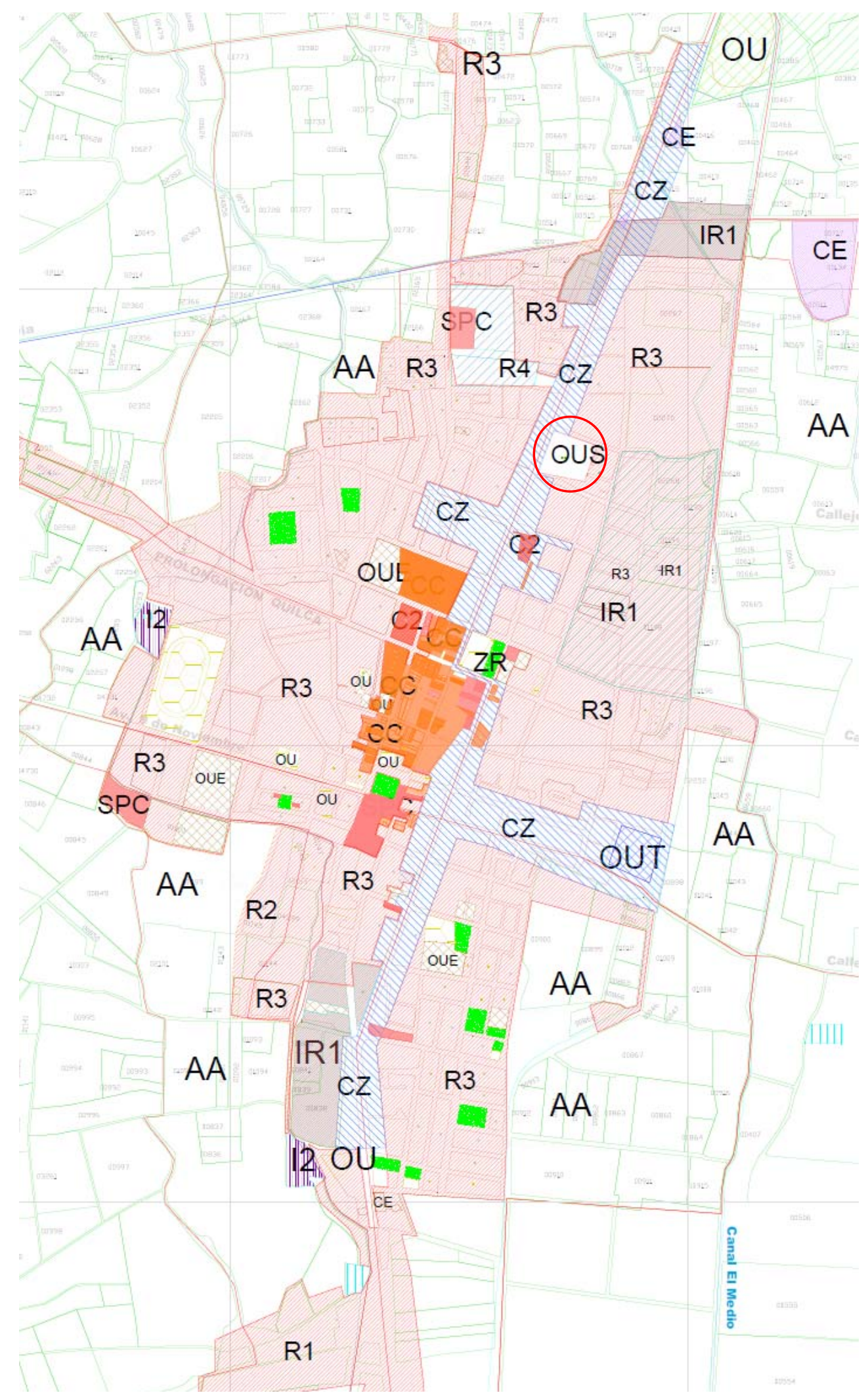

Fuente: Plan Camaná 2015 


\section{$\underline{\text { ACCESIBILIDAD }}$}

Se accede al hospital con facilidad pues se encuentra en la carretera panamericana Sur.

Figura 6: Accesibilidad al Hospital de Camaná

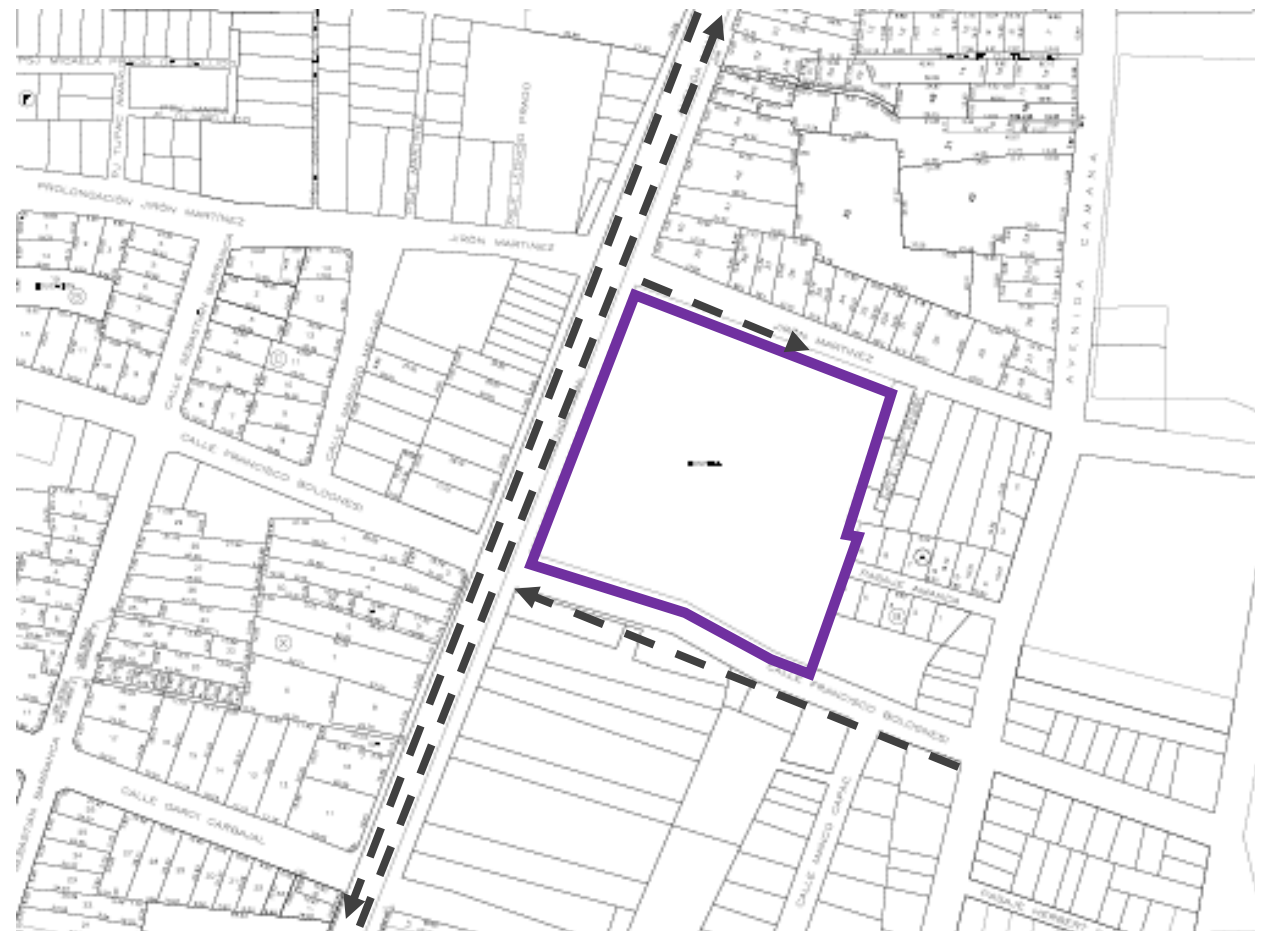

Fuente: Elaboración propia

\section{ENTORNO}

El entorno del hospital es la ciudad y los cultivos, alrededor del hospital hay comercio especializado en salud, además de consultorios, farmacias y rayos $\mathrm{x}$.

Figura 7: Fotografía del entorno inmediato

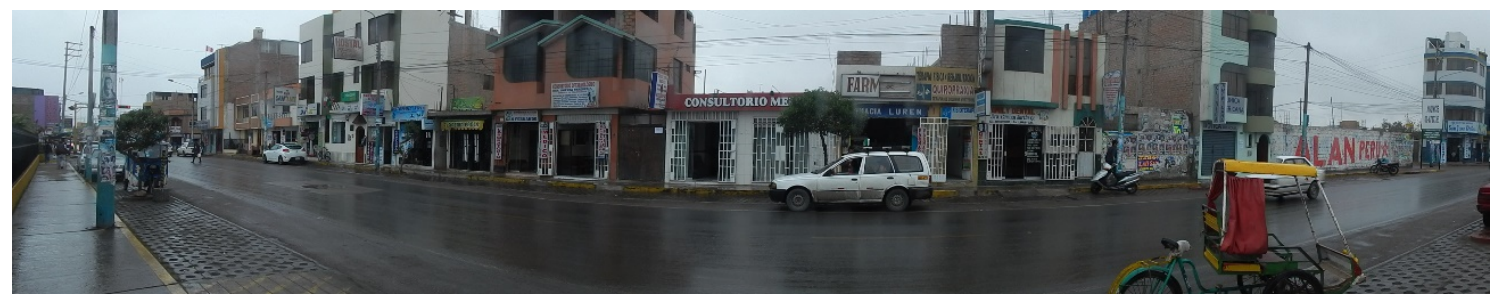

Fuente: Toma de fotografía y edición propia. 
Figura 8: Fotografía del entorno inmediato

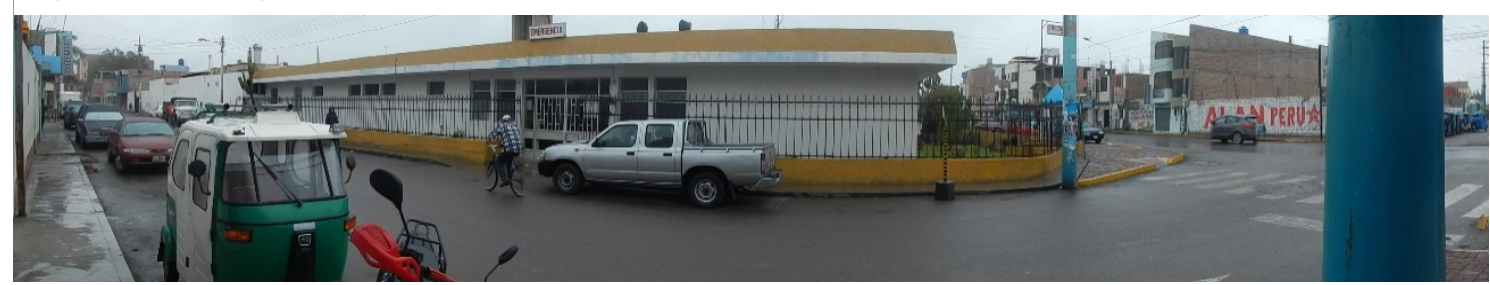

Fuente: Toma de fotografía y edición propia

Figura 9: Fotografía del entorno inmediato

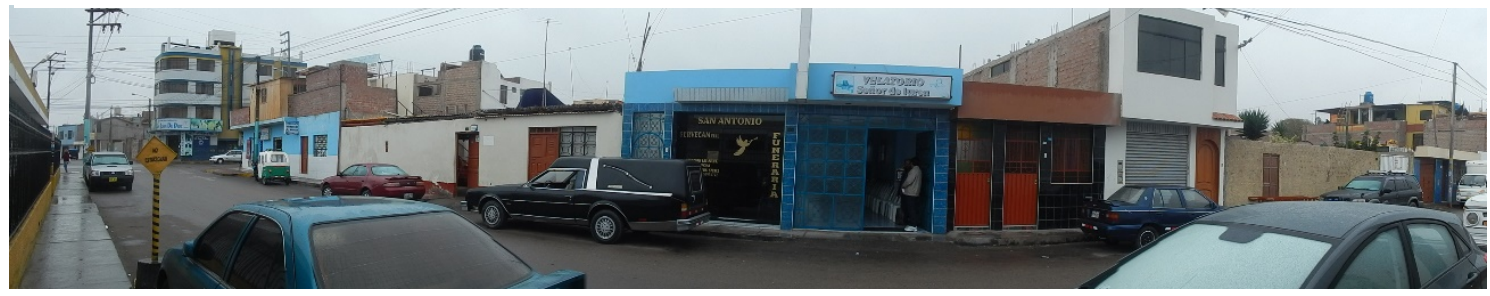

Fuente: Toma de fotografía y edición propia.

Figura 10: Toma de fotografía del entorno inmediato

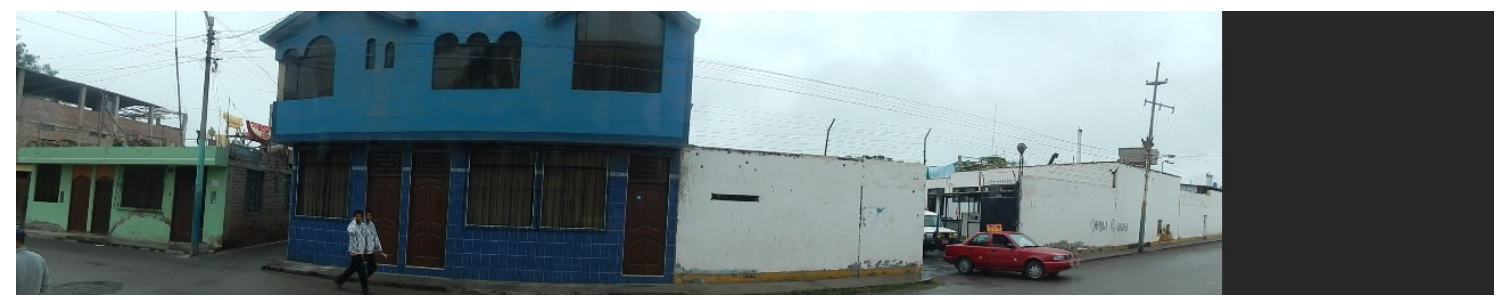

Fuente: Toma de fotografía y edición propia.

Figura 11: Toma de fotografía del entorno inmediato

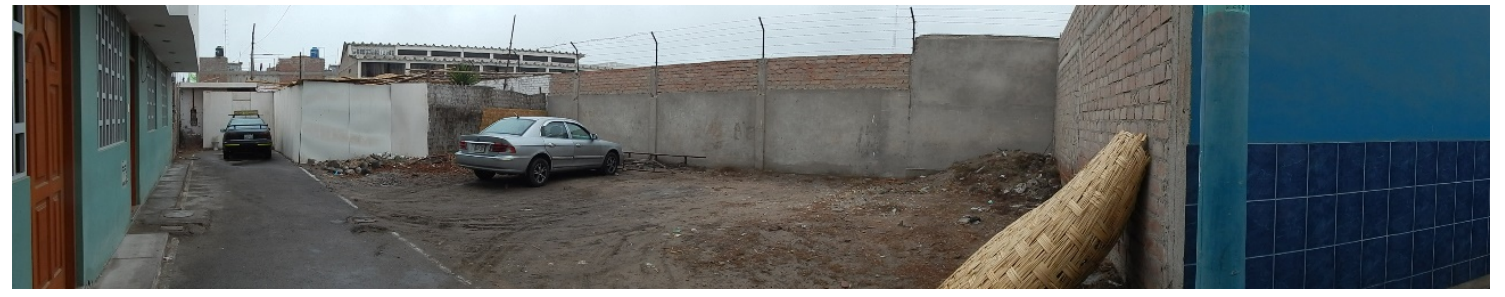

Fuente: Toma de fotografía y edición propia.

Figura 12: Fotografía de Google Earth

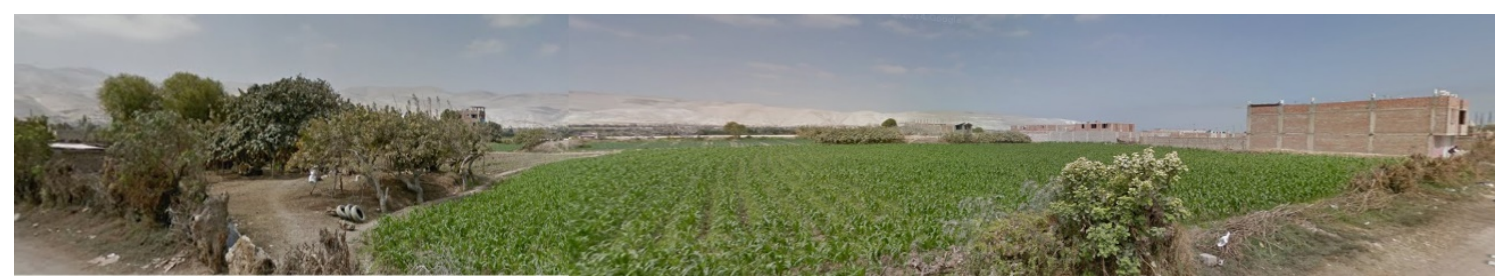

Fuente: Toma de fotografía y edición propia. 


\section{CONSTRUCCION}

Fue construida en el año 1944 e inaugurada en el 1953 el abastecimiento del hospital fue para 10 000 personas pero con el aumento de la población en la actualidad el hospital no se abastece de atención para Camaná y toda la Red de Salud Camaná - Caravelí.

Figura 14: Fotografía del Hospital en 1953

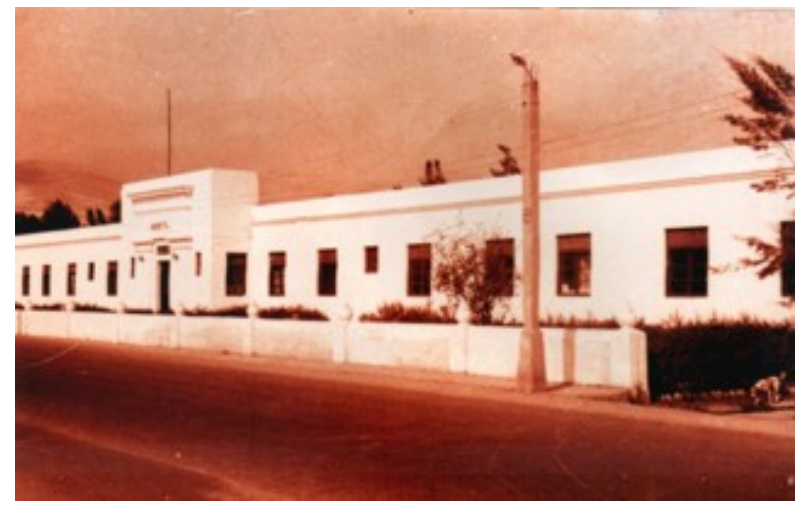

Figura 13: Fotografía del cuerpo médico en 1953

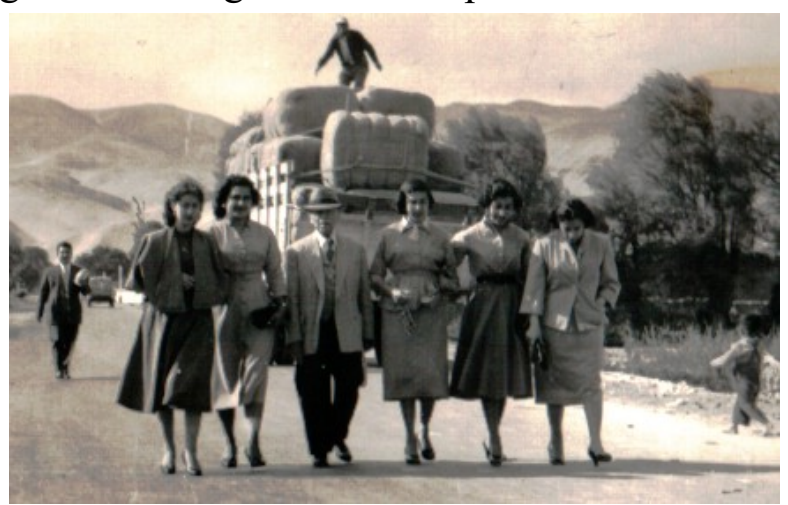

Fuente : http://www.saludarequipa.gob.pe/camana/resena.html

Figura 15: Fotografía del cuerpo médico del Hospital en 1953

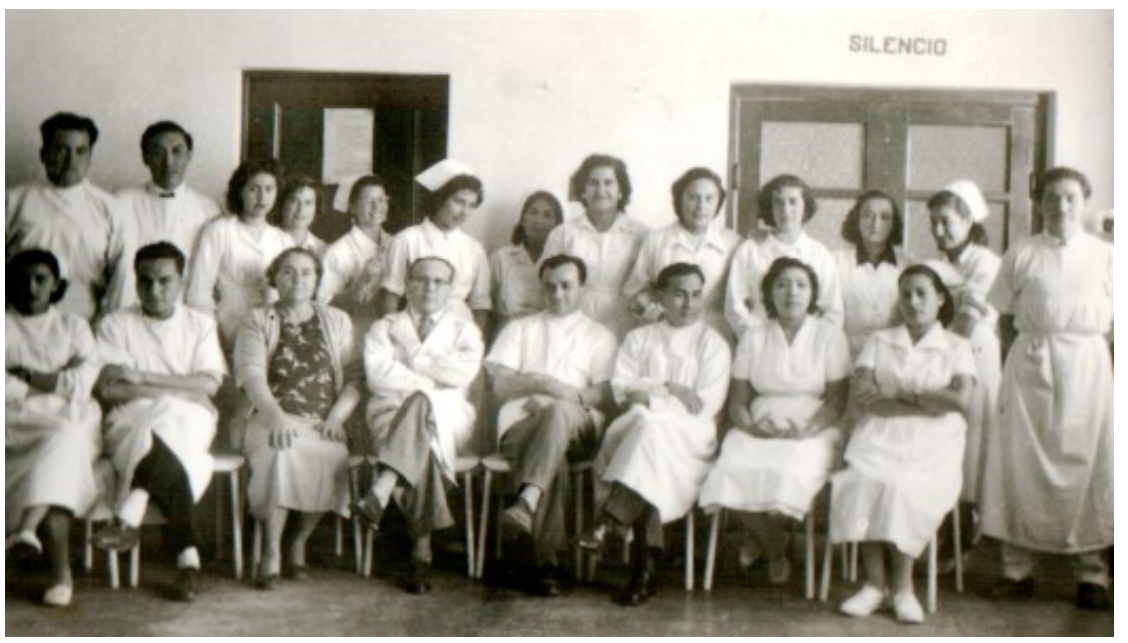

Fuente : http://www.saludarequipa.gob.pe/camana/resena.html 
ZONIFICACIÓN

CONSULTORIOS

EMERGENCIA Y CIRUGÍA

SERVICIOS Y SALA DE CONFERENCIA

HOSPITALIZACIÓN

ADMINISTRACIÓN

INSTITUTO DE NEUMONOLOGÍA

DIAGNÓSTICO Y LABORATORIOS

Fuente: Elaboración propia.
Figura 16: Zonificación del actual hospital de Camaná

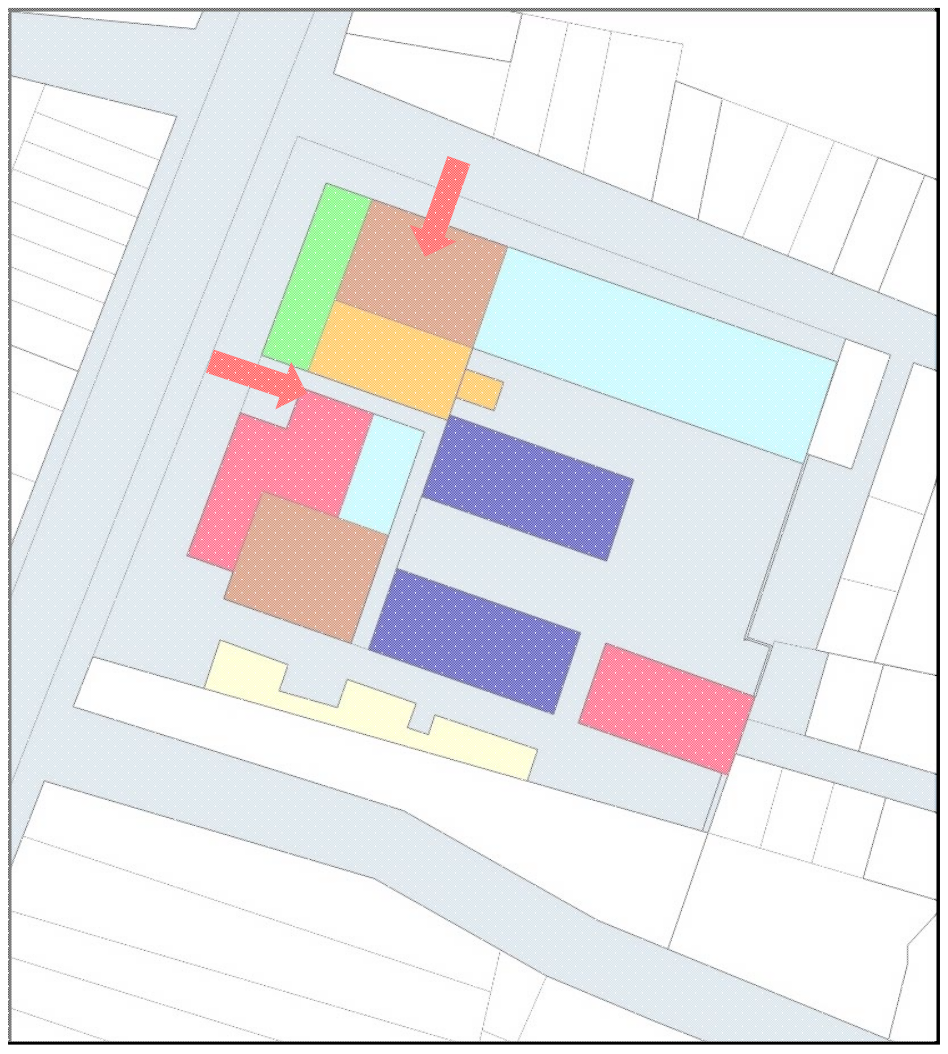

Figura 17: Vista de la Zonificación del Hospital de Apoyo

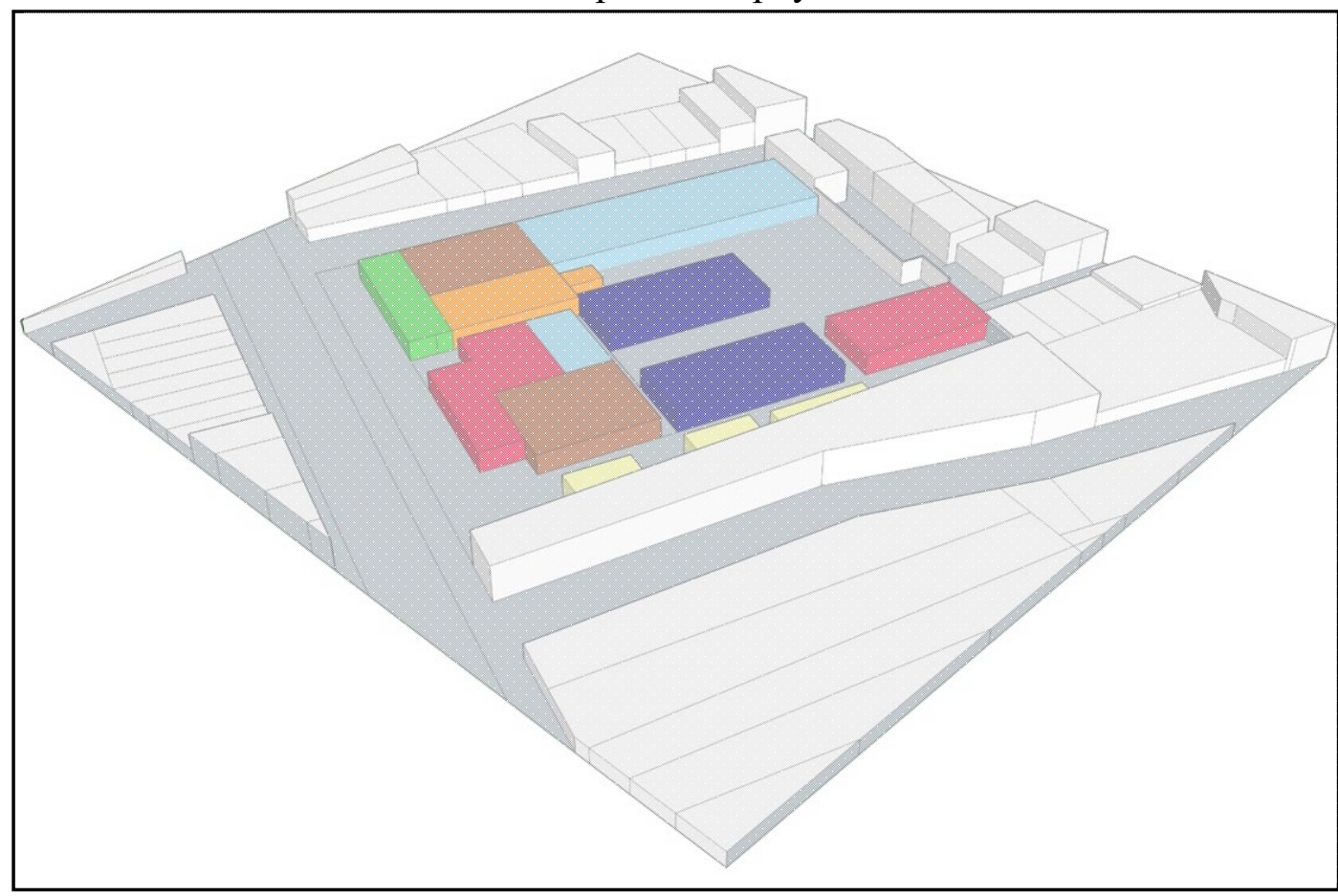

Fuente: Elaboración propia 
Figura 18: Zonificación del Hospital de Apoyo de Camaná

\section{INGRESO PRINCIPAL}

Se accede por la Av. Lima, la cual La Av. principal de la ciudad, que además es la continuación de la carretera Panamericana Sur

\section{INGRESO A EMERGENCIAS}

Se accede por la calle Martínez, que es una calle local

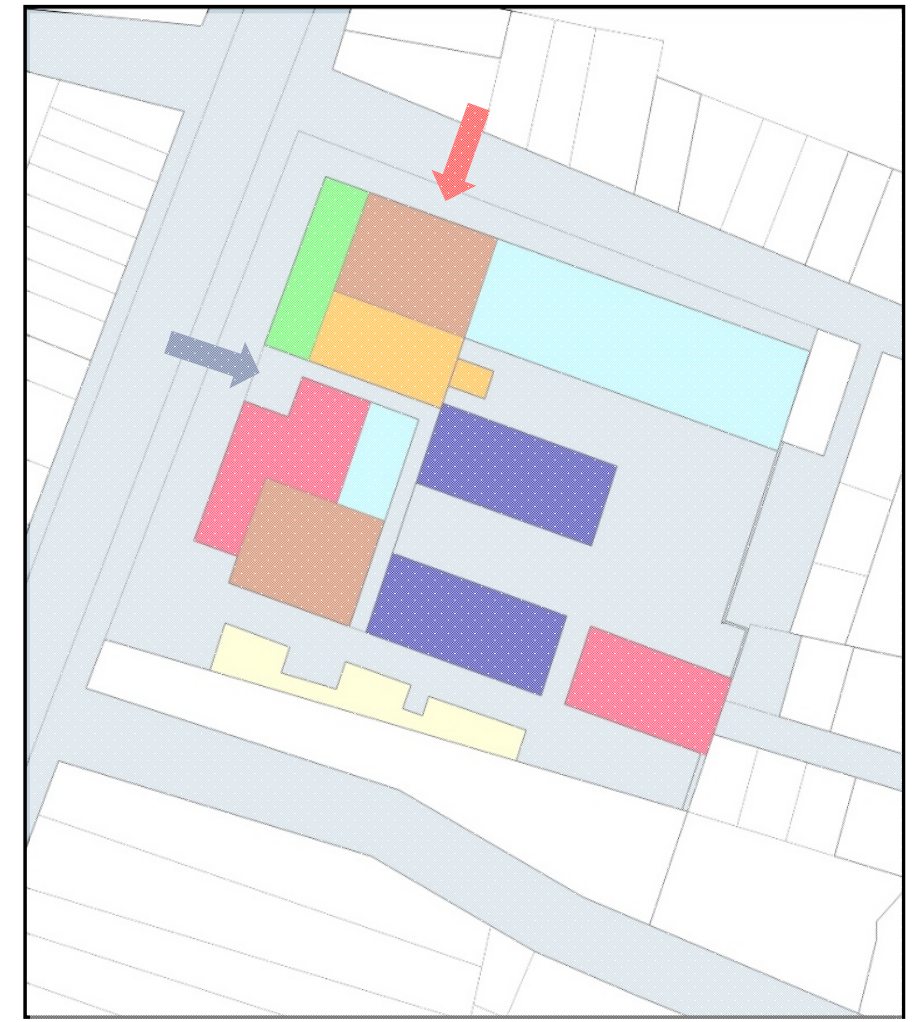

Fuente: Elaboración propia 


\section{$\underline{\text { RECORRIDO FOTOGRÁFICO }}$}

\section{INGRESO PRINCIPAL}

Figura 19: Fotografía del ingreso del Hosnital

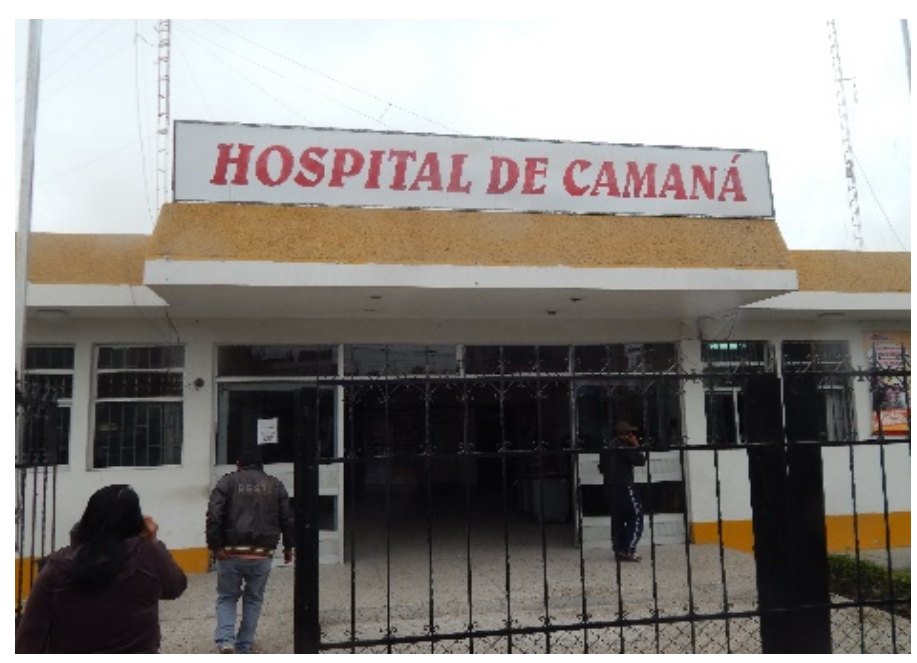

En su borde tiene estacionamiento público, cajero automático y un altar de la Virgen María, como borde físico del terreno están las rejas que circundan todo el terreno frontal.

La edificación se mantiene como fue construida en el 1953.

El ingreso está rodeado de rejas, no hay un ingreso arquitectónicamente marcado para diferenciar que es un espacio importante.

Fuente: Elaboración propia

Figura 21: Fotografia del exterior del hospital

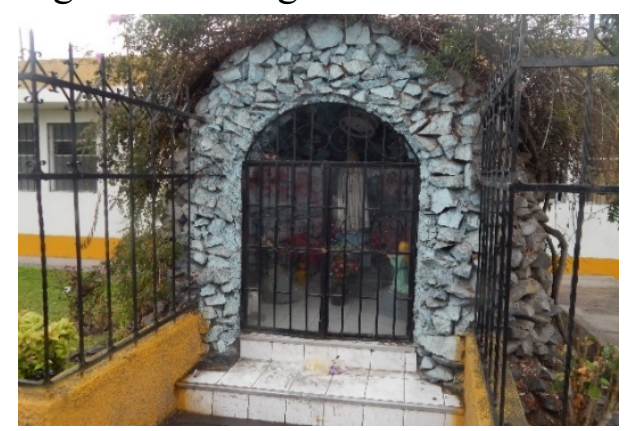

Fuente: Elaboración propia

Figura 23: Fotografía de los exteriores

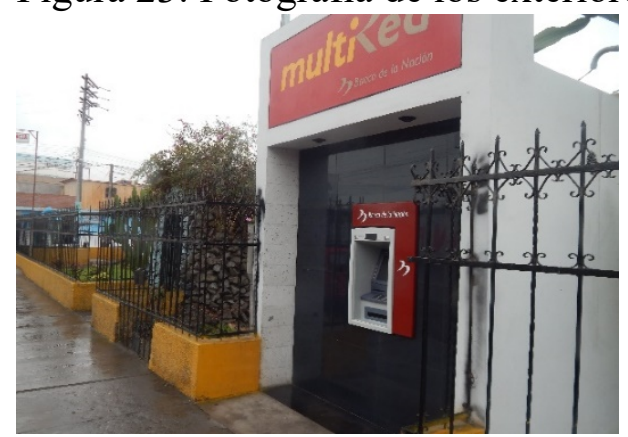

Fuente: Elaboración propia
Figura 20: fotografía del exterior del hospital

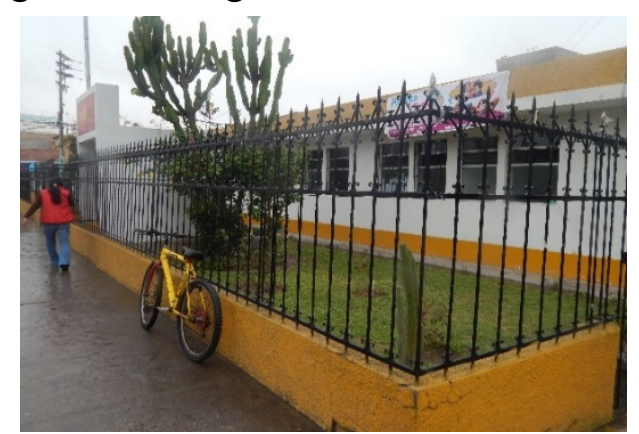

Fuente : Elaboración propia

Figura 22: Fotografía de los exteriores

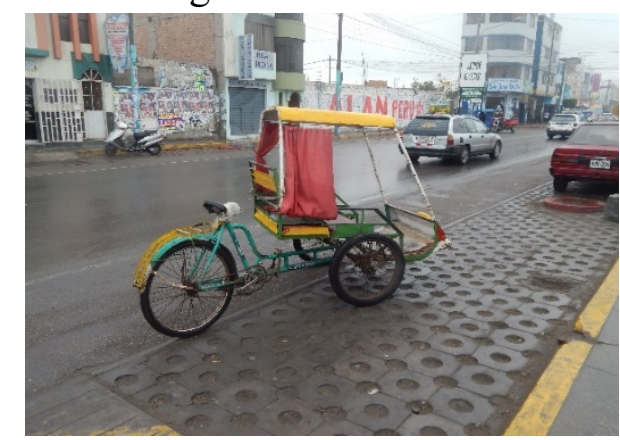

Fuente: Elaboración propia 
El hospital no cuenta con una zona de estacionamiento lo cual genera que los vehículos se estacionen en la zona de aparcamiento municipal, en el cual se estacionan desde automóviles hasta bicicletas y "taxi cholo" vehículo no motorizado que hace la función de taxi. (Imagen 27).

Figura 24: Fotografía del hall de ingreso

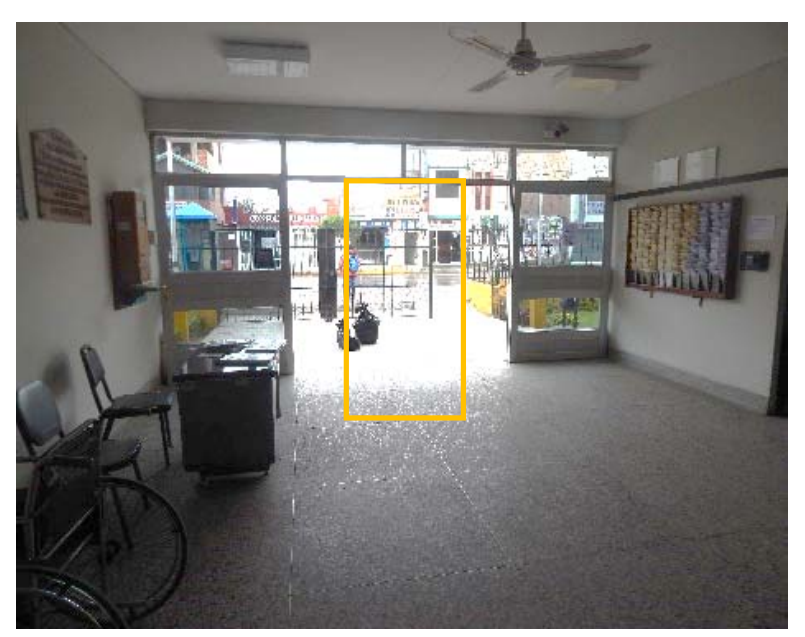

El usuario del hospital en la actualidad es de personas de bajos recursos por ende no tienen vehículo motorizado, esto es por la atención que brinda el hospital, como mencioné en capítulos anteriores otros usuarios prefieren hacer sus chequeos o consultas médicas en clínicas u hospitales en la ciudad de Arequipa. Este es un problema se puede resolver teniendo un hospital que llene las expectativas de los usuarios y así puedan atenderse en su ciudad y evitar los hacinamientos en otros hospitales.

Fuente: Elaboración propia

Hall del ingreso principal espacio de $5 \mathrm{~m}$ x $5 \mathrm{~m}$. El cual no cuenta con zona de espera haciendo que el ingreso en horas de la mañana sea caótico por la cantidad de personas que ingresan para solicitar una cita. Las colas de ingreso se hacen desde las 5:00 am, el hospital abre sus puertas a las 6:00 am y se cierra la atención de citas a las 7:00 am. Dejando a muchas personas sin atención. Esta es la nueva modalidad del Hospital de Camaná para evitar el hacinamiento en los consultorios del hospital. En este hall se encuentra una recepción donde se encuentra el marcador de ingreso de los trabajadores,es decir no hay una diferenciación de circulación.

Figura 25: Fotografía de Admisión

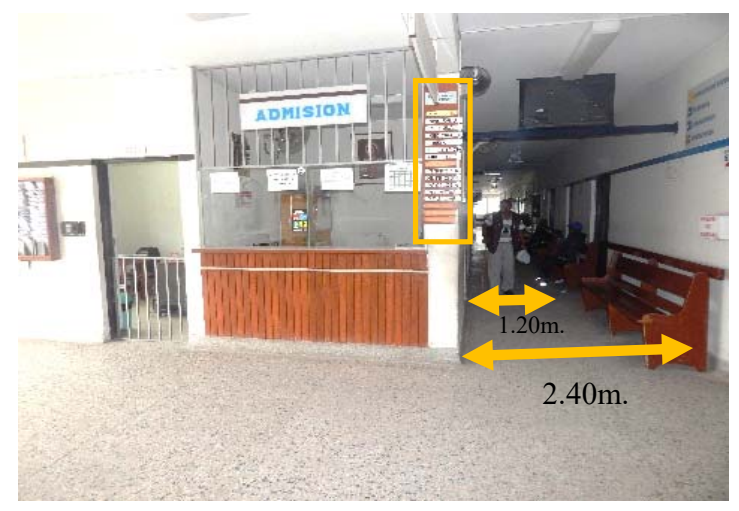

Admisión se encuentra en el Hall de ingreso este espacio no cuenta con zona de espera tan solo con una banca situada dentro de la circulación que tiene $2.40 \mathrm{~m}$ de ancho dejando como espacio de circulación $1.20 \mathrm{~m}$. la circulación está en la zona de los consultorios haciendo que el ingreso a estos sea dificultoso.

Fuente: Elaboración propia. 
En la zona de admisión hay una tabla donde figura las especialidades que atenderán en el día como si se tratará de un restaurante de menú, con esto se puede concluir que no están todos los días las especialidades médicas que deberían de atender con lo cual es una incertidumbre para el usuario.

\section{$\underline{\text { EMERGENCIA }}$}

En el siguiente esquema se muestra la distribución de la zona de emergencia en el hospital, está desarrollada en torno a un pasillo cuenta con dos salas de emergencia y dos salas de observación las cuales son insuficientes para la demanda. La zona de emergencia comparte la sala de espera con el área de consulta externa. No hay una clara diferenciación de los espacios. No existen circulaciones diferenciadas, es decir circulaciones para cada usuario (médico - paciente - limpieza - visita)

Figura 26: Distribución del área de Emergencia

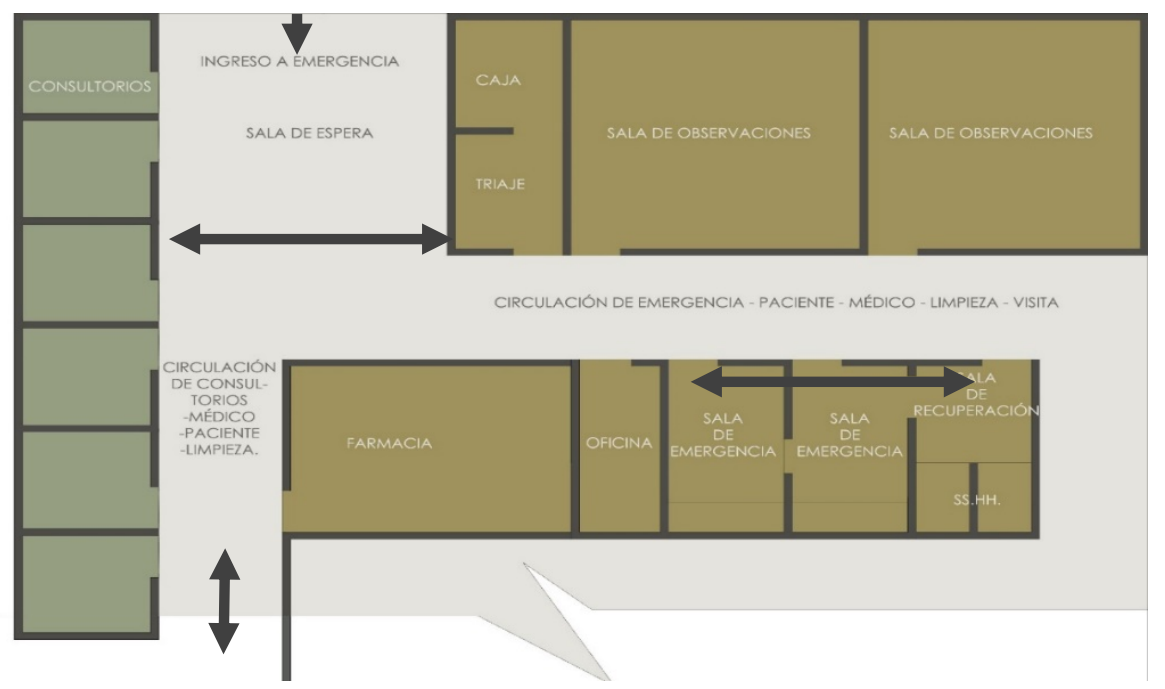

Fuente: Visita Elaboración propia.

Figura 27: Fotografía del hall de ingreso a Emergencia.

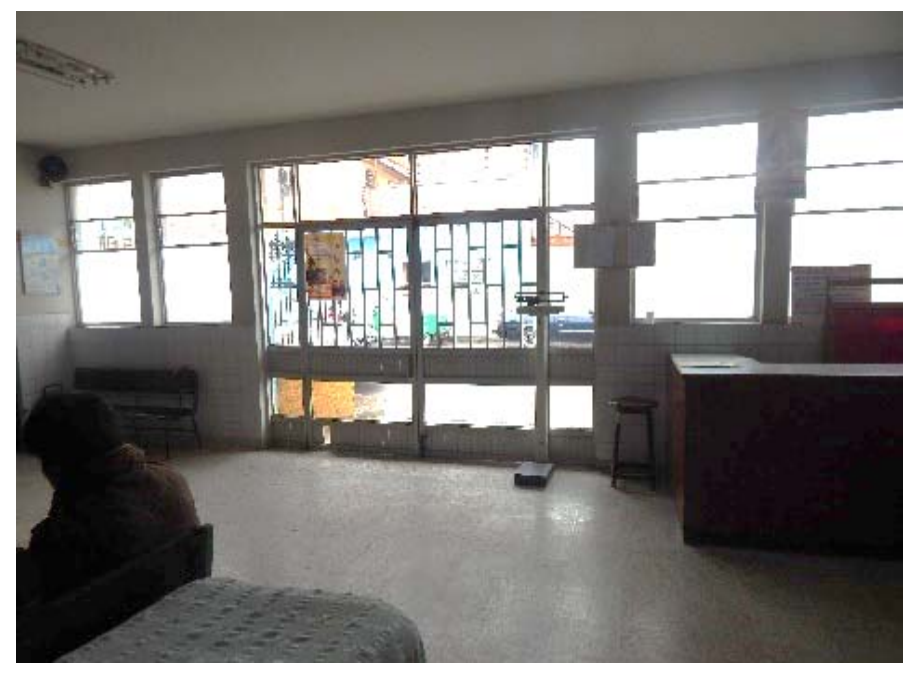

El ingreso a emergencia es restringido solo ingresa el paciente y un acompañante, por esta zona sólo se ingresa peatonalmente, si se viene en auto o ambulancia este no tiene zona de parqueo o bahía para el ingreso correspondiente. Cuenta con una zona de recepción que tambien hace el trabajo de triaje del area de consulta externa.

Fuente Elaboración propia 
Figura 28: Fotografía de hall de ingreso de Emergencia y consulta externa

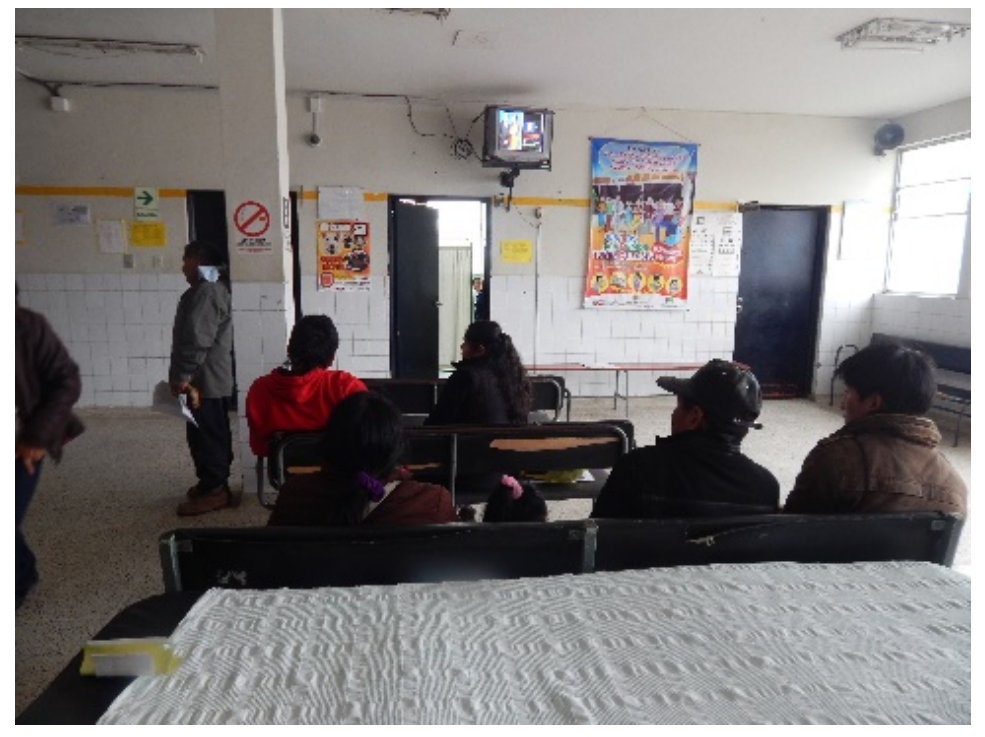

Sala de Espera del área de emergencia y consultorio (puertas azules) el afóro es para 20 personas lo cual no es suficiente, esta sala de espera es para consulta externa y para emergencia. No puede haber mixidad de usuarios en este espacio. (foto tomada al terminar el día)

Fuente : Elaboración propia.

Figura 29: Fotografía de caja y Triaje de Emergencia

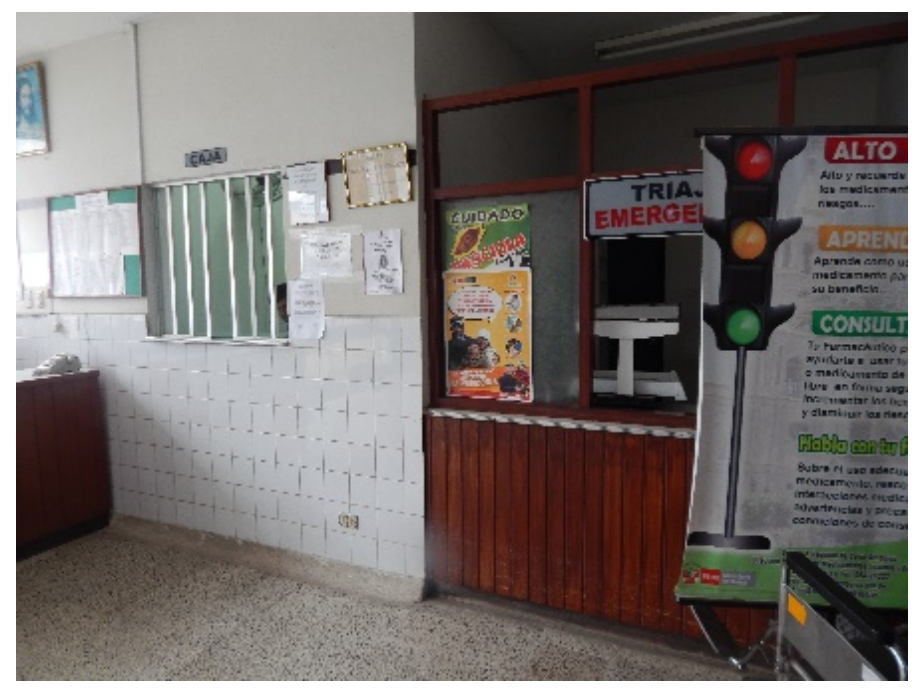

Triaje y Caja

Se encuentra en el hall de ingreso a emergencia, esta caja es la única en todo el hospital generando colas largas en horas de la mañana para el pago de consultas, historia clínica y otros.

Triaje se encuentra en el mismo hall es un espacio improvisado de paneles de madera.

Fuente: Elaboración propia. 
Figura 30: Fotografía de la Farmacia del Hospital

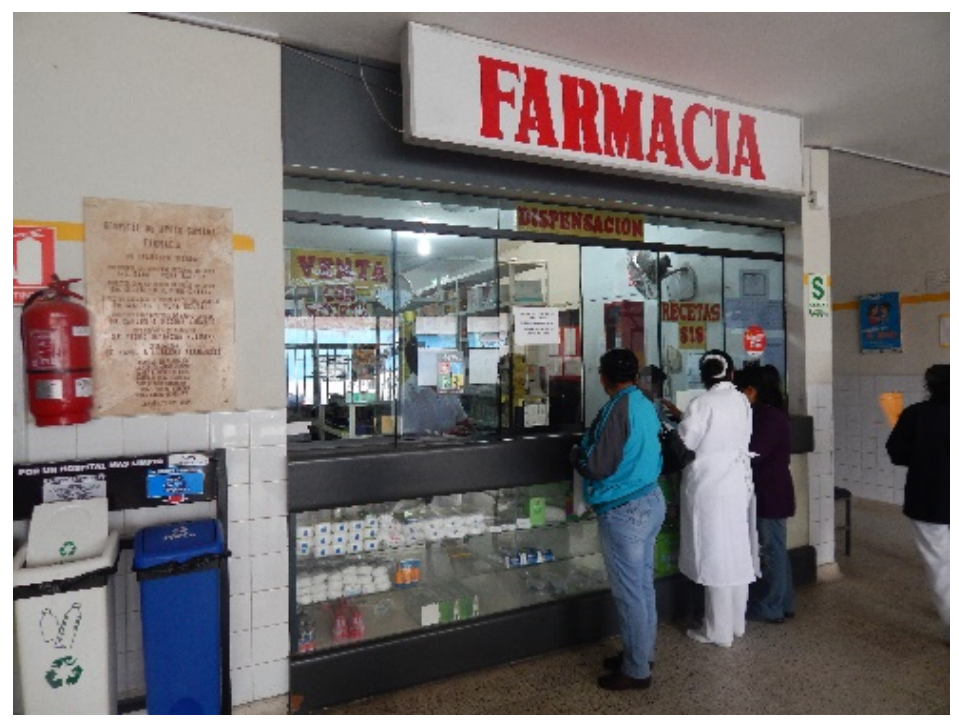

Farmacia se encuentra en el hall de emergencia es la única en todo el establecimiento, tiene dos tipos de venta para usuarios particulares (sin seguro) y para los asegurados del SIS (Seguro Integral de Salud, seguro que brinda el estado a personas de bajos recursos). Esta farmacia opera las 24 horas del día.

Fuente: Elaboración propia.

Figura 31: Fotografía de la sala de Observación

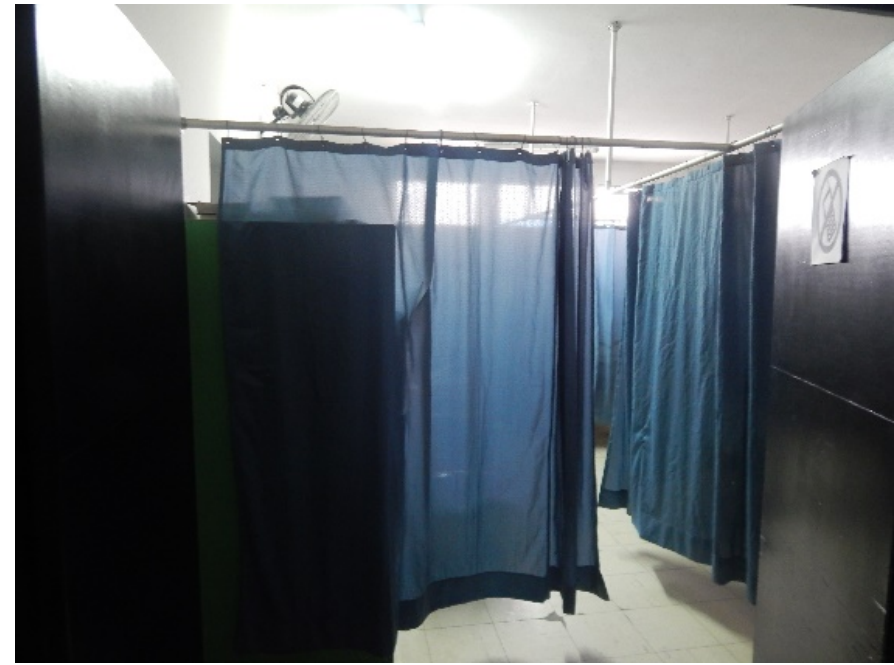

Salas de observación según visita guiada al hospital hay dos salas de observación que solo son espacios con camillas separadas por cortinas lo cual es un foco infeccioso para los pacientes debido a que no se cuenta con el espacio necesario y la separación adecuada para evitar contagios.

Fuente: Elaboración propia. 
Figura 33: Fotografía de la sala de emergencia

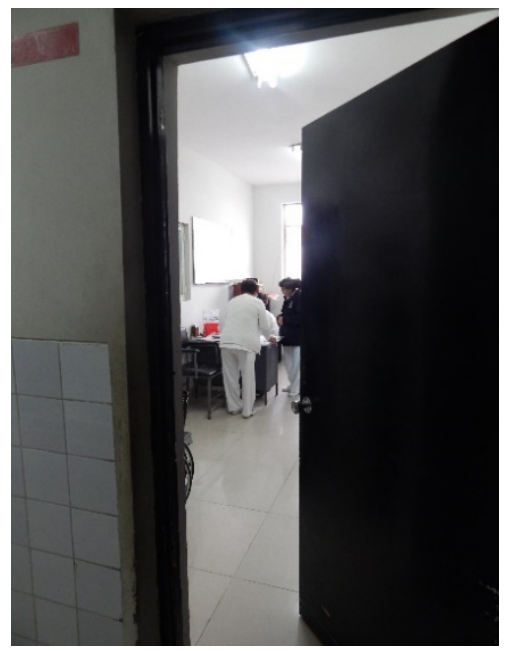

Fuente : Elaboración propia.

Figura 34: Fotografía de sala de recuperación

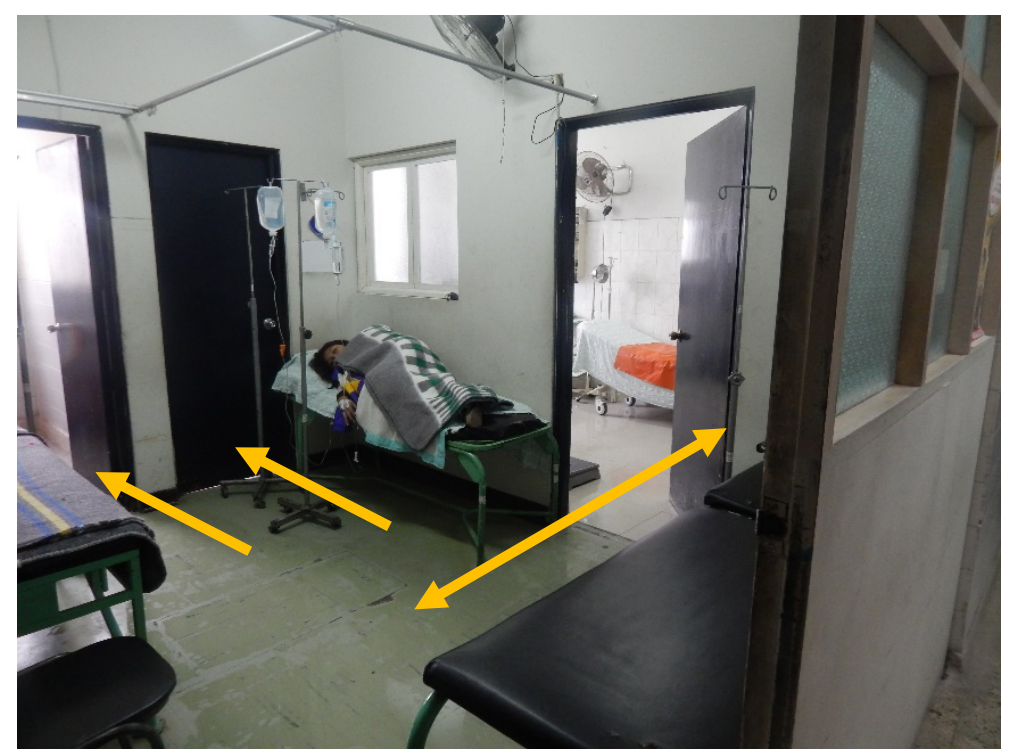

Fuente : Elaboración propia.
Figura 32: Fotografía de los pasillos de emergencia

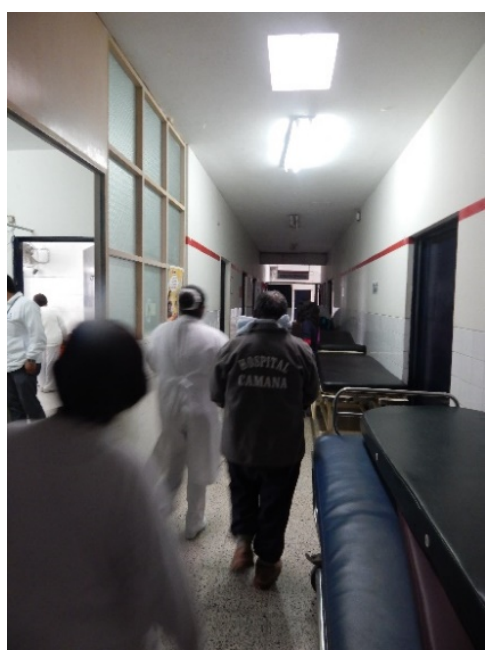

La atención en el área de emergencia es deficiente pues no hay espacio para la atención médica que se necesita, por esta razón colocan camillas en los pasillos obstruyendo el espacio mínimo requerido

Sala de recuperación (Este espacio estaba destinado a oficina) cuenta con tres camillas en lugares que impiden la circulación del espacio, por ejemplo obstruyen el paso a los servicios higiénicos, otros obstruyen el ingreso debido a que la camilla es más grande que el largo del muro. 
Figura 35: Distribución de Hospitalización

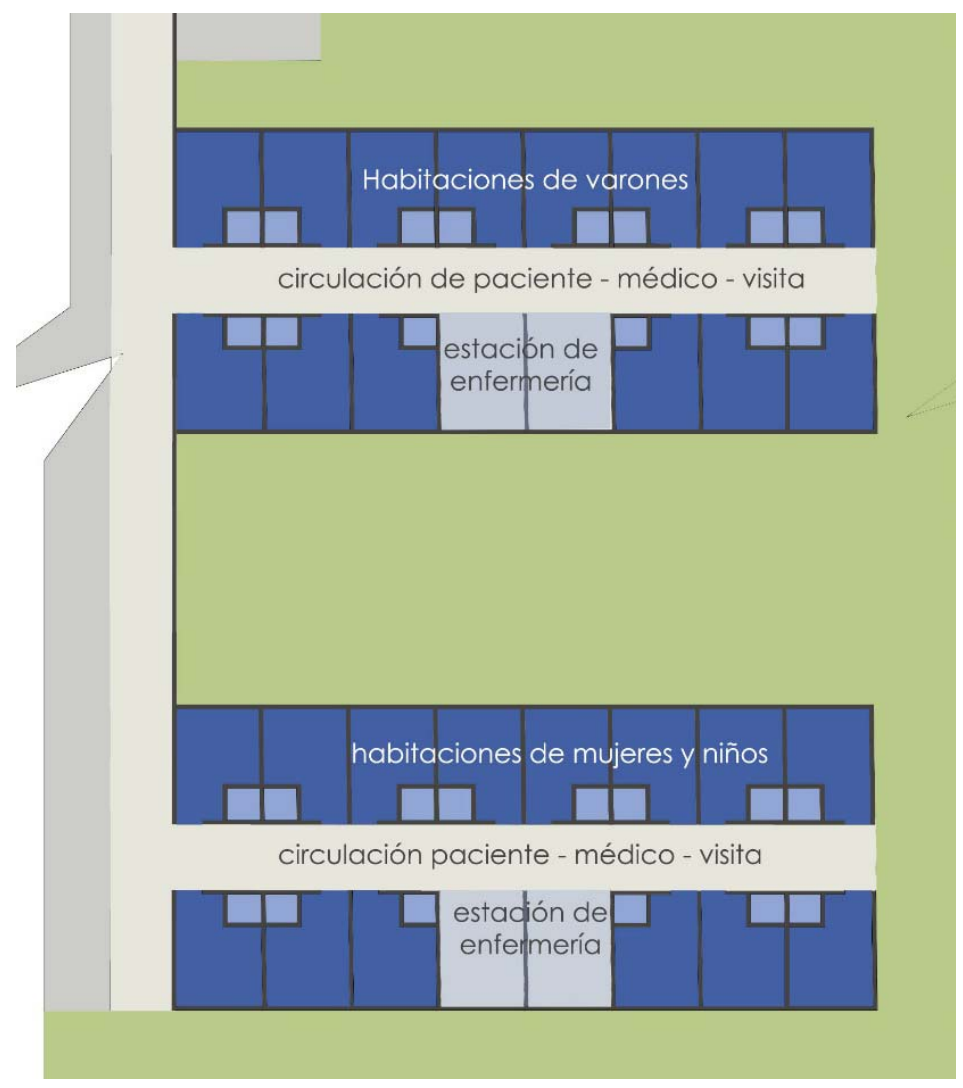

La zona de hospitalización está

separada por dos bloques uno dirigido para los varones, y otro para mujeres y niños. Estos pabellones están nexos a la zona de cirugía y tiene una conexión directa con el área de emergencia por la circulación lateral. Sin embargo solo cuenta con 28 habitaciones dobles y en algunos casos triples lo cual no abastece a la población.

Fuente : Elaboración propia según visita
Figura 37: Fotografía Circulación

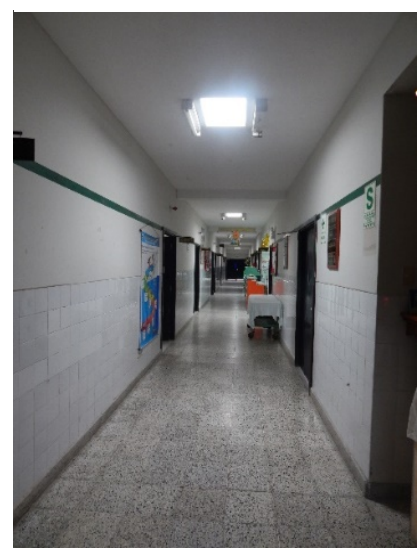

Figura 36: Fotografía estación de enfermería

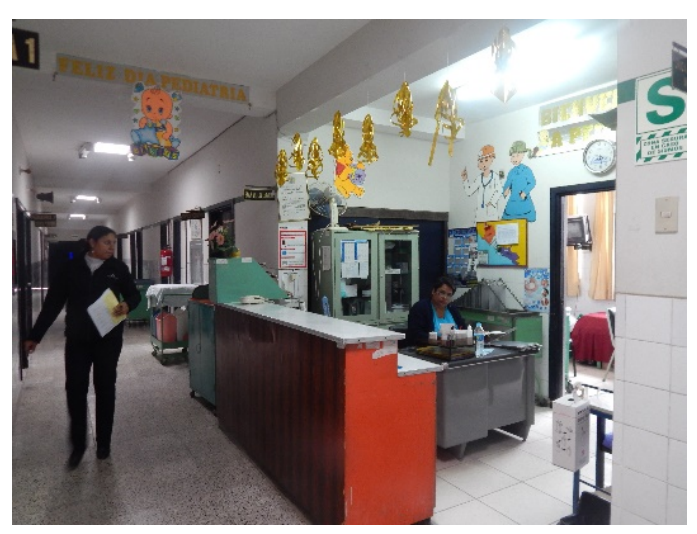



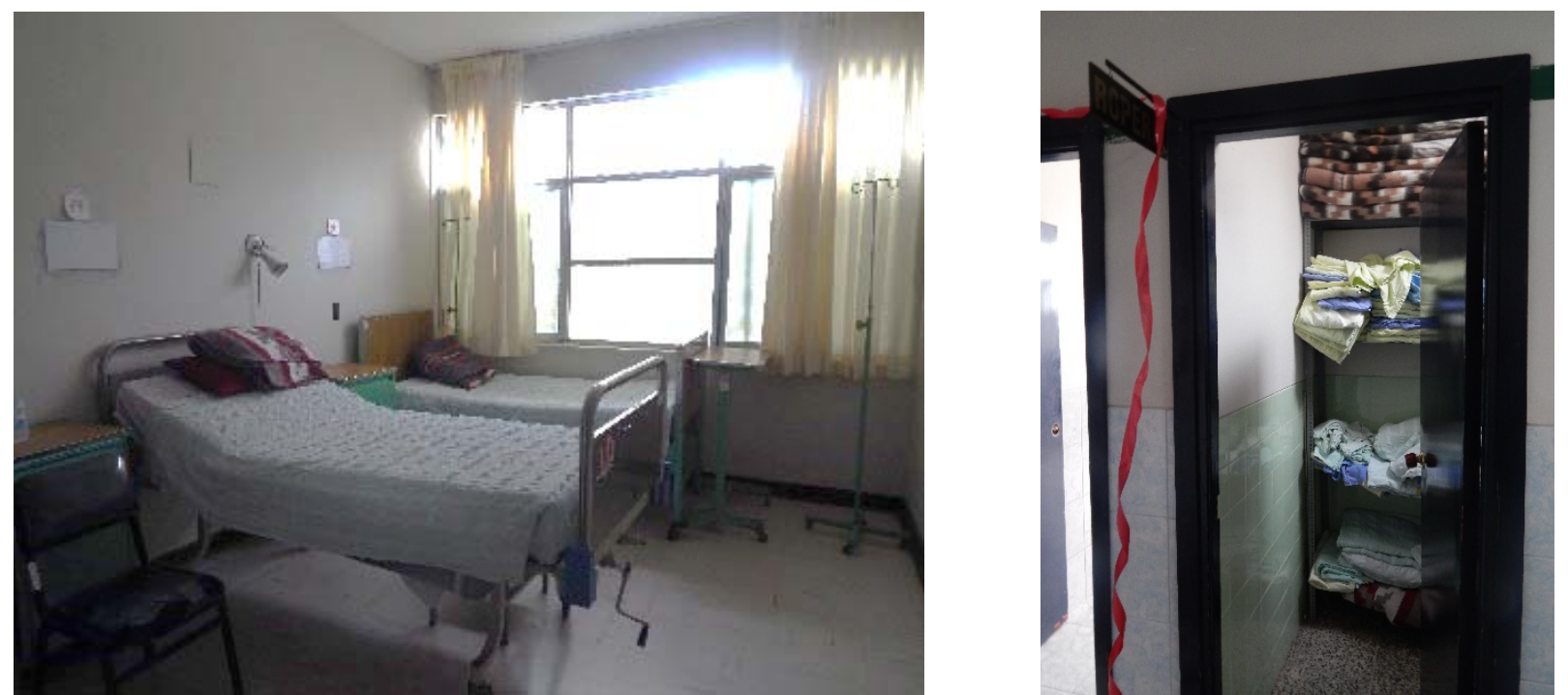

Figura 40: Fotografía de Habitación

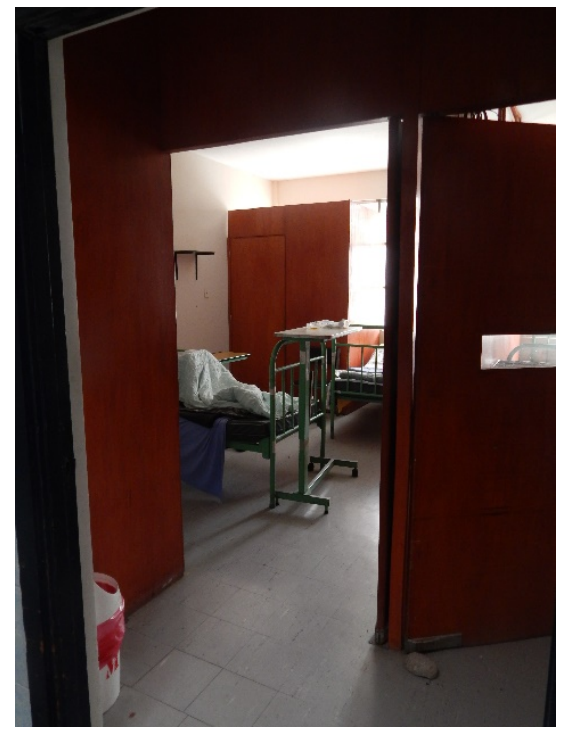

Fuente: Fotografías propias

La demanda del hospital ha dado como consecuencia el hacinamiento del hospital, además de la mala gestión de la Red de Salud como se puede observar hay habitaciones que tienen tabiques de madera los cuales no están en buenas condiciones y no es el material idóneo para un hospital. 
Figura 42: Lavandería

\section{AMBIENTES}

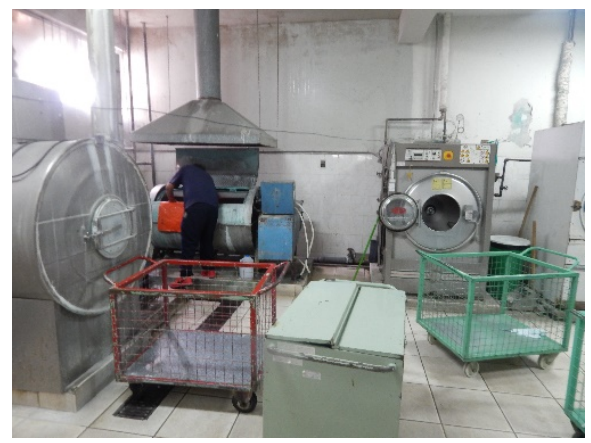

Figura 44: Estacionamiento de ambulancias.

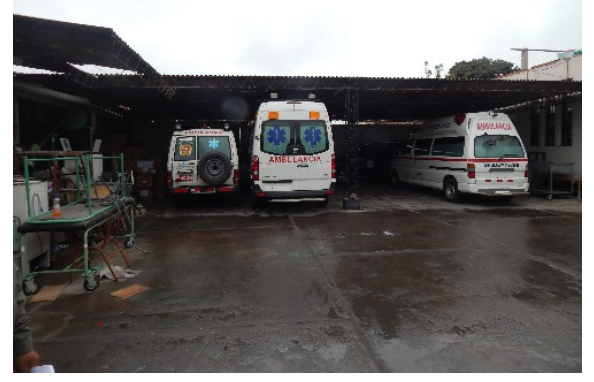

Figura 45: Auditorio

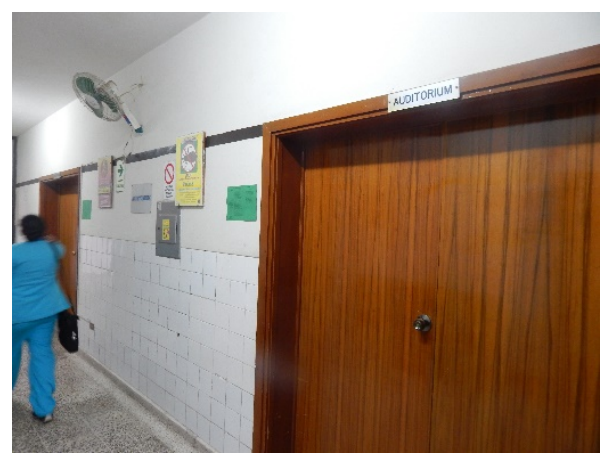

Figura 41: Cuarto de máquinas

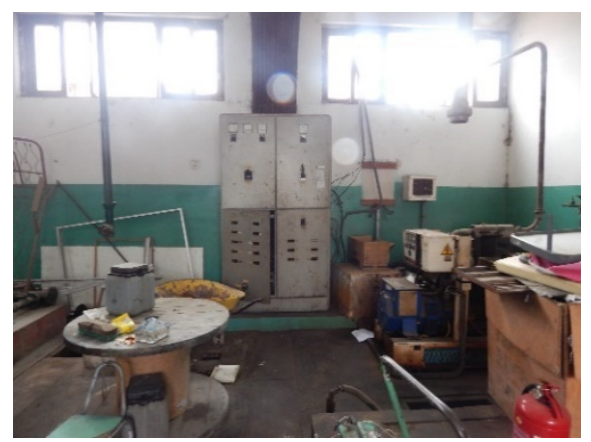

Figura 43: Comedor del personal

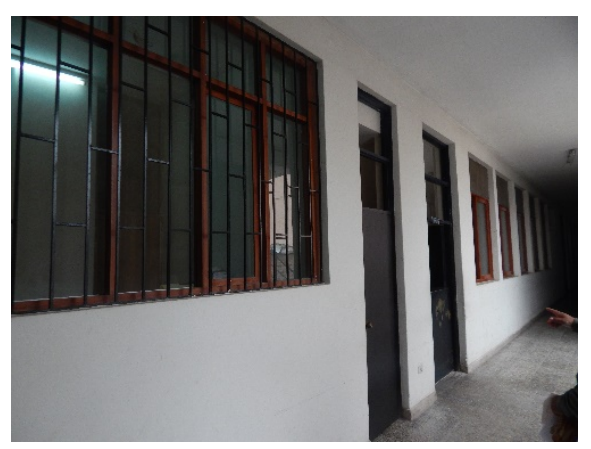

Figura 46: Tienda de snacks

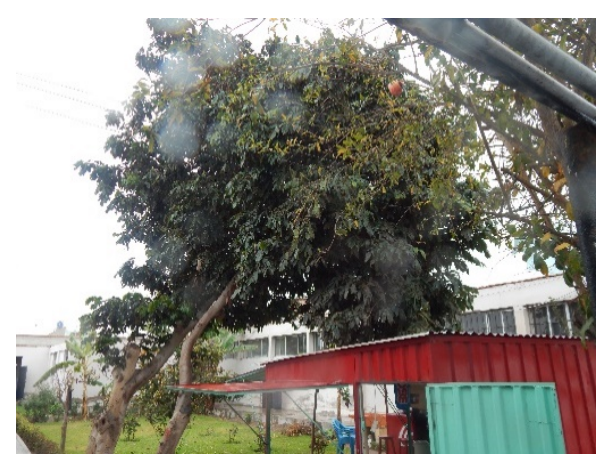


Figura 48: Loza deportiva

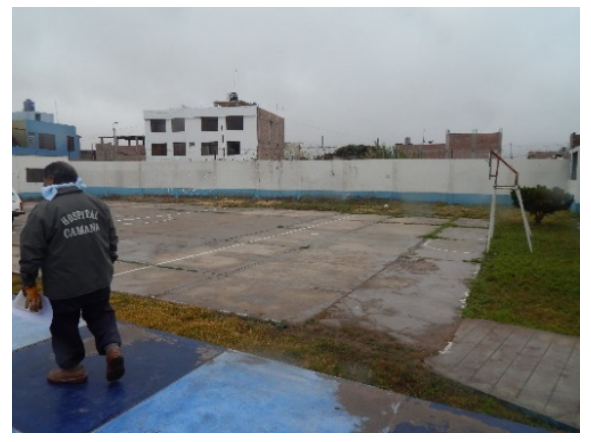

Figura 47: Sindicato de Trabajadores

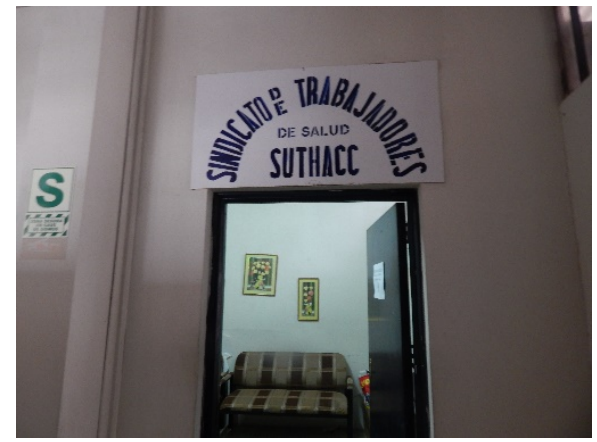

Fuente: Fotografías propias.

\section{$\underline{\text { PROBLEMAS }}$}

Ambientes- los ambientes no son los adecuados para un hospital, son insalubres, de material desgastado, con plagas de animales.

Abastecimiento.- no abastece a toda la población el hospital fue construido para abastecer a 10000 personas y en la actualidad tenemos más de 50000 personas

Déficit.- Déficit de profesionales, los profesionales de la salud no quieren trabajar en el hospital de Camaná por las condiciones antes mencionadas, por el mal pago y por no tener un lugar donde quedarse.

\section{CONCLUSIÓN}

Un nuevo diseño del hospital que abastezca a la población nueva, además que sea atractivo a los profesionales donde puedan trabajar a gusto y que ayude a la recuperación de los pacientes sería la solución para el equipamiento de salud de la provincia de Camaná. 


\subsection{MARCO HISTÓRICO}

\subsubsection{ARQUITECTURA HOSPITALARIA EN EL PERÚ}

En la época colonial en Lima los establecimientos de salud responden a tres condicionantes.

El rápido crecimiento de una ciudad y sus espacios urbanos.

El aumento de la población.

La aparición de perfiles de salud (morbilidad-mortalidad) en la población.

Es así que en 1538 se crea la primera casa de Enfermería de la ciudad de Lima que en el año 1552 se convertiría en el Hospital San Andrés especial para españoles, dos años después se creó otro Hospital de nombre Santa Ana para indios, en 1646 se fundó otro Hospital llamado San Bartolomé, para negros.

\subsubsection{HOSPITAL SAN ANDRÉS}

El hospital San Andrés tenía forma de cruz donde el altar se encontraba en el crucero del cual salían cuatro naves, donde la más corta correspondía a la capilla y las tres naves restantes eran las salas, donde se encontraban los enfermos que desde sus camas escuchaban la misa.

Figura 49: Bosquejo del Hospital Real de San Andrés

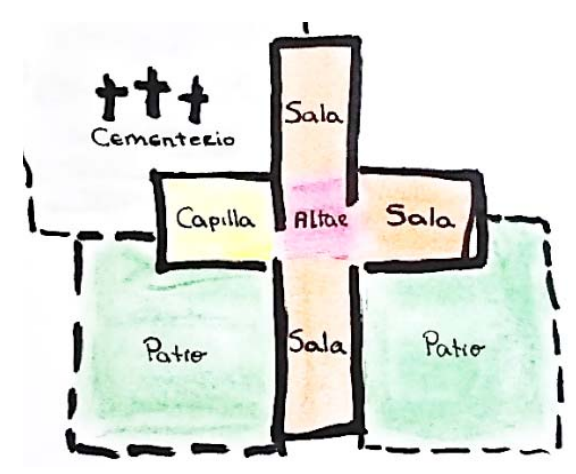

Fuente: Escrito de Hart terré Elaboración propia 
Figura 50: Hospital de Santa Ana.

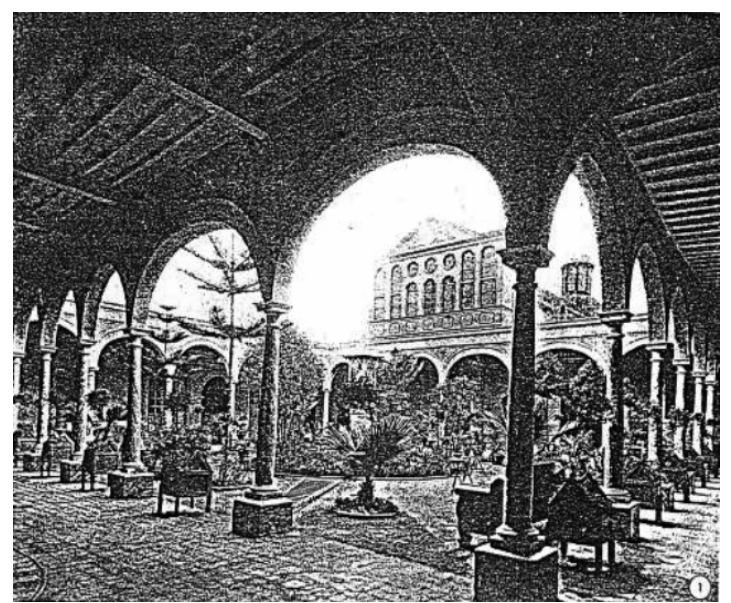

La arquitectura de los hospitales tempranos era similar a las plantas de los conventos. Las salas de enfermería estaban dispuestas en forma de cruz en este hospital habían dos pabellones en cruz el más grande era para los varones y el más pequeño para las mujeres, acompañado de un pabellón perimetral donde estaban los servicios de baño, cocina lavandería y ropería contaba con dos patios, un cementerio, huertos y una iglesia que daba a la calle.

Fuente: Quiroz Rivas Jorge. Desarrollo histórico social de la Arquitectura para la Salud.

Figura 51: Planta de Hospital Santa Ana

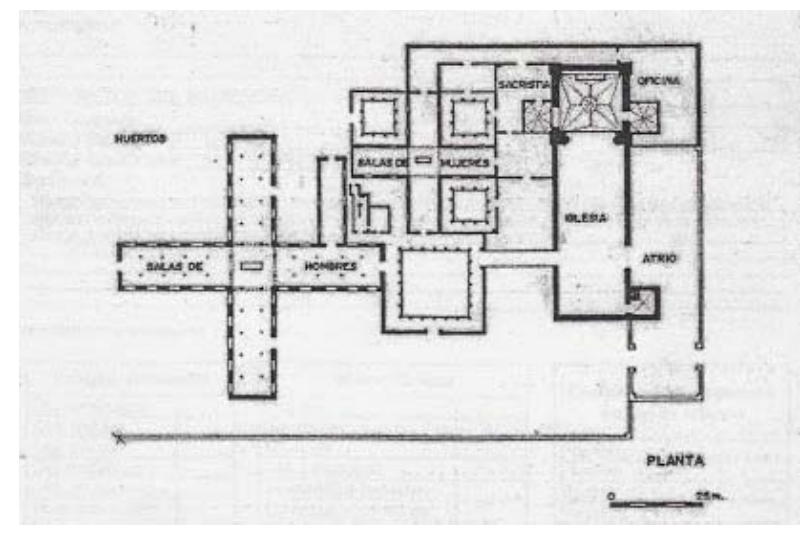

Fuente: Inventario Faua uni 1993

\subsubsection{HOSPITAL SAN BARTOLOME.}

Se construyó en 1661 cerca a los dos hospitales antes mencionados, en 1855 fue convertido en hospital militar, en 1961 como Hospital central de Salud Materno Infantil bajo el mando del Ministerio de Salud, en la actualidad funciona como Maternidad de Lima.

Ha sido el mejor ejemplo que hemos recibido y la más cercana experiencia de atención a pacientes por medio de "consultas externas" que se dio con éxito cuando estaba funcionando bajo el mando militar. 
Figura 52: Hospital San Bartolomé

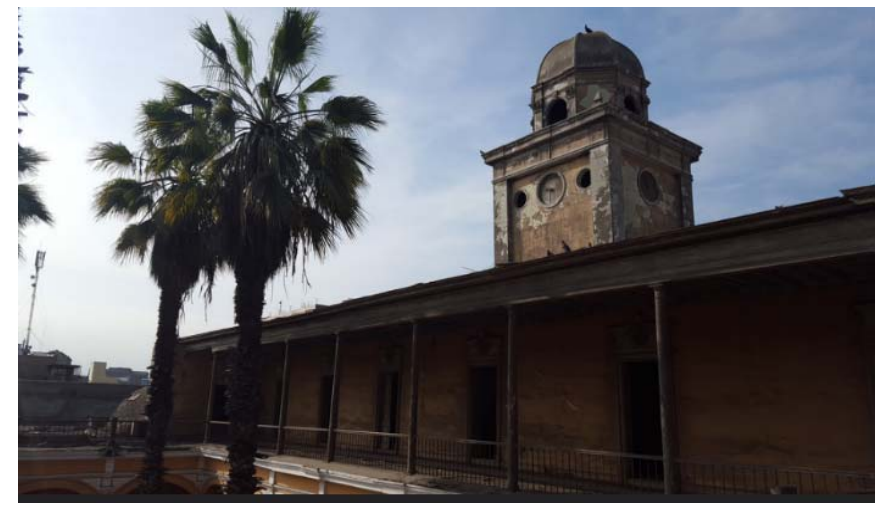

Fuente: Fotografía tomada por Santiago Stucchi

\subsubsection{HOSPITAL LOAYZA}

Figura 53: Planta y Fotografía del Hospital Arzobispo Loayza
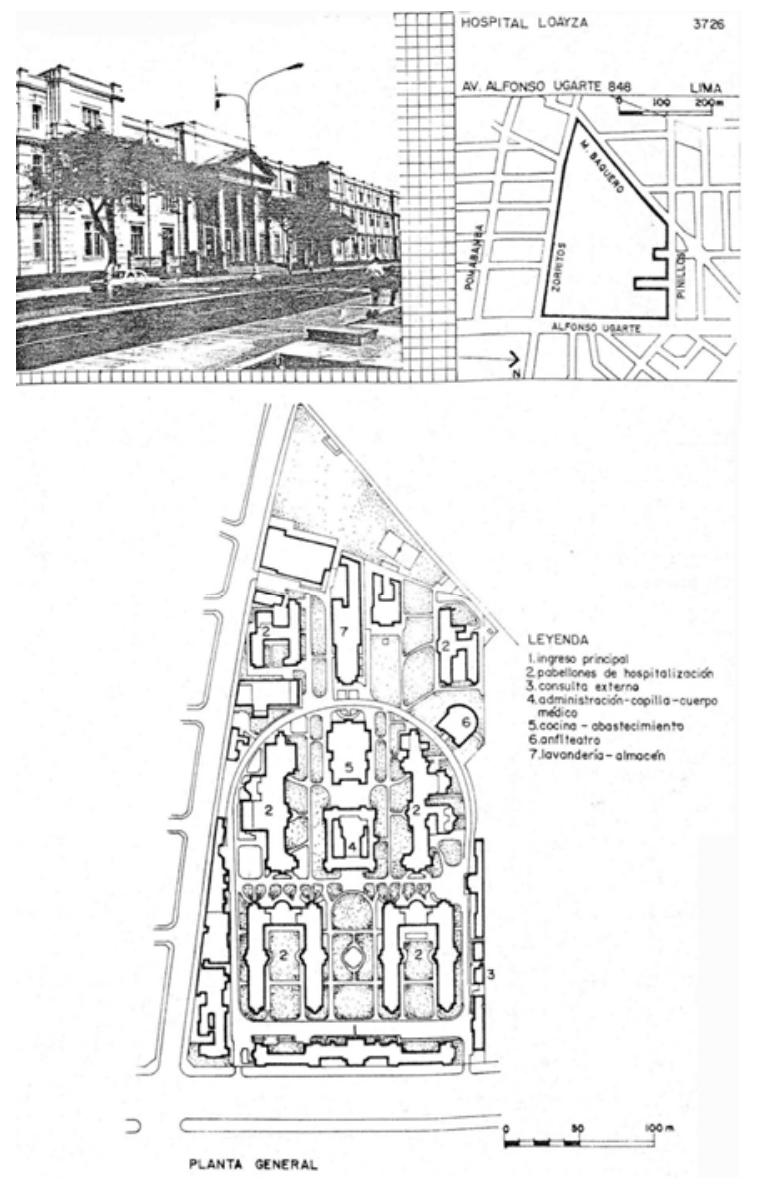

Fuente: Inventario Faua uni 1993
El cambio viene con este nuevo impulso que inició la nueva política sanitaria del Perú Republicano. El ímpetu "romántico" de las Sociedades Públicas de Beneficencia surgidos de los días "afiebrados" de la Revolución Francesa rompen -con los nuevos vientosla línea tradicional de las "Hermandades" triseculares del Virreinato que administraban los hospitales. Empieza una nueva preocupación por el manejo "funcional" del espacio arquitectónico destinado para la atención de los pacientes y el trabajo profesional del médico. 


\subsubsection{HOSPITAL DOS DE MAYO}

Figura 54: Planta Hospital Dos de Mayo

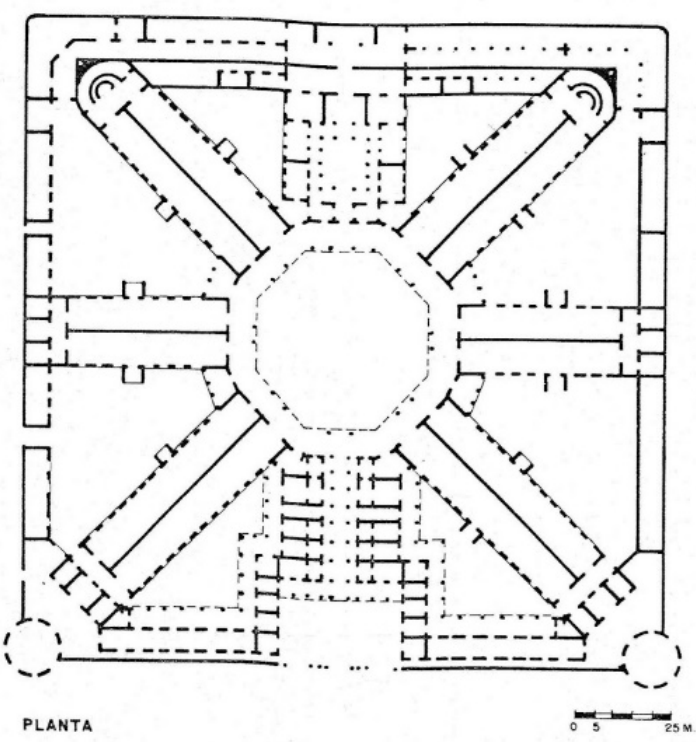

En 1868, la Sociedad de Beneficencia Pública de Lima mandó a construir el Hospital Dos de mayo, que se terminó de edificar en 1875. El diseño del hospital estuvo a cargo del Arq. Miguel Trefogli y el Arq. Mateo Graziani, hasta esa fecha los hospitales eran solucionados de manera cruciforme, este hospital toma como punto de partida un sistema de pabellones independientes unidos por un núcleo central conformado por un patio octogonal.

Fuente: Inventario Faua uni 1993

\subsubsection{HOSPITAL EDGARDO REBAGLIATI, LIMA-PERU}

Figura 55: Fotografia Hospital Edgardo Rebagliati 1958

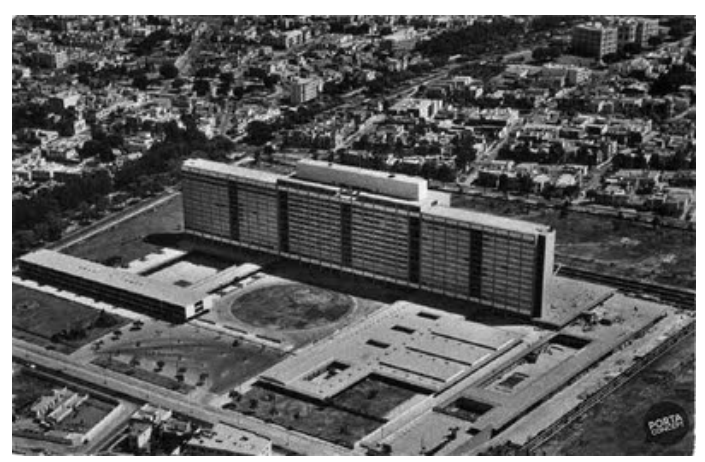

Fuente: Edward Durell Stone y Alfred Aydelott

La necesidad de dar respuesta a las preocupaciones higiénicas, la búsqueda del confort o el crecimiento demográfico propició la evolución de la arquitectura que tratará de presentar soluciones cada vez más válidas. Durante esta época se manifiesta la utilización de nuevos materiales como el hormigón o el cristal y surgimiento de nuevos movimientos como el racionalismo arquitectónico. Se 
puede resaltar la modernización llevada a cabo durante el gobierno Augusto B. Leguía o la revelación de nuevos arquitectos como los peruanos Rafael Maquina y Héctor Velarde. 


\section{3 - MARCO CONCEPTUAL}

\subsubsection{DEFINICIONES}

\subsubsection{HOSPITAL}

Establecimiento de salud destinado a la atención integral de consultantes en servicios ambulatorios y de hospitalización, proyectando sus acciones a la comunidad.

\subsubsection{UNIDAD DE EMERGENCIA}

Unidad operativa que califica, admite, evalúa, estabiliza e inicia el tratamiento a pacientes no programados, con estados de presentación súbita que comprometen la integridad y la vida del paciente y por lo tanto requieren una atención inmediata.

Es un establecimiento de salud que satisface las necesidades de salud de una zona determinada, estas necesidades pueden ser de emergencia, urgencia, ambulatoria, prevención de la salud y rehabilitación.

\subsubsection{URGENCIA}

Es la aparición fortuita de un problema de etiología diversa y de gravedad variable, que genera la conciencia de una necesidad inminente de atención por parte del sujeto o de sus allegados (OMS). Podemos definirla también como toda aquella patología cuya evolución es lenta y no necesariamente mortal pero que obligatoriamente su atención no debe retrasarse más de seis horas.

\subsubsection{EMERGENCIA}

Es toda situación urgente en la que está en peligro la vida de la persona o la función de algún órgano. Es aquel caso en el que la falta de asistencia sanitaria conduciría a la muerte en minutos (hora dorada) y en el que la aplicación de los primeros auxilios por cualquier persona es de importancia primordial. Algunos autores americanos promovieron el concepto de hora dorada como la primera hora de un suceso en la que la mortalidad es elevada por la alta frecuencia de aparición de complicaciones mortales.

\subsubsection{CLASIFICACIÓN DE HOSPITALES}

Los Hospitales se clasifican por el grado de complejidad, el número de camas y por el radio geográfico de cubrirá y por el tipo de hospital según entidad. 


\section{CUADRO COMPARATIVO NACIONAL}

En el Perú hay 6 categorías de hospitales según entidad a la que pertenece, MINSA (Ministerio de Salud), EsSalud (Seguro Social de Salud del Perú), PNP (Policía Nacional del Perú), FAP (Fuerza Aérea del Perú), NAVAL (Centro Naval del Perú) y los de carácter de privado.

Tabla 2: Tabla de Categoría de Hospitales

\begin{tabular}{|c|c|c|c|c|c|c|}
\hline CATEGORÍAS & MINSA & EsSALUD & PNP & FAP & NAVAL & Privado \\
\hline I - 1 & $\begin{array}{c}\text { Puesto de } \\
\text { Salud }\end{array}$ & $\begin{array}{l}\text { Posta } \\
\text { médica }\end{array}$ & $\begin{array}{c}\text { Puesto } \\
\text { Sanitario }\end{array}$ & $\begin{array}{l}\text { Posta } \\
\text { médica }\end{array}$ & $\begin{array}{c}\text { Enfermería ó } \\
\text { Servicios de } \\
\text { sanidad }\end{array}$ & $\begin{array}{c}\text { Consultori } \\
\text { o }\end{array}$ \\
\hline I - 2 & $\begin{array}{l}\text { Puesto de } \\
\text { Salud con } \\
\text { Médico }\end{array}$ & $\begin{array}{l}\text { Centro } \\
\text { médico }\end{array}$ & $\begin{array}{l}\text { Posta } \\
\text { médica }\end{array}$ & $\begin{array}{l}\text { Departamen } \\
\text { to Sanitario }\end{array}$ & $\begin{array}{c}\text { Departamento } \\
\text { de sanidad + } \\
\text { Posta Naval }\end{array}$ & $\begin{array}{l}\text { Consultori } \\
\text { o Médico }\end{array}$ \\
\hline I - 3 & $\begin{array}{c}\text { Centro de } \\
\text { Salud }\end{array}$ & Policlínico & Policlínico &.-- & Centro médico & $\begin{array}{c}\text { Policlínico } \\
\mathrm{s} \\
\end{array}$ \\
\hline I - 4 & $\begin{array}{c}\text { Centro de } \\
\text { Salud con } \\
\text { internamie } \\
\text { nto }\end{array}$ & Hospital I & $\begin{array}{l}\text { Hospital } \\
\text { Regional }\end{array}$ & $\begin{array}{c}\text { Hospital } \\
\text { Zonal }\end{array}$ & $\begin{array}{l}\text { Policlínico } \\
\text { Naval }\end{array}$ & $\begin{array}{l}\text { Centros } \\
\text { médicos }\end{array}$ \\
\hline II - 1 & Hospital I & Hospital II &.-- & $\begin{array}{l}\text { Hospital } \\
\text { Regional }\end{array}$ & Clínica Naval & Clinicas \\
\hline II - 2 & $\begin{array}{c}\text { Hospital } \\
\text { II }\end{array}$ & $\begin{array}{c}\text { Hospital } \\
\text { III }\end{array}$ &.-- &.-- &.-- & Clínicas \\
\hline III - 1 & $\begin{array}{c}\text { Hospital } \\
\text { III }\end{array}$ & $\begin{array}{l}\text { Hospital } \\
\text { Nacional }\end{array}$ & $\begin{array}{l}\text { Hospital } \\
\text { Nacional }\end{array}$ & $\begin{array}{c}\text { Hospital } \\
\text { Central } \\
\text { FAP }\end{array}$ & Hospital Naval & Clínicas \\
\hline III - 2 & $\begin{array}{l}\text { Instituto } \\
\text { Especializ } \\
\text { ado }\end{array}$ & Instituto &.-- &.-- &.-- & Institutos \\
\hline
\end{tabular}

Fuente: MINSA

Este establecimiento de Salud es de segundo nivel de atención, responsable de satisfacer las necesidades de salud de la población de su ámbito referencial, brindando atención integral ambulatoria y hospitalaria especializada, con énfasis en la recuperación y rehabilitación de problemas de salud.

\section{CARACTERÍSTICAS}

Pertenece al segundo nivel de atención de salud.

Para el ministerio de salud esta categoría corresponde al Hospital II. 
En el sector público, no tiene población asignada directa, sino población referencial regional de las redes y establecimientos de categoría II -1 de su jurisdicción.

La cantidad de recursos humanos será establecida con precisión en función a la demanda.

Esta categoría de establecimiento de salud, contará como mínimo con los siguientes recursos humanos del nivel profesional, técnico y auxiliar además de lo consignado en la categoría anterior.

Tabla 3: Tabla de profesionales de un Hospital

\begin{tabular}{|c|c|c|}
\hline Profesionales médicos:* & Otros profesionales: & Técnicos y/o Auxiliares: \\
\hline $\begin{array}{l}\text { Adicionalmente } \text { a lo } \\
\text { consignado en la categoría } \\
\text { anterior } \\
\text { Cardiólogo } \\
\text { Médico especialista en } \\
\text { Medicina de Rehabilitación } \\
\text { Neurólogo } \\
\text { Neumólogo } \\
\text { Gastroenterólogo } \\
\text { Reumatólogo } \\
\text { Psiquiatra. } \\
\text { Oftalmólogo } \\
\text { Otorrinolaringólogo } \\
\text { Traumatólogo } \\
\text { Urólogo } \\
\text { Patólogo Clínico } \\
\text { Radiólogo } \\
\text { Anátomo-Patólogo }\end{array}$ & $\begin{array}{l}\text { Profesional de la salud con } \\
\text { post grado (maestria o PREC) } \\
\text { en epidemiología } \\
\text { Administrador } \\
\text { Estadistico } \\
\text { Contador. }\end{array}$ & $\begin{array}{l}\text { Técnico de laboratorio } \\
\text { Técnico de Enfermería } \\
\text { Auxiliar de Enfermería } \\
\text { Técnico en Estadística } \\
\text { Técnico o Auxiliar } \\
\text { Administrativo } \\
\text { Personal Servicios Generales } \\
\text { Técnicos especialistas en } \\
\text { Informática } \\
\text { Auxiliares } \\
\text { Artesanos }\end{array}$ \\
\hline
\end{tabular}

Fuente : Minsa 
Tabla 4: Cuadro comparativo de las UPS según las diferentes categorías.

Fuente:

Minsa

\begin{tabular}{|c|c|c|c|c|c|c|c|c|}
\hline UNIDADES PRODUCTORAS & $I-1$ & $I-2$ & $I-3$ & $I-4$ & II-1 & II-2 & III-1 & III-2 \\
\hline SALUD COM. Y AMBIENTAL & SI & SI & sI & SI & SI & & & \\
\hline CONSULTA EXTERNA MEDICA & Itinerante & $\begin{array}{l}6 \mathrm{a} \\
12 \mathrm{Hs} .\end{array}$ & $12 \mathrm{Hs}$ & 12 Hrs. & $12 \mathrm{Hrs}$. & $12 \mathrm{Hrs}$ & $12 \mathrm{Hs}$. & $12 \mathrm{Hs}$. \\
\hline PATOLOGIA CLINICA (Laboratorio) & & & SI & SI & SI & SI & SI & SI \\
\hline ESPECIALIDAD & & & & $\begin{array}{c}\text { Medicina } \\
\text { Geleral y } \\
\text { adgunas } \\
\text { especiaidades } \\
\text { (Ginecologia y } \\
\text { Pediatria } \\
\text { priaritariamerte) }\end{array}$ & 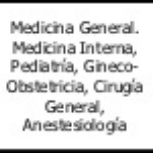 & $\begin{array}{l}\text { TODAS LAS } \\
\text { ESPEGALIDADES }\end{array}$ & $\begin{array}{l}\text { Además } \\
\text { TODAS LAS SUB } \\
\text { ESPECIALIDADES }\end{array}$ & $\begin{array}{c}\text { SOLO } \\
\text { ESPECIALIDADES } \\
\text { CORRESPONDIE } \\
\text { NTES AL } \\
\text { INSTITUTO } \\
\text { ESPECIALIZAOO }\end{array}$ \\
\hline CENTRO OBSTETRICO & & & & Sala de Parto & SI & SI & sI & sI \\
\hline HOSPITALIZACION & & & & Intemaniento & SI & SI & SI & sI \\
\hline CENTRO QUIRURGICO & & & & & SI & SI & SI & CONDICIONAL \\
\hline EMERGENCIA & & & & & sI & sI & SI & CONDICIONAL \\
\hline DIAGNOSTICO POR IMÁGENES & & & & & SI & sI & sI & sI \\
\hline HEMOTERAPIA & & & & & SI & SI & SI & \\
\hline ANATOMIA PATOLOGICA & & & & & SI & SI & SI & sI \\
\hline HEMODIALISIS & & & & & & & sI & \\
\hline U. C.I. & & & & & & General & ESPECIALIZADA & \multirow{4}{*}{$\begin{array}{l}\text { De acuerdo asu } \\
\text { Especialidad }\end{array}$} \\
\hline RADIO TERAPIA & & & & & & & SI & \\
\hline MEDICINA NUCLEAR & & & & & & & SI & \\
\hline TRANSPLANTE DE ORGANOS & & & & & & & SI & \\
\hline $\begin{array}{l}\text { INVESTIGACICON / DOCENCIA } \\
\text { INTERVENC.DE SUB-ESPECIALIDAD }\end{array}$ & & & & & & & st & SI \\
\hline
\end{tabular}

Fuente: MINSA

Tabla 5: Cuadro comparativo de tipos de hospital

\begin{tabular}{|c|c|c|}
\hline & II - 1 & \\
\hline DEFINICIÓN & $\begin{array}{l}\text { E.S. Brinda atención integral ambulatoria y hospitalaria } \\
\text { en cuatro especialidades básicas }\end{array}$ & $\begin{array}{l}\text { E.S. Brinda atención integral ambulatoria y } \\
\text { hospitalaria especializada. }\end{array}$ \\
\hline $\begin{array}{c}\text { CARACTERIS } \\
\text { TICAS }\end{array}$ & $\begin{array}{l}\text { Población asignada y referencial. } \\
\text { Corresponde a hospital I }\end{array}$ & Población referencial regional \\
\hline $\begin{array}{l}\text { RECURSOS } \\
\text { HUMANOS }\end{array}$ & $\begin{array}{l}\text { Además de lo anterior cuenta con médico intemista, } \\
\text { pediatra, gineco-obstetra, cirujano general, } \\
\text { anestesiólogo, nutiricionista, psicólogo, tecnólogos } \\
\text { médicos y químico farmacéutico. }\end{array}$ & $\begin{array}{l}\text { Además de las anteriores otras especialidades } \\
\text { médico quinúricas (14) }\end{array}$ \\
\hline FUNCIONES & Todas las anteriores principalmente recupérativa & Recuperativo \\
\hline $\begin{array}{l}\text { TIPO DE } \\
\text { SERVICIOS }\end{array}$ & $\begin{array}{l}\text { Además de lo anterior, hospitalización, emergencia, } \\
\text { epidemiología, centro QX, centro obstétrico, } \\
\text { esterilización, rehabilitación, nutrición, diagnóstico por } \\
\text { imágenes, patología clínica y hemotera pia }\end{array}$ & $\begin{array}{l}\text { Además de lo anteiror anatomía patológica, } \\
\text { neonatología y UCI general }\end{array}$ \\
\hline $\begin{array}{l}\text { CAPACIDAD } \\
\text { RESOLUTIVA }\end{array}$ & $\begin{array}{l}\text { Atención integral a la demanda, según daños } \\
\text { trazadores de baja complejidad. } \\
\text { Atenciones integrales programáticas según etapas de } \\
\text { vida (MAIS) }\end{array}$ & $\begin{array}{l}\text { Atención intetgral a la demanda, según daños } \\
\text { trazadores de mediana complejidad }\end{array}$ \\
\hline
\end{tabular}

Fuente: MINSA 


\subsection{3 ÉNFASIS ARQUITECTÓNICO}

(La arquitectura y el paisaje como estimulador positivo del usuario en un entorno hospitalario)

“Los espacios físicos pueden afectar los resultados del tratamiento y la satisfacción de los pacientes, la satisfacción del personal y los resultados de la organización. Los efectos pueden ser positivos y negativos. No existen ambientes neutrales” (Bambarén Alatrista, 2008)

\subsubsection{EL PAISAJE EN LA ARQUITECTURA}

“El acto de la construcción puede ser brutal cuando se construye en un sitio donde está la naturaleza, es una lucha, un ataque por nuestra cultura, en esta confrontación, me esfuerzo por hacer un edificio que hará que la gente sea más consciente de la belleza del entorno y que cuando miren el edificio haya una esperanza para crear una nueva conciencia de ver la belleza allí también”. (Sverre Fehn) ${ }^{5}$

“Arquitectura es la lucha constante entre el hombre y la naturaleza, la lucha para abrumar a la naturaleza, para poseerla. El primer acto de la arquitectura es poner una piedra en el suelo. Ese acto transforma una condición de la naturaleza en una condición de la cultura; que es un acto sagrado". (Mario Botta) ${ }^{6}$

“La arquitectura del paisaje es la disciplina que conforma tres elementos la arquitectura, la ciudad y el medio ambiente. Se podría considerar una prolongación de la arquitectura hacia sus alrededores e influye en el diseño de formas arquitectónicas”. (Plazola Cisneros, 1995-2001).

Según A. Plazola 2001 en las primeras culturas como Egipto y Mesopotamia se ve las primeras intervenciones de la arquitectura del paisaje como los jardines en los templos o los parques reales, en Grecia también se refleja en los alrededores de los templos como lugares de placer y relajo. En China se creaba una atmósfera de soledad y aislamiento de respeto pues consideraban la naturaleza como parte de ellos caso similar con Japón que se traduce en una expresión del profundo amor hacia la naturaleza y del deseo de estar en síntesis constante con ella.

\footnotetext{
${ }^{5}$ The Architect Says, Laura S Dushkes pag-58

${ }^{6}$ The Architect Says, Laura S Dushkes pag- 77
} 
Hoy en día los parques y jardines no se pueden concebir como elementos independientes ya que no sólo hay que tener en cuenta la escala urbana y humana, sino también el carácter para el que es concebido, tomando en cuenta la arquitectura, el paisaje y la ciudad.

Figura 56: Ejemplo de integración de la Arquitectura y el paisaje Hospital John Klinikum Minden Wesling - Alemania

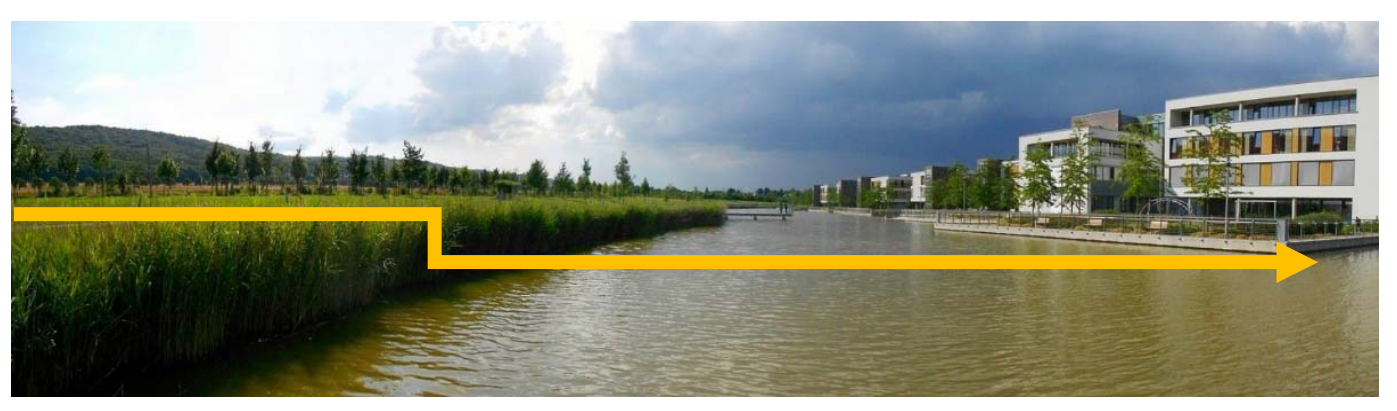

Fuente: http://www.tmk-architekten.de/de/projekte/projekt,4553 Edición propia

\subsubsection{LOS ENTORNOS CURATIVOS.}

La importancia del medio ambiente construido para la salud del paciente y el bienestar viene discutiéndose desde 400 a.C con Hipócrates en la teoría de los 4 temperamentos donde una de sus teorías se refiere a la capa instintivo-afectiva de la personalidad del paciente, en la que influye el entorno que lo rodea dominando su humor y motivación.

"La salud del hombre es un estado dado por la naturaleza, la cual no emplea elementos extraños sino una cierta armonía entre el espíritu, la fuerza vital y la elaboración de los humores”. (Hipócrates)

En el siglo 19 con Florence Nightingale promovió la importancia de la iluminación y ventilación natural y de la tranquilidad para la curación diciendo "los proveedores de salud deben poner al paciente en las mejores condiciones posibles para que la naturaleza pueda actuar y la curación se produzca.” (Zborowsky, Terri, 2015)

Según estudios realizados por el Center Health Design (organización norteamericana dedicada a en los últimos años, los efectos que causan los entornos físicos en el proceso de curación y recuperación de la salud han demostrado ser cada vez más relevantes para los pacientes, familiares y el Staff médico, estos estudios se realizaron en establecimientos de salud (hospitales), los cuales probaron lo antes mencionado. 
En la década de los 90's las soluciones de diseño en la asistencia sanitaria, con base en investigaciones publicadas, se definieron como: "Diseño basado en la Evidencia" (EBD en inglés), es decir basado en los resultados de los estudios previos, lo cual dio como resultado que "los entornos de curación a través de EBD, hacen hospitales menos estresantes, promueven la curación más rápida para los pacientes y mejoran el bienestar de sus familias, así como la creación de un ambiente agradable, cómodo y seguro de trabajo para el personal.” (Huisman, Morales, Van Hoof y Kort, 2015).

Roger Ulrich profesor de la facultad de Arquitectura en la Universidad Tecnológica Chalmers en Suecia, es el investigador más citado internacionalmente en el diseño de la asistencia sanitaria basada en la evidencia, fue quien inició este movimiento de la EBD en los establecimientos de salud, quien comparó el efecto positivo de las vistas del paisaje natural en la recuperación de los pacientes de cirugía a comparación con los que fueron expuestos a una vista de pared de ladrillos. A continuación un cuadro comparativo de los resultados.

Tabla 6: Cuadro comparativo de resultados

\begin{tabular}{|c|c|c|c|c|}
\hline & ESTANCIA & MEDICAMENTOS & COMPLICACIONES & COMENTARIOS \\
\hline $\begin{array}{l}\text { GRUPO } 1 \\
\text { VISTA A } \\
\text { PAISAJE }\end{array}$ & $\begin{array}{c}\text { ESTANCIA POST } \\
\text { OPERATORIA } \\
\text { CORTA }\end{array}$ & $\begin{array}{c}\text { MENOS MEDICINAS } \\
\text { MODERADAMENTE } \\
\text { FUERTES }\end{array}$ & $\begin{array}{c}\text { PUNTAJES DE } \\
\text { COMPLICACIONES } \\
\text { BAJOS }\end{array}$ & $\begin{array}{c}\text { COMENTARIOS } \\
\text { VALORATIVOS } \\
\text { POSITIVOS HACIA LA } \\
\text { ATENCIÓN }\end{array}$ \\
\hline $\begin{array}{l}\text { GRUPO } 2 \\
\text { VISTA A } \\
\text { PARED }\end{array}$ & $\begin{array}{c}\text { ESTANCIA POST } \\
\text { OPERATORIA } \\
\text { PROLONGADA }\end{array}$ & $\begin{array}{l}\text { MAS MEDICINAS } \\
\text { MODERADAMENTE } \\
\text { FUERTES }\end{array}$ & $\begin{array}{c}\text { PUNTAJES DE } \\
\text { COMPLICACIONES } \\
\text { ALTOS }\end{array}$ & $\begin{array}{c}\text { COMENTARIOS } \\
\text { VALORATIVOS } \\
\text { POSITIVOS HACIA LA } \\
\text { ATENCIÓN }\end{array}$ \\
\hline
\end{tabular}

Fuente: Ulrich, R.S.; Simons, R.F.;Losito,B.D.; Fiorito,E.; Miles, M.A. Y Zelson, M. , 1991 Edición propia. El objetivo de la investigación de los entornos curativos es mostrar una visión de la evidencia de esta teoría La hipótesis es que los entornos de curación, a través de EBD, hacen hospitales menos estresantes y promueven la curación más rápida para los pacientes y mejorar el bienestar de sus familias, así como la creación de un ambiente agradable, cómodo y seguro para el personal. ${ }^{7}$ Según Roger Ulrich "los entornos de curación pueden ser considerados como inversiones inteligentes, ya que ahorran dinero, aumentan la eficiencia del personal, y reducen la estancia

\footnotetext{
7 “Entorno de curación”, E.R.C.M. Huisman, E. Morales, J Van Hoof, H.S.M. kort, Dinamarca
} 
hospitalaria del paciente, haciendo la estancia menos estresante". (Ulrich, R.S.; Simons, R.F.;Losito,B.D.; Fiorito,E.; Miles, M.A. Y Zelson, M. , 1991)

\subsubsection{RECOMENDACIONES SEGÚN EBD (DISEÑO BASADO EN LA EVIDENCIA)}

\section{$\underline{\text { REDUCCIÓN DE ERRORES }}$}

Que se traducen en las preocupaciones de los pacientes a ser sometidos a errores humanos por parte del staff médico, esto se puede relacionar con el medio físico y la iluminación.

La igualdad de la concepción de las habitaciones, cuando las habitaciones son idénticas el personal puede encontrar la misma distribución y el mismo diseño e iluminación de esta manera se familiariza con el espacio y haciendo que la atención sea rutinaria y simple lo cual disminuye los errores que pueda haber por parte del personal.

Según Booker y Roseman, investigadores sobre los entornos curativos, investigaron un patrón estacional de los errores de medicación en un hospital en Alaska, esta investigación consistió en calibrar la iluminación de los consultorios de menor a mayor potencia, el cual el de nivel más alto arrojaba menos errores de medicación. ${ }^{8}$

\section{$\underline{\text { AUMENTO DE LA SEGURIDAD }}$}

En este punto se refiere a las intervenciones y elementos arquitectónicos que se deben tomar en cuenta para aumentar la seguridad de los usuarios, asi como también la reducción de caídas, infecciones, mejoras en la higiene y accesibilidad.

Tabla 7: Tabla de recomendaciones para el aumento de la seguridad

\footnotetext{
8 "Un patrón estacional de los errores de medicación hospitalario en Alaska” JM. Booker, C. Roseman. 1995
} 


\begin{tabular}{|c|c|c|}
\hline $\begin{array}{c}\text { REDUCCIÓN DE } \\
\text { CAIIDAS }\end{array}$ & $\begin{array}{l}\text { REDUCCIÓN DE } \\
\text { INFECCIONES }\end{array}$ & $\begin{array}{l}\text { CALIDAD EN EL } \\
\text { INTERIOR }\end{array}$ \\
\hline $\begin{array}{l}\text { SE DEBEN TOMAR EN } \\
\text { CUENTA LA } \\
\text { FRAGIBILIDAD DE LOS } \\
\text { PACIENTES, LA } \\
\text { REDUCCION DE CAIDAS } \\
\text { EN LA INVESTIGACIÓN } \\
\text { FUE DE UN } 30 \% \text { A UN } \\
17 \% .\end{array}$ & $\begin{array}{l}\text { EXPLICA COMO EL DISEÑO } \\
\text { DE LA HABITACIÓN PUEDE } \\
\text { AYUDAR A LA REDUCCION } \\
\text { DE LA PROPAGACIÓN DE } \\
\text { VIRUS. LA LIMPIEZA ESTÁ } \\
\text { RELACIONADA CON LAS } \\
\text { INFECCIONES QUE A SU } \\
\text { VEZ TAMBIEN SE } \\
\text { RELACIONA CON LOS } \\
\text { MATERIALES UTILIZADOS } \\
\text { EN UN HOSPITAL }\end{array}$ & $\begin{array}{l}\text { EN ESTE PUNTO SE } \\
\text { RECOMIENDA TENER } \\
\text { AMBIENTES CON } \\
\text { VENTILACIÓN NATURAL, } \\
\text { LIBRES DE POLVO, } \\
\text { MALOS OLORES, Y } \\
\text { TEMPERATURA } \\
\text { RELATIVA }\end{array}$ \\
\hline
\end{tabular}

Fuente: “Entorno de curación”, E.R.C.M. Huisman, E. Morales, J Van Hoof, H.S.M. kort. Edición propia.

\section{MEJORAR EL CONTROL}

Según Ulrich, hay una tendencia que está creciendo en algunos Hospitales que consiste en dar a los pacientes control sobre su propio espacio, en este caso la habitación, es decir controlar las posiciones de la cama por controles, temperatura, luces y ventilación. Esto al darles cierto control, hace que se sientan seguros, con lo cual hace que sus emociones sean positivas.

Privacidad.- la privacidad se da en las habitaciones, consultorios y salas de espera. La investigación demostró que cada espacio mencionado necesita privacidad tanto para el paciente como para el médico, esto se puede traducir en espacios acústicos o en la distribución adecuada.

Según Mlinek y Pierce "las conversaciones oyen por casualidad en el mostrador de recepción era el principal problema en la sala de espera."

\section{CONFORT}

para lograr el confort se debe tomar en cuenta los materiales, el confort visual, confort acústico y el arte, estos temas influyen en el entorno físico de un paciente.

Materiales.- este tema es el más discutido en el área de hospitalización, unos apoyan que el material sea un material fácil de limpiar mientras que otros dicen que un material más cálido como la alfombra ayudaría a la recuperación del paciente pues se asocia frecuentemente al entorno de un hogar. Sin embargo este último material va en contra de las recomendaciones de tener superficies lavables en un hospital.

Arte.- según Ulrich y Giplin las obras de arte que sean "psicológicamente apropiadas", incluyendo aquellas imágenes que representen temas de paisajes naturales, o arte figurativo que muestren 
gestos emocionales positivos puede reducir el estrés y mejorar los resultados. Sin embargo las obras que sean abstractas o que tengan imágenes ambiguas, pueden provocar reacciones negativas entre los pacientes.

Confort visual.- el confort visual se logra a través de la luz natural, luminosidad y la intensidad. El acceso de la luz natural o intensidad de la misma crea un impacto positivo en los pacientes.

Tabla 8: Comparativo del uso de la luz

\begin{tabular}{|c|c|c|}
\hline EASTMAN & LEWY & BEAUCHEMIN Y HAYS \\
\hline $\begin{array}{c}\text { utiliza el tratamiento } \\
\text { con luz brillante para } \\
\text { la depresión }\end{array}$ & $\begin{array}{c}\text { comparó la luz } \\
\text { matutina y vespertina } \\
\text { para tratamiento de } \\
\text { depresión }\end{array}$ & $\begin{array}{c}\text { concluyó que los } \\
\text { pacientes tenian } \\
\text { estancias mas cortas } \\
\text { si se encontraban en } \\
\text { habitaciones } \\
\text { soleadas. }\end{array}$ \\
\hline
\end{tabular}

Fuente: “Entorno de curación”, E.R.C.M. Huisman, E. Morales, J Van Hoof, H.S.M. kort. Edición propia.

Confort acústico.- Blomkvist, investigador sobre la acústica y el ambiente psicosocial en una unidad de cuidados intensivos, mostró que las condiciones acústicas mejoradas ayudan al entorno sanitario a reducir los riesgos de conflictos y errores, los efectos negativos del ruido están asociados con la recuperación de los pacientes y el aumento del nivel de estrés de los mismos. Para lograr una adecuada acústica hay que tener en cuenta la presión sonora y los tiempos de reverberación.

\section{$\underline{\text { APOYO FAMILIAR }}$}

Si bien es cierto el apoyo de los visitantes es importante para la recuperación de los pacientes, también hay consecuencias como la transmisión de infeccione. En este estudio se demostró que no hubo tasas de infección asociadas a los horarios de visita.

Los investigadores Foss y Tenholde aseguran en los entornos curativos que los familiares de lo pacientes en UCI (Unidad de Cuidados Intensivos) deberían de contar con sala de espera y alojamiento además de información frecuente sobre el paciente, proximidad a él, apoyo emocional, y un entorno físico para atender sus necesidades básicas como servicios higiénicos, teléfono, muebles y alimentación las 24 horas del día.

La mayoría de la composición de los hospitales en nuestro país son bloques o pabellones los cuales por su forma y orientación no dejan una posibilidad a una conexión directa con el paisaje, que es lo 
mínimo que en un proyecto relacionado a la salud debe tener, ya sea una paisaje natural o manipulado por el hombre, el entorno físico se ha convertido en un punto más importante en el diseño de nuevos hospitales, es así que en nuestro país se ha publicado un libro donde se muestra la importancia de la humanización de los espacios, la reducción del estrés del personal y otros temas relacionados al entorno hospitalario, este libro se titula "programa médico arquitectónico para el diseño de hospitales seguros" fue publicado en el año 2008 y debería ser la base para cualquier planeamiento de un establecimiento de Salud.

\subsubsection{SENSACIONES Y PERCEPCIONES}

"La sensación es la impresión que percibe un ser vivo cuando uno de sus órganos receptores es estimulada. Sensaciones olfativas, visuales, táctiles. Sensación de dolor.” (RAE, 2015)

“La sensación se refiere a experiencias inmediatas básicas, generadas por estímulos aislados simples.” (MATLIN \& FOLEY, 1996)

“La sensación también de define como la respuesta de los órganos de los sentidos frente a un estímulo.” (Feldman, 1999)

“La percepción es la interpretación de esas sensaciones, dándoles, significado y organización.” (MATLIN \& FOLEY, 1996)

“La organización, interpretación, análisis e integración de los estímulos, es la actividad de nuestros órganos sensoriales y también de nuestro cerebro.” (Feldman, 1999)

En palabras simples la sensación es lo que sentimos frente a algo y la percepción es el análisis de esa sensación

En síntesis las sensaciones son impresiones inmediatas ante un estímulo, cuando esta sensación se convierte en significado se convierte en percepción.

En la arquitectura las sensaciones serían la primera impresión que uno tiene al momento de ingresar a un espacio y la percepción sería cuando el usuario detecta que tipo de espacio es en el que se encuentra.

En el entorno hospitalario estas sensaciones y percepciones son muy importantes debido a que se integrará el diseño arquitectónico con el entorno natural para que causen un impacto positivo en el usuario a través de las sensaciones. 


\subsubsection{GLOSARIO DE TÉRMINOS}

Hoy en día la arquitectura hospitalaria ha evolucionado en cuanto a tema de sostenibilidad, de confort, y de humanización; esto se logra teniendo en cuenta diferentes factores tales como:

Áreas libres / Espacios abiertos.- estos espacios se pueden dividir en público y privado; el primero sería aquel que rodea el equipamiento como zonas de espera los privados pueden estar nexo a la zona de hospitalización donde los pacientes puedan tener una visual a ello y poder calmar las ansias de su enfermedad, o cercano a las oficinas de staff médico y/o administrativo para así ayudar a reducir el estrés de trabajo.

Iluminación.- la iluminación debería ser natural en la mayoría de los espacios del hospital "el uso apropiado de iluminación requiere la selección de un buen sistema en los puesto de trabajo para conseguir un cierto confort visual y evitar la fatiga visual.

Colores.- debido al constante estrés del staff médico se optó por la solución cromática, es decir utilizar una gama de colores dependiendo del usuario al que va dirigido en este caso los médicos, ya que estos colores provocan efectos psicológicos en el trabajador, por ejemplo para estimular serían los colores naranja, amarillo o violeta, pero en pequeñas superficies del ambiente, ya sean marcos de puertas, ventanas esto se podría aplicar en los consultorios u oficinas. A diferencia de la paleta de colores verdes y celestes que son necesarias para lugares de concentración en este caso podrían ser los quirófanos.

Acústica.- "los niveles de ruidos superiores a los 55-65 Db pueden provocar molestia al personal", esto se puede evitar teniendo en cuenta la separación acústica entre la zona de trabajo del personal y las habitaciones de los pacientes. Esto incluye pasillos y zona de enfermería.

Espacios privados.- llamo espacios sociales a aquellos espacios en los que los pacientes puedan meditar, relajarse o reducir su nivel de estrés estos ambientes pueden ser jardines, espacios libres, capillas, o espacios para la meditación

Espacios sociales.- estos espacios serían dirigidos a los visitantes y familiares de los pacientes el cual tendrá como objetivo ser confortable ya que será el lugar en el que pasará más tiempo a la vez que será el lugar de encuentro con el paciente y el médico.

Flexibilidad.- la arquitectura debe ser flexible ya que será propuesta en una ciudad en crecimiento y su estructura debe estar preparada para nuevas ampliaciones.

Arquitectura y Paisaje.- este último engloba todo lo mencionado es la combinación de la naturaleza con la arquitectura para jugar un rol importante en la recuperación del paciente así como también en el desempeño del staff médico y la reducción de estrés en los familiares. 
Si bien es cierto en el Perú la arquitectura hospitalaria sigue siendo un bloque frío, pues esto me impulsa a tomar con mayor interés el tema. 
CAPÍTULO 3 ANÁLISIS DE PROYECTOS

REFERENCIALES 


\subsection{HOSPITAL MARÍA AUXILIDORA}

Figura 57: lámina de análisis del hospital María Auxiliadora en Lima

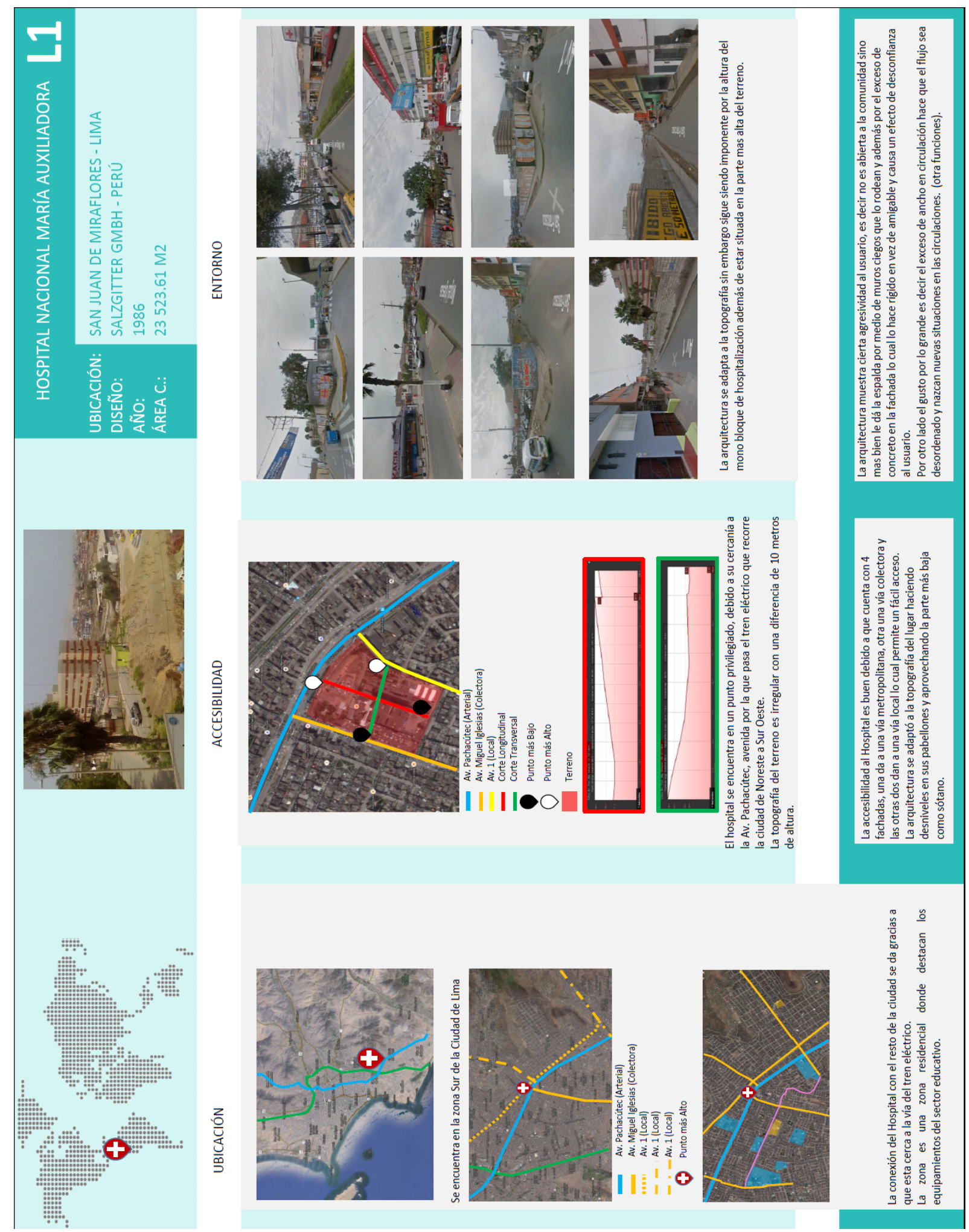

Fuente: Indicada en lámina Elaboración propia. 
Figura 58: lámina analítica Hospital María Auxiliadora

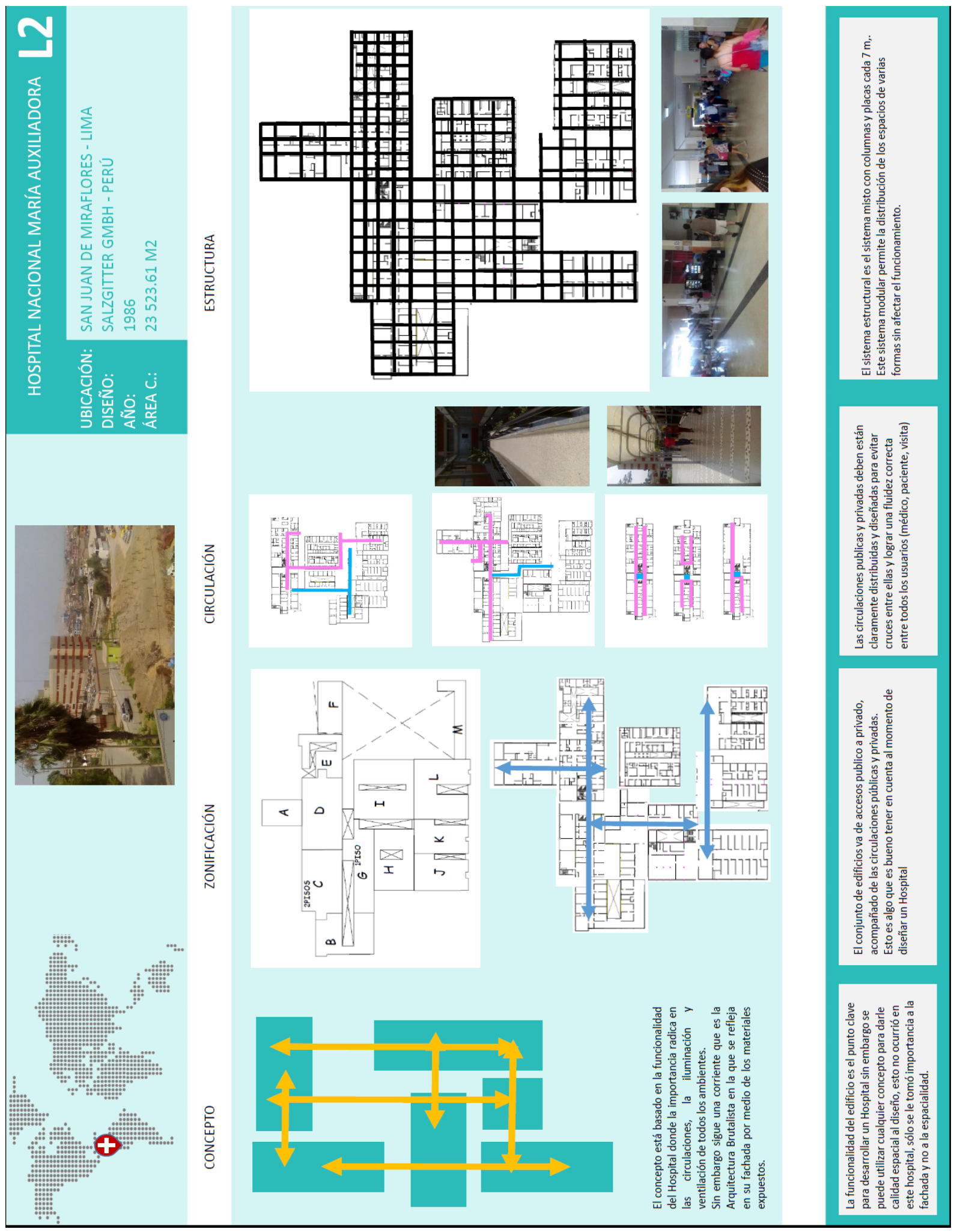

Fuente: Indicada en lámina Elaboración propia 
Figura 59: Lámina analítica Hospital María Auxiliadora

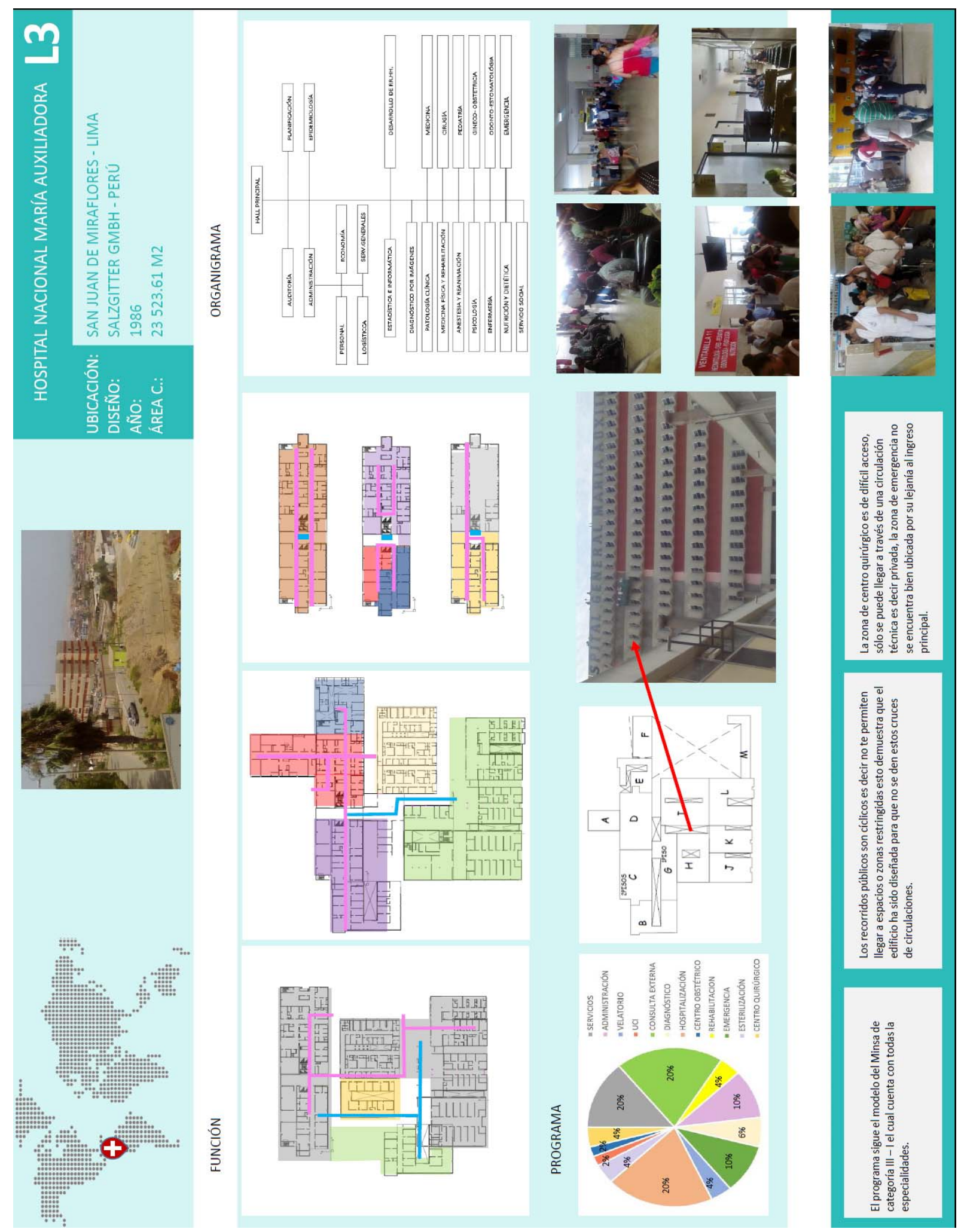

Fuente: Indicada en lámina Elaboración propia 


\subsection{HOSPITAL CAYETANO HEREDIA}

Figura 60: Lámina analítica Hospital Cayetano Heredia

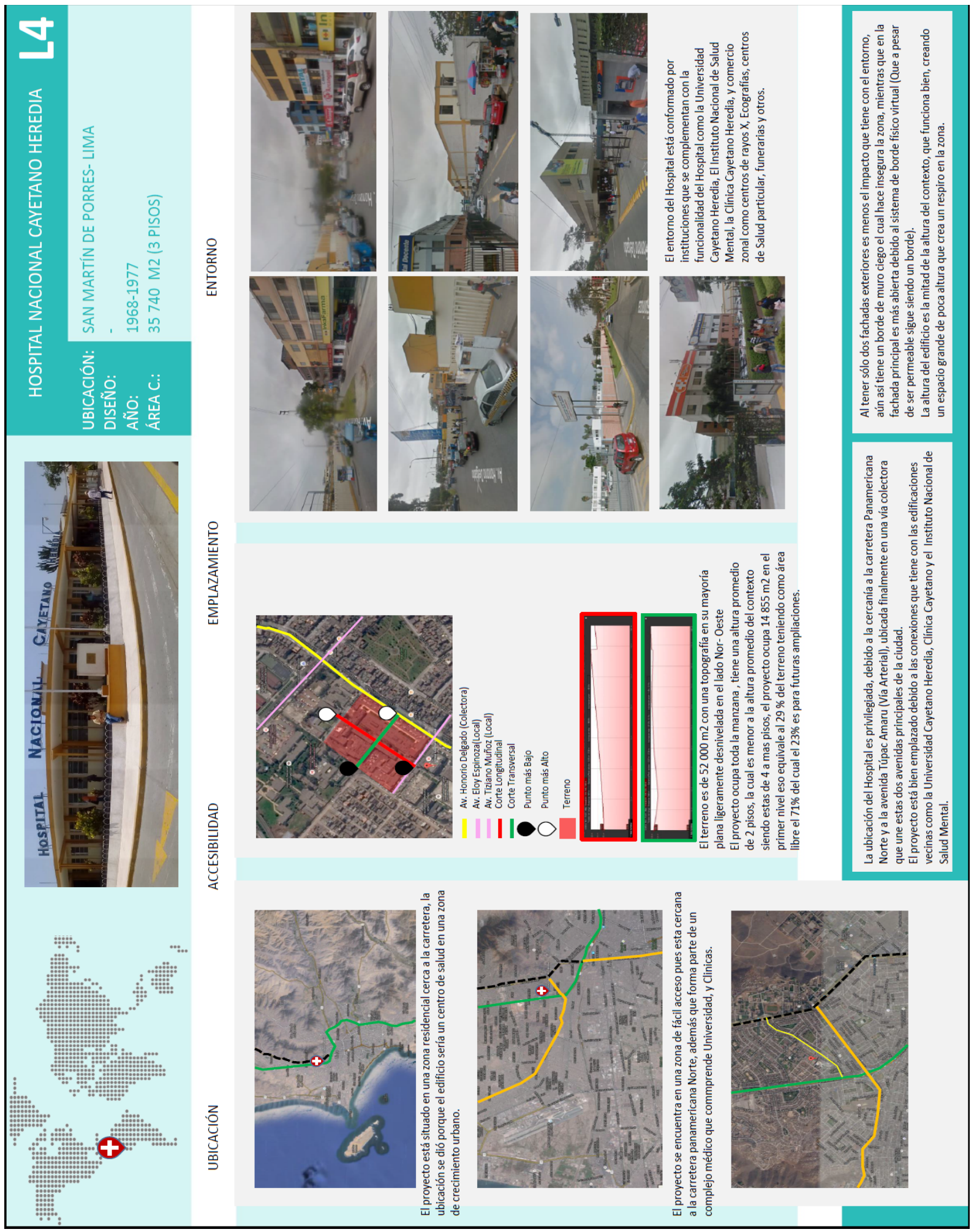

Fuente: Indicada en lámina Elaboración propia 
Figura 61: Lámina analítica Hospital Cayetano Heredia

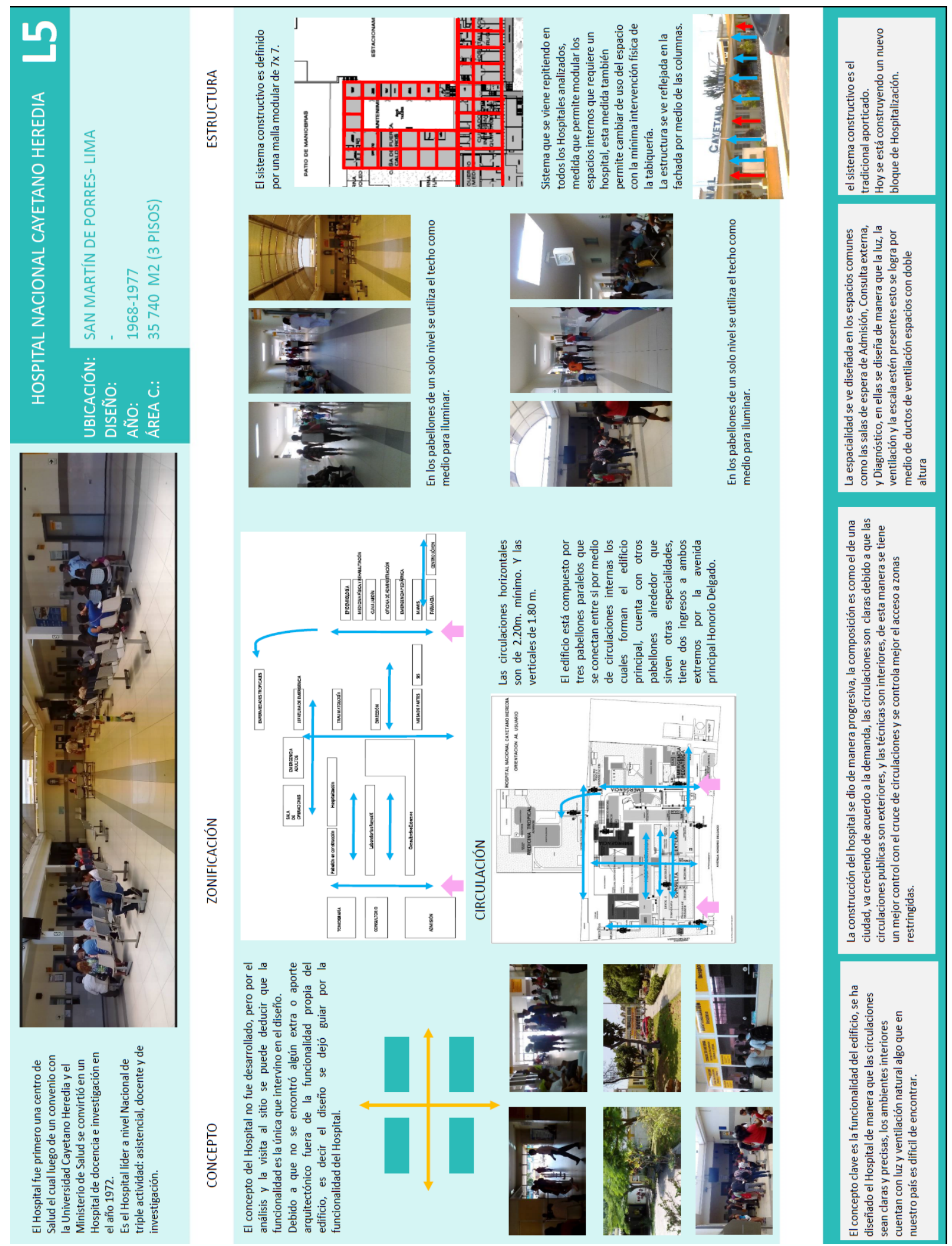

Fuente: Indicada en lámina Elaboración propia 
Figura 62: Lámina analítica Hospital Cayetano Heredia

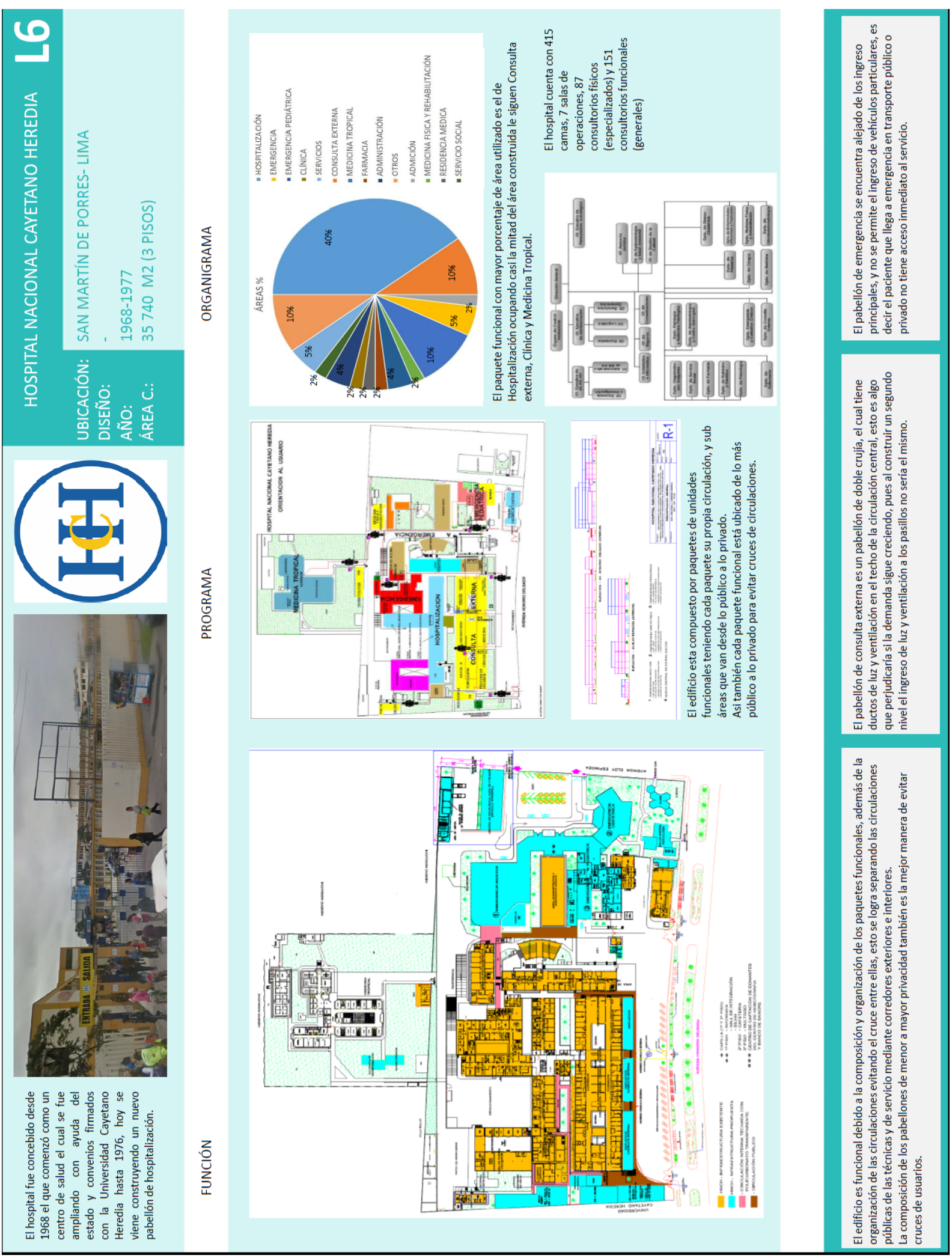

Fuente: Indicada en lámina Elaboración propia 


\subsection{HOSPITAL EL CARMEN DE MAIPÚ}

Figura 63: Lámina analítica Hospital El Carmen de Maipú

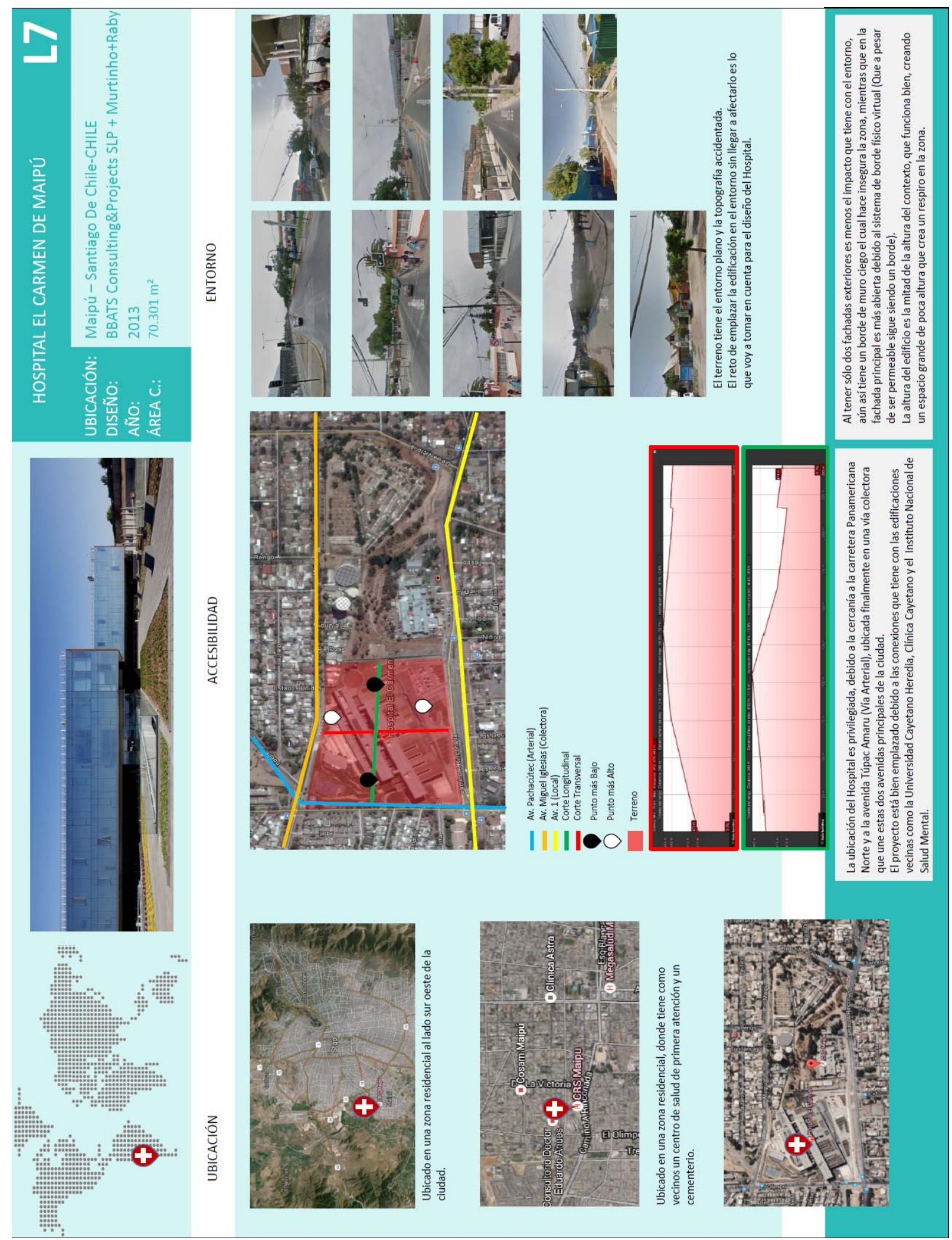

Fuente: Indicada en lámina Elaboración propia 
Figura 64: Lámina analítica Hospital El Carmen de Maipú

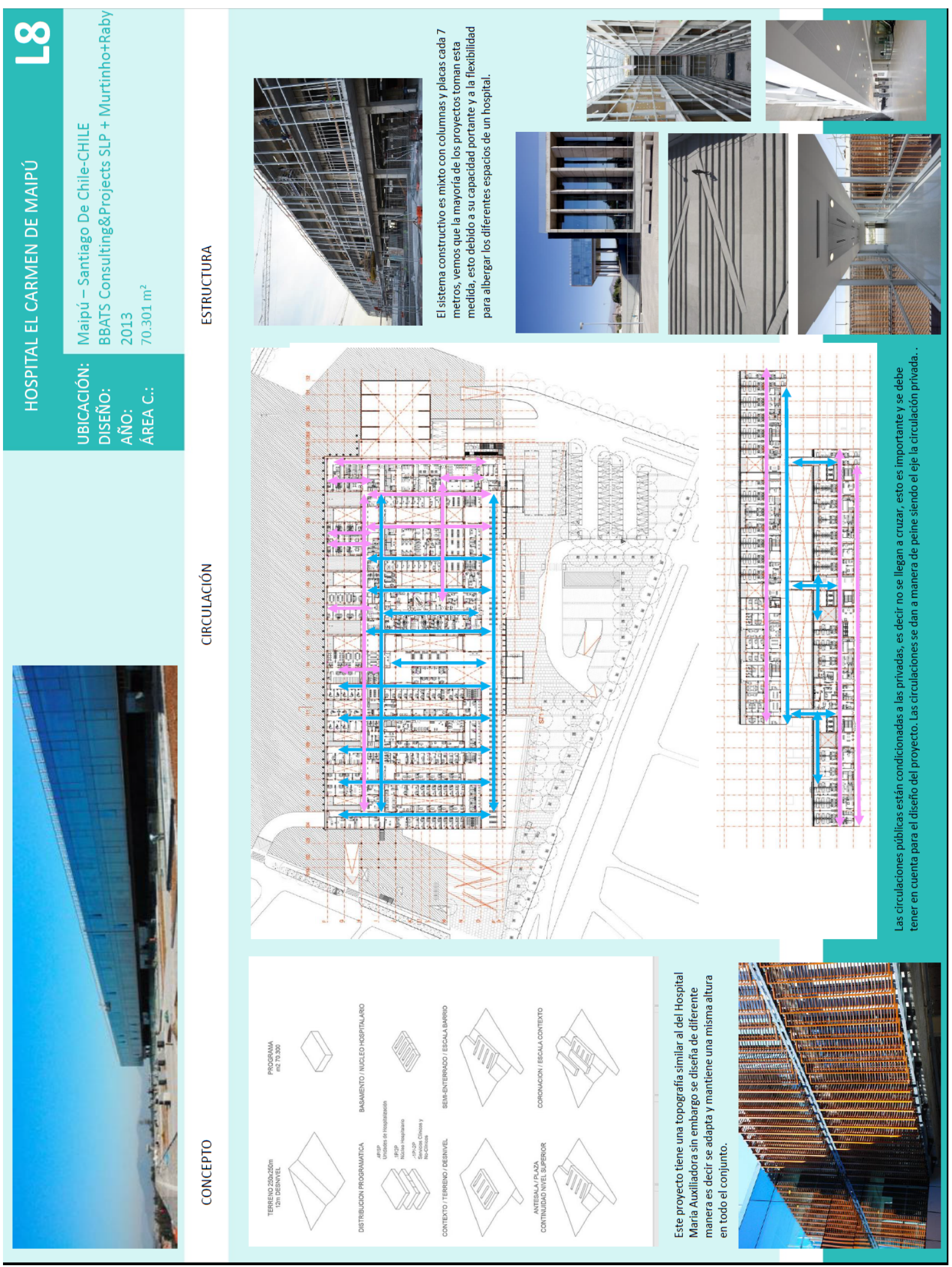

Fuente: Indicada en lámina Elaboración propia 
Figura 65: Lámina analítica Hospital El Carmen de Maipú

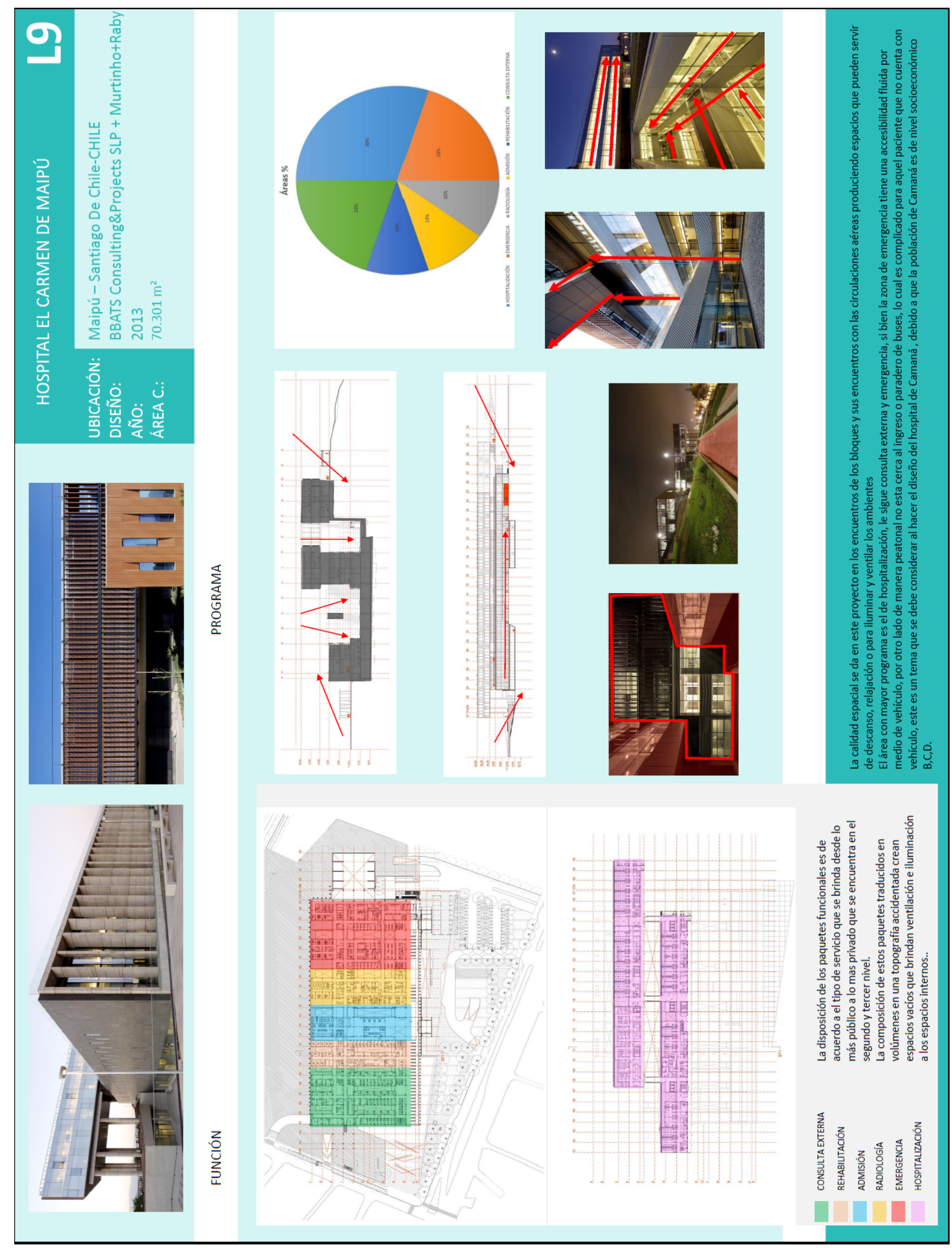

Fuente: Indicada en lámina Elaboración propia 


\subsection{HOSPITAL CLEMENTE ÁLVAREZ}

Figura 66: Lámina analítica Hospital Clemente Álvarez

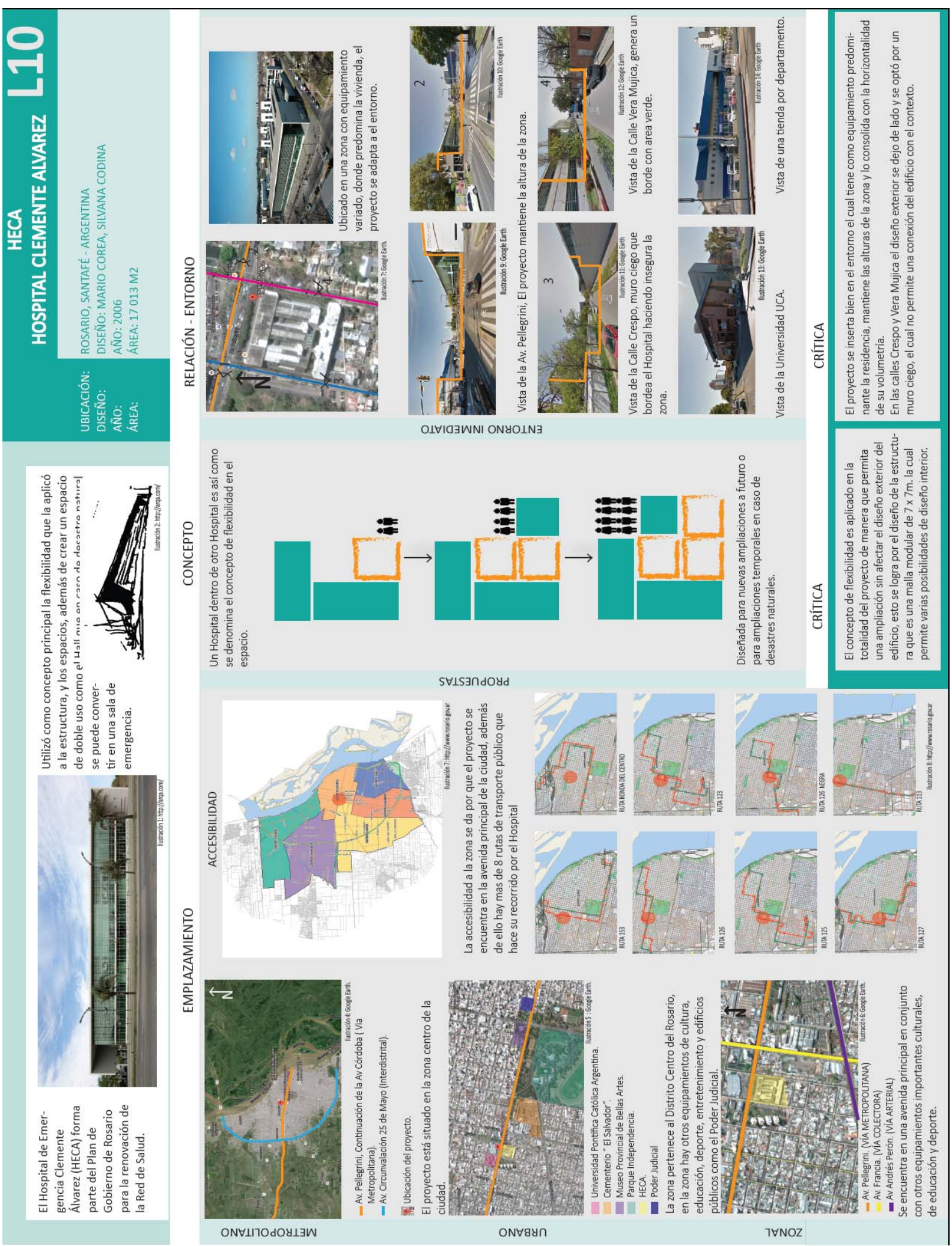

Fuente: Indicada en lámina Elaboración propia 
Figura 67: Lámina analítica Hospital Clemente Álvarez
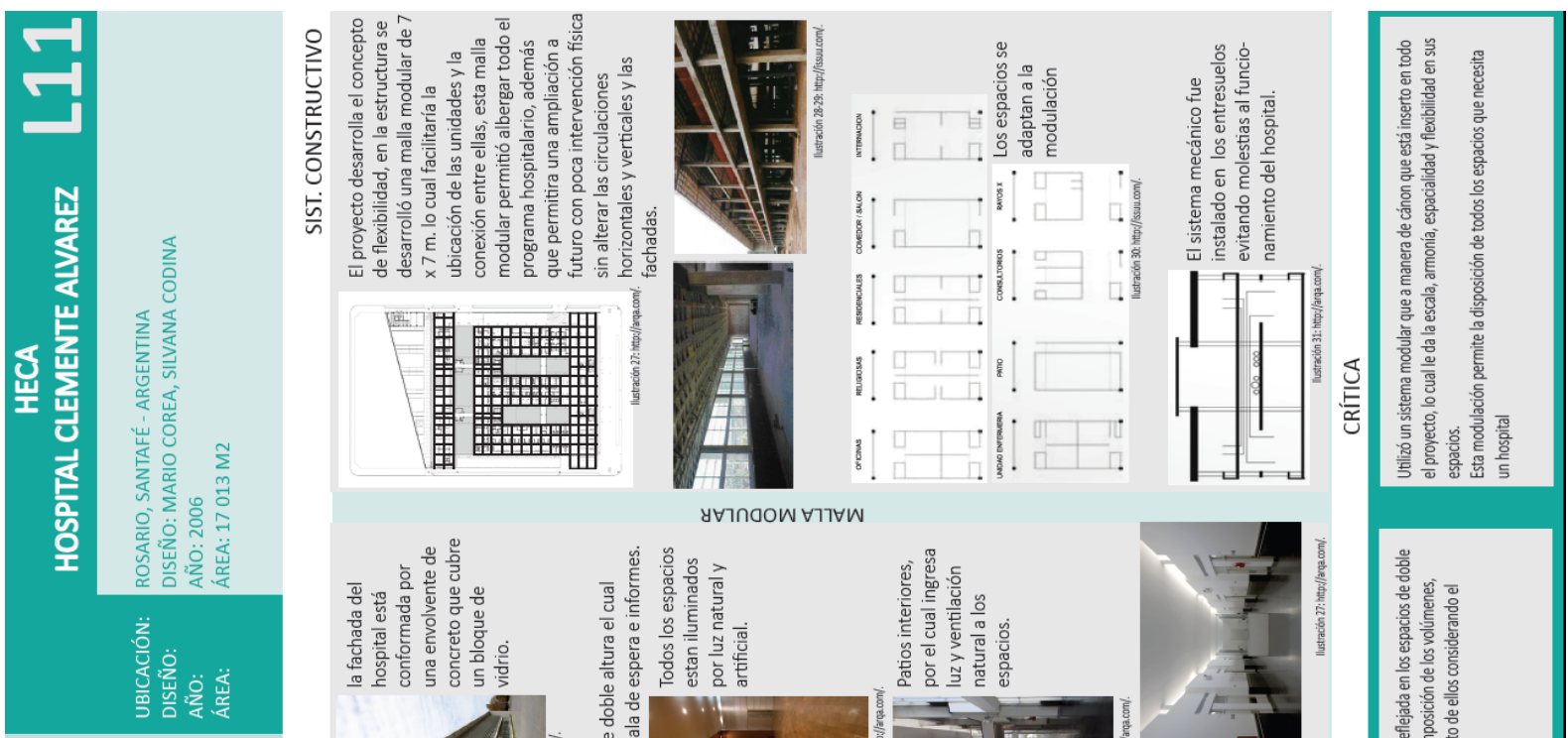

บทากอัพ $\forall า 7 \forall W$
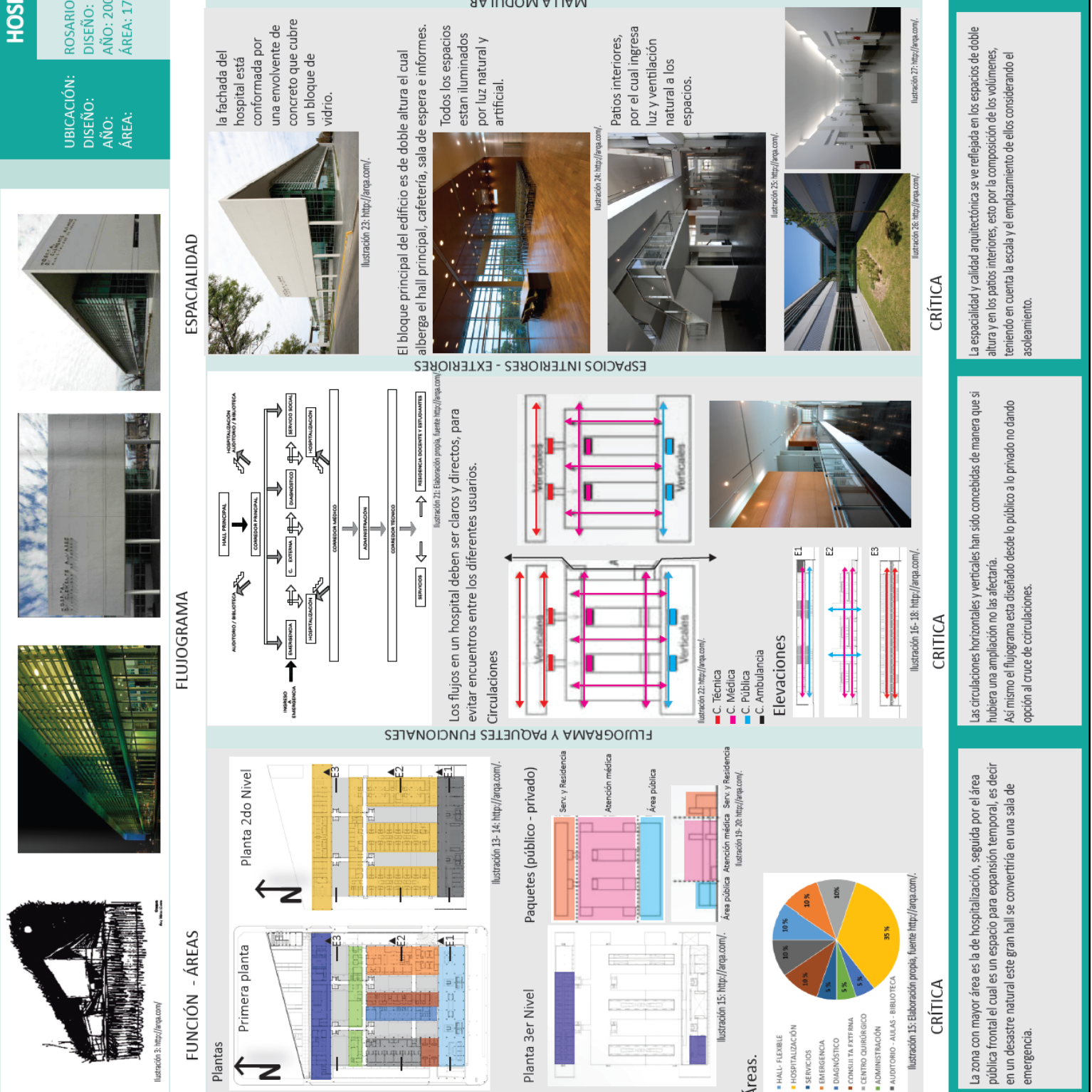

$$
\text { 1) }
$$$$
\div 2
$$
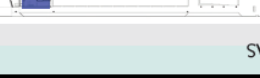

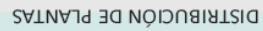

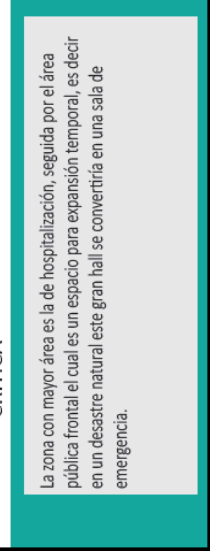

Fuente: Indicada en lámina Elaboración propia 


\subsection{HOSPITAL CAN MISSES}

Figura 68 : Lámina analítica Hospital Can Misses

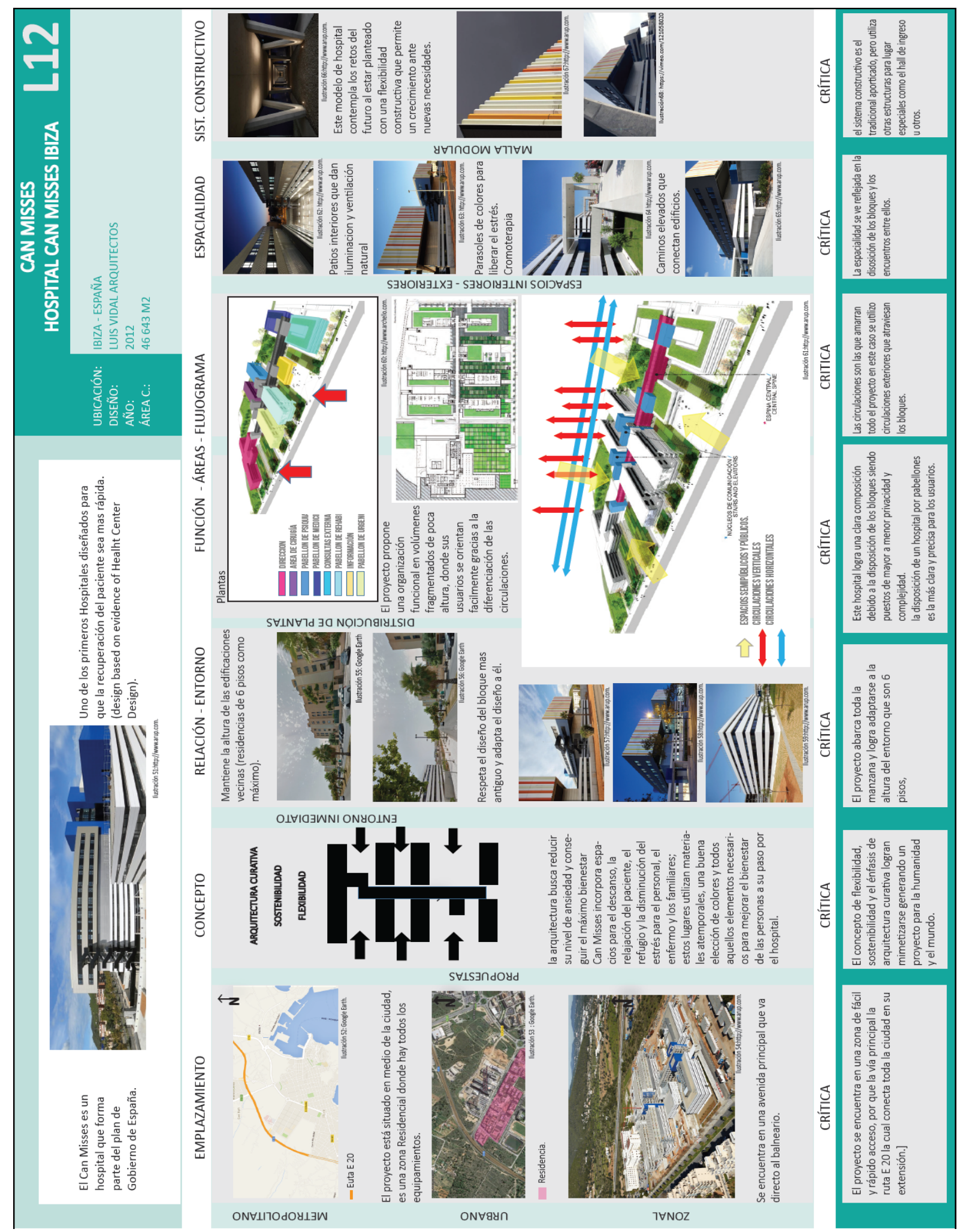

Fuente: Indicada en lámina Elaboración propia 


\subsection{HOSPITAL SWARZWALD}

Figura 69: Lámina analítica Hospital Swarzwald

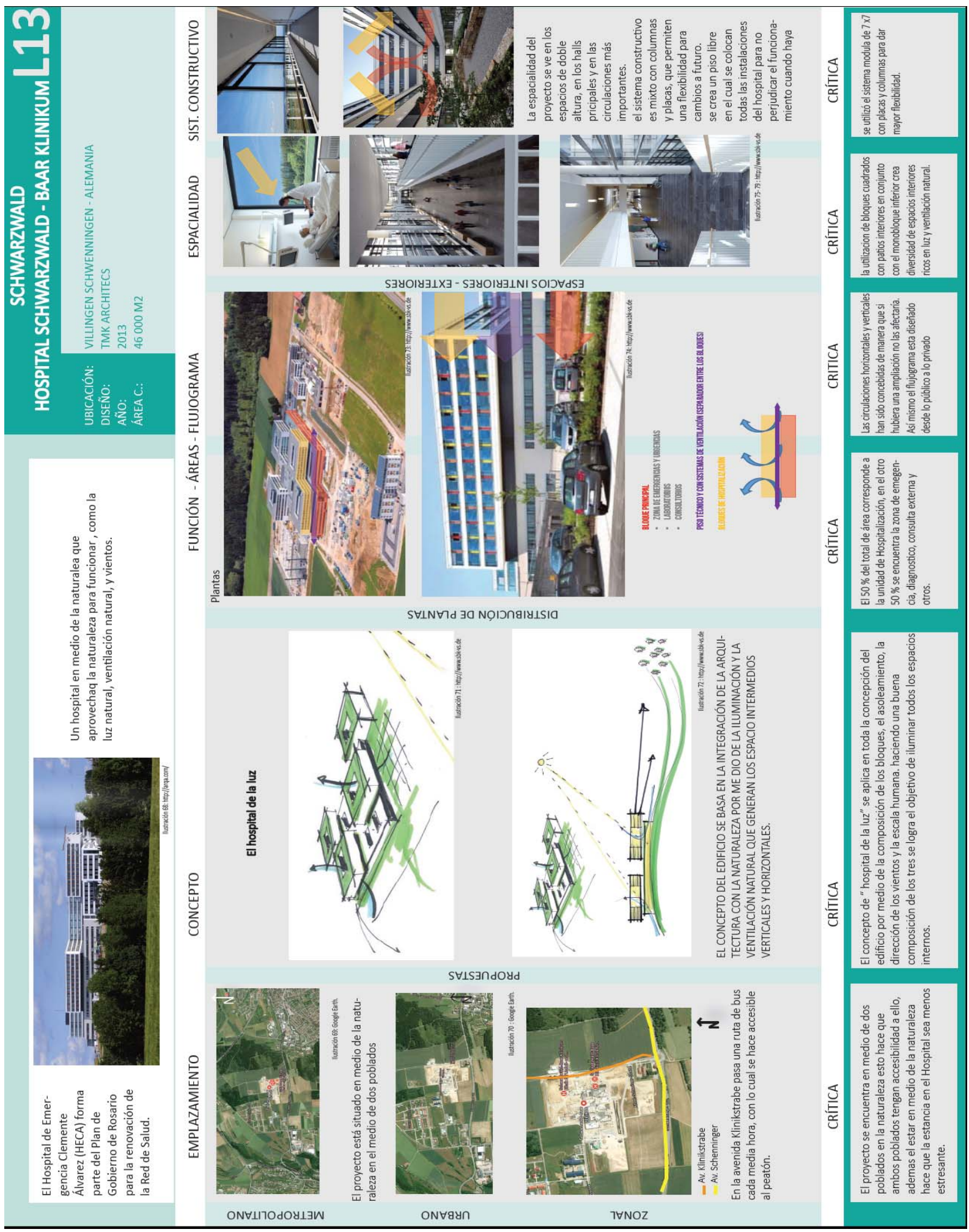

Fuente: Indicada en lámina Elaboración propia 


\subsection{HOSPITAL JOHANNES WESLING}

Figura 70: Lámina analítica Hospital Johannes Wesling

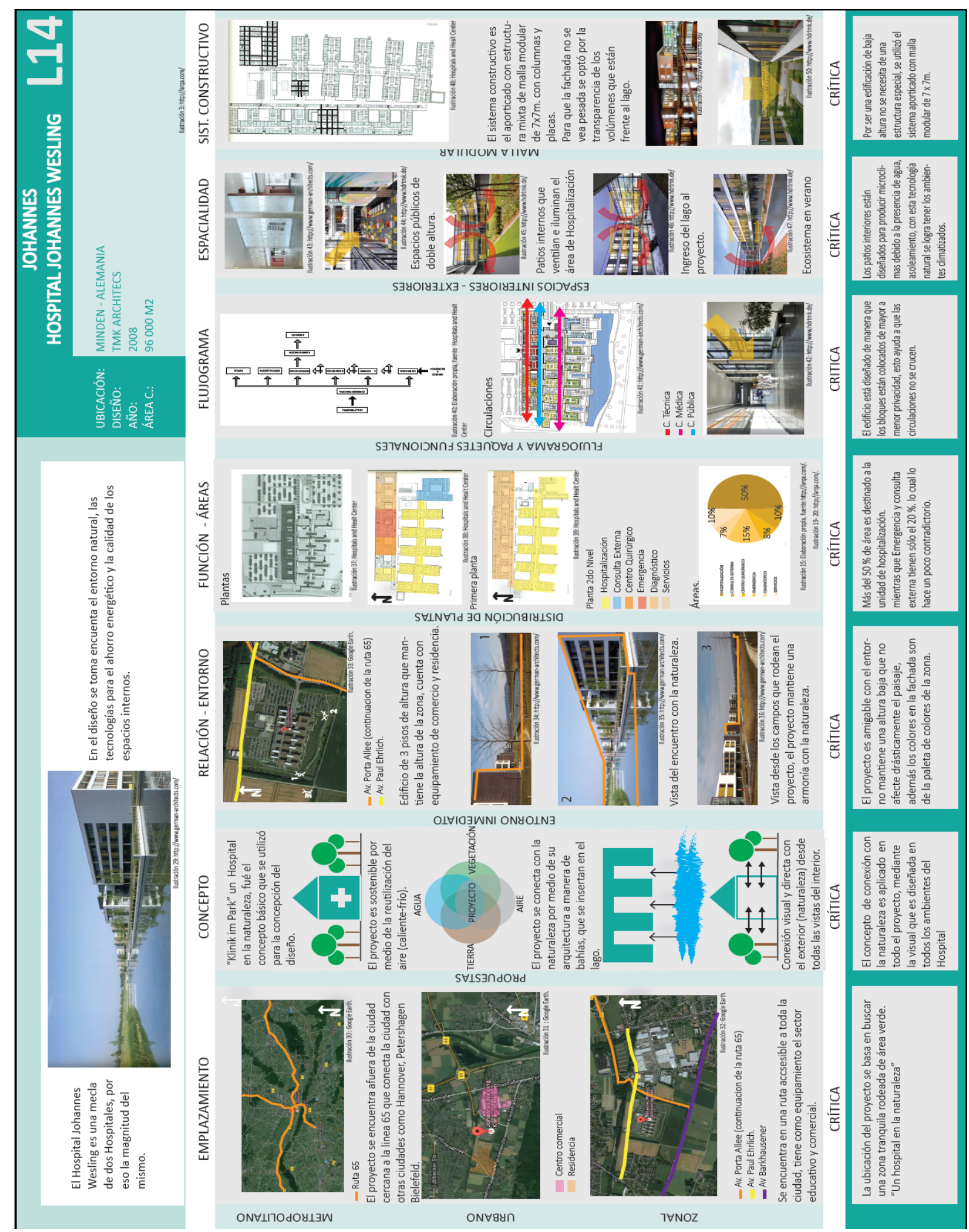

Fuente: Indicada en lámina Elaboración propia 
CAPÍTULO 4 - LUGAR 
La provincia de Camaná, posee un Hospital de Apoyo, 9 Centros de Salud y 30 Puestos de Salud (posta médica) en funcionamiento, sin embargo estos establecimientos se encuentran en deficientes condiciones.

\subsection{ANÁLISIS DEL LUGAR}

\subsubsection{LOCALIZACIÓN}

La provincia de Camaná - Arequipa es mi lugar natal, la cual tiene muchas deficiencias arquitectónicas pero la principal es un establecimiento de Salud.

Figura 71: Mapa Departamental del Perú

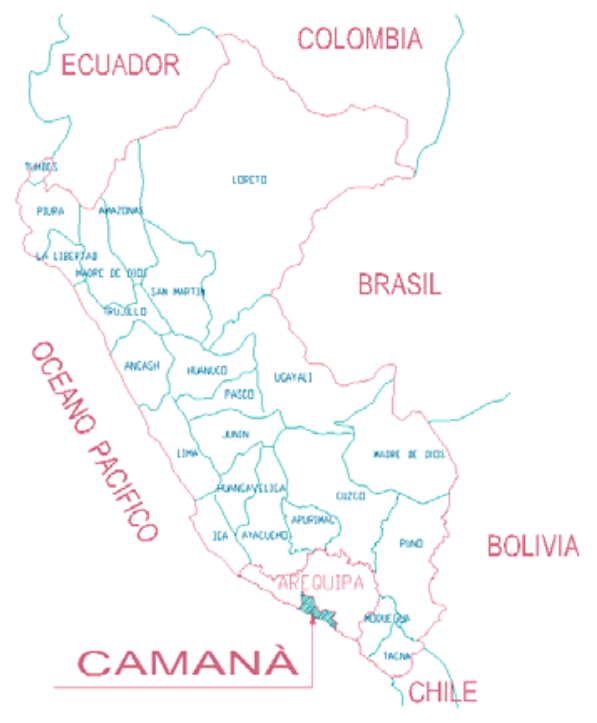

Fuente: Geresa Plan de Camaná 2015

Figura 72: Mapa del Provincial de Arequipa

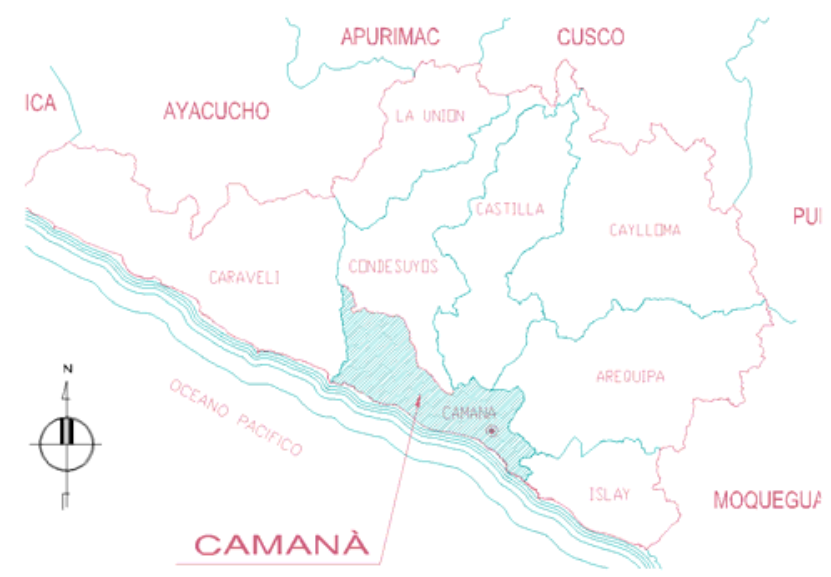

Fuente: Geresa Plan de Camaná 2015 
Figura 73: Mapa de Sectorización de la Red de Salud de Arequipa

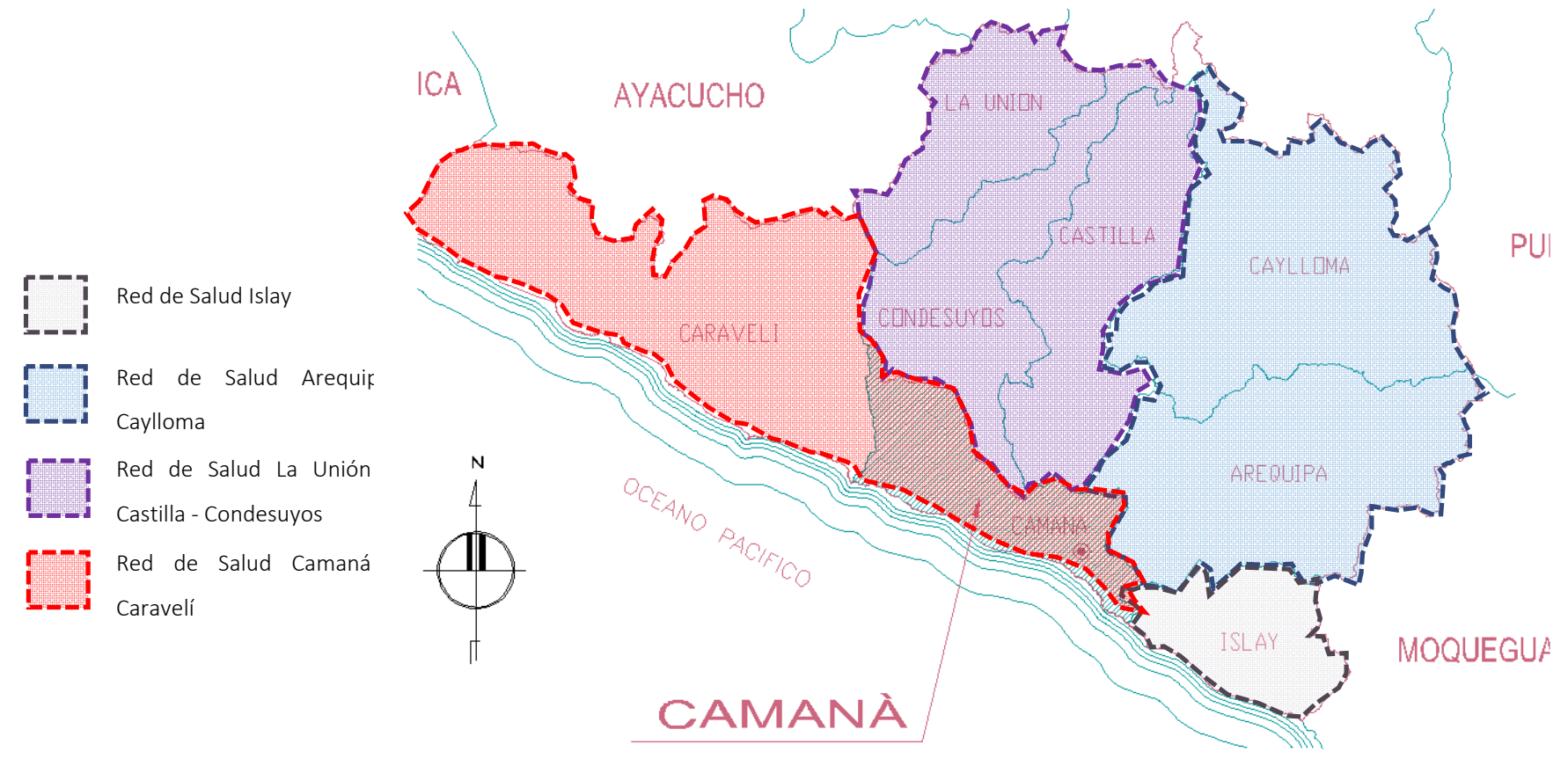

Fuente: Geresa Plan de Camaná 2015 


\subsubsection{FICHA TÉCNICA}

\section{CAMANÁ}

La provincia de Camaná se encuentra ubicado en la zona Sur oeste del Departamento de Arequipa al Sur del Perú a 179 Km de la Ciudad de Arequipa.

\begin{tabular}{|l|l|}
\hline DATOS & CIFRAS \\
\hline EXPANSIÓN & $5.36 \mathrm{Km} 2$ \\
\hline ALTITUD & DE OA 2,100 m.s.n.m. \\
\hline FUNDACIÓN & 09 DE NOVIEMBRE 1539 \\
\hline DISTRITOS & 8 \\
\hline$N^{\circ}$ DE HABITANTES & 58,939 \\
\hline LATITUD & $16^{\circ} 37^{\prime} 46^{\prime \prime}$ \\
\hline LONGITUD OESTE & $72^{\circ} 42^{\prime} 00^{\prime \prime}$ \\
\hline
\end{tabular}

Sus límites son:

-Por el Norte.- las provincias de Condesuyos, Castilla y Arequipa.

- Por el Noroeste.- la provincia de Caravelí.

- Por el Sur- Océano Pacífico.

- Por el Este.- las provincias de Islay y Arequipa.

\section{iii}

La población actual es de 58,952 habitantes, segun INEI

\section{3er la tercera provincia más poblada de Arequipa del Dpto. de Arequipa.}

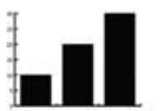

Tasa de crecimiento anual de $1.6 \%$ como lo señala el INEI.

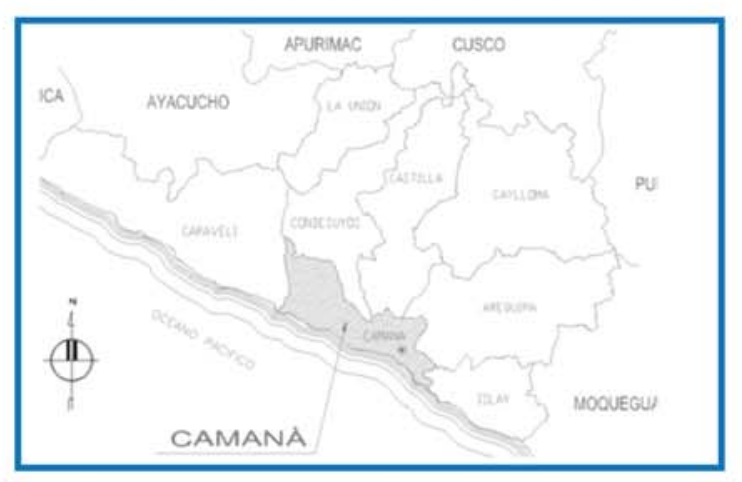

Fuente: Elaboración propia

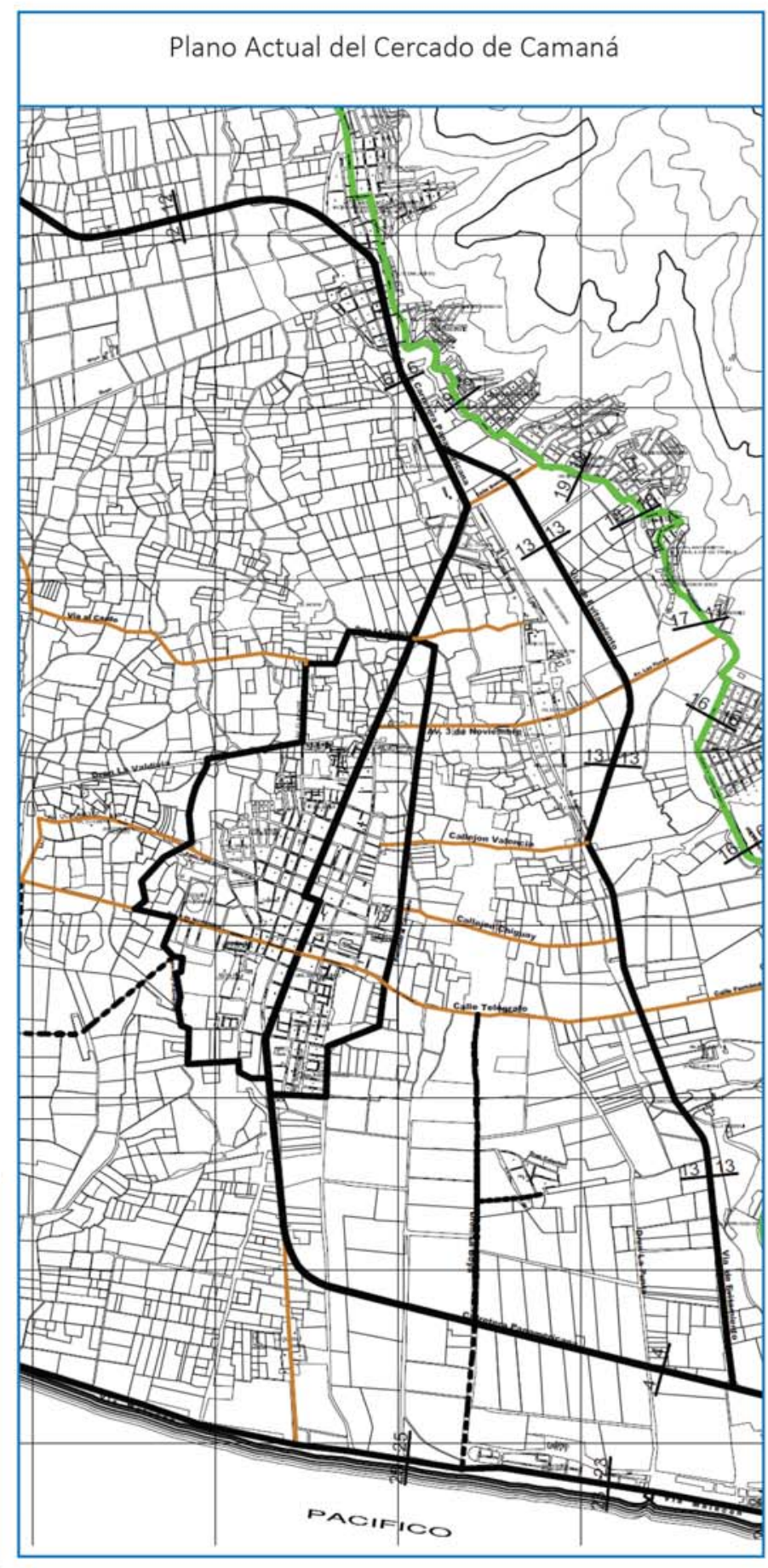




\subsubsection{EVOLUCIÓN Y CRECIMIENTO DE CAMANÁ}

La provincia de Camaná inició su crecimiento con los grupos étnicos Uros o Changos del Imperio Incaico, teniendo como fundación incaica la fecha del 1282 por el Inca Roca declarándola como "CAMANÁ".

En 1539 fue fundada por los españoles con el mismo nombre "Camaná - Villa hermosa".

Figura 74 - 61:Foto aérea
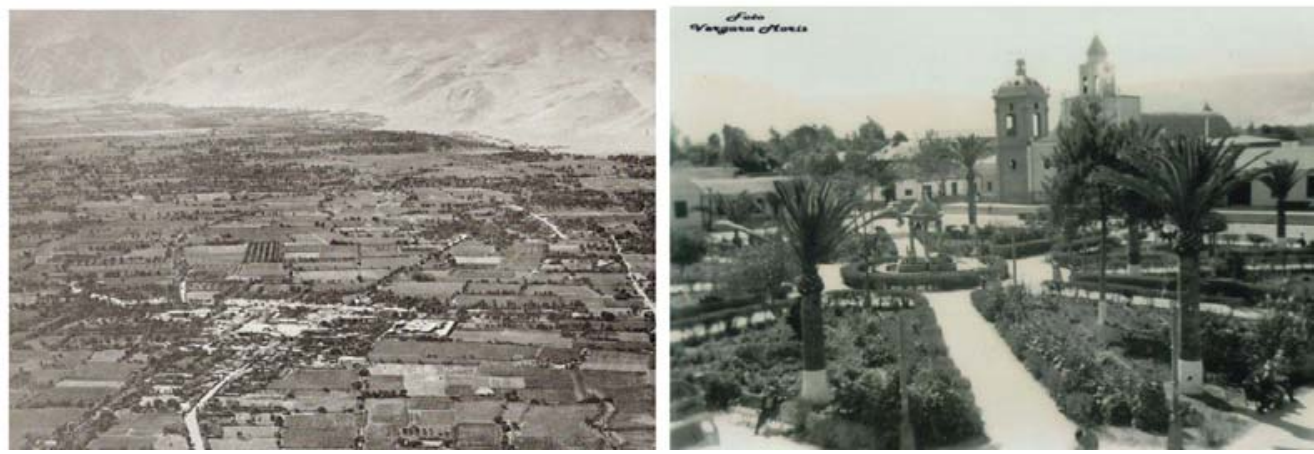

Fuente: http:/www.skycrapercity.com/show-thread.php't=6180038\&page=8

Figura 75: Evolución de Camaná

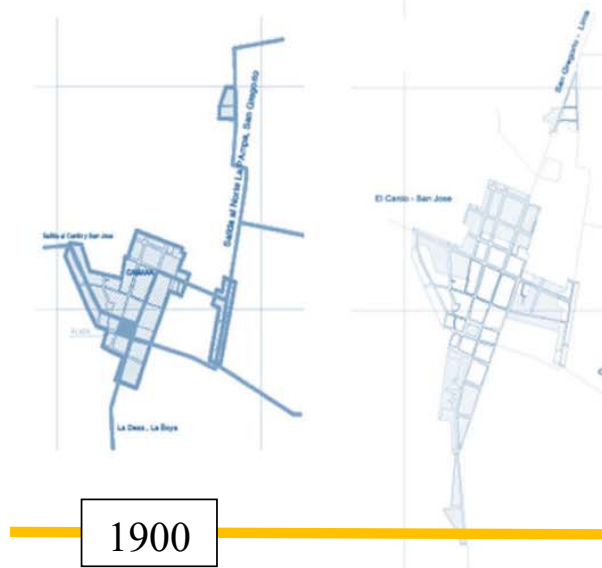

\section{0}
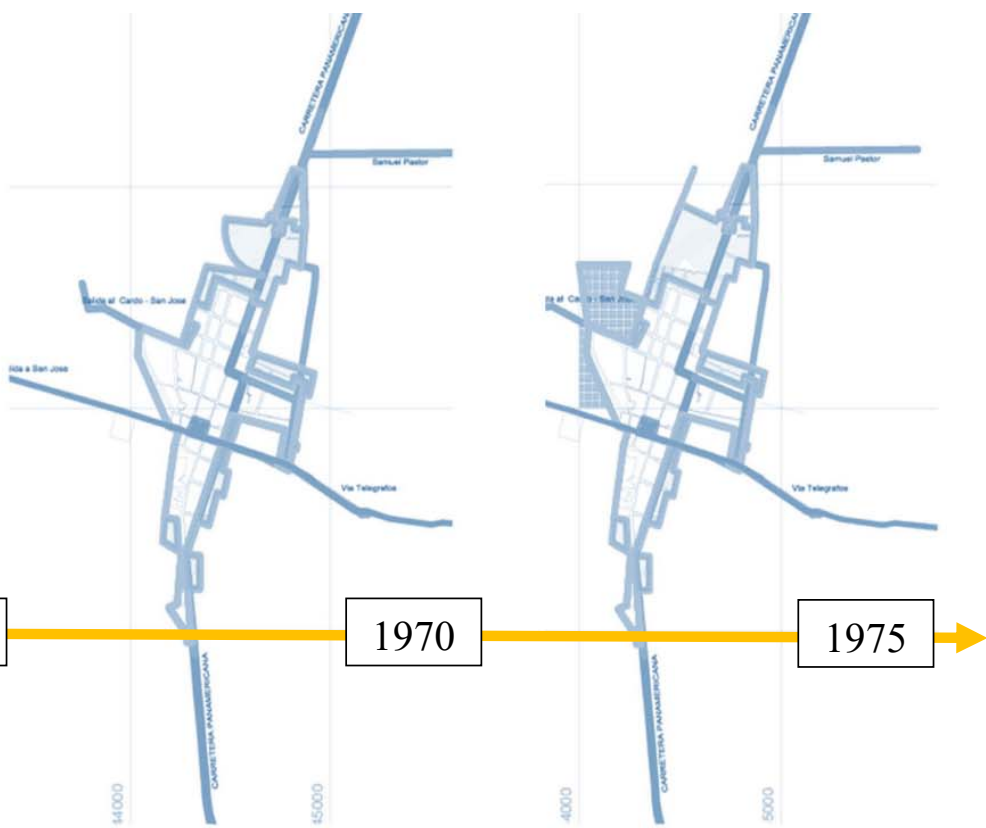

Fuente: Plan de Camaná 2015

El crecimiento territorial de Camaná se dio por medio de un damero inicial teniendo dos vías principales que son los ejes de la ciudad, las cuales son las avenidas más importantes de la ciudad. 


\subsubsection{CONDICIONES TERRITORIALES}

En este capítulo se muestra las condiciones territoriales del lugar.

\subsubsection{DE UBICACIÓN}




\section{A. TIPOS DE SUELOS}

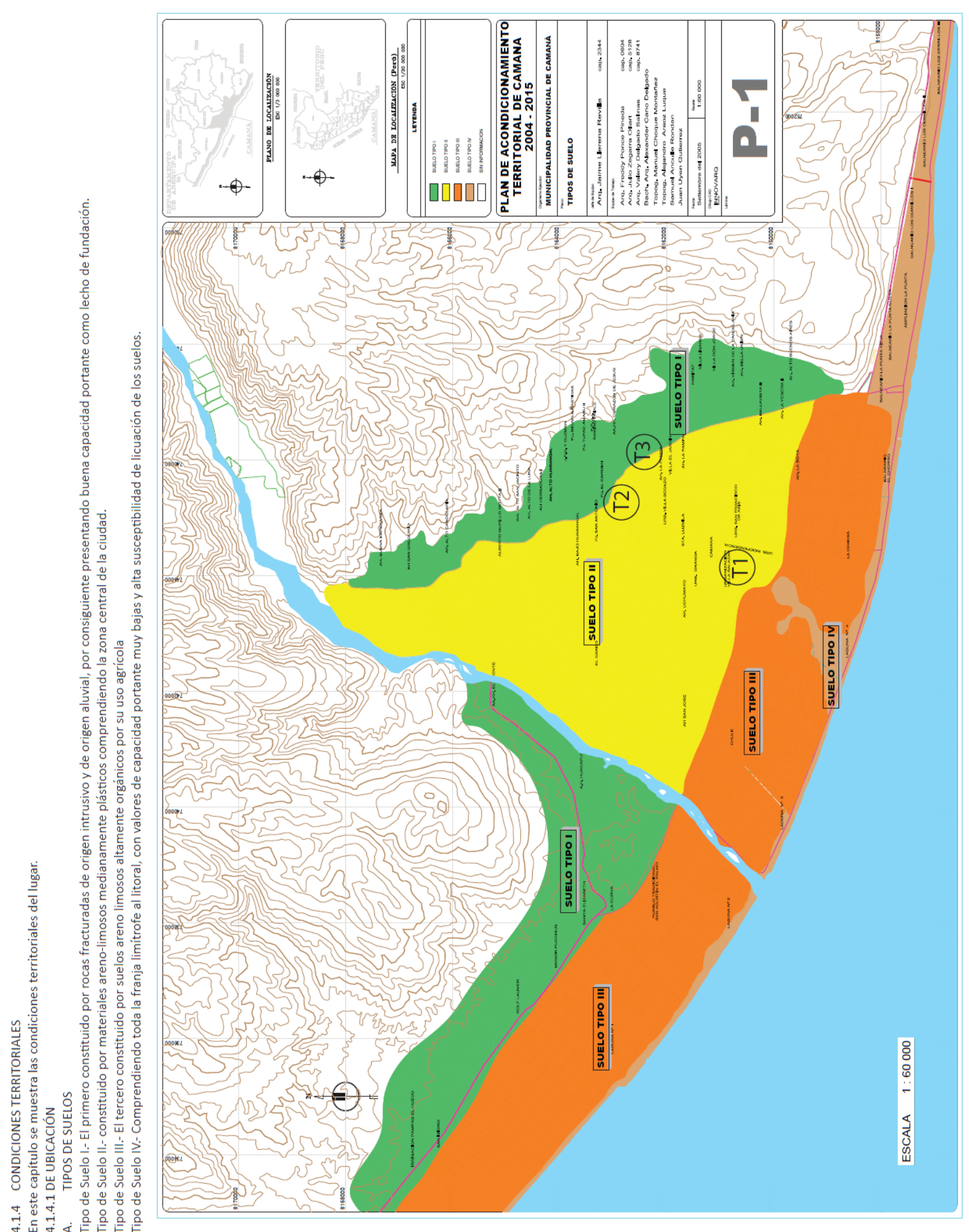

Fuente: Plan Camaná 2015, Edición propia. 


\section{B. PENDIENTES}

La provincia de Camaná tiene como pendiente de $0^{\circ}$ a $60^{\circ}$ dividiéndose en sub zonas. Agrícola de $0^{\circ}$ (Zona denominada al área que no tiene pendientes)

Pendiente $<15^{\circ}$

Pendiente $15^{\circ}$ a $30^{\circ}$

Pendiente $<60^{\circ}$

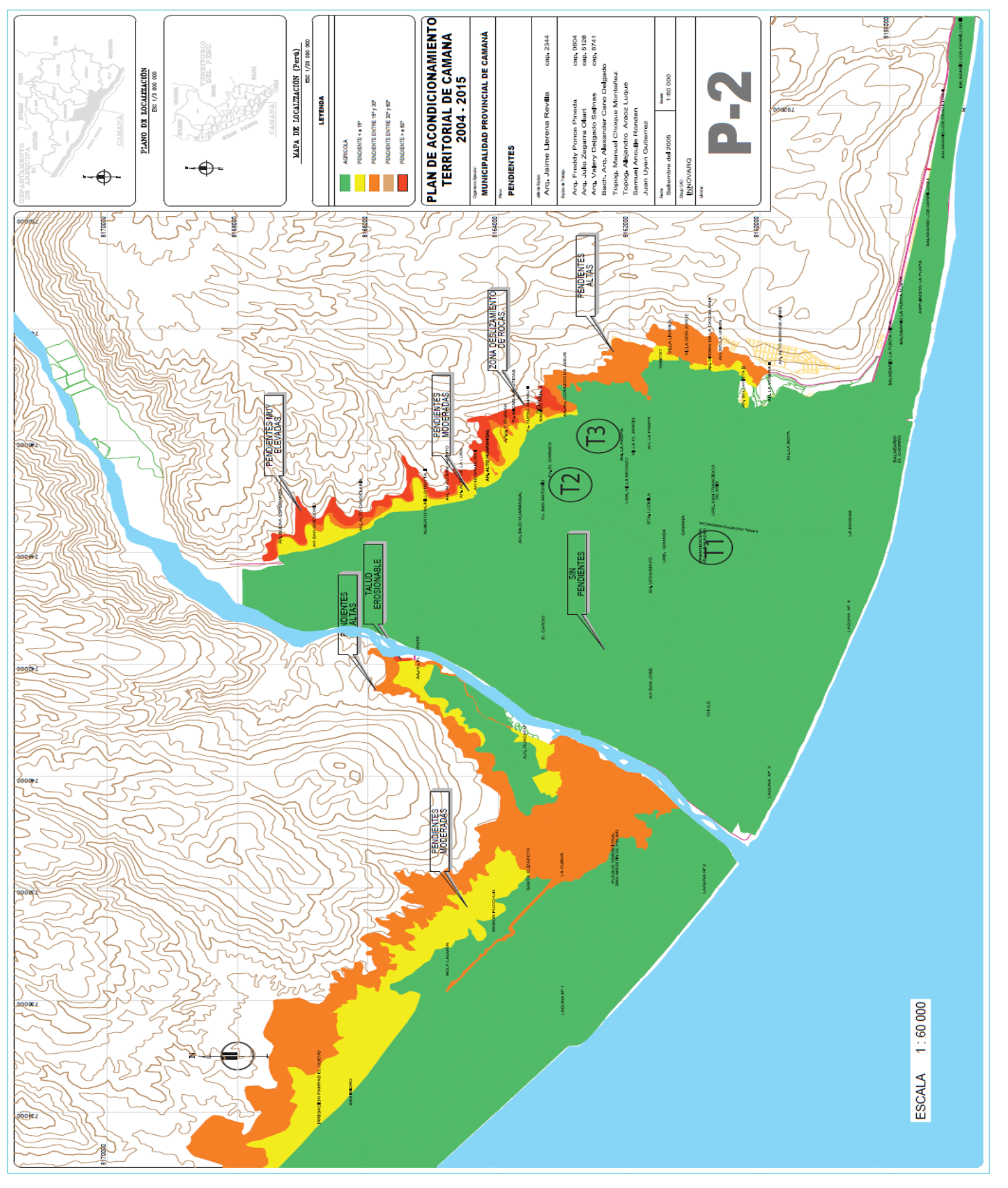

Fuente: Plan Camaná 2015, Edición propia. 


\section{MAPA DE QUEBRADAS}

Las quebradas se forman entre los cerros, los terrenos elegidos no se encuentran en dicha zona.

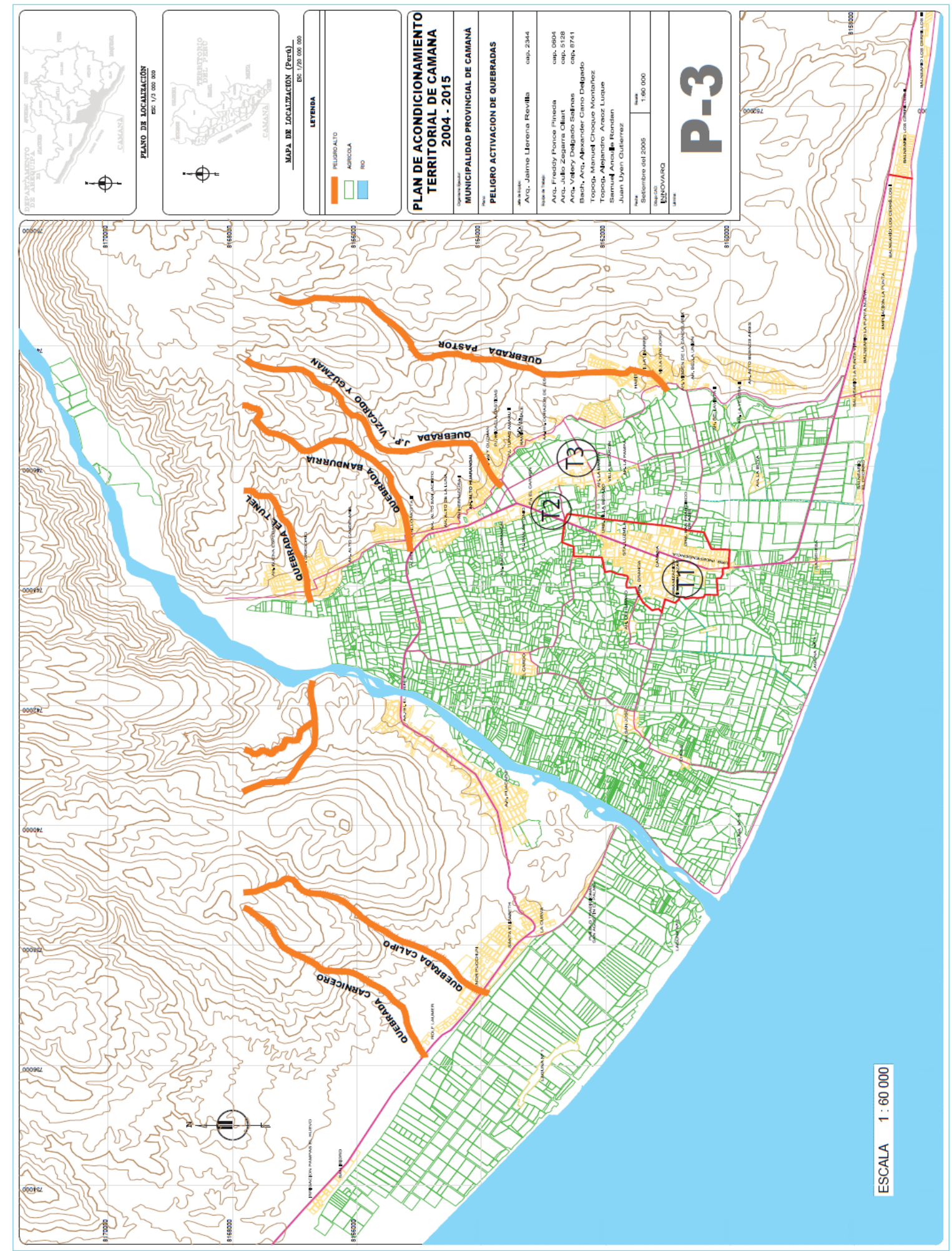

Fuente: Plan Camaná 2015, Edición propia 


\section{MAPA DE INUNDACIÓN POR DIQUE}

Se da inundación por dique en dos zonas al borde del río. Los terrenos elegidos están fuera de esta área.

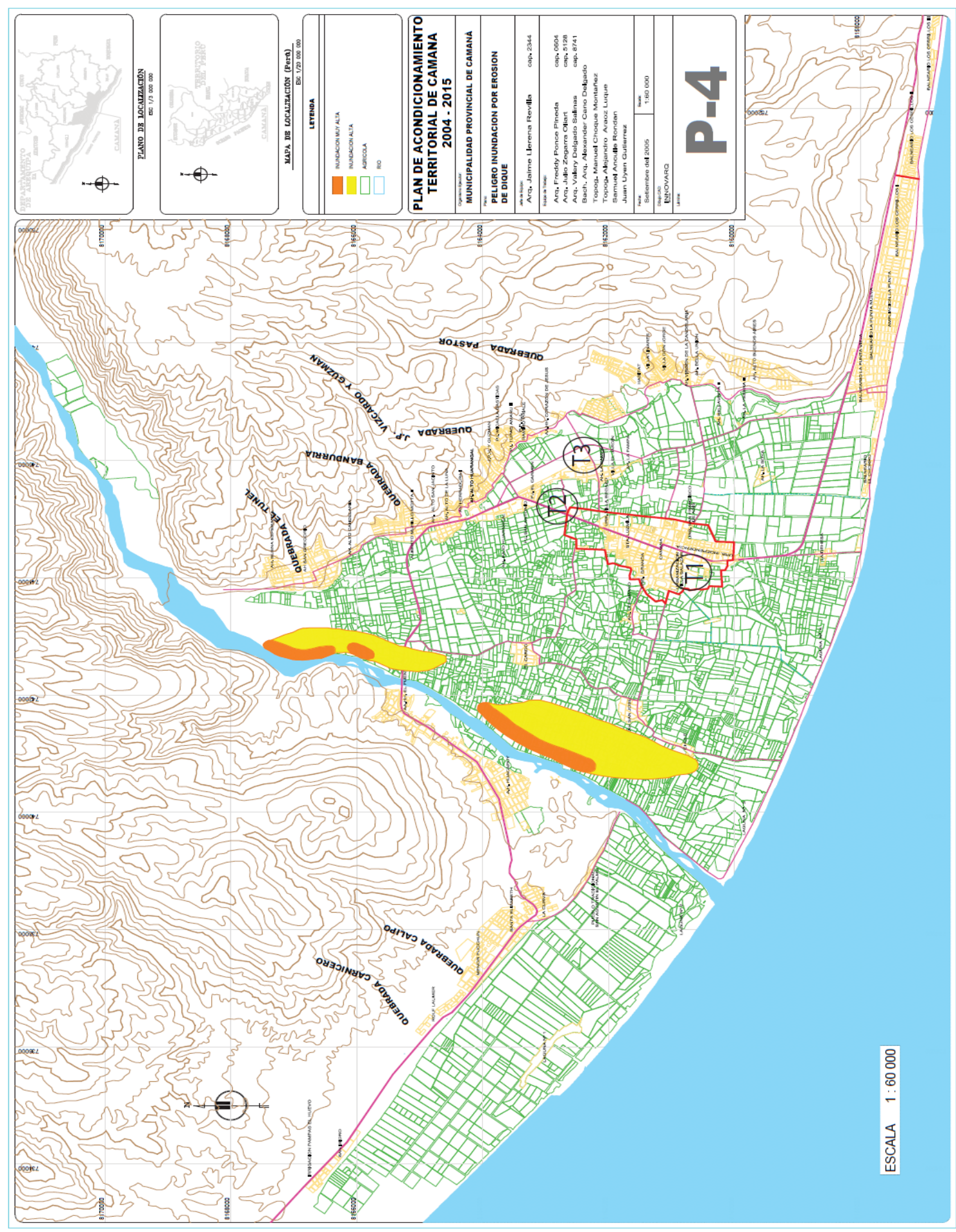

Fuente: Plan Camaná 2015, Edición propia 


\section{E. MAPA DE INUNDACIÓN POR RÍO}

La inundación por desborde de ríos se da por el aumento del caudal del mismo, según el mapa de peligro una inundación por causa de río llegaría a afectar la parte agrícola y parte de los distritos de El cardo, San José y Chule, los terrenos elegidos no se verían afectados por la inundación.

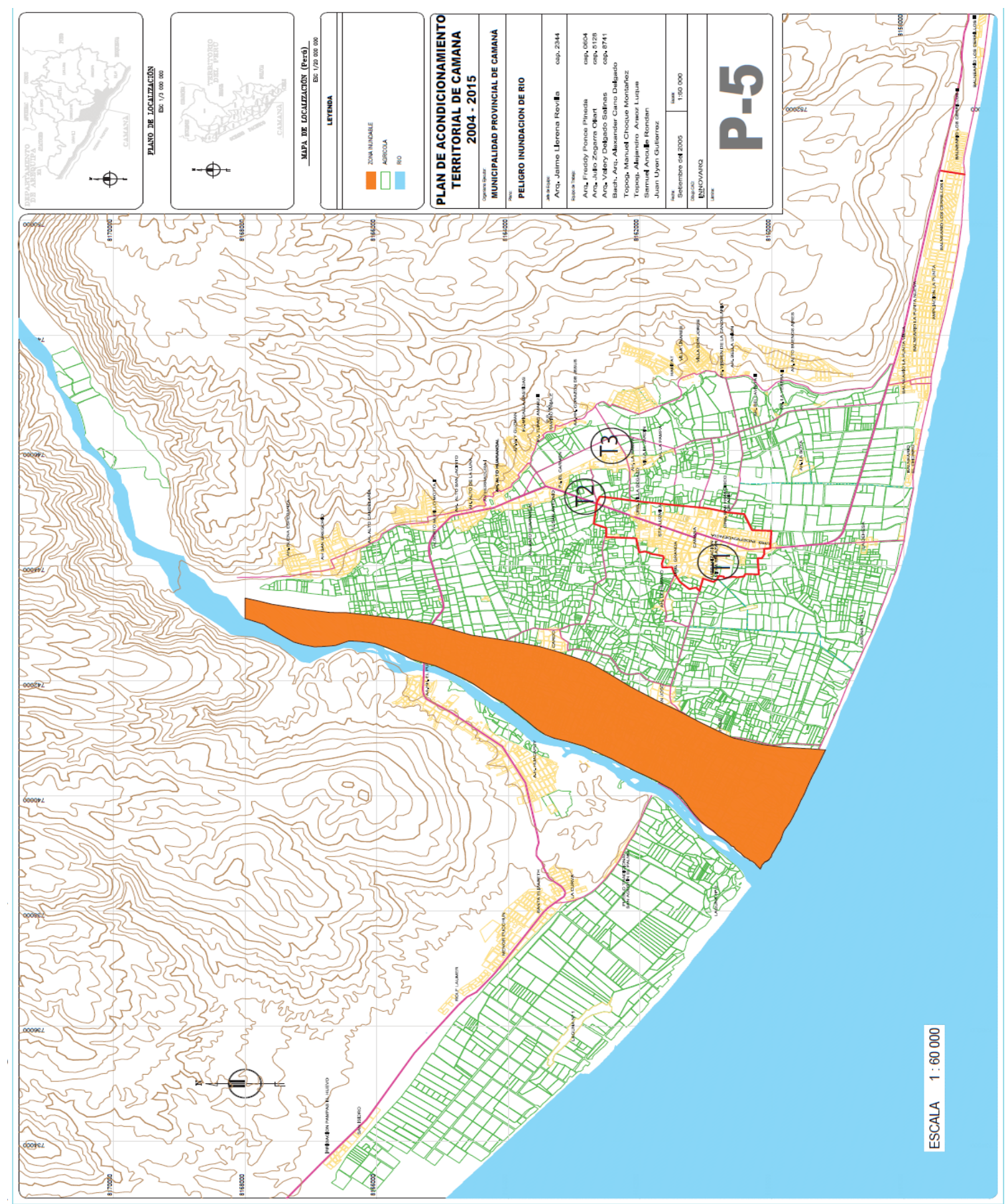

Fuente: Plan Camaná 2015, Edición propia 


\section{F. MAPA DE TSUNAMI}

En el año 2001 ocurrió el tsunami de mayor alcance en la provincia de Camaná, los terrenos elegidos no están dentro del rango de alcance máximo.

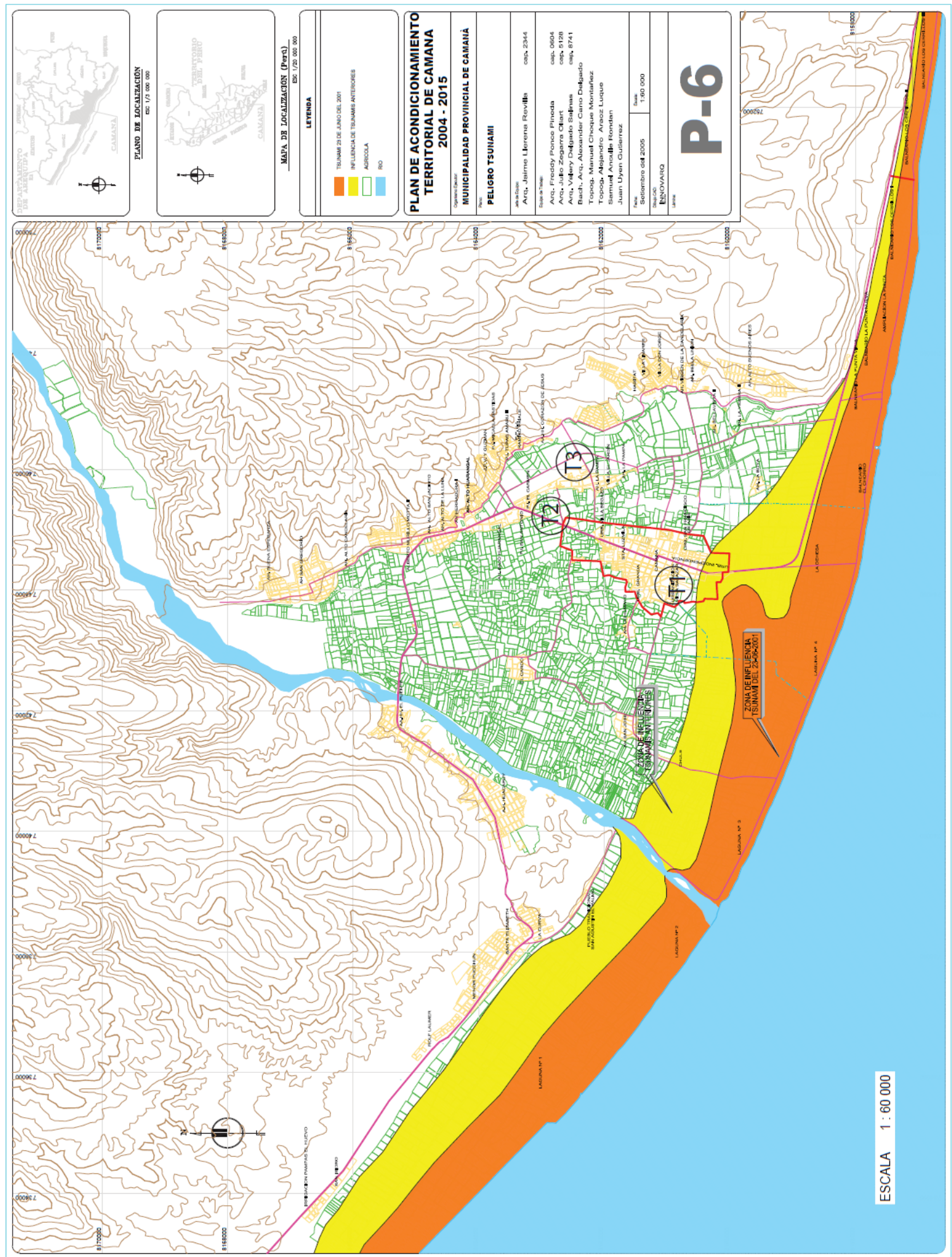

Fuente: Plan Camaná 2015, Edición propia 


\subsubsection{CONDICIONES FÍSICAS}

\subsubsection{TOPOGRAFÍA}

La topografía de Camaná es plana alcanza hasta los 25 m.s.n.m. en el centro de la ciudad, mientras que en

Figura 76: Mapa topográfico de la ciudad de Camaná

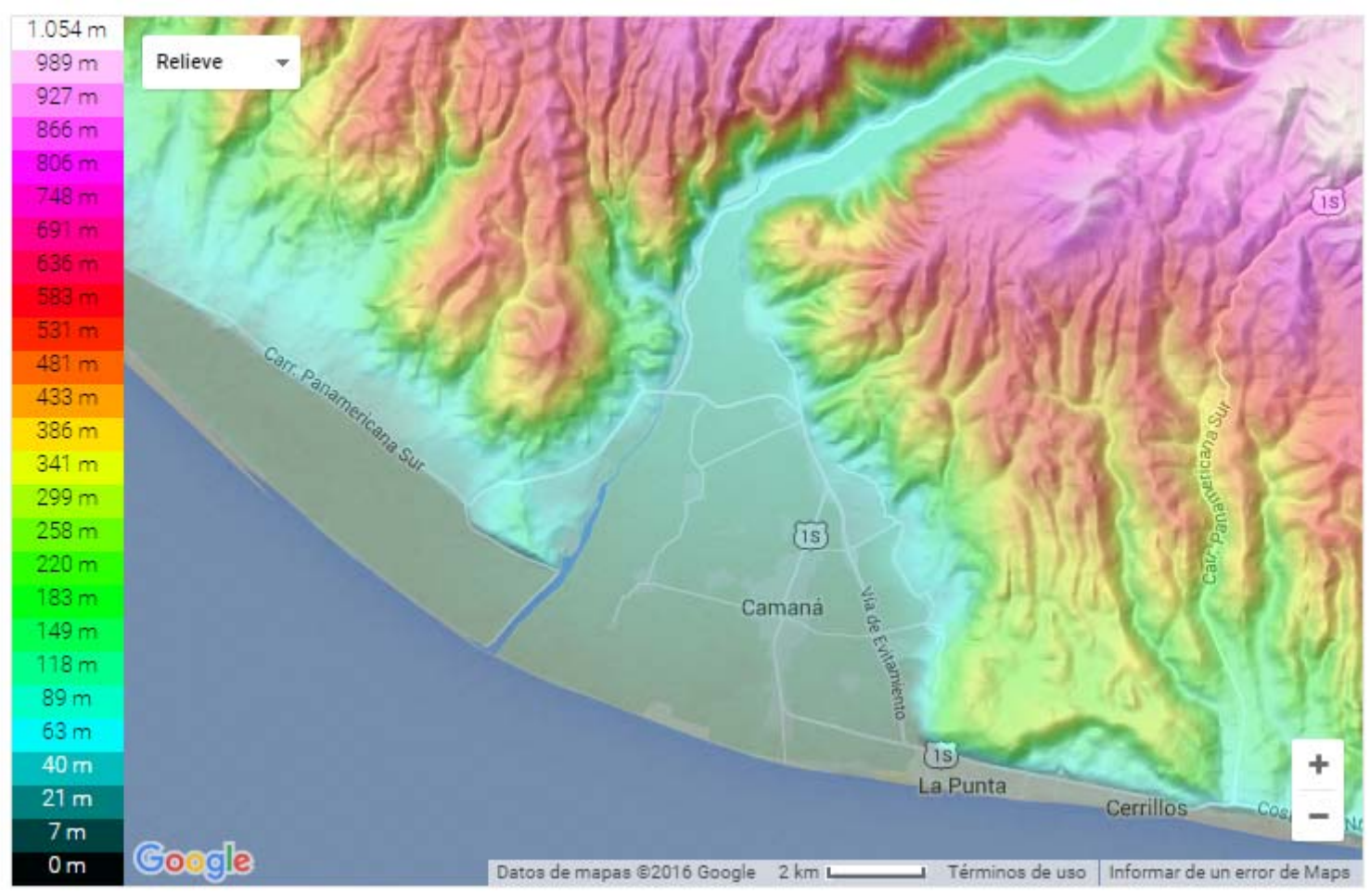

Fuente: Google Earth

Figura 77:Corte Transversal de la ciudad

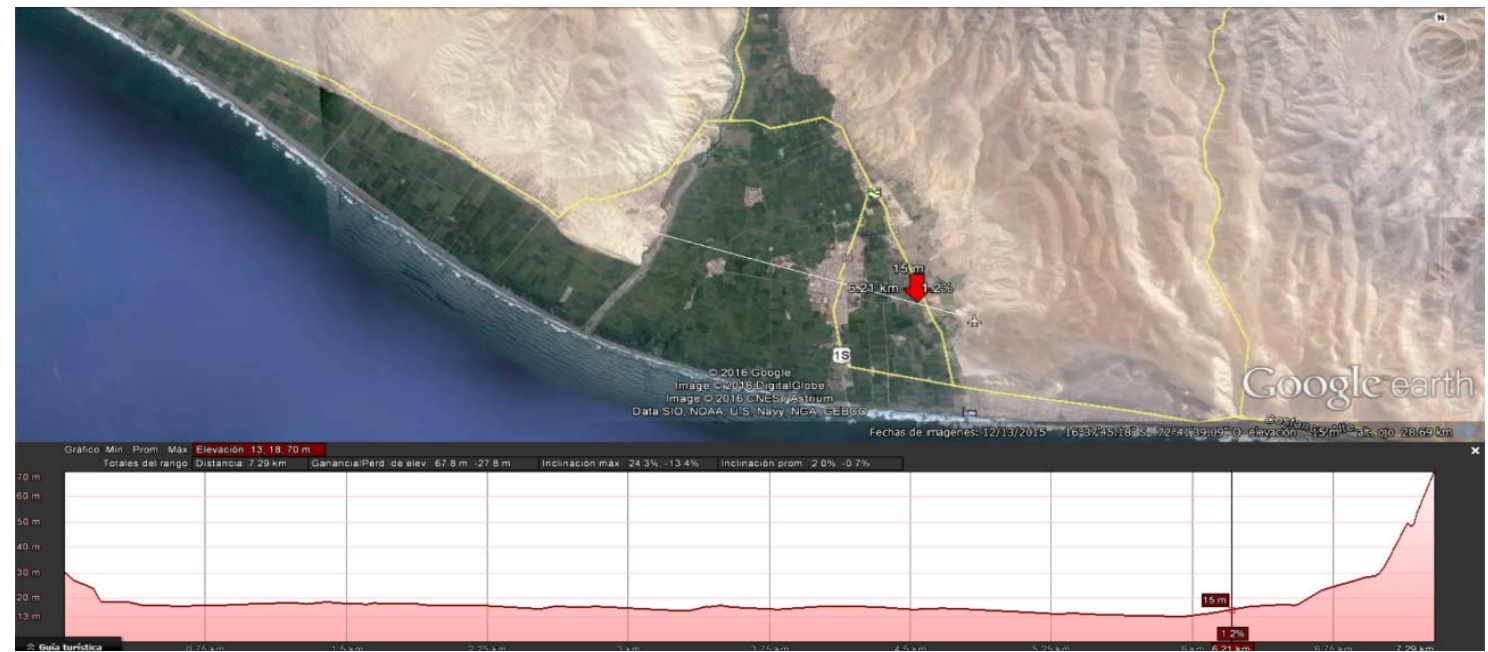

Fuente: Google Earth 


\subsubsection{FACTORES CLIMÁTICOS}

A. $\underline{\text { Clima }}$

El clima en Camaná es similar al de toda la costa del país, con escasas lluvias y variaciones térmicas marcadas entre el verano y el invierno marcadas.

Figura 78: Gráficas del clima

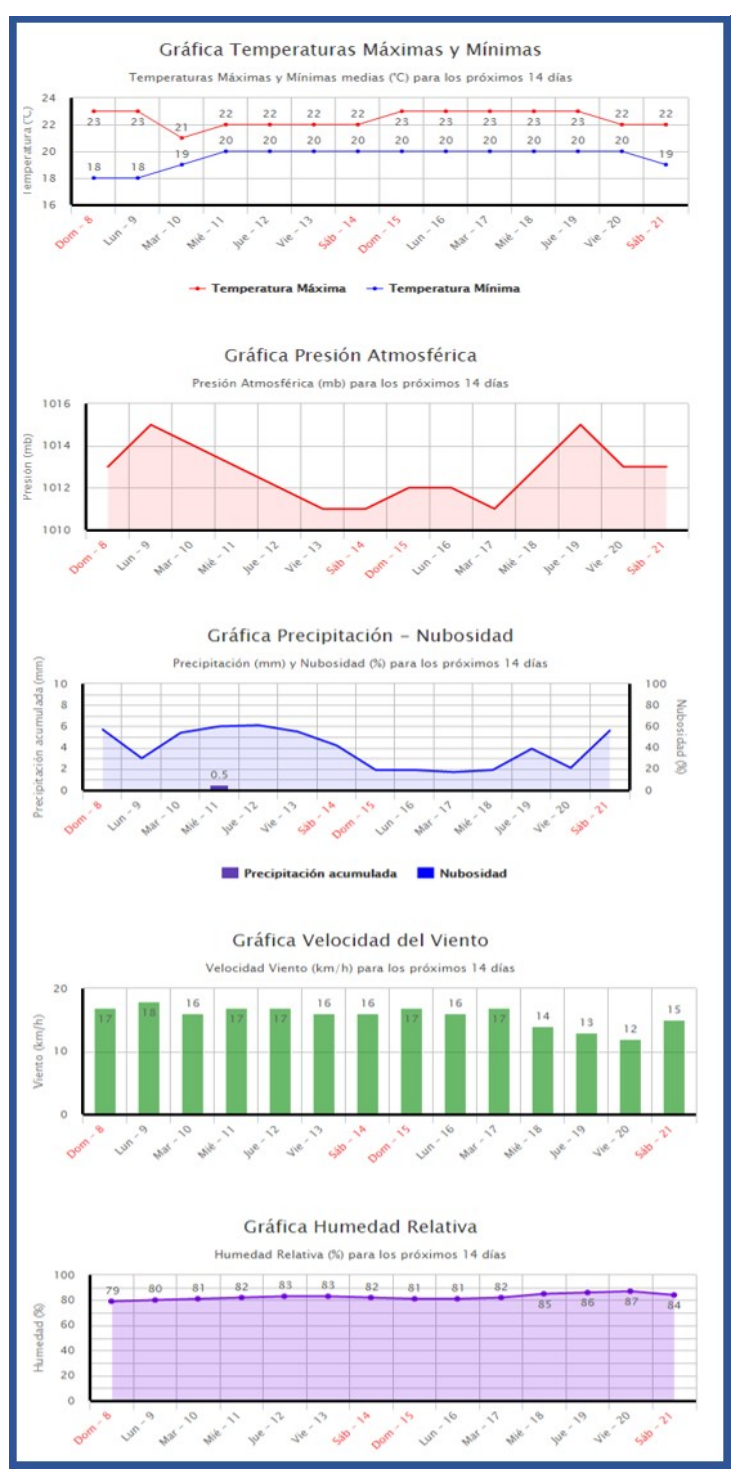

Figura 79: Graficas del clima

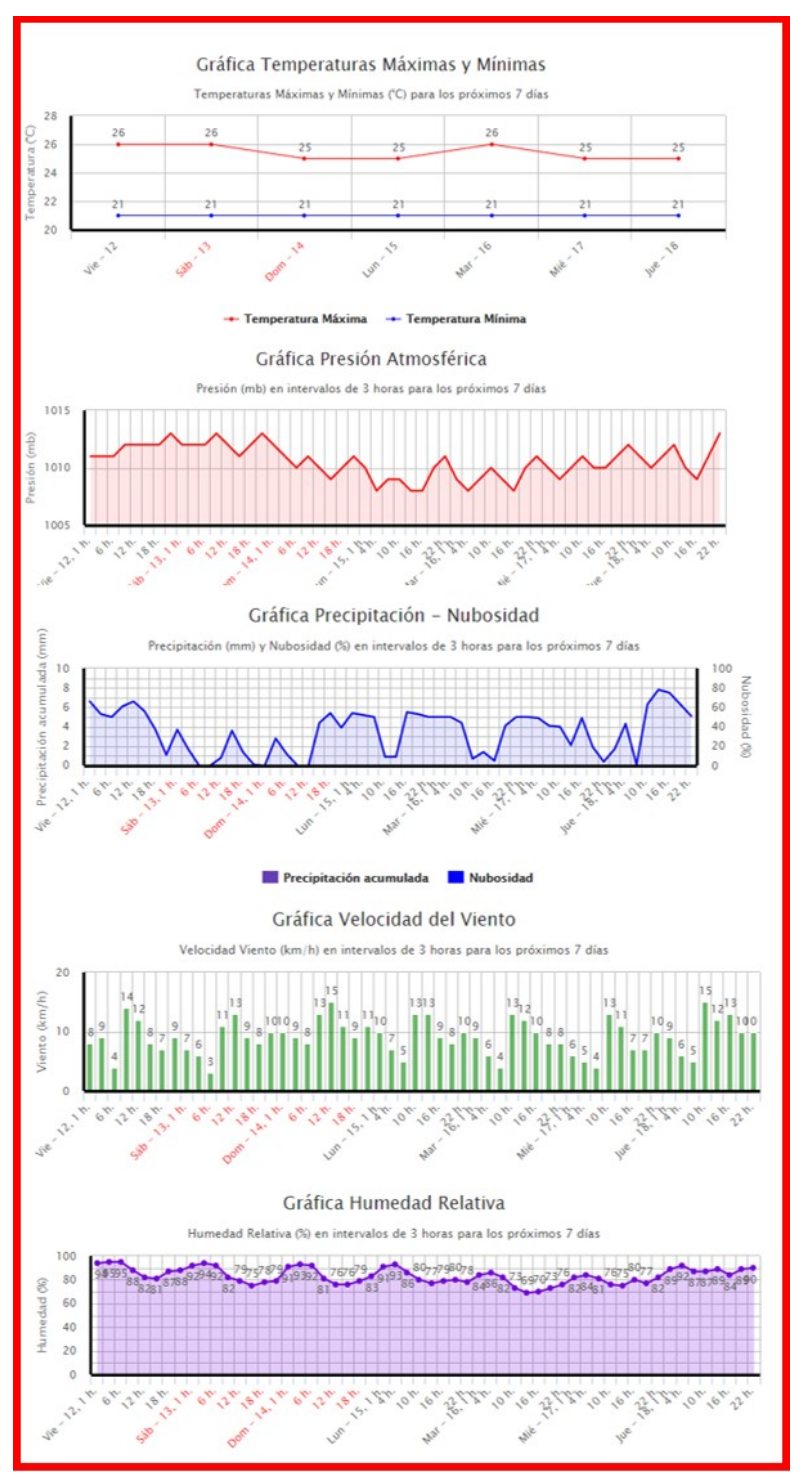

Fuente: http://Meteored.pe 


\section{DIRECCIÓN DEL VIENTO}

Figura 80: Mapa Camaná

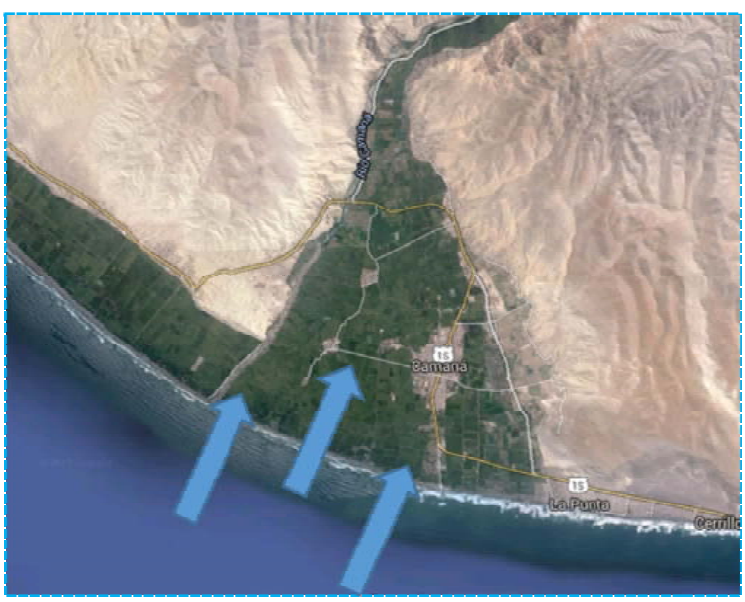

\section{Viento}

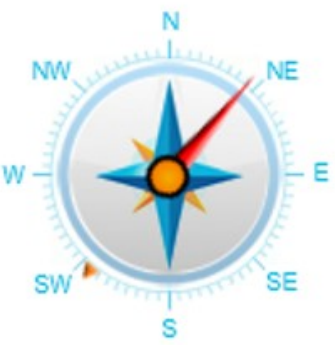

Dirección

$40^{\circ}$ (NNE)

Velocidad

$11 \mathrm{~km} / \mathrm{h}$

Fuente: Google Earth

Los vientos en Camaná llegan de SUR OESTE A NORESTE, lo cual se tomará en cuenta para la ubicación del proyecto en el terreno.

\section{$\underline{\text { Recorrido Solar }}$}

El recorrido solar y asoleamiento se tomará en cuenta para el diseño del proyecto.

Figura 81: Mapa de recorrido solar en Camaná

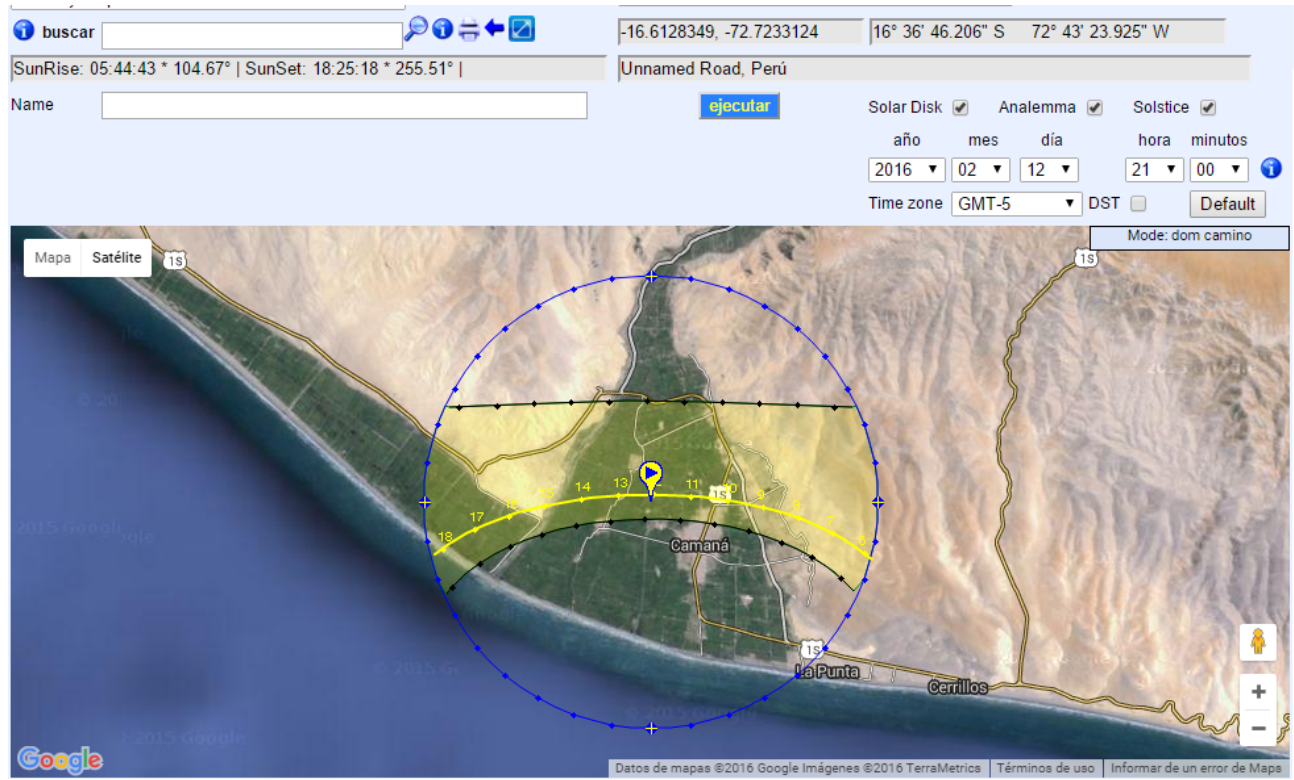

Fuente: http://www.sunearthtools.com 


\subsubsection{ANÁLISIS URBANO}

\subsubsection{MAPA DE ZONIFICACIÓN DE LA CIUDAD DE CAMANÁ}

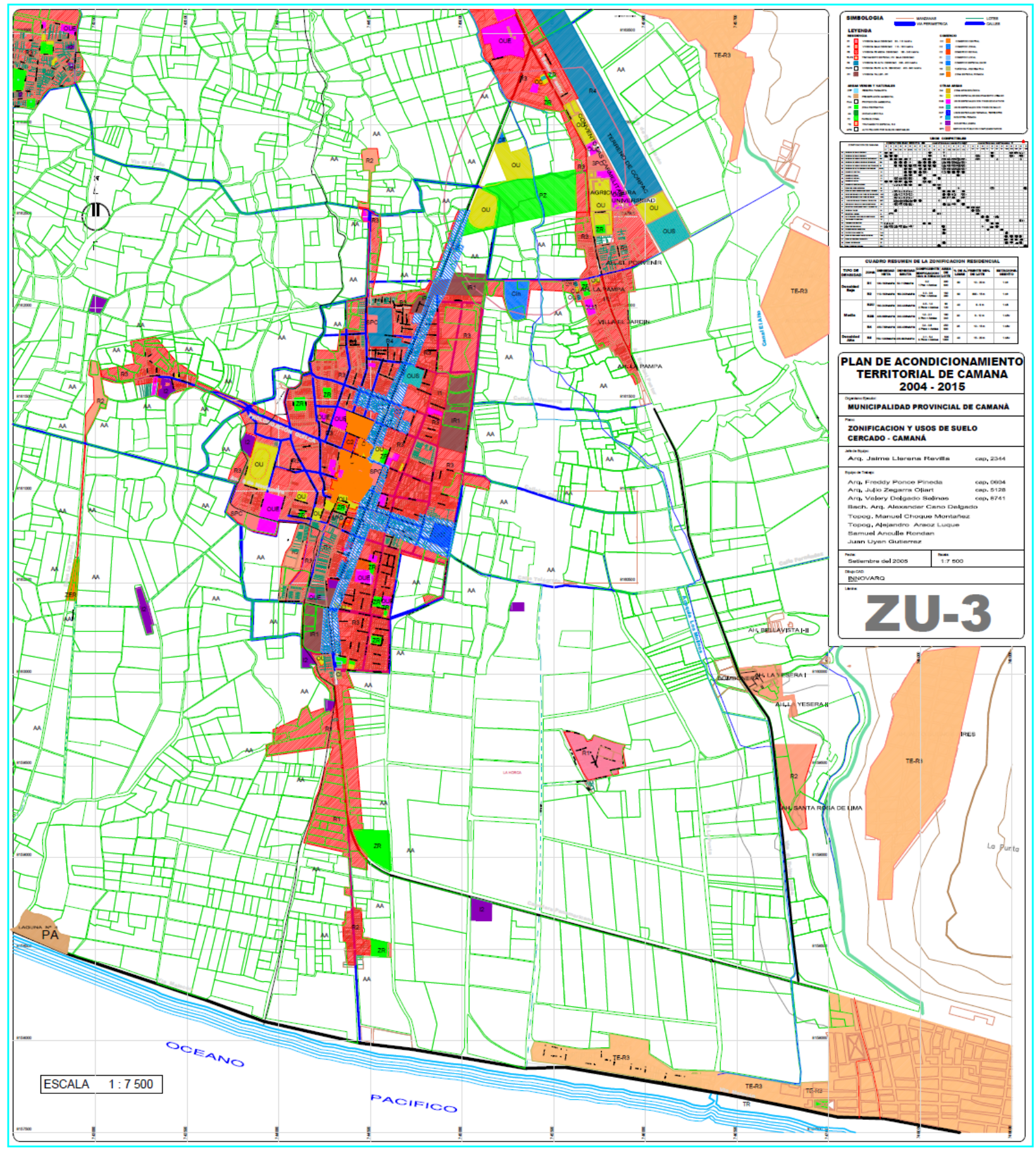

Fuente: Plan Camaná 2015, Edición propia 


\subsubsection{SISTEMA VIAL}

Figura 82: Lámina analítica del Sistema Vial

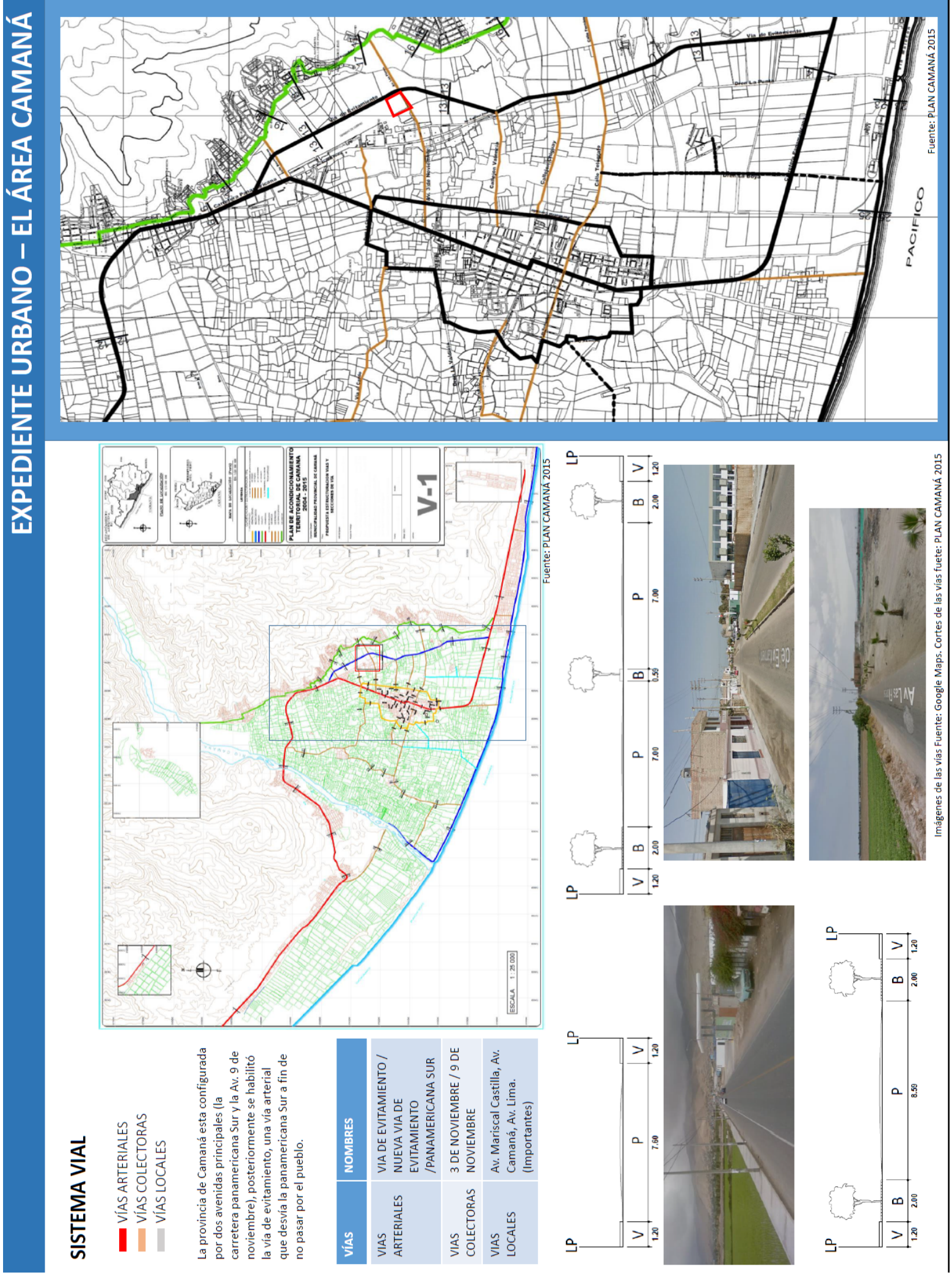

Fuente: Plan Camaná 2015, Edición propia 


\subsubsection{SISTEMA DE CENTROS}

\section{A. EQUIPAMIENTO}

Figura 83: Lámina analítica de Equipamiento

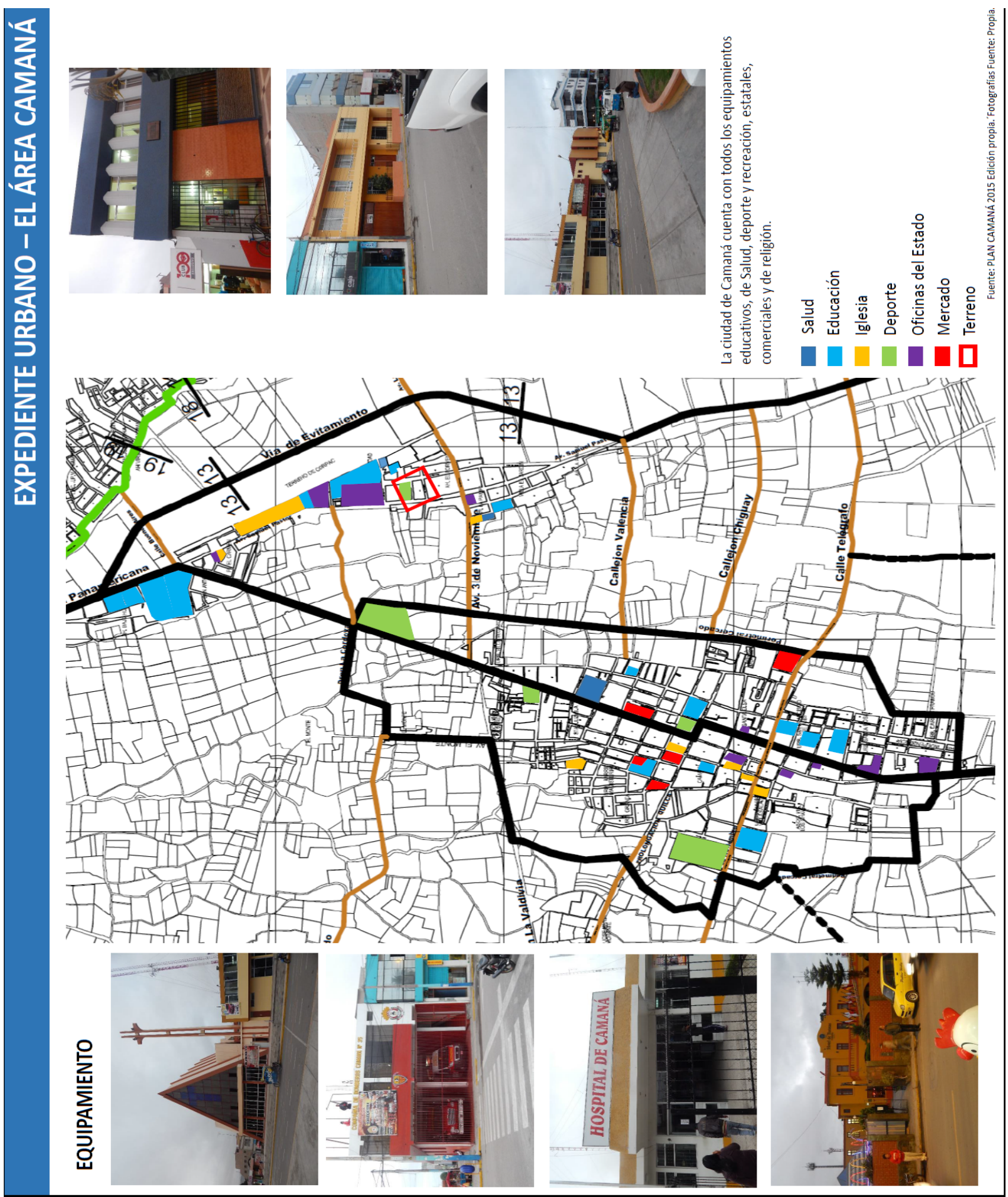

Fuente: Plan Camaná 2015, Edición propia 


\section{B. ÁREAS VERDES}

Figura 84: Lámina analítica de Áreas verdes

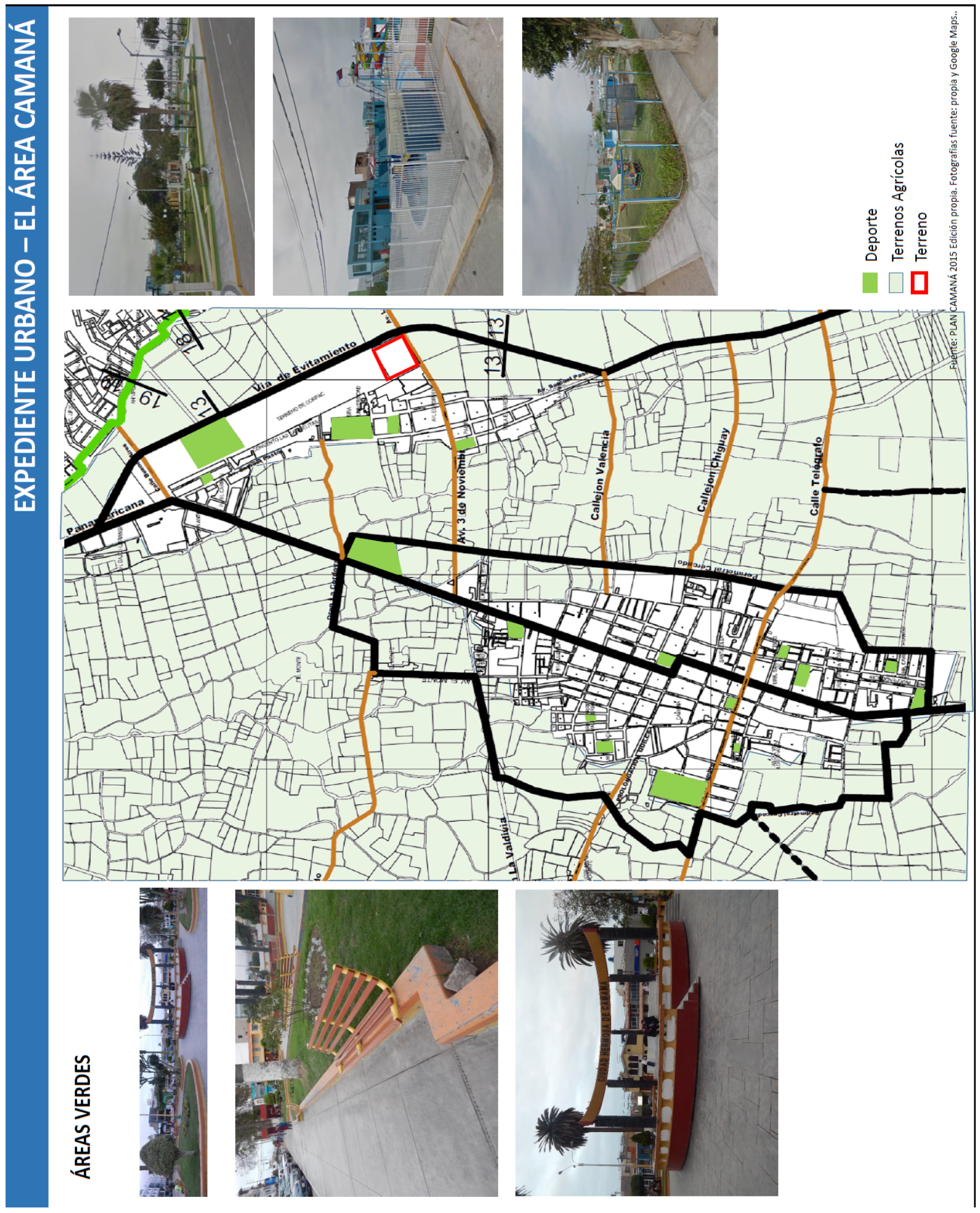

Fuente: Plan Camaná 2015, Edición propia 


\subsection{CRITERIOS DE SELECCIÓN}

Los criterios de selección planteados por el MINSA para proyectar un Hospital se rige por las siguientes normas.

\subsubsection{RELACIONADO A LA DISPONIBILIDAD DE SERVICIOS BÁSICOS}

a) Debe contar con servicios básicos de agua, desagüe y/o alcantarillad\& energía eléctrica comunicaciones y gas natural (de existir en la zona). La red de desagüe debe estar conectada a la red pública.

b) En terrenos donde no se cuente con servicios de agua, desagüe y/o alcantarillado se debe proponer alternativas de solución para el tratamiento y/o disponibilidad de estos servicios.

c) En terrenos donde no exista suministro de energía eléctrica pública, se deberá dotar de Grupo Electrógeno o de otro sistema alternativo de fuente de energía.

FUENTE MINSA

\subsubsection{RELACIONADO A LA LOCALIZACIÓN ACCESIBILIDAD}

a) La localización de todo terreno destinado a un proyecto de establecimiento debe ser de salud compatible con el Plan de Desarrollo Urbano o Plan de Ordenamiento Territorial del Gobierno Local o Regional, según corresponda.

b) La localización del terreno propuesto debe ser concordante con la sobre posición de instrumentos que permitan su evaluación y análisis consecuente como son los mapas, imágenes satelitales, entre otros.

c) Los terrenos elegidos deben ser accesibles acorde a la infraestructura vial y/o medio existente de tal manera que garanticen ut) efectivo y fluido tránsito de los pacientes, personal y público en general al establecimiento de salud.

d) En aquellos casos donde sea factible, se podrán instalar aerogeneradores independientes (parque eólico), para lo cual se debe disponer de un centro de A transformación que permita transformar la energía eléctrica a niveles de tensión de uso (usualmente $220 \mathrm{~V}$ ).

FUENTE MINSA

\subsubsection{RELACIONADO A LA UBICACIÓN DEL TERRENO}


a) Los terrenos destinados al desarrollo de proyectos para establecimientos de salud se ubicarán acorde a la zonificación permisible en el Certificado de Parámetros Urbanísticos y Edificatorios expedido por el Gobierno Local correspondiente.

b) b) Los terrenos para establecimientos de salud no deben ubicarse:

- En terrenos vulnerables a fenómenos naturales, inundaciones, desbordes por corrientes o fuerzas erosivas y/o deslizamientos.

- En cuencas con topografía accidentada, como lecho de ríos aluviones y huaycos. • En terreno con pendiente inestable, ni al pie o borde de laderas.

- Donde existan evidencias de restos arqueológicos (declarados como zonas arqueológicas por el Ministerio de Cultura).

- A una distancia menor a $100 \mathrm{~m}$. equidistantes al límite de propiedad del terreno de estación de servicios de combustibles. - A una distancia no menor a 300 ro lineales al borde de dos, lagos o lagunas ni a $1 \mathrm{Km}$. del litoral.

FUENTE MINSA

\subsubsection{CARACTERÍSTICAS BÁSICAS}

a) Las características físicas de un terreno y su dimensionamiento proyectado, que sea destinado a la edificación de un establecimiento de salud, estará sujeto a lo establecido en el Certificado de Parámetros Urbanísticos y Edificatorios expedido por el Gobierno Local correspondiente.

b) Para establecimientos de salud con población asignada, los terrenos deben ser predominantemente planos y de preferencia de forma regulan siendo recomendable su acceso diferenciado. ubicación en esquina o con dos (02) frentes libres como mínimo a fin de facilitar los

c) El dimensionamiento de la infraestructura de un proyecto de salud se estimará en función a su capacidad resolutiva proyectada.

FUENTE MINSA

\subsubsection{DISPONIBILIDAD DE LAS ÁREAS DE TERRENO}

Para el caso de establecimientos de salud públicos, respecto al primer nivel de edificación del terrena se considerará la siguiente proporción: 
o 50\% para el diseño de las áreas destinadas al cumplimiento del Programa Arquitectónica. 20a para el diseño de obras exteriores (como veredas y patios exteriores, rampas, estacionamiento, entre otros) y futuras ampliaciones.

o 30\% para área libre, que incluye el diseño de áreas verdes.

\subsubsection{PARÁMETROS URBANÍSTICOS}

USOS ESPECIALES CON FINES DE SALUD - OUS: Son aquellas áreas destinadas a la localización y funcionamiento de establecimientos de salud en todos los niveles:

$\rightarrow$ Hospital-Camaná H3

$\rightarrow$ Centro de Salud: H2

$\rightarrow$ Posta Médica: H1

Las áreas existentes o destinadas al uso de Salud no podrán subdividirse, ni reducirse; en cambio sí podrán incrementarse en los casos que el diseño vial y urbano así lo permitan.

Las edificaciones para el uso de Equipamiento de Salud, además de ceñirse a lo establecido en el R.N.C. y las disposiciones particulares del Ministerio de Salud, deberán respetar las disposiciones urbanísticas municipales en lo referente a retiros, altura de edificación y volumetría del área en que se ubican.

Los centros de salud o postas sanitarias requeridas en las áreas de expansión urbana, podrán localizarse en las áreas de aporte de las nuevas habilitaciones.

La localización de nuevas edificaciones destinadas al Equipamiento de Salud deberá ubicarse de acuerdo al Cuadro de Compatibilidad de Usos de Suelo del Plan de Desarrollo Urbano de la Ciudad de Camaná, 2004-2020.

\section{Retiros}

OUS Usos Especiales Fines Salud: 12.00 metros lineales.

Para los usos OU, OUE, OUS,I1, serán obligatorios los retiros laterales y posterior de 5.00 metros lineales 


\subsection{SELECCIÓN DE TERRENO}

Figura 85: Lámina analítica de ubicación de los terrenos.
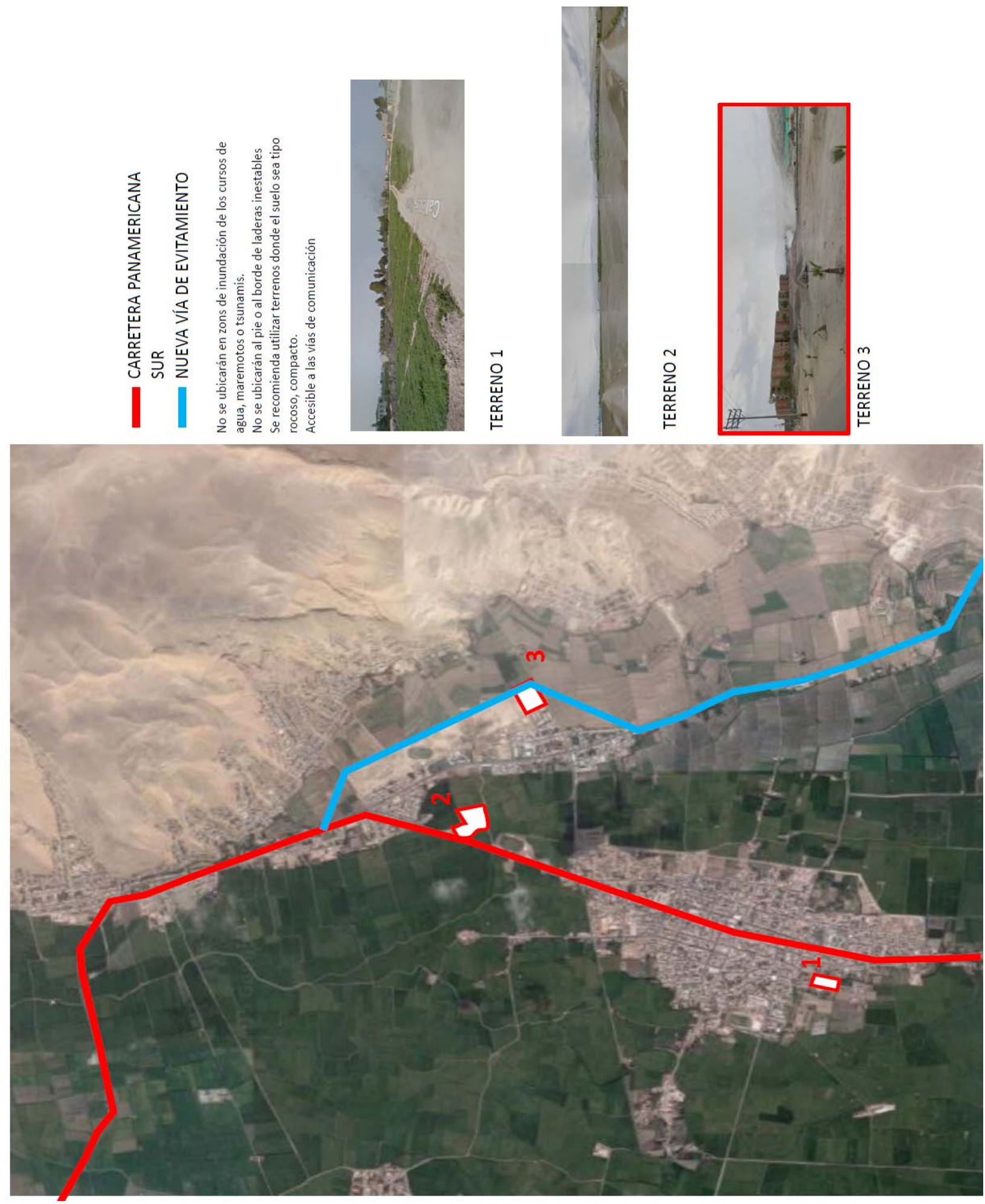

Fuente: Plan Camaná 2015, Edición propia 
Figura 86: Lámina analítica de Equipamiento

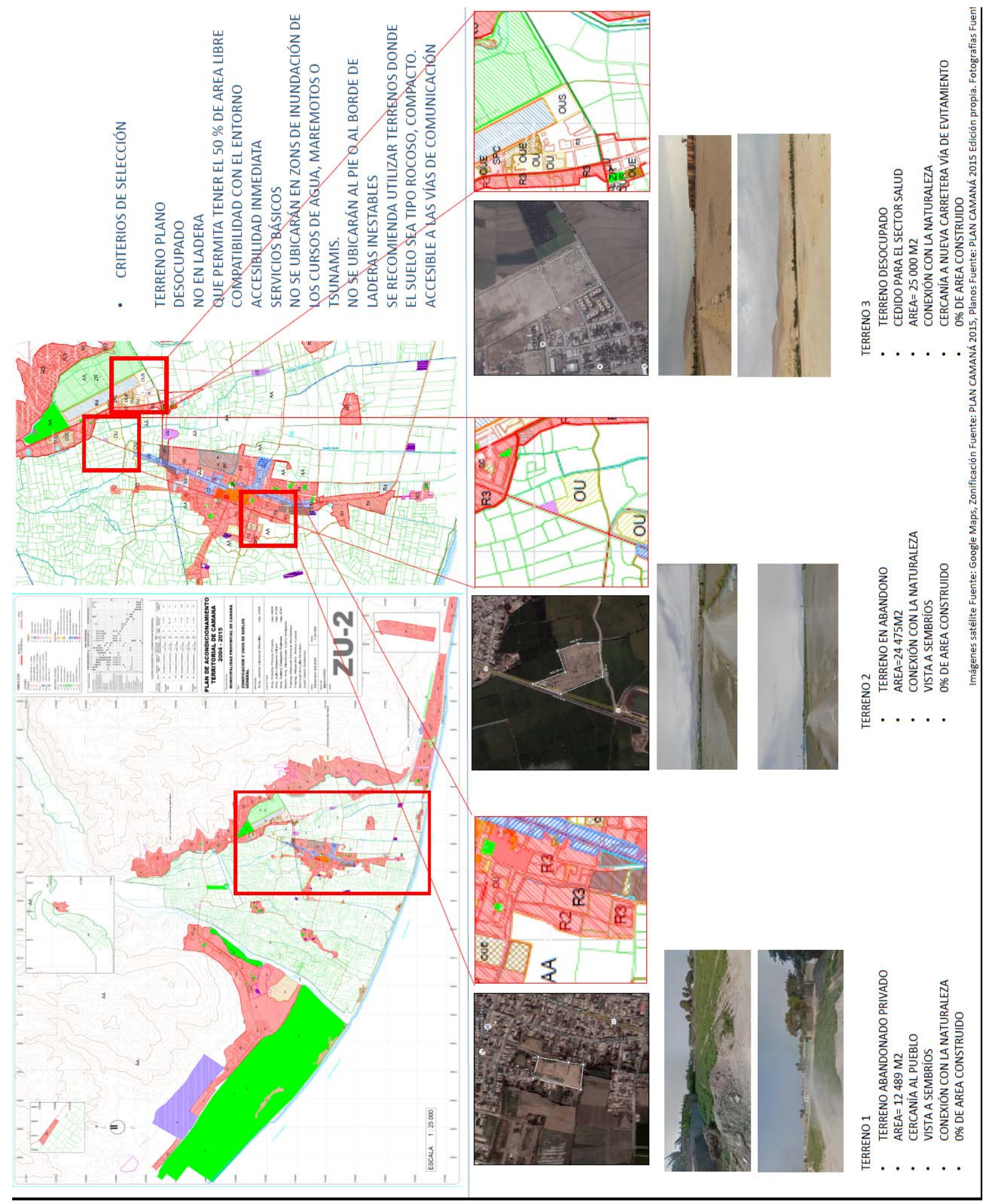

Fuente: Plan Camaná 2015, Edición propia 


\subsubsection{TERRENO 1}

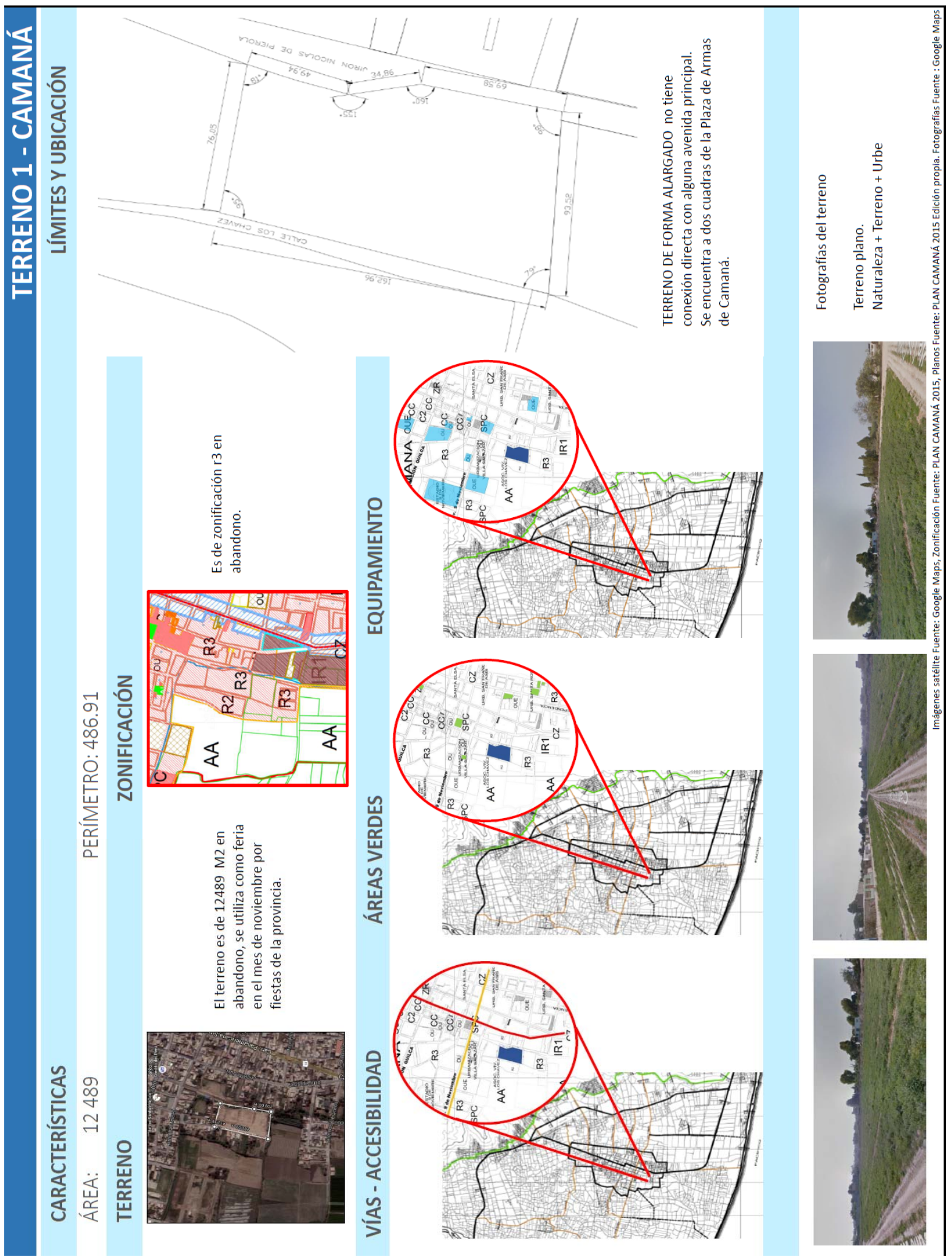

Fuente: Plan Camaná 2015, Edición propia 


\subsubsection{TERRENO 2}

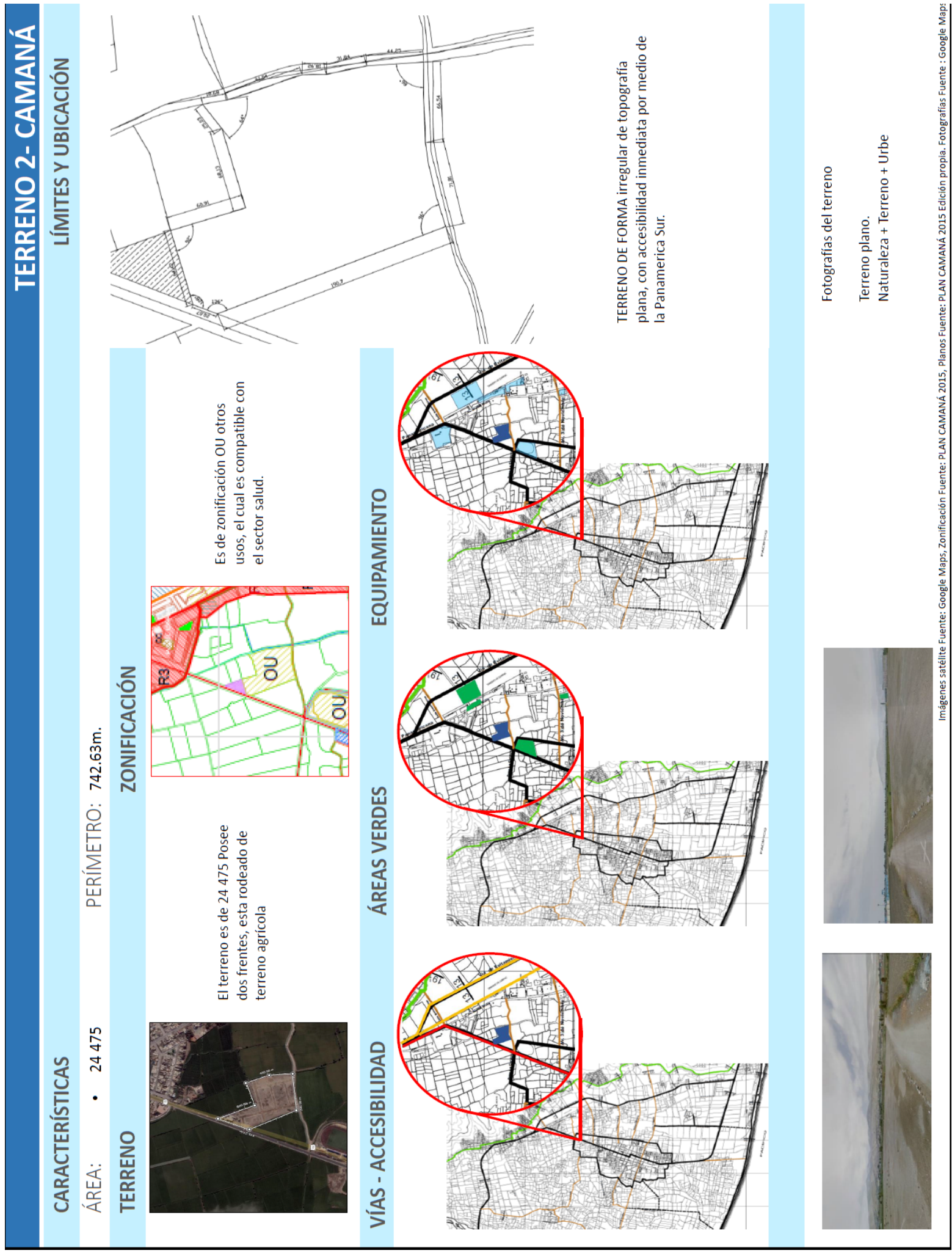

Fuente: Plan Camaná 2015, Edición propia 


\subsubsection{TERRENO 3}

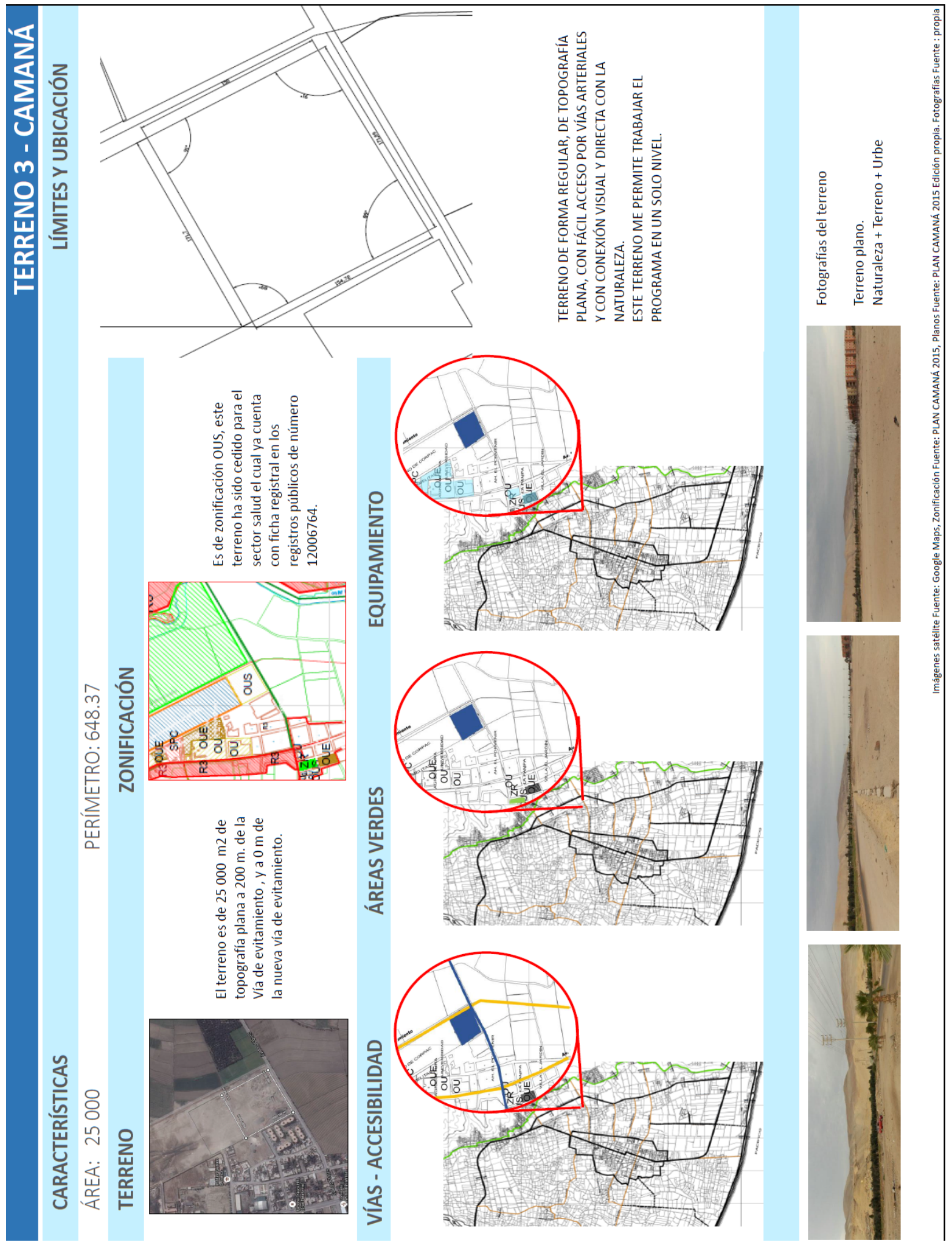

Fuente: Plan Camaná 2015, Edición propia 


\subsubsection{PUNTAJE DE TERRENOS}

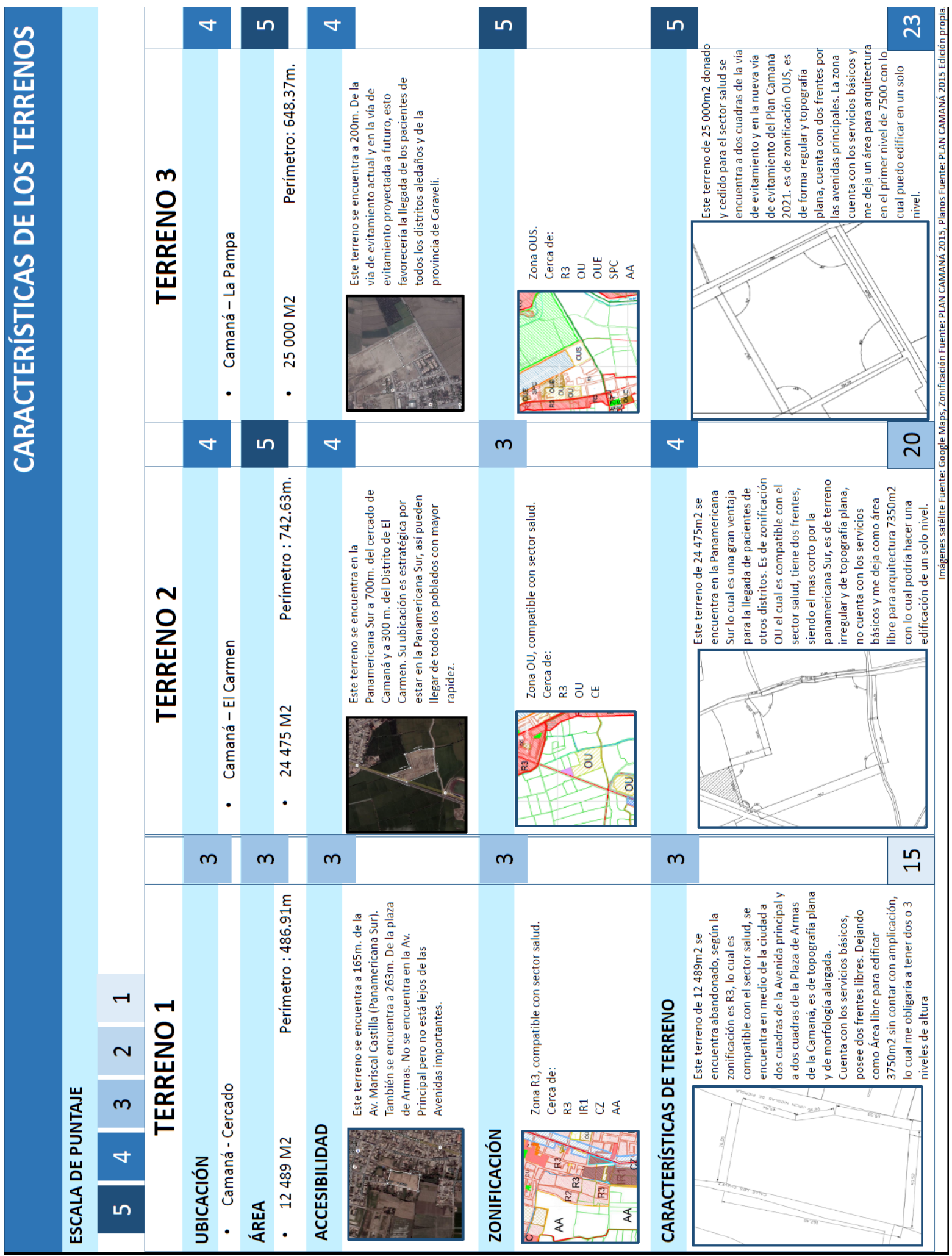

Fuente: Plan Camaná 2015, Edición propia 
CAPÍTULO 5- EXPEDIENTE URBANO 


\subsection{EL ÁREA}

\subsubsection{SISTEMA VÍAL}

Figura 87: Sistema Vial

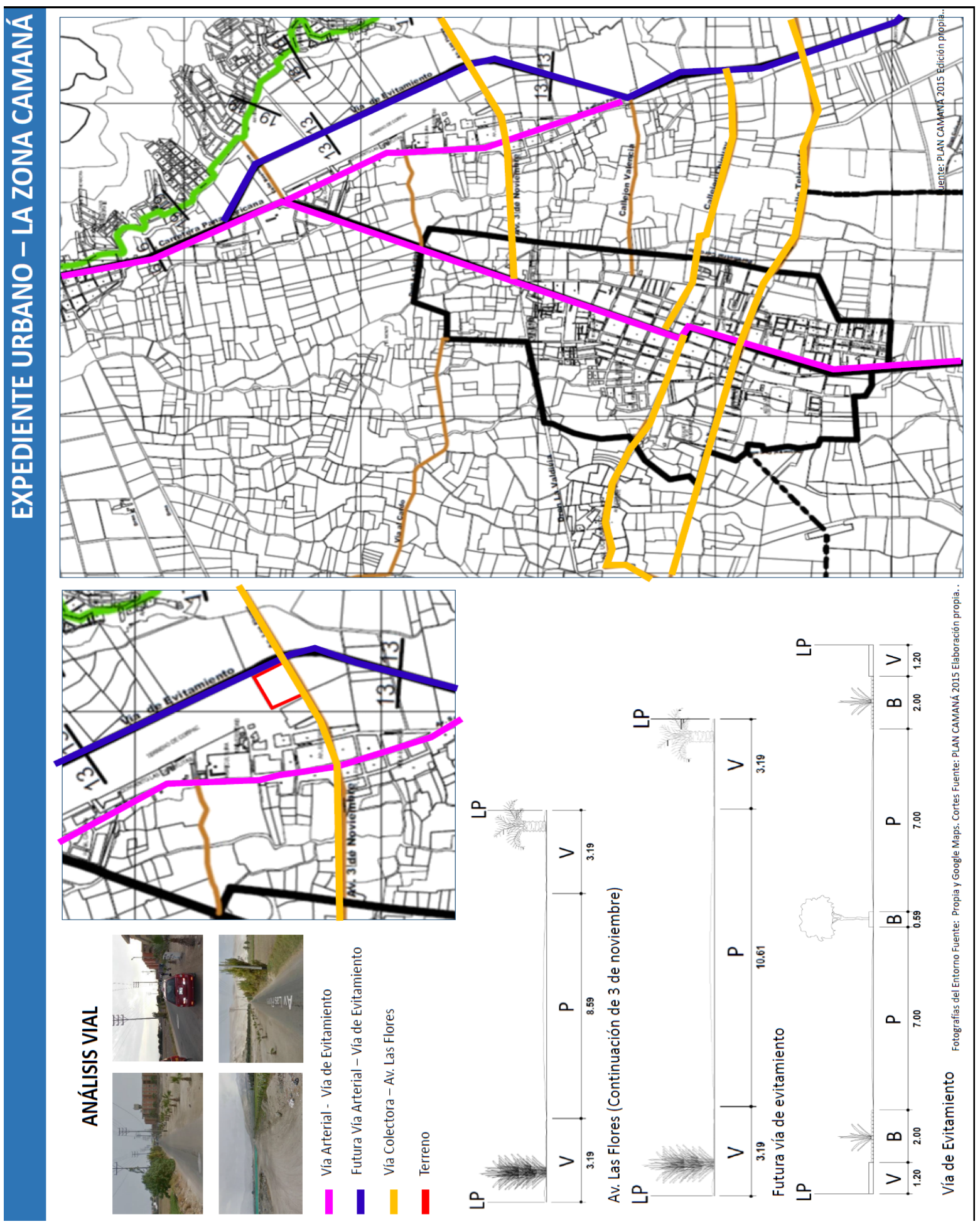

Fuente: Plan Camaná 2015, Edición propia 


\subsection{3 ÁREAS VERDES}

Figura 88: Lámina de áreas verdes

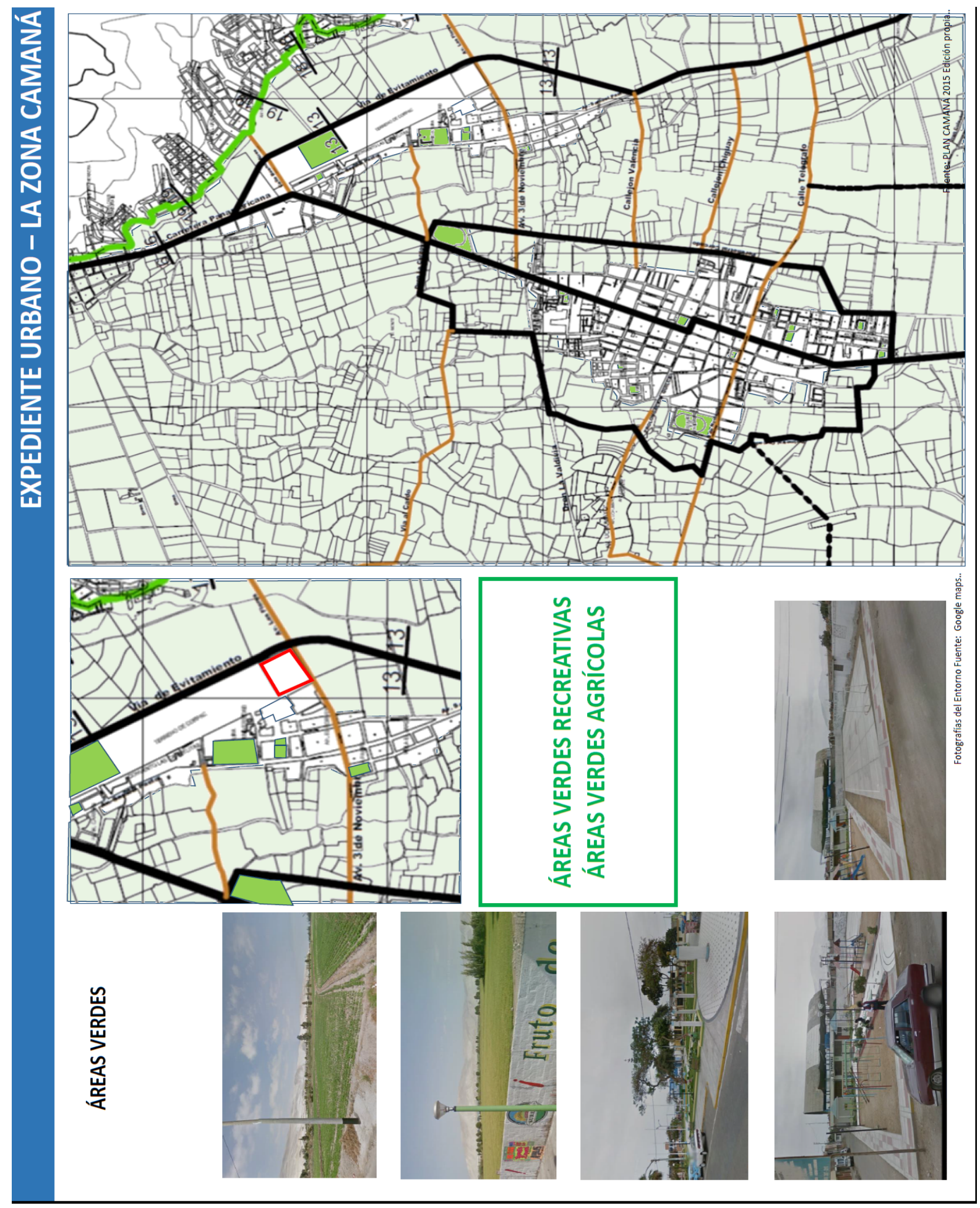

Fuente: Plan Camaná 2015, Edición propia 


\subsubsection{TIPOLOGÍA}

Figura 89: Lámina de tipología

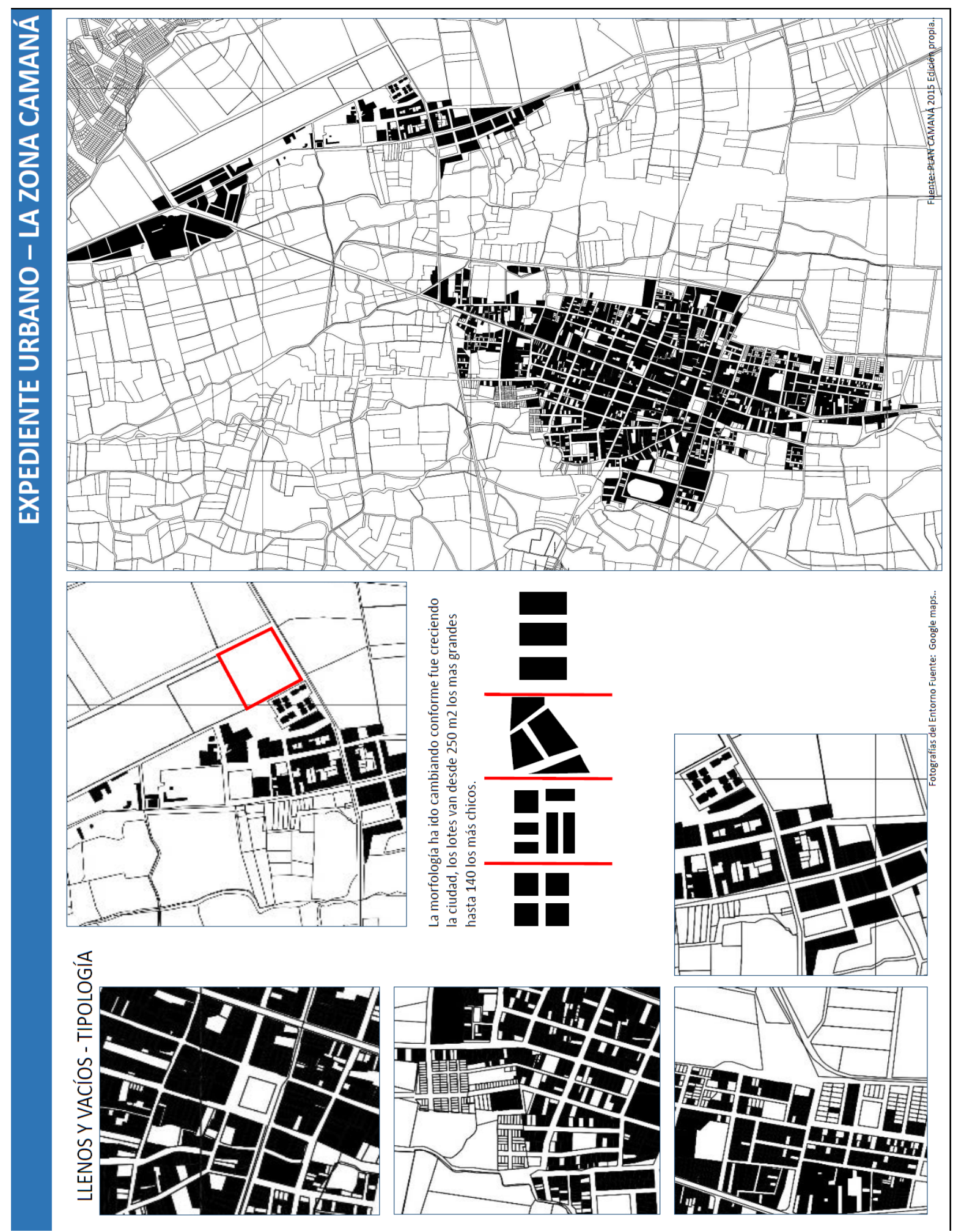

Fuente: Plan Camaná 2015, Edición propia 


\subsubsection{ZONIFICACIÓN- USO DE SUELO- ALTURAS}

Figura 90: Zonificación, usos de suelo y alturas

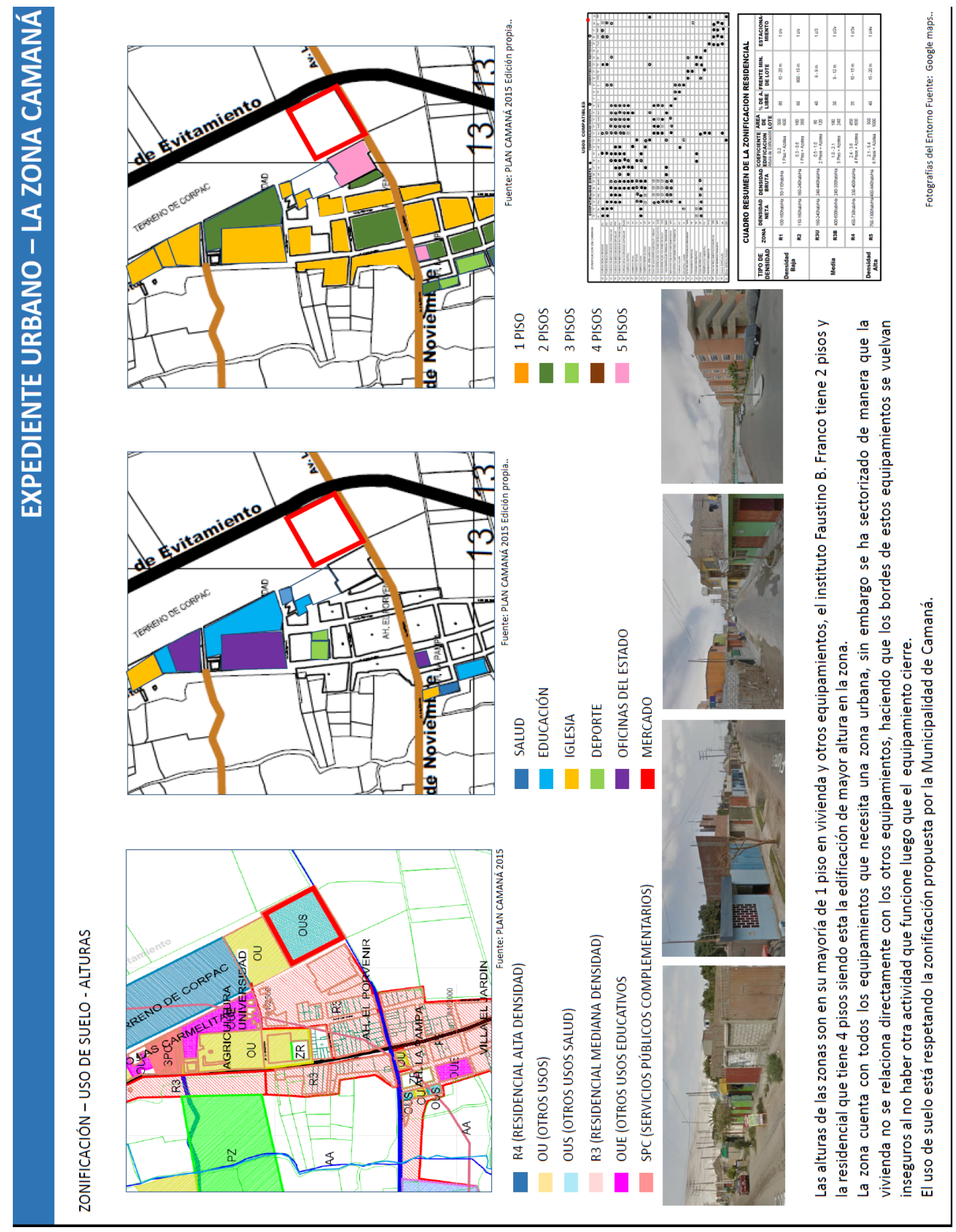

Fuente: Plan Camaná 2015, Edición propia 


\subsubsection{SENDAS-BORDES-NODOS-HITOS}

Figura 91: Senda, bordes, nodos e hitos

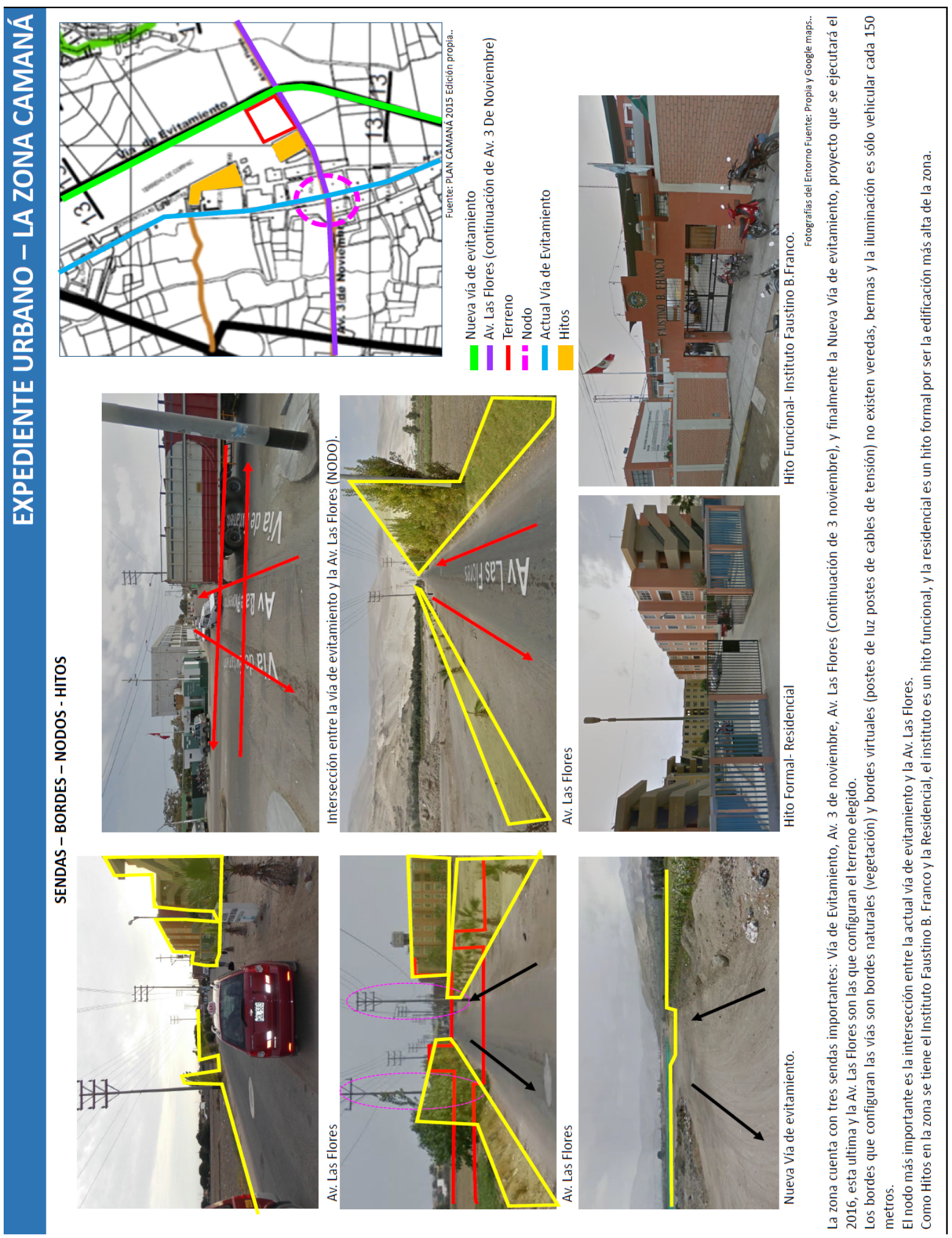

Fuente: Plan Camaná 2015, Edición propia 
Figura 92: Entorno

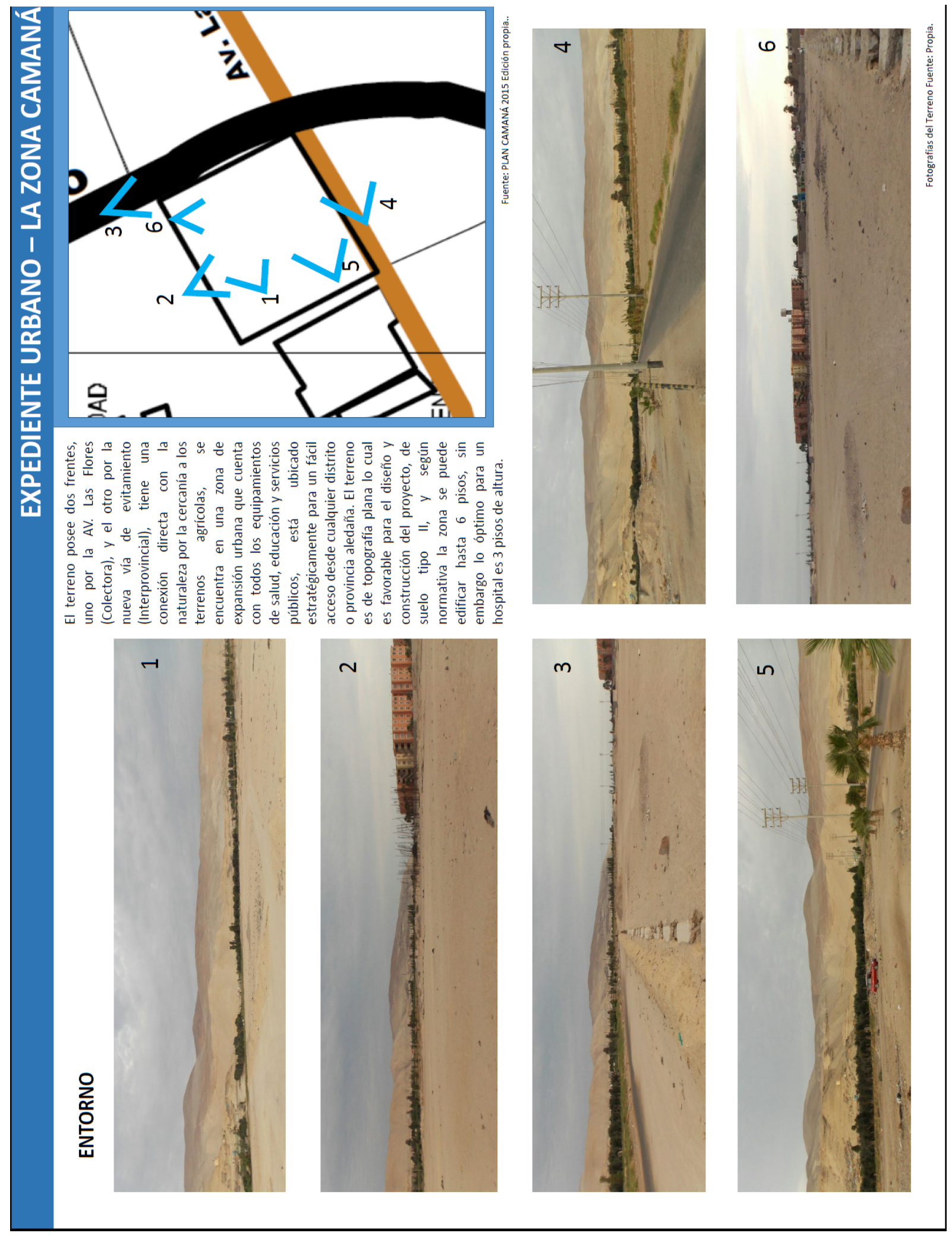

Fuente: Visita, Edición propia 


\subsubsection{ANEXOS NORMAS LEGALES}

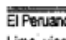

NORMAS LEGALES

401659

Dispónen independización de terreno urbano ubicado en el distrito de Samuel Pastor, provincia de Camaná

RESOLUCIÓN GERENCIAL GENERAL REGIONAL No 076-2009-GRAVR-GGR

VISTO:

EI Oficio No 252-2009-GRANOOT, la Oficina de Ordenamiento Territorial remite 'expediente sobre independización de áreas dé terreno urbano ubicado en
distrito de Samuel Pastor, provincia de Camaná.

CONSIDERANDO:

Que, el Estado es propietario de un terreno eriazo de $257 \cdot 160.33 \mathrm{~m} 2$. ubicado en el distrito de Samuel Pastọr, provincia de Camaná, el mismo que se encuentra inscrito en la Partida $\mathrm{N}^{\circ}$-12006764 de Registro de Predios.

Que, a través del Oficio No 251-2009-MPC-A Municipalidad Provincial de Camana solicita el aneamiento fisico legal del terreno mencionado, para ser estinado a vivienda, área deportiva y recreación infanti estion y comercio, hospital y centro de altos estudios.

Que, el inciso b) del artículo 62 de la Ley $\mathrm{N}^{\circ} .27867$. Ley Orgánica de Gobiernos Regionales, respecto a funciones de propiedad del Estado, señala que es función de los Gobiernos Regionales:

- "b)'Realizar los actos de inmatriculación, saneamiento adquisición, enajenación, administración y adjudicación de los terrenos urbanos y eriazos de propiedad del Estado en su jurisdicción, con excepción de los terrenos de propiedad municipal."

Que, en virtud de 'lo establecido en la Resolución Gerencial N 045-2006-CND/GTA y Acta de Transferencia de Funciones Sectoriales a los Gobiernos' Regionales, de fecha 26 de mayo de 2006, se ha concretado la ransferencia de funciones al Gobierno Regional de Arequipa las que se encuentran establecidas en los inciso a), b) y c) del articulo 62

Que, estando a la normatividad legal referida, el Gobierno Regional de Arequipa, es competente para pronunciarse sobre el presente procedimiento encontrandose normado por to establecido en la Ley $\mathrm{N}^{\circ}$ 29151, Ley General del Sistema Nacional de Biene Estatales y su Reglamento aprobado por Decreto Supremo $N^{\circ}$ 007-2009-VIVIENDA y Decreto Supremo N

Que, el Decreto Supremo No 130-2001-EF establece que las entidades públicas, deberán por su propia cuenta, efectuar el saneamiento técnico, legal y contable de los

Que, el articulo 7 del dispositivo legal antes mencionado señala las inscripciones a ser realizadas al amparo de Decreso desmembraciones y fraccionamientos.

Que, conforme obra de la documentación remitida acción a realizar es una de independización, pue se requiere independizar extensiones: de terreno de una matriz, creándose partidás independientes de las 'areas a independizar, lo que es: concordante con lo establecido en el articulo 40 y siguientes del Reglamento de Inscripciones del Registro de Predios. aprobada por Resolución de la Superintendencia Nacional de los Registros Públicos $N^{\circ}$ 248-2008SUNARP-SN.

Que estando a lo señalado en el Informe Técnico Legal No 019-2009-GRA-OOT, Informe $N^{\circ} .492$ y 495 2009-GRA-OO la Oncina de Ordenamiento Termitorial,

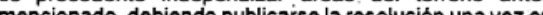
el Diario Oficial El Peruano y otro de circulación regionat en la página Web institucionel.

la página Web institucional. mayor de sesenta dias calendario deberá presentarse. ante el Registro de Predios la solicitud de anotación preventiva. Transcurrido el plazo de 30 dias calendario de fectuada la inscripción provisional, sin que haya mediado! posición ${ }_{n}$ deber solicitarse la inscripción definitiv

ficina Regional de Asesoria Juridica y de confo por la.' con lo prescrito en la Ley $N^{\circ} 27783$ Ley de Bases de a Descentralización. $\mathrm{N}^{0} 27867$ Ley $\mathrm{N}^{0} 27444$ la Descentralizacion, Ley $N^{\circ}$ 27867, Ley $N^{\circ}$ 27444, facultades conferidas mediante Resolución Ejecutiva Regional No 337-2007-GRA/PR:

SE RESUELVE Árticulo $1^{\circ}$ - Disponer la INDEPENDIZACION del terreno urbano de $257160.33 \mathrm{~m} 2$. ubicado en el distritón de Samuel Pastor, provincia de Camaná, el mismo que se encuentra inscrito en la Partida $N^{\circ} 12006764$ del Registro; de Predios, en siete areas con las siguientes extensiones: conforme a los documentos tacnicos que

AREAA : Con una área de terreno de $25996.97 \mathrm{~m} 2$ AREA B Con una área de terreno de $63793.72 \mathrm{m2}$ AREA C Con una área de tereno de $65814.66 \mathrm{~m} 2$ AREA : Con una área de terreno de $29005.43 \mathrm{~m} 2 \mathrm{r}$ AREA Con una área de terreno de $2520357 \mathrm{m2}$. AREA F : Con una área de terreno de $26240.68 \mathrm{~m} 2$ AREA G : Con una áręa de terreno de $21105.30 \mathrm{~m} 2$ \%

Articulo $2^{\circ}$ - Disponer que la presente resolución sea publicada por única vez en el Diario Oficial EI Peruano, otro de circulación regional y en la página Web institucional. Artículo $3^{\circ}$ - Encargar a la Oficina Regional de. Planeamiento, Presupuesto y Ordenamiento Territorial. realice el procedimiento señalado en los considerandosn de la presente resolución, para obtener la inscripción de: a independización de terrenos dispuesta en el articulo:

Articulo $4^{\circ}$ - La Zona Registral $N^{\circ}$ XII Sede Arequipa de la superintendencia Nacional de Registros Públicos,por el merito de la presente Resolucion efectuará la

Dada en la Sede del Gobierno Regional de Arequipa a los doce dias del mes de agosto del Dos Mil Nueve. :

Registrese y comiuniquese.

BERLY JOSÉ GONZALES ARIAS

Gerente General Regional

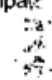

388997-2

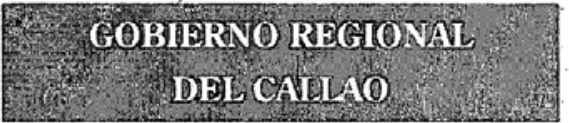

Establecen la Autoridad de Salud en la Provincia Constitucional del Callao ORDENANZA REGIONAL N` 009

Callao, 24 dé agosto de 2009

EL PRESIDENTE DEL GOBIERNO

REGIONAL DEL CALLAO

POR CUANTO

El Consejo Regional del Gobierno Regional del Caliaon. en Sesión de 24 de Agosto de 2009; aprobó la siguiente ORDENANZA QUE ESTABLECE LA AUTORIDAD DE SALUD EN LAPROVINCIA CONSTITUCIONAL DEL

CONSIDERANDO: CALLAO

Que, mediante Resolución Ministerial 003-2009/ MINSA publicada el 10 de enero de 2009 en el Diario del Callao ha culminado el'proceso de transferencia de' 
CAPÍTULO 6 - EL USUARIO 


\subsection{INFORMACIÓN CUALITATIVA}

\subsubsection{USUARIO POTENCIAL}

\subsubsection{POBLACIÓN}

La población de la ciudad de Arequipa al 2015 asciende a 969,284 habitantes, en las provincias de Camaná y Caravelí a un total de 99,856 habitantes.

Tabla 9: Cuadro comparativo de Población en Arequipa

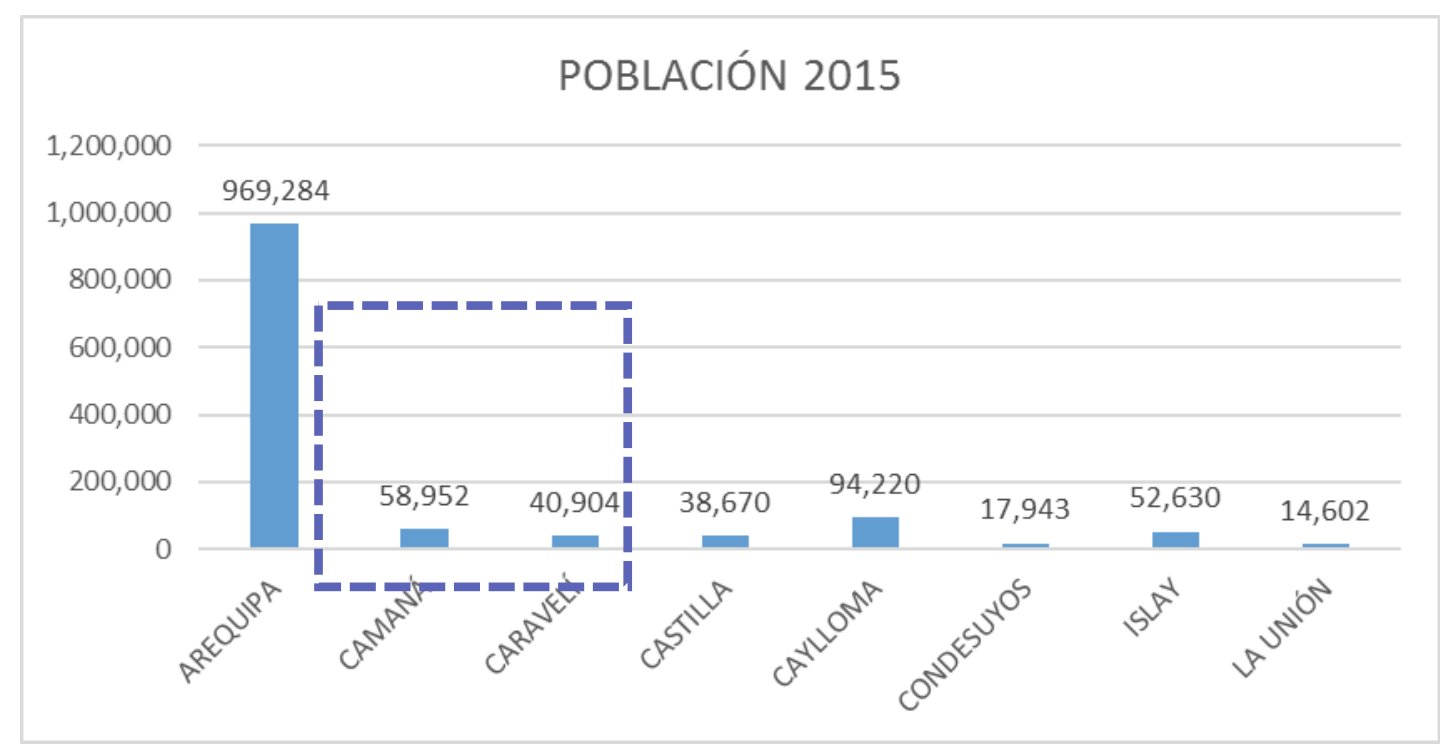

Fuente: INEI - Elaboración propia

Tabla 10: cuadro comparativo de tasa de crecimiento poblacional

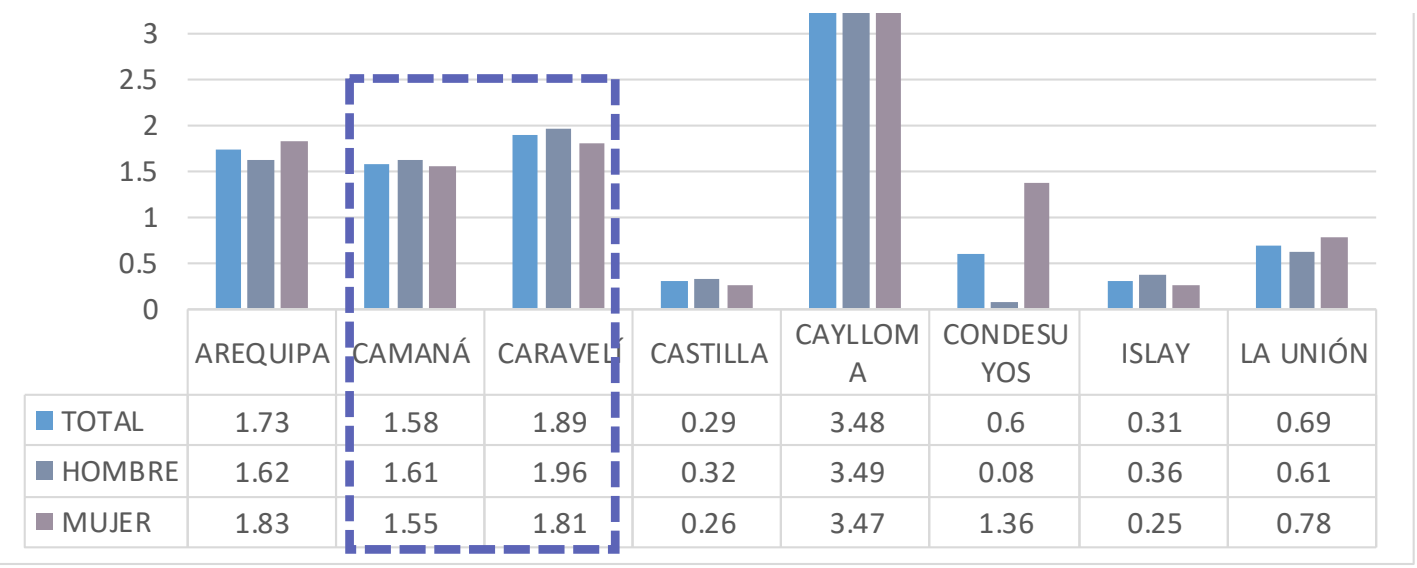

Fuente: INEI - Elaboración propia 


\subsubsection{SALUD}

El sector salud del departamento de Arequipa está dividido en cuatro redes de salud.

\begin{tabular}{|l|}
\hline RED DE SALUD CAMANÁ - CARAVELÍ \\
\hline RED DE SALUD CASTILLA - CONDESUYOS-LA UNIÓN \\
\hline RED DE SALUD AREQUIPA - CAYLLOMA \\
\hline RED DE SALUD ISLAY \\
\hline
\end{tabular}

El departamento de Arequipa cuenta con 5 hospitales en toda la región divididos de la siguiente manera.

\begin{tabular}{|l|l|l|}
\hline RED DE SALUD & TIPO DE HOSPITAL & NOMBRE \\
\hline AREQUIPA - CAYLLOMA & $\begin{array}{l}\text { HOSPITAL IV } \\
\text { HOSPITAL III }\end{array}$ & $\begin{array}{l}\text { HOSPITAL REGIONAL HONORIO DELGADO. } \\
\text { HOSPITAL GOYENECHE }\end{array}$ \\
\hline CAMANÁ - CARAVELÍ & HOSPITAL II-1 & HOSPITAL DE APOYO CAMANÁ \\
\hline $\begin{array}{l}\text { CASTILLA - CONDESUYOS - LA } \\
\text { UNIÓN }\end{array}$ & HOSPITAL I & HOSPITAL DE APOYO APLAO \\
\hline ISLAY & HOSPITAL I & HOSPITAL CENTRAL DE MAJES \\
\hline
\end{tabular}

Tabla 11: Cuadro de infraestructura asistencial

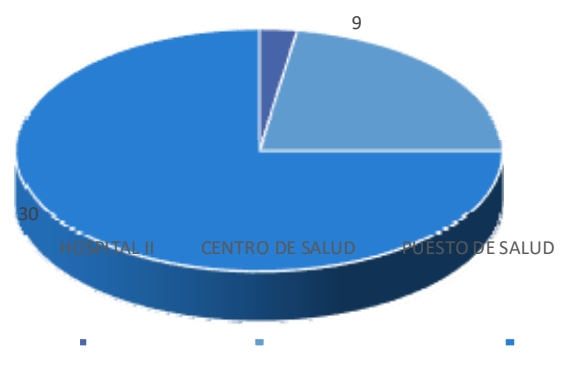

La red de Camaná Caravelí cuenta con un Hospital II de categoría I, 9 Centros de Salud Y 30 Postas Médicas.

Es necesario para una mejor atención ampliar el hospital a una categoría mayor para así evitar trasladar al paciente hasta

el siguiente hospital de mayor categoría en Arequipa que se encuentra a una distancia de $179 \mathrm{~km}$. Fuente: INEI - Elaboración propia...

Hospital de Apoyo Camaná en números 
Tabla 12: Tabla de atendidos y atenciones del 01 de enero al 31 de marzo del 2015

\begin{tabular}{|l|l|l|l|l|l|l|l|}
\hline \multicolumn{2}{|c|}{ TOTAL } & \multicolumn{3}{c|}{ ACUDEN AL SERVVICIO } & \multicolumn{3}{c|}{ ACTIVIDADES } \\
\hline ATENDIDO & ATENCIÓN & NUEVO & CONTINUADOR & REINGRESO & VISITA DOM. & APP & ANIMALES \\
\hline 2788 & 8787 & 1004 & 5999 & 1784 & 216 & 226 & 18 \\
\hline
\end{tabular}

Fuente: INEI- Elaboración propia

\begin{tabular}{|l|l|}
\hline GÉNERO & RED DE SALUD CAMANÁ-CARAVELÍ \\
\hline TOTAL & 663 \\
\hline FEMENINO & 449 \\
\hline MASCULINO & 214 \\
\hline
\end{tabular}

Tabla 13: Tabla de número de trabajadores en la Red de Salud 2015

Fuente: INFORHUS.RR.HH. - Elaboració propia

Tabla 14: Tabla de profesionales de la salud en el hospital de Camaná 2015

\begin{tabular}{|c|c|}
\hline CARGOS & TOTAL \\
GENERAL \\
\hline ABOGADO & 1 \\
\hline ARTESANO & 3 \\
\hline ASIST EN SERV DE SALUD,ASIST SERV SOCIAL,ASIST REC. NATURALES & 3 \\
\hline ASISTENTE ADMINISTRATIVO & 4 \\
\hline AUX DE ARTESANIA & 5 \\
\hline AUX DE LABORATORIO & 1 \\
\hline AUX DE NUTRICION & 10 \\
\hline BIOLOGO & 2 \\
\hline CHOFER & 7 \\
\hline CONTADOR & 1 \\
\hline DIGITADOR P A D, DIGITADOR & 12 \\
\hline DIRECTOR, SUB DIRECTOR & 1 \\
\hline ENFERMERO & 54 \\
\hline ESPEC ADMIN / PROF ADMIN & 3 \\
\hline INSPECTOR SANITARIO & 2 \\
\hline JEFE, GERENTE, SUB JEFE & 1 \\
\hline MEDICO & 32 \\
\hline MEDICO VETERINARIO & 1 \\
\hline NUTRICIONISTA & 2 \\
\hline OBSTETRA & 20 \\
\hline ODONTOLOGO & 4 \\
\hline OFICINISTA & 1 \\
\hline EPERAD DE CENTRAL TELEF / IMPRENTA/ MUUIP MEDIC / MAQ INDUSTRIAL / RADIO/ & 6 \\
\hline PSICOLOGO & 3 \\
\hline QUIMICO FARMACEUTICO & 1 \\
\hline
\end{tabular}




\begin{tabular}{|c|c|}
\hline SECRETARIA & 3 \\
\hline TEC ADMINISTRATIVO / APOYO ADMINS & 24 \\
\hline TEC EN ARCHIVO & 1 \\
\hline TEC EN COMPUTACION & 1 \\
\hline TEC EN ESTADISTICA & 3 \\
\hline TEC MED - LABORATORIO CLINICO Y ANATOMIA PATOLOGICA & 1 \\
\hline TEC. ASIS. ASISTENCIA SOCIAL & 1 \\
\hline TEC. ASIS. EN SANEAMIENTO & 2 \\
\hline TEC. ASIS. ENFERMERIA & 59 \\
\hline TEC. ASIS. ESPECIALIZADO LABORATORIO & 1 \\
\hline TEC. ASIS. FARMACIA & 7 \\
\hline TEC. ASIS. LABORATORIO & 3 \\
\hline TEC. ASIS. SANITARIO & 2 \\
\hline TRABAJADORA SOCIAL & 12 \\
\hline TRABAJADOR DE SERVICIOS / AUX LAV / LIMPIEZA/AUX MANT/CONSERJE & 4 \\
\hline
\end{tabular}

Fuente: INFORHUS RR.HH.- Elaboración propia

Tabla 15: Tabla de mortalidad por edades(2014)

\begin{tabular}{|l|c|c|}
\hline \multicolumn{1}{|c|}{ Edades } & Camaná & Caraveli \\
\hline Total & 182 & 81 \\
\hline $0-7$ días & 2 & \\
\hline $8-28$ días & & \\
\hline $0-28$ días & 2 & \\
\hline 29 d - 11m & & \\
\hline-1 año & 2 & \\
\hline $1-4$ años & 6 & \\
\hline $5-11$ años & 3 & \\
\hline $12-14$ años & & 2 \\
\hline $15-17$ años & 3 & \\
\hline $18-24$ años & 6 & 3 \\
\hline $25-29$ años & 5 & 4 \\
\hline $30-39$ años & 20 & 6 \\
\hline $40-59$ años & 30 & 17 \\
\hline $60-79$ años & 60 & 25 \\
\hline 80 y más años & 47 & 24 \\
\hline Fuent:GERES- Elabon propia
\end{tabular}

Fuente:GERESA- Elaboración propia

El número de fallecidos fue de 263. 
Tabla 16: Tabla de causas principales de mortalidad

\begin{tabular}{|l|l|l|}
\hline MORTALIDAD & \multicolumn{2}{|c|}{ CAMANÁ } \\
\hline CAUSA & NRO. & $\%$ \\
\hline NEUMONÍA & 17 & 4.67 \\
\hline BRONCONEUMONÍA & 11 & 3.02 \\
\hline ACCIDENTE DE TRÁNSITO & 19 & 5.20 \\
\hline
\end{tabular}

Fuente: GERESA- Elaboración propia

\begin{tabular}{|l|l|l|}
\hline MORTALIDAD & \multicolumn{2}{|c|}{ CARAVELÍ } \\
\hline CAUSA & NRO & $\%$ \\
\hline INFARTO AGUDO & 11 & 6.79 \\
\hline BRONCONEUMONÍA & 3 & 1.85 \\
\hline SEPTICEMIA & 4 & 2.46 \\
\hline
\end{tabular}

Fuente: GERESA- Elaboración propia

Tabla 17: Nacimiento por edad de madre 2014

\begin{tabular}{|l|c|c|}
\hline \multicolumn{1}{|c|}{ Edades } & Camaná & Caraveli \\
\hline Total Dpto. & $\mathbf{1 1 7 4}$ & $\mathbf{1 9 5}$ \\
\hline 14-15 años & 7 & 0 \\
\hline 16-17 años & 35 & 4 \\
\hline 18-19 años & 98 & 19 \\
\hline 20-21 años & 125 & 22 \\
\hline 22-23 años & 147 & 25 \\
\hline 24-5 años & 107 & 20 \\
\hline 26-27 años & 117 & 18 \\
\hline 29-29 años & 118 & 20 \\
\hline 30-31 años & 103 & 25 \\
\hline 32-33 años & 81 & 14 \\
\hline $34-35$ años & 72 & 11 \\
\hline $36-37$ años & 66 & 7 \\
\hline $38-39$ años & 56 & 4 \\
\hline $40-41$ años & 29 & 3 \\
\hline $42-43$ años & 9 & 3 \\
\hline $44-45$ años & 3 & 0 \\
\hline $46-47$ años & 1 & 0 \\
\hline Funte: GERESA & & \\
\hline
\end{tabular}

Fuente: GERESA - Elaboración propia 
Tabla 18: Nacimientos en el 2014

\begin{tabular}{|c|c|c|}
\hline Prov/Distrito & $\begin{array}{l}\text { Procedencia de la } \\
\text { Madre }\end{array}$ & $\begin{array}{l}\text { Lugar del } \\
\text { Nacimiento }\end{array}$ \\
\hline PROV. CAMANA & 1012 & 1174 \\
\hline CAMANA & 275 & 961 \\
\hline JOSE MARIA QUIMPER & 86 & \\
\hline MARIANO N VALCARCEL & 44 & 1 \\
\hline $\begin{array}{l}\text { MARIANO NICOLAS } \\
\text { VALCARCEL }\end{array}$ & 2 & \\
\hline MARISCAL CACERES & 110 & \\
\hline NICOLAS DE PIEROLA & 126 & \\
\hline OCO¥A & 10 & \\
\hline OCONA & 64 & \\
\hline QUILCA & 14 & \\
\hline SAMUEL PASTOR & 281 & 212 \\
\hline PROV. CARAVELI & 321 & 195 \\
\hline ACARI & 23 & 37 \\
\hline ATICO & 62 & 34 \\
\hline ATIQUIPA & 8 & 1 \\
\hline BELLA UNION & 11 & \\
\hline CAHUACHO & 4 & \\
\hline CARAVELI & 44 & 23 \\
\hline CHALA & 95 & 100 \\
\hline CHAPARRA & 21 & \\
\hline HUANUHUANU & 25 & \\
\hline JAQUI & 3 & \\
\hline QUICACHA & 16 & \\
\hline YAUCA & 9 & \\
\hline
\end{tabular}

Fuente: GERESA - Elaboración propia 
Tabla 19:Indice de desarrollo Humano según provincias 2007

\begin{tabular}{|c|c|c|c|c|c|c|c|c|c|c|c|c|c|c|}
\hline \multirow[t]{2}{*}{ Provincias } & \multicolumn{2}{|c|}{$\begin{array}{l}\text { Población } \\
2007\end{array}$} & \multicolumn{2}{|c|}{$\begin{array}{l}\text { Indice de } \\
\text { Desarrollo } \\
\text { Humano }\end{array}$} & \multicolumn{2}{|c|}{$\begin{array}{l}\text { Esperanza de } \\
\text { vida al nacer }\end{array}$} & \multicolumn{2}{|c|}{ Alfabetismo } & \multicolumn{2}{|c|}{ Escolaridad } & \multicolumn{2}{|c|}{$\begin{array}{l}\text { Logro } \\
\text { Educativo }\end{array}$} & \multicolumn{2}{|c|}{$\begin{array}{c}\text { Ingreso } \\
\text { familiar per } \\
\text { capita }\end{array}$} \\
\hline & habitantes & ranking & $\mathrm{IDH}$ & ranking & años & ranking & \% & ranking & $x$ & ranking & $x$ & ranking & \begin{tabular}{l|} 
N.S. \\
mes
\end{tabular} & ranking \\
\hline Total & 1152303 & 8 & 0,648 & 5 & 73,5 & 8 & 95,9 & 6 & 90,7 & 2 & 94,2 & 3 & 434,8 & 2 \\
\hline Arequips & 864250 & 3 & 0,659 & 5 & 73,9 & 37 & 96,8 & 13 & 91,5 & 3 & 95,1 & 5 & 469,3 & 5 \\
\hline Camana & Jsubs & 10us & $0,0+0$ & 1כ) & 12,0 & 22 & | & $\Leftrightarrow$ & so, & 20 & $y s, y$ & |כני & $s / / 7,2$ & 21 \\
\hline Caravelí & 35928 & 137 & 0,636 & 31 & 79,1 & 19 & 95,4 & 33 & 86,0 & 91 & 92,3 & 33 & 348,1 & 31 \\
\hline Castua & 18423 & 130 & u,ous & כנכ & 11,4 & 100 & $y, y$ & 14 & $0,0,0$ & se & $s u, s$ & 24 & 2000,0 & 47 \\
\hline Cayiloms & 73718 & 78 & 0,602 & 96 & 71,6 & 100 & 91,7 & 68 & 87,5 & 68 & 90,3 & 92 & 295,4 & 91 \\
\hline Condesuyos & 18991 & 175 & 0,995 & 63 & 72,0 & 87 & 89,9 & 83 & 87,5 & 69 & 89,1 & 66 & 269,2 & 99 \\
\hline Isisy & 32264 & 109 & 0,637 & 30 & 72,3 & 76 & 95,9 & 26 & 91,2 & 5 & 94,3 & 10 & 405,1 & 14 \\
\hline La Unión & 15662 & 179 & 0,553 & 135 & 71,1 & 116 & 79,2 & 155 & 85,1 & 103 & 81,2 & 147 & 196,5 & 113 \\
\hline
\end{tabular}

Fuente: PNUD informe sobre desarrollo humano Perú

Tabla 20: Tasa de analfabetismo por sexo

\begin{tabular}{|c|c|c|c|c|c|}
\hline \multirow{2}{*}{ Provincia: } & \multirow{2}{*}{ Total } & \multicolumn{2}{|c|}{ Seno } & \multicolumn{2}{|c|}{ Ambito geográfico } \\
\hline & & Hombre & Mujer & Urbono & Rursl \\
\hline Total & 4,1 & 1,6 & 6,5 & 3,5 & 10,0 \\
\hline Arecuipa & 32 & 1.1 & 50 & 3,1 & 72 \\
\hline Camani & 4,2 & 21 & 6,6 & 4,1 & 4,9 \\
\hline Carmelí & 4,6 & 22 & 60 & 3,6 & 5,9 \\
\hline Castilla & 9,1 & 30 & 13.4 & 0,6 & 1,1 \\
\hline Cryloma & 63 & 29 & 140 & 7,2 & 10,4 \\
\hline Conderuyos: & 101 & 3,3 & 19.4 & 7,4 & 11.9 \\
\hline leslay & 4,1 & 1.6 & 6,6 & 4,0 & 5,3 \\
\hline La Unión & 208 & 8.6 & 32,6 & 15,1 & 263 \\
\hline
\end{tabular}

Fuente: INEI 
Tabla 21: Indicadores de pobreza

10.10 PROVINCIA CAMANA: PRICIPALES INICADORES DE PROBREZA MONETARIA Y NO MONETARIA, 2607

\begin{tabular}{|c|c|c|}
\hline Indieador & Nismero & et \\
\hline \multicolumn{3}{|l|}{ UBICACION } \\
\hline Codip de dstrito & 0402 & \\
\hline Proviateia & CAMANA & \\
\hline Departanente & AREQUTPA & \\
\hline \multicolumn{3}{|l|}{ POBLACION } \\
\hline Poliaciba Censala & 53065 & - \\
\hline 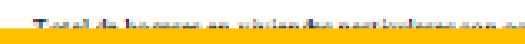 & 15012 & \\
\hline \multicolumn{3}{|l|}{ POBRDIA MONITARIA - LP } \\
\hline Incidencia de Polrera Total & 14110 & 26,5 \\
\hline Incidencia de Polrera Extrema & 2007 & 3.9 \\
\hline \multicolumn{3}{|l|}{ Gasto per cipien } \\
\hline Gaste per clapita en survos wies & 377,5 & - \\
\hline \multicolumn{3}{|c|}{ 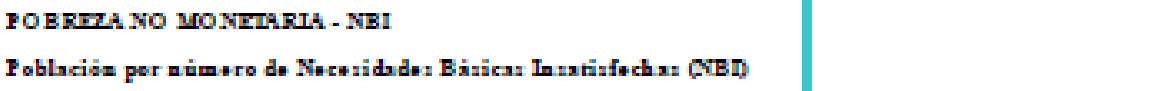 } \\
\hline Con al menos ana NBr & 23994 & 46,1 \\
\hline Con 2 o mas NBE & 9698 & 18,6 \\
\hline \multicolumn{3}{|c|}{ Poblaciön por tipo de Necesidaden Bisicax Insatisfechas (NBD } \\
\hline Viviendas cea caracteristicas fiscicas inalocuadus & 17795 & 34,2 \\
\hline Viviendas con lacinamiento & 9329 & 18,3 \\
\hline Viviendas sin deagle $\mathbf{a}$ aingin tipe & 6370 & 12,2 \\
\hline Hogares con siffos que so asiden a le escurla & 814 & 3,3 \\
\hline Hogares eon alua dependencí econbrtica & 1822 & 3,5 \\
\hline \multicolumn{3}{|c|}{ Hagarex par nuimero do Nocuridadox Biniess Insutinfochax (XBD) } \\
\hline Con al menos an NBr & 6983 & 46,5 \\
\hline Con 2 o más NBC & 2728 & 18,2 \\
\hline \multicolumn{3}{|c|}{ Hogarex por tipo de Nocesidader Bisicax Inzatisfochas COBD } \\
\hline Viviendes con caracteriaticas fricas inabecualus & 5354 & 3,7 \\
\hline Viviendas cea lacinamiento & 1907 & 12,7 \\
\hline Viviendas sin desagle $\mathbf{k}$ aingin tipe & 2253 & 1,5 \\
\hline Hogares oon sifios que no asiden a le escurla & 173 & 3,3 \\
\hline Hogares con alı dependencit econbrnica & 330 & 2,2 \\
\hline
\end{tabular}

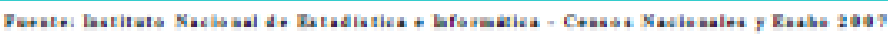


Tabla 22: Indicadores de pobreza

COMPENDIO ESTADISTICO REGIONAL 2008 - 2009

10.11 PROVINCIA CARAVIII PRTCIPAIES NDICADOKES DE PROBKFZAMONETARIAY NO MONETARIA, 2007

\begin{tabular}{|c|c|c|}
\hline Indicador & Nizmero & u \\
\hline \multicolumn{3}{|l|}{ UBICACION } \\
\hline Codigo of distrio & 0403 & \\
\hline Provincia & CARAVELI & \\
\hline Depaztamento & AREQUTPA & \\
\hline \multicolumn{3}{|l|}{ POBLACION } \\
\hline Pollacion Censula & 35928 & - \\
\hline Total de hoextes en viviendas sect iculates con ocurantes presentes & 9689 & - \\
\hline \multicolumn{3}{|l|}{ POBREZA MONEIARIA - LP } \\
\hline Incilencia de Pobrera Total & 8702 & 24,2 \\
\hline Incidencia de Polresa Extrema & 1246 & 3,6 \\
\hline \multicolumn{3}{|l|}{ Gata per cipien } \\
\hline Gasto per cipita en nuevos soles & 349,1 & - \\
\hline Gaso per cipila a procios de Lima Metropolina & 485,6 & - \\
\hline \multirow{2}{*}{\multicolumn{3}{|c|}{ 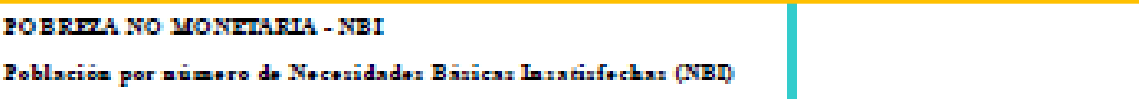 }} \\
\hline & & \\
\hline Con al menestau NBr & 16732 & $\$ 1,6$ \\
\hline Con 20 mis NBT & 7625 & 23.5 \\
\hline \multicolumn{3}{|l|}{ Población por tipo de Neceridades Baxicas Insatizfecbas (NBD } \\
\hline Viviendas eon caracterisicas fbicas inadecuales & 6668 & 20,6 \\
\hline Viviendas con hacinamiento & 6753 & 20,8 \\
\hline Viviendas sin dedale de aìngin tipo & 11462 & 35,4 \\
\hline Hogeres con sifios que no asisen a la everele & 605 & 3,8 \\
\hline Hogeres con alta depend́ncía económica & 1387 & 4,3 \\
\hline \multicolumn{3}{|l|}{ 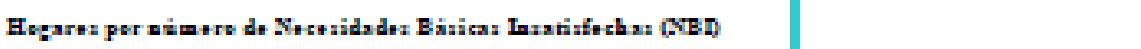 } \\
\hline Con al meaesua NBR & 4858 & so, 1 \\
\hline Con 20 mis NBI & 2197 & 22,7 \\
\hline \multicolumn{3}{|l|}{ Hegarex per tipo de Necesidades Bisicas Insatisfechas CNBD } \\
\hline Viviendas ece earacteriscicas fracicas inadecualus & 2248 & 23,2 \\
\hline Viviendas eca lacinamiento & 1269 & 13,1 \\
\hline Viviendas sin deatge de aingin tipo & 3655 & 37,7 \\
\hline Hoperes con sifios que no asisen a la escurlu & 116 & 3,6 \\
\hline Hoperes con alta depend́ncia eçonómica & 243 & 2,5 \\
\hline
\end{tabular}

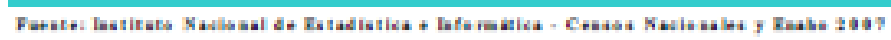




\subsubsection{USUARIO DIRECTO E INDIRECTO}

\subsubsection{USUARIO DIRECTO}

Es el usuario que pasa mayor tiempo en el edificio, a estos usuarios se les llama permanentes como los pacientes, profesionales médicos y no médicos y en algunos casos familiares.

\section{A. PACIENTES}

POR GRUPO ETARIO

Neonato.-

Se le denomina así a un bebé de 4 semanas de nacido o menos, también se le llama "recién nacido", a ellos se les debe dar un cuidado especial pues en este periodo llamado periodo neonatal ocurren cambios que se pueden desencadenar en eventos críticos en la que se presentan la mayoría de los defectos congénitos y pueden aparecer las anomalías genéticas. En las provincias de Camaná y Caravelí se presentaron dos casos de fallecimiento por inmaturidad extrema y por dificultad respiratoria en el año 2014.

Representa el 1\% de la población en Camaná Representa el 1\% de la población en Caravelí

Infante.-

Se considera infante al bebé de 30 días hasta los 4 años de edad es una etapa de maduración inmunológica que es la posibilidad de la defensa propia del organismo ante cualquier enfermedad, también es la etapa en la que el infante aprende a caminar y hablar. En Camaná se encontró tres casos de fallecimiento, por Enfermedad de VIH, Hidrocéfalo, Accidente de Tránsito.

Representa el 10\% de la población en Camaná. Representa el 10\% de la población en Caravelí.

Niño.-

Se considera niñez a la etapa de 5 a 11 años de edad. En el 2014 se han registrado 2 causas de muerte en niño como la parálisis cerebral y accidente de tránsito

Representa el 14\% de la población de Camaná. Representa el 14\% de la población de Caravelí.

\section{Adolescente.-}


Es la etapa en la que el niño se convierte en adolescente diferenciada por los cambios biológicos hormonales de la pubertad lo que indica que se convertirán en adultos. Esta etapa comprende desde los 12 hasta los 19 años de edad.

El desarrollo hormonal tiene 5 etapas o fases.

Tabla 23: Etapas del desarrollo hormonal en Niñas

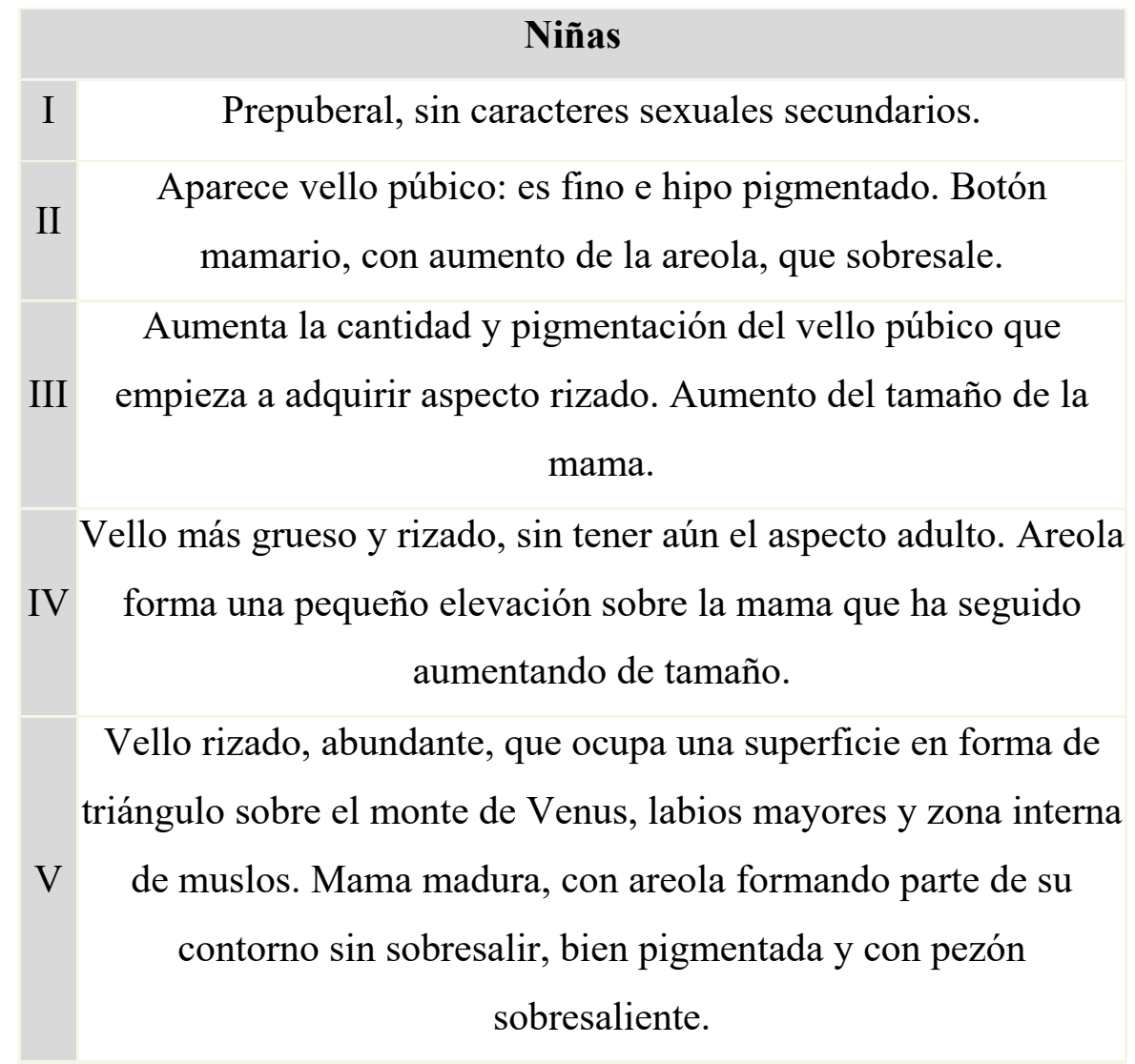

Tabla 24: Etapas del desarrollo hormonal en Niños

\begin{tabular}{|c|c|}
\hline Niños & Prepuberal, sin caracteres sexuales secundarios. \\
\hline I & Aparece vello púbico; es largo, fino e hipo pigmentado. \\
\hline II & $\begin{array}{r}\text { Empieza a cambiar la textura del escroto y aumentar el tamaño } \\
\text { de testículos y pene. }\end{array}$ \\
\hline III & Vello púbico empieza a rizarse. Siguen aumentando testículos y \\
& escroto.
\end{tabular}


Vello más grueso y rizado, sin tener aún el aspecto adulto.

IV

Sigue el aumento de tamaño de pene y testículos. El glande adquiere mayor tamaño y el escroto, un aspecto más pigmentado.

$\mathrm{V}$

Vello de aspecto y disposición adulta, extendiéndose hacia la parte interna de los muslos. Pene y testículos de aspecto adulto.

Fuente: Desarrollo infantil.net

Representa el 16\% de la población de Camaná.

Representa el 16\% de la población de Caravelí.

Jóvenes.-20-29 años

Etapa de reproducción en el año 2014 se ha contabilizado 614 embarazos en Camaná y 105 en Caravelí.

El reporte de fallecimiento en mayor porcentaje es por accidente de tránsito.

Representa el 17\% de la población de Camaná.

Representa el 20\% de la población de Caravelí.

\section{Adultos.-30-59 años}

Es la etapa de la madurez en la que a su término ocurre el climaterio que implica cambios físicos, biológicos, sexuales y sociales.

Representa el 39\% de la población de Camaná.

Representa el 38\% de la población de Caravelí.

\section{Adulto mayor.-60 a más años}

Es la etapa en la que aparecen múltiples enfermedades como artrosis, artritis, Alzheimer, Parkinson, hipertrofia de próstata, neumonía, fibrosis pulmonar, problemas visuales, auditivos, demencia senil osteoporosis etc. Se han reportado fallecimientos en mayor porcentaje por tumores, septicemia, cáncer de próstata, neumonía, bronconeumonía e infarto.

Representa el 9\% de la población de Camaná.

Representa el 9\% de la población de Caravelí.

Personas con capacidades especiales.- Ocupan el $6.6 \%$ a nivel departamental.

POR ESTANCIA CORTA.- son los pacientes que van a una determinada área para una consulta o un examen médico. 
- $\quad$ Pacientes de análisis clínicos.- Aquellos pacientes que por orden del médico va al área de análisis.

Pacientes de diagnóstico por imágenes.- Aquellos pacientes que por orden del médico acude Diagnóstico por imágenes.

- $\quad$ Pacientes en consulta externa.- Pacientes que tienen alguna dolencia no grave que acude a una consulta con un médico de alguna especialidad

POR ESTANCIA LARGA.- Son los pacientes que permanecerán más de un día en el hospital, ya sea ingresado por emergencia, hospitalización o que es frecuente por terapia de rehabilitación o control médico frecuente.

Pacientes en emergencia.- pacientes que llegan con alguna dolencia aguda, pueden permanecer horas o días.

- Pacientes de rehabilitación.- pacientes que acuden de manera regular para terapia de rehabilitación.

- $\quad$ Pacientes de cirugía.- pacientes que acuden para alguna cirugía mayor esto implica quedarse en el área de hospitalización. (tiempo aproximado 7 días)

Pacientes de hospitalización.- pacientes que se internan por cirugía, programada o por cirugía espontánea en emergencia.

- Pacientes de cuidados especiales.- pacientes que ingresan después de alguna intervención en el área de emergencia.

Pacientes de control médico frecuente.- pacientes que por indicaciones del médico tiene que acudir al hospital por controles frecuente para la estabilidad del paciente.

PERSONAL.- Son los usuarios que permanecen en el hospital por ser su centro de trabajo estos se pueden dividir en profesionales médicos, profesionales no médicos, profesionales de la salud, y personal de servicios generales y mantenimiento.

Doctor medicina general

Doctor especialista

Doctor residente

Licenciada en enfermería

Enfermera

Técnico de laboratorio, imagenología, farmacia.

Personal administrativo 
- $\quad$ Personal de servicios generales

- $\quad$ Personal de mantenimiento

\subsubsection{INDIRECTO}

FAMILIARES.- usuario indirecto, que en algunos casos juega el rol de directo, cuando el paciente es menor de edad requiere del acompañamiento del padre o apoderado.

Tabla 25:Tipos de usuario

\begin{tabular}{|c|c|c|c|c|}
\hline \multicolumn{4}{|c|}{ DIRECTO } & INDIRECTO \\
\hline PACIENTES & $\begin{array}{l}\text { PROFESIONALES } \\
\text { DE LA SALUD }\end{array}$ & $\begin{array}{l}\text { PERSONAL } \\
\text { ADMINISTRATIVO }\end{array}$ & $\begin{array}{ll}\text { PERSONAL } & \text { DE } \\
\text { SERVICIO } & \end{array}$ & VISITAS \\
\hline $\begin{array}{l}\text { PACIENTES DE } \\
\text { ESTANCIA } \\
\text { CORTA }\end{array}$ & MÉDICOS & DIRECTIVOS & $\begin{array}{l}\text { PERSONAL DE } \\
\text { COCINA }\end{array}$ & $\begin{array}{l}\text { FAMILIARES } \mathrm{Y} \\
\text { AMIGOS }\end{array}$ \\
\hline \multirow[t]{4}{*}{$\begin{array}{l}\text { PACIENTES DE } \\
\text { ESTANCIA } \\
\text { LARGA }\end{array}$} & NO MÉDICOS & ADMINISTRATIVOS & $\begin{array}{ll}\text { PERSONAL } & \text { DE } \\
\text { LAVANDERÍA } & \end{array}$ & \\
\hline & TÉCNICOS & TÉCNICOS & $\begin{array}{l}\text { PERSONAL DE } \\
\text { LIMPIEZA }\end{array}$ & \\
\hline & & AUXILIARES & $\begin{array}{l}\text { PERSONAL DE } \\
\text { MANTENIMIENTO }\end{array}$ & \\
\hline & & & $\begin{array}{ll}\text { PERSONAL } & \text { DE } \\
\text { AMBULANCIA } & \end{array}$ & \\
\hline
\end{tabular}

Fuente: INEGI, MINSA, (Bambarén Alatrista, 2008) Elaboración propia 


\subsubsection{FLUJOGRAMAS}

\subsubsection{FLUJO DE PACIENTES}
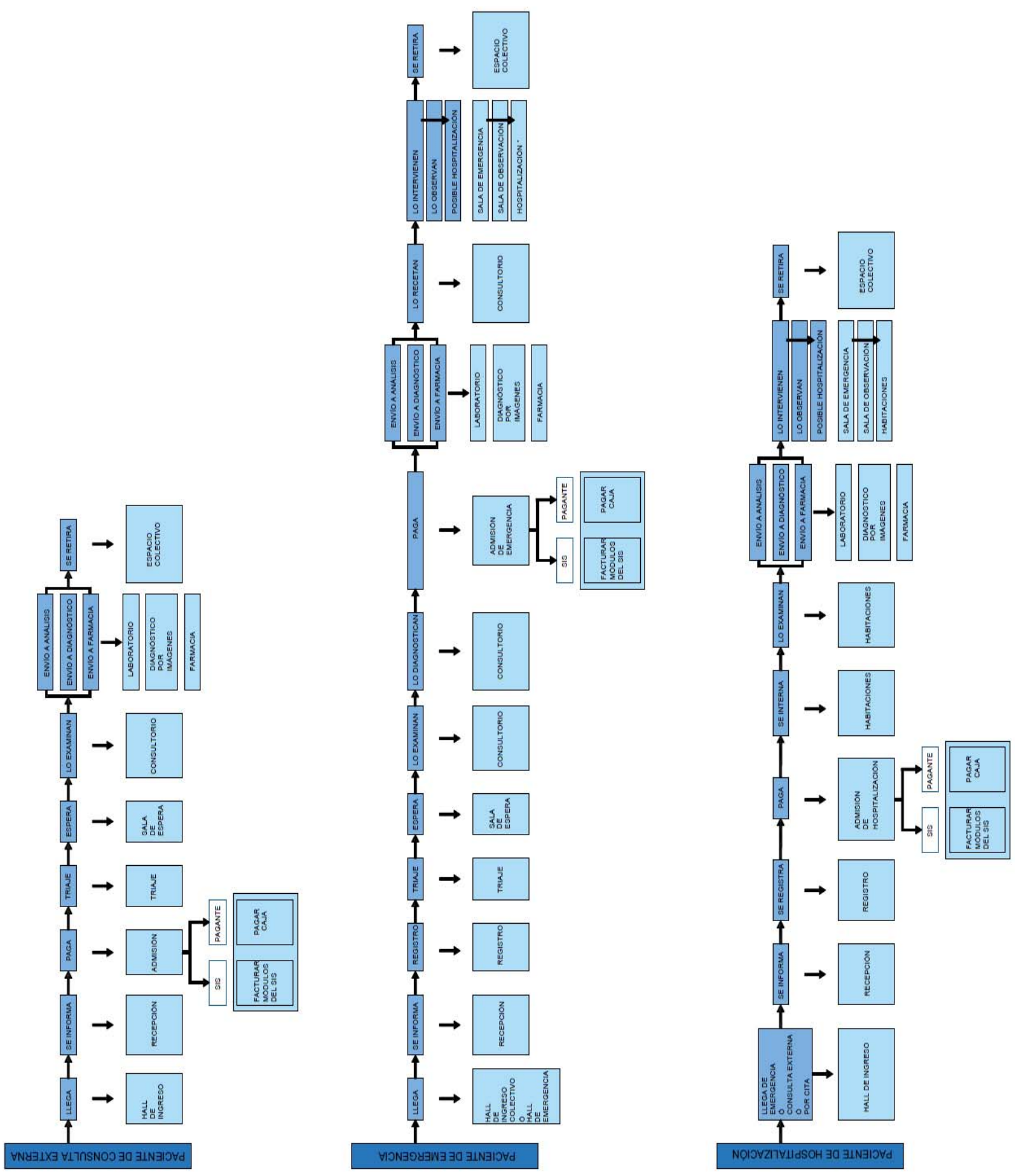

Fuente: MINSA y visita a Hospitales. Elaboración propia 


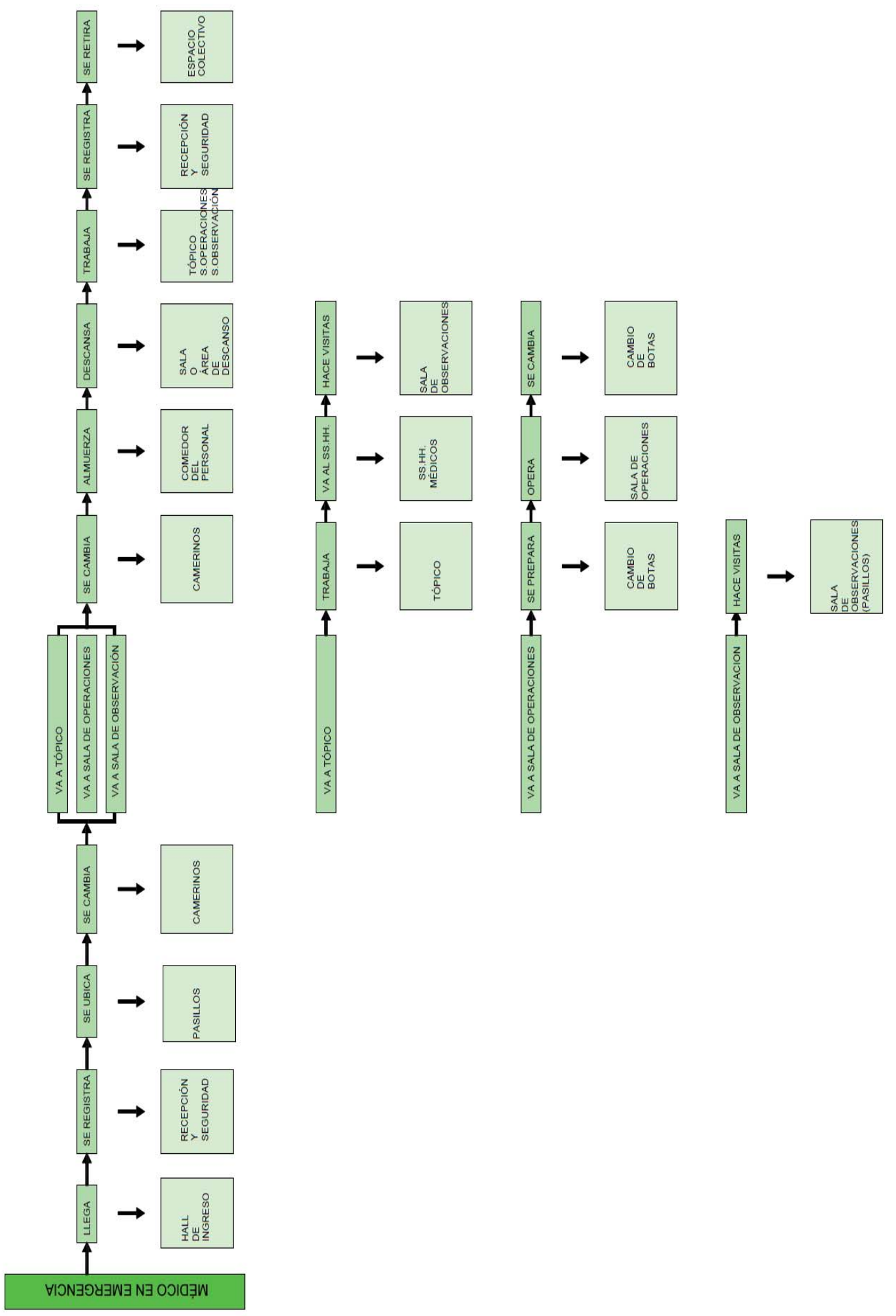

Fuente: MINSA y visita a Hospitales. Elaboración propia 

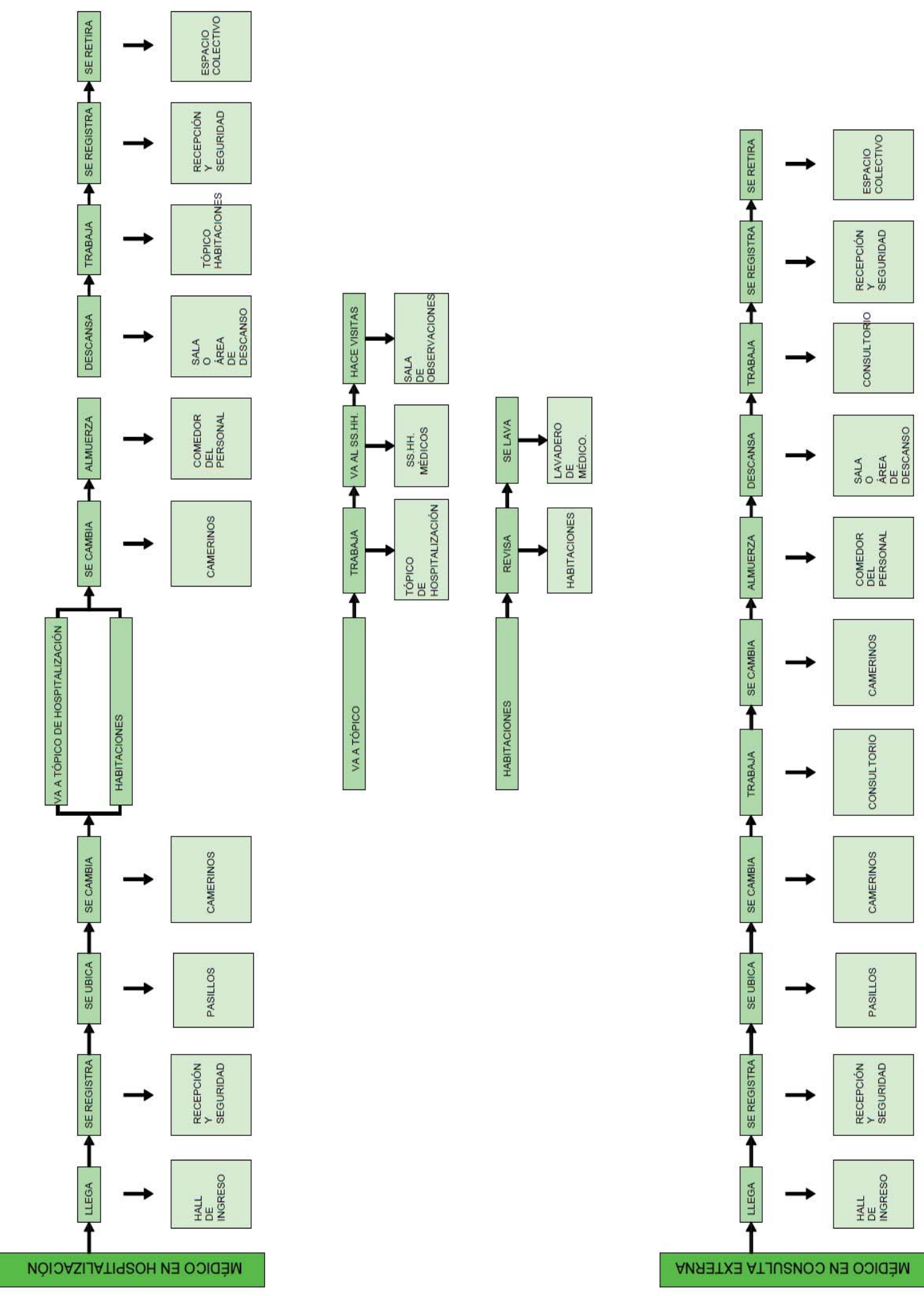

Fuente: MINSA y visita a Hospitales. Elaboración propia 


\subsubsection{FLUJO DE PERSONAL ADMINISTRATIVO}

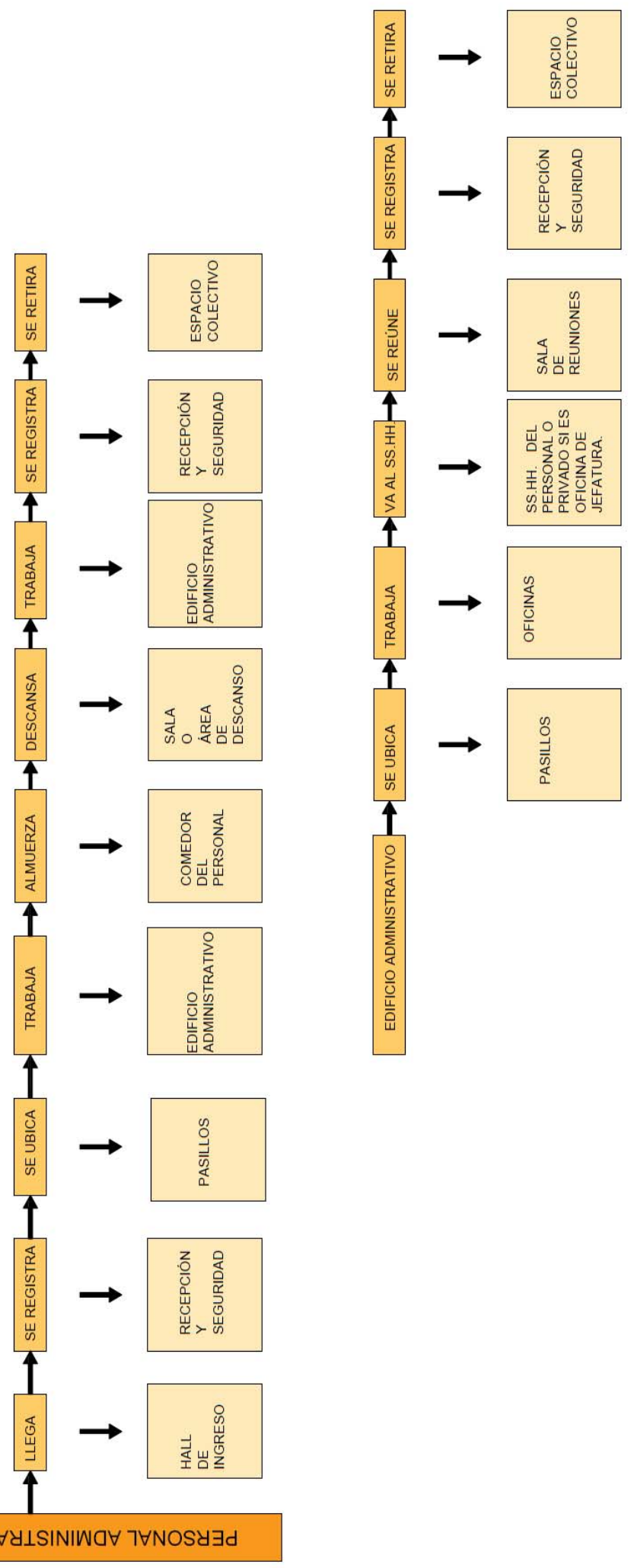

Fuente: MINSA y visita a Hospitales. Elaboración propia 


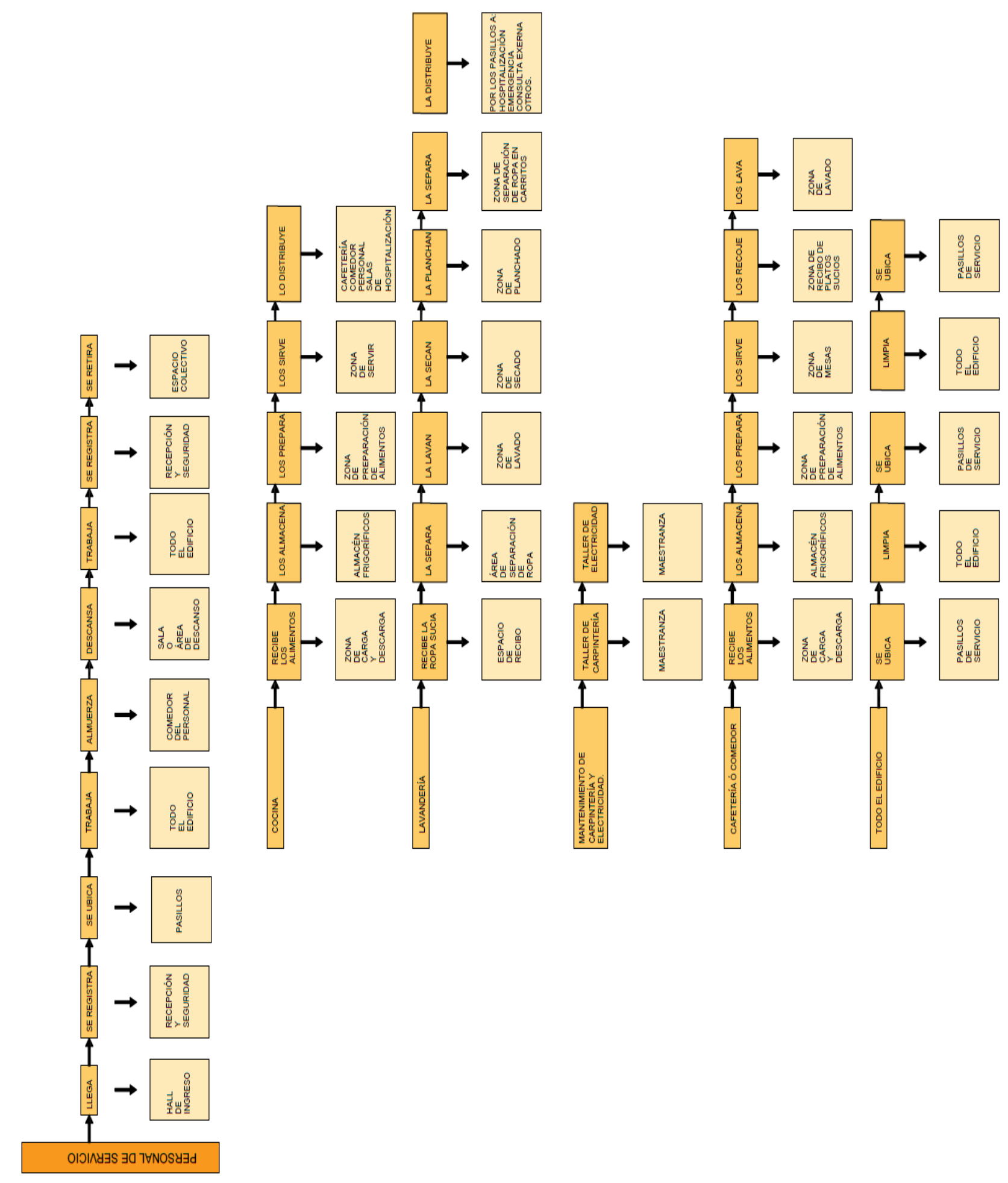

Fuente: MINSA y visita a Hospitales. Elaboración propia 

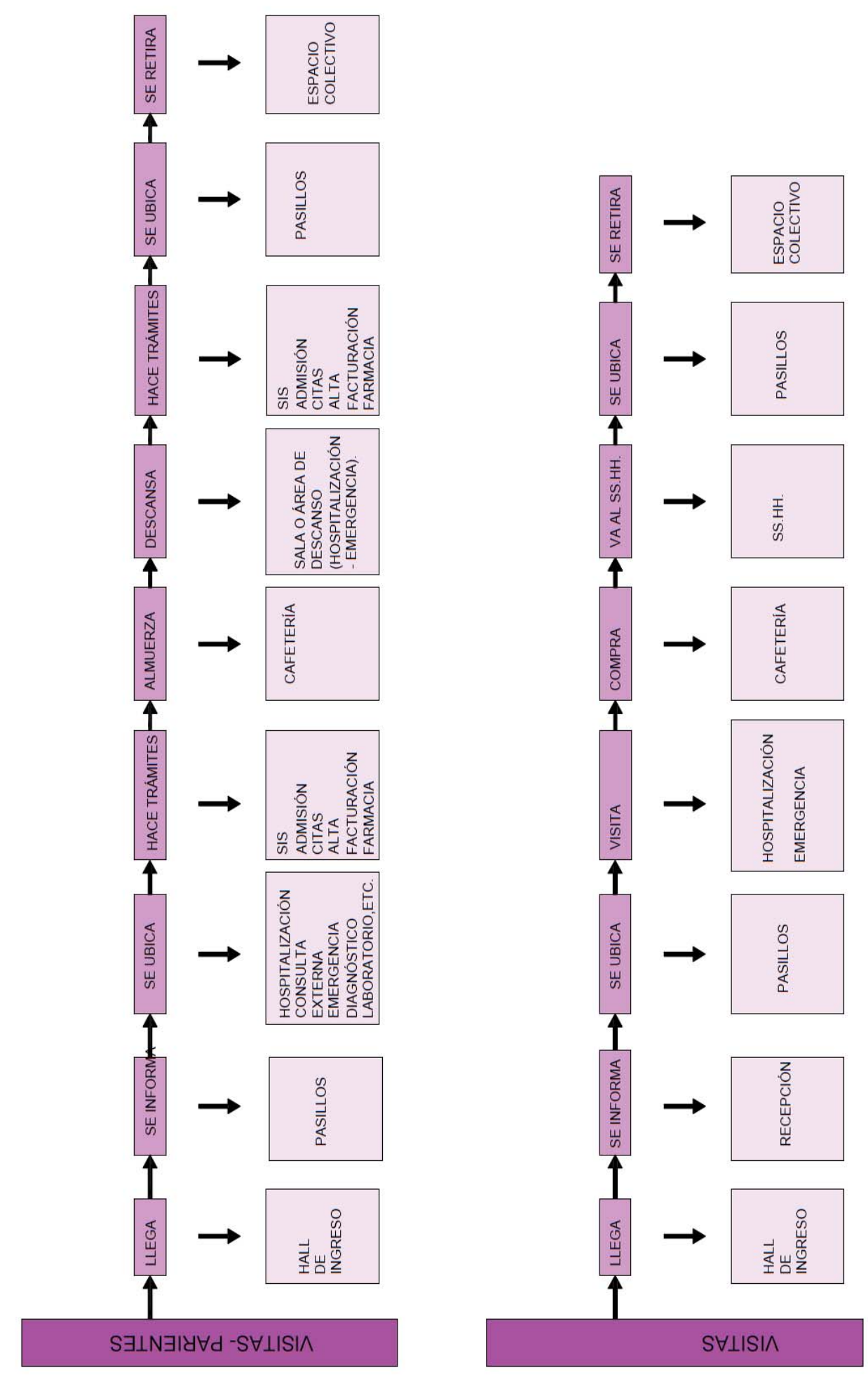

Fuente: MINSA y visita a Hospitales. Elaboración propia 


\subsubsection{HORARIO DE USUARIOS}

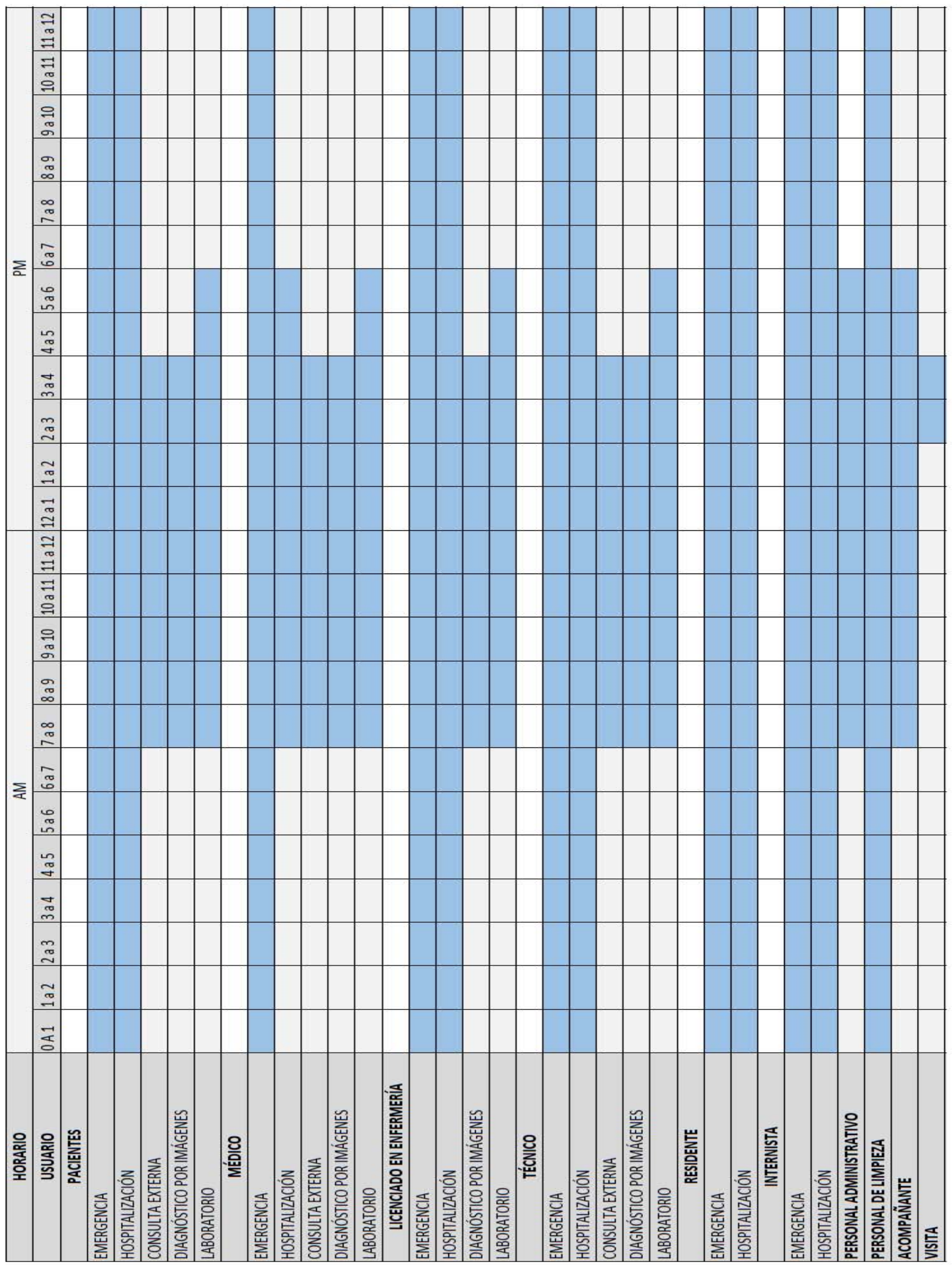

Fuente: MINSA y visita a Hospitales. Elaboración propia 


\subsection{INFORMACIÓN CUANTITATIVA}

La población de Camaná es 58,952 Caravelí es 40,904 lo cual nos suma 99856 habitantes.

Tabla 26: Cuadro de relación de nro de atendidos en tres hospitales

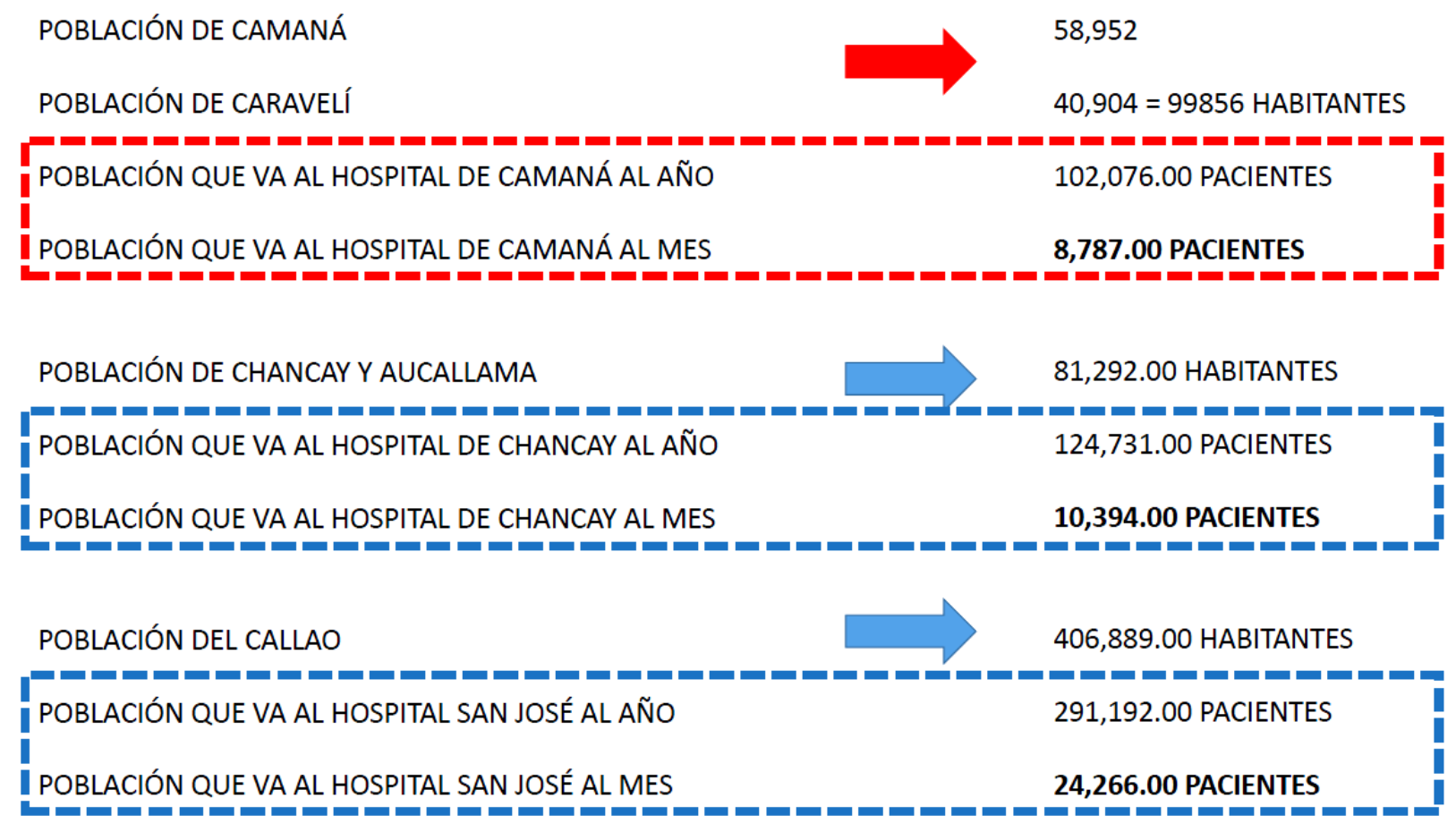

Fuente: INEI, MINSA, GERESA, GRLIMA. Elaboración propia.

\section{Población que visita al Hospital proyectada.}

El ministerio de Salud pide una proyección de la población a 20 años para poder elaborar un proyecto de establecimiento de Salud.

Pf - Población Final

Pi - Población Inicial

$\mathrm{r}$ - Tasa de crecimiento

$\mathrm{n}$ - Número de años a proyectar

$\mathrm{Pf}=\mathrm{Pi}(1+\mathrm{r})^{\mathrm{n}}$

Fuente: INEGI

Considerando que la tasa de crecimiento de Arequipa es de 1.6\% anual.

Para obtener el número población que se atenderá en el hospital no se tomará en cuenta la población que se encuentre afiliado al seguro (ESSALUD). Por lo tanto la población inicial de 78313 
habitantes en dic del 2015 es la suma de la población de Camaná y Caravelí sin asegurados con una tasa de crecimiento $1.6 \%$ número de proyección de años 22 con lo cual da una población final de y 111044 habitantes en Diciembre del 2037 que acudiría al hospital.

Tabla 27: Tabla de años de proyección

\begin{tabular}{|l|r|r|}
\cline { 2 - 3 } \multicolumn{1}{c|}{} & 2015 & 2037 \\
\hline CAMANA & 58952 & 83712 \\
\hline CARAVELI & 40904 & 58084 \\
\hline ASEGURADOS & $\mathbf{2 1 5 4 3}$ & $\mathbf{3 0 5 9 1}$ \\
\hline población a considerar & 78313 & 111204 \\
\hline
\end{tabular}

\begin{tabular}{|l|r|r|}
\hline AÑO & 2015 & 2037 \\
\hline POBLACIÓN & 78313 & 111044 \\
\hline
\end{tabular}

Fuente: INFORHUS - INEI - GERESA Elaboración propia.

Otra forma de obtener el número de población a la que va dirigida es haciendo la fórmula que se utiliza para hacer los proyectos de pre inversión del ministerio de salud, en esta tabla se utilizan los datos de población demandante, efectiva, atendida así como tambien las demandas atendidas, efectivas y la oferta disponible.

A continuación una tabla del año 2015 con proyección al 2037.

\begin{tabular}{|c|c|c|c|c|c|c|c|c|c|}
\hline & $\begin{array}{l}\text { poblacion } \\
\text { referencial }\end{array}$ & $\begin{array}{c}\text { pob.demandant } \\
\text { e potencial }\end{array}$ & pob. Efectiva & pob. Atendida & $\begin{array}{c}\text { demanda } \\
\text { efectiva }\end{array}$ & $\begin{array}{l}\text { demanda } \\
\text { atendida }\end{array}$ & $\begin{array}{c}\text { produccion } \\
\text { actual }\end{array}$ & $\begin{array}{c}\text { oferta } \\
\text { disponible }\end{array}$ & $\begin{array}{c}\text { oferta } \\
\text { optimizada }\end{array}$ \\
\hline & $100 \%$ & $35 \%$ & $25 \%$ & $20 \%$ & x 4 días q regresa & $\mathrm{x} 4$ días que regre & nro de atencione & anual & cero \\
\hline 2015 & 78313 & 27410 & 6852 & 1370 & 27410 & 5482 & 35148 & 35148 & 0 \\
\hline 2037 & 111204 & 38922 & 9730 & 1946 & 38922 & 7784 & 49910 & 49910 & 0 \\
\hline
\end{tabular}

Fuente: Curso de Planeamiento y diseño de establecimientos de salud

Como vemos la población sigue siendo la misma que en la fórmula anterior, por lo tanto tenemos el dato de 111204 personas.

\section{Personal que trabaja en el Hospital.}

Para determinar el número de usuario del personal médico, administrativo y servicio, se tomará en cuenta otros hospitales de categoría II-2 en el Perú.

Número de trabajadores del hospital de Chancay en Huaral 427

Número de trabajadores del hospital San José en el Callao 771

Número de trabajadores del hospital Santa Rosa de Puerto Maldonado 331 
Tabla 28: cuadro de grupo ocupacional en comparativo con tres Hospitales

\begin{tabular}{|l|r|r|r|}
\hline \multicolumn{1}{|c|}{ GRUPO OCUPACIONAL } & $\begin{array}{c}\text { HOSPITAL DE } \\
\text { CHANCAY }\end{array}$ & $\begin{array}{c}\text { HOSPITAL } \\
\text { SANTA ROSA }\end{array}$ & $\begin{array}{c}\text { HOSPITAL SAN } \\
\text { JOSE }\end{array}$ \\
\hline FUNCIONARIOS Y DIRECTIVOS & 2 & 10 & 2 \\
\hline PROFESIONALES ADMINISTRATIVOS & 6 & 13 & 105 \\
\hline TÉCNICOS ADMINISTRATIVOS & 49 & 43 & 51 \\
\hline PROFESIONALES MÉDICOS & 50 & 31 & 143 \\
\hline PROFESIONALES NO MÉDICOS & 102 & 70 & 214 \\
\hline TECNICOS ASISTENCIALES & 203 & 152 & 256 \\
\hline SERVICIOS GENERALES & 15 & 12 & 30 \\
\hline
\end{tabular}

Fuente: INFORHUS MINSA Elaboración propia.

El rango de trabajadores debe oscilar entre 331 a 771 trabajadores según la tabla de trabajadores de hospitales similares, la cifra será más exacta después de elaborar el programa arquitectónico.

Usuario diario

\begin{tabular}{|l|r|}
\cline { 2 - 2 } \multicolumn{1}{c|}{} & USUARIO POR DÍA \\
\hline PACIENTES & 383 \\
\hline VISITAS & 156 \\
\hline TRABAJADORES & 453 \\
\hline & $\mathbf{9 9 1}$ \\
\hline
\end{tabular}

Tomando en cuenta para el número de trabajadores un promedio de 600 trabajadores se tendrá un total de 1147 usuarios diarios. 
CAPÍTULO 7 - EL PROGRAMA ARQUITECTÓNICO 


\subsection{PROCESO DE ELABORACIÓN Y FUENTES}

Para desarrollar el programa arquitectónico se tomará en cuenta las siguientes normas y datos proyectados.

Tabla 29: Cuadro de Utilización de fuentes

\begin{tabular}{|c|c|}
\hline FUENTE & UTILIZACIÓN \\
\hline MINSA & AMBIENTES \\
\hline NORMAS & DOTACIONES, AREAS, AMBIENTES \\
\hline NEUFERT & UNIDADES ESPACIO FUNCIONALES \\
\hline DATOS PROYECTADOS & AFÓRO \\
\hline $\begin{array}{c}\text { PROGRAMA ARQUITECTÓNICO PARA EL DISEÑO DE } \\
\text { HOSPITALES SEGUROS }\end{array}$ & AREAS MINIMAS, EQUIPAMIENTO \\
\hline REFERENTES & ORGANIGRAMAS, AMBIENTES \\
\hline TASAS DE MORBILIDAD & N $^{\circ}$ DE AMBIENTES, CAMAS \\
\hline
\end{tabular}

Fuente: Elaboración propia

\subsection{INFORMACIÓN CUANTITATIVA}

Tabla 30: Egresos Hospitalarios

\begin{tabular}{|l|r|}
\hline \multicolumn{2}{|c|}{ EGRESOS HOSPITALARIOS = POBLACIÓN X FRECUENTACIÓN / 1000 HAB } \\
\hline POBLACIÓN & 111044 \\
\hline FRECUENTACIÓN & 100 \\
\hline 1000 HAB & $\mathbf{1 1 1 0 4}$ \\
\hline \multicolumn{2}{|c|}{} \\
\hline \multicolumn{2}{|c|}{ NRO DE CAMAS = EGRESOS X ESTANCIA MEDIA / 365 DIAS X INDICE DE OCUPACIÓN OPTIMO } \\
\hline EGRESOS & 11104 \\
\hline ESTANCIA MEDIA & 7 \\
\hline INDICE DE OCUPACIÓN OPTMIO & 0.85 \\
\hline AÑO & 365 \\
\hline
\end{tabular}

Fuente: INEGI, Elaboración propia

A continuación un comparativo de los proyectos referenciales nacionales e internacionales con el proyecto

\begin{tabular}{|c|c|c|c|c|c|c|c|}
\hline & LUGAR & POBLACIÓN & CATEGORÍA & NRO DE CAMAS & TERRENO & A.CONSTRUIDA & \\
\hline HOSPITAL JOHANNES WESLING & ALEMANIA & 211718 & III & 879 & $220000 \mathrm{M} 2$ & $96000 \mathrm{M} 2$ & INTERNACIONAL \\
\hline HOSPITAL CLEMENTE ALVAREZ & ARGENTINA & 90500 & II & 155 & $15000 \mathrm{M} 2$ & $17013 \mathrm{M} 2$ & INTERNACIONAL \\
\hline HOSPITAL EL CARMEN DE MAIPÚ & CHILE & 464882 & III & 375 & $52000 \mathrm{M} 2$ & $70301 \mathrm{M} 2$ & INTERNACIONAL \\
\hline HSP. GUILLERMO DE LA VEGA & ABANCAY & 57750 & $\mathrm{II}-2$ & 150 & $68500 \mathrm{M} 2$ & $37900 \mathrm{M} 2$ & NACIONAL \\
\hline HSP. DEPARTAMENTAL MOQUEGUA & MOQUEGUA & 170480 & $\mathrm{II}-2$ & 120 & $31438 \mathrm{M} 2$ & $20564 \mathrm{M} 2$ & NACIONAL \\
\hline HSP. SANTA ROSA & MADRE DE DIOS & 92024 & II-2 & 120 & $27890 \mathrm{M} 2$ & $11500 \mathrm{M} 2$ & NACIONAL \\
\hline HSP. CAMANÁ & CAMANÁ & 111044 & $\mathrm{II}-2$ & 181 & $25996 \mathrm{M} 2$ & 25778.2M2 & PROPUESTA \\
\hline
\end{tabular}


Tabla 31: Proyecciones de atenciones y atendidos; Consultas al año; Horas médicos, Nro de camas

\begin{tabular}{|l|r|r|}
\hline \multicolumn{3}{|c|}{ PROYECCION DE ATENCIONES Y ATENDIDOS SEGÚN ZONA } \\
\hline & 2015 & 2037 \\
\hline ATD & 11152 & 15836 \\
\hline ATC & 35148 & 49910 \\
\hline EMERGENCIA & 9648 & 13700 \\
\hline HOSPITALIZACIÓN & 9985 & 14179 \\
\hline LABORATORIOS & 2496 & 3545 \\
\hline
\end{tabular}

\begin{tabular}{|l|r|}
\hline ATD & 15836 \\
\hline ATC & 49910 \\
\hline VECES QUE ACUDE AL HOSPITAL & 4 \\
\hline CONSULTAS POR HORA & 2 \\
\hline DÍAS UTILES & 275 \\
\hline HORAS DE TRABAJO & 8 \\
\hline HORAS MEDICO AL AÑO POR MÉDICO & 2200 \\
\hline
\end{tabular}

CONSULTAS ESPERADAS AL AÑO

VECES QUE ACUDE POR AÑO X NRO DE CONSULTAS ESPERADAS

HORAS MÉDICO AL AÑO TOTAL

CONSULTAS ESPERADAS AL AÑO/NRO DE CONSULTAS POR HORA

NRO DE MÉDICOS

HORAS MÉDICO AL AÑO(TOTAL) / HORAS MEDICO AL AÑO POR MÉDICO

médicos (cada 8 horas)

\begin{tabular}{|l|r|}
\hline \multicolumn{2}{|c|}{ CAMAS PARA HOSPITALIZACIÓN } \\
\hline NRO DE CAMAS 2015 & 128 \\
\hline NRO DE CAMAS 2037 & 181 \\
\hline
\end{tabular}

- En la actualidad hay 60 camas. ( no cumple con la demanda)

Fuente: GERESA, INEGI, (Bambarén Alatrista, 2008), MINSA. Elaboración propia 
Distribución de camas según tasas de morbilidad y necesidades según Departamento de Estadísticas del Hospital de Camaná.

Tabla 32: Distribución de camas según morbilidad

\begin{tabular}{|l|r|}
\hline \multicolumn{2}{|c|}{ CONSULTA EXTERNA } \\
\hline Medicina Interna & 1 \\
\hline Pediatría & 1 \\
\hline Cirugía General & 1 \\
\hline Ginecología y obstetricia & 1 \\
\hline medicina familiar & 1 \\
\hline medicina de rehabilitación & 1 \\
\hline traumatología y ortopedia & 1 \\
\hline cardiología & 1 \\
\hline neurología & 1 \\
\hline neumología & 1 \\
\hline gastroenterología & 1 \\
\hline reumatología & 1 \\
\hline psiquiatría & 1 \\
\hline oftalmología & 1 \\
\hline urología & 1 \\
\hline otorrinolaringología & 1 \\
\hline dermatología & 1 \\
\hline nutricion y dietética & 1 \\
\hline tópico en consulta & 1 \\
\hline cirujano dentista & 1 \\
\hline psicólogía & 1 \\
\hline endocrinología & 1 \\
\hline & 1 \\
\hline
\end{tabular}

\begin{tabular}{|l|r|}
\hline \multicolumn{2}{|c|}{ HOSPITALIZACIÓN } \\
\hline Medicina Interna & 46 \\
\hline Cirugía General & 42 \\
\hline Pediatría & 48 \\
\hline Ginecología y obstetricia & 45 \\
\hline \multicolumn{2}{|r}{} \\
\cline { 2 - 2 }
\end{tabular}

\begin{tabular}{|l|r|}
\hline \multicolumn{2}{|c|}{ EMERGENCIA } \\
\hline DEMANDA & 37 \\
\hline
\end{tabular}




\begin{tabular}{|l|c|}
\hline \multicolumn{2}{|c|}{ C. QUIRÚRGICO } \\
\hline Cirugía General & 1 \\
\hline Pediatría & 1 \\
\hline Ginecología y obstetricia & 3 \\
\hline traumatología y ortopedia & 1 \\
\hline \multicolumn{2}{|c|}{ OTROS } \\
\hline \multicolumn{2}{|c|}{} \\
\hline UCINTERMEDIO & 16 \\
\hline UCI & 8 \\
\hline & 24 \\
\hline
\end{tabular}

Fuente: GERESA, INEGI, (Bambarén Alatrista, 2008) Elaboración propia

A continuación se detalla los cálculos del personal médico y técnico del hospital según tiempo de horas trabajadas y otros datos.

\begin{tabular}{|c|c|c|c|}
\hline \multicolumn{4}{|c|}{ HOSPITALIZACIÓN MÉDICOS } \\
\hline SERVICIO & CAMAS & $\begin{array}{l}\text { TIEMPO EN HORAS } \\
\text { ATENDIENDO CADA } \\
\text { PACIENTE } 10 \text { MIN }\end{array}$ & $\begin{array}{c}\text { MÉDICOS NECESARIOS } \\
\text { HORAS ASISTENCIALES } \\
\text { (2) }\end{array}$ \\
\hline MEDICINA INTERNA & 46 & 8 & 4 \\
\hline PEDIATRÍA & 45 & 8 & 4 \\
\hline CIRUGÍA & 42 & 7 & 4 \\
\hline GINECOLOGÍA & 48 & 8 & 4 \\
\hline NEONATOLOGÍA & 8 & 1 & 1 \\
\hline \multirow[t]{2}{*}{ AISLADOS } & 9 & 2 & 1 \\
\hline & \multicolumn{2}{|c|}{ MÉDICOS } & 17 \\
\hline
\end{tabular}

\begin{tabular}{|c|c|c|c|c|}
\hline \multicolumn{5}{|c|}{ CONSULTA EXTERNA MÉDICOS } \\
\hline & & TURNOS & & MÉDICOS \\
\hline NRO CONSULTORIOS & 22 & & 2 & 44 \\
\hline & & MÉDICOS & & 22 \\
\hline
\end{tabular}

\begin{tabular}{|c|c|c|c|}
\hline \multicolumn{4}{|c|}{ CIRUGÍA MÉDICOS } \\
\hline SERVICIO & AMBIENTES & $\begin{array}{c}\text { TIEMPO EN HORAS (3) } \\
\text { TURNOS (3) }\end{array}$ & MÉDICOS \\
\hline SALA DE EXPULSIÓN & 1 & 9 & 3 \\
\hline C. DE EMERGENCIA & 1 & 9 & 3 \\
\hline C. DE GINECO-OBSTETRA & 1 & 9 & 3 \\
\hline C. DE PEDIATRÍA & 1 & 9 & 3 \\
\hline C. DE TRAUAMATOLOGÍA & 1 & 9 & 3 \\
\hline \multirow[t]{2}{*}{ C. GENERAL } & 1 & 9 & 3 \\
\hline & & MÉDICOS & 18 \\
\hline
\end{tabular}

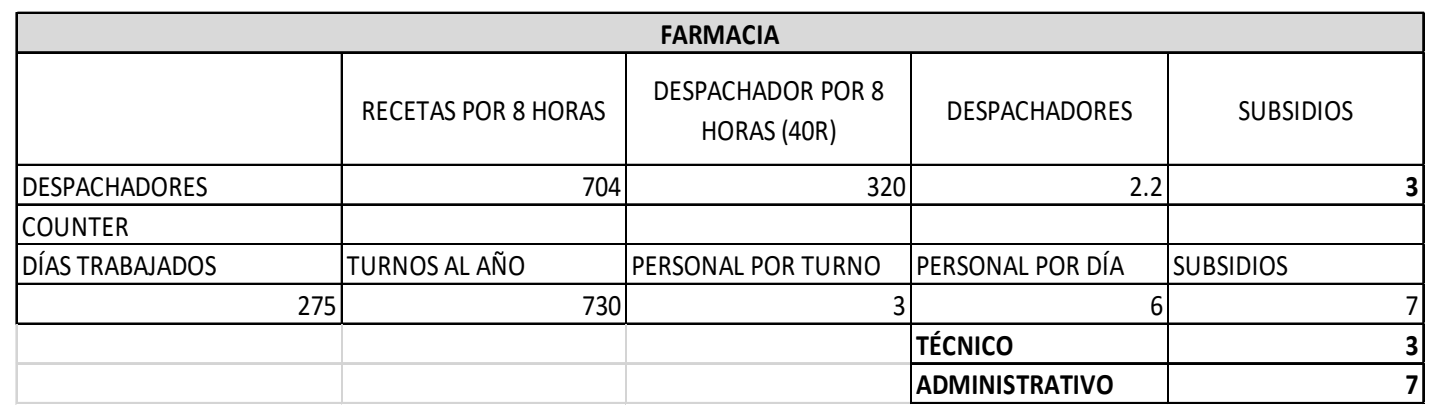




\begin{tabular}{|c|c|c|c|c|c|c|c|}
\hline \multicolumn{8}{|c|}{ ANATOMÍA PATOLÓGICA } \\
\hline PERFIL & $\begin{array}{c}\text { CANTIDAD PIEZAS } 30 \\
\text { minima }\end{array}$ & RECURSOS NECESARIOS & $\begin{array}{c}\text { CITOLOGÍAS EN } 8 \\
\text { HORAS }\end{array}$ & $\begin{array}{l}\text { RECURSOS } \\
\text { NECESARIOS }\end{array}$ & AUTOPSIAS & $\begin{array}{l}\text { RECURSOS } \\
\text { NECESARIOS }\end{array}$ & total \\
\hline PATÓLOGO & 30 & 1 & 60 & 5 & 2 & 1 & 7 \\
\hline TÉCNICO & & & & & & 1 & 1 \\
\hline \multirow[t]{5}{*}{ COUNTER } & & & & & & 1 & 1 \\
\hline & & & & & & & 9 \\
\hline & & & & & \multicolumn{2}{|c|}{ MÉDICO } & 7 \\
\hline & & & & & \multicolumn{2}{|c|}{ TÉCNICO } & 1 \\
\hline & & & & & \multicolumn{2}{|c|}{ ADMINISTRATIVO } & 1 \\
\hline
\end{tabular}

\begin{tabular}{|l|r|r|r|r|r|}
\hline \multicolumn{2}{|c|}{ RADIOLOGÍA } \\
\hline NRO DE SALAS & PACIENTES POR HORA & RAYOS X POR 8 HORAS & TÉCNICOS EN 8 HORAS & SUBSIDIOS \\
\hline & 4 & 4 & 96 & 3 & 1 \\
\hline
\end{tabular}

\begin{tabular}{|c|c|c|c|c|}
\hline \multicolumn{5}{|c|}{ LABORATORIO CLÍNICO } \\
\hline SERVICIOS & $\begin{array}{l}\text { CANTIDAD DE EXAMENES } \\
\text { POR JORNADA LABORAL }\end{array}$ & $\begin{array}{c}\text { RECURSOS NECESARIOS } 3 \\
\text { CADA / } 100 \text { EXÁMENES. }\end{array}$ & 3 TÉCNICOS & SUBSIDIOS \\
\hline CONSULTA EXTERNA & 44 & & & \\
\hline HOSPITALIZACIÓN & 181 & & & \\
\hline EMERGENCIA & 40 & & & \\
\hline $\mathrm{UCl}$ & 32 & & & \\
\hline & 297 & 3.0 & 9 & 1 \\
\hline & & \multicolumn{2}{|c|}{ MÉDICO } & 10 \\
\hline \multirow[t]{2}{*}{ TOMA DE MUESTRAS } & 264.35 & \multirow{2}{*}{\multicolumn{2}{|c|}{\begin{tabular}{l|l} 
& TÉCNICO \\
\end{tabular}}} & 1 \\
\hline & & & & 9 \\
\hline
\end{tabular}

\begin{tabular}{|c|c|c|c|}
\hline \multicolumn{4}{|c|}{ NUTRICIÓN } \\
\hline PERFIL & RECURSOS NECESARIOS & $2 T$ & \\
\hline NUTRICIONISTA & 1 & & 2 \\
\hline TECNICO ADMINISTRADOR & 1 & & 2 \\
\hline TECNICO ALIMENTACION / CC & 4 & & 9 \\
\hline AYUDANTE & 9 & 18 & 18 \\
\hline KARDISTA & 1 & & 2 \\
\hline \multirow[t]{6}{*}{ ENCARGADO DE DESPENSA } & 1 & & 2 \\
\hline & 17 & 35 & 35 \\
\hline & MÉDICO & & 1 \\
\hline & TÉCNICO & 13 & 13 \\
\hline & ADMINISTRACIÓN & & 1 \\
\hline & SERVICIO & & 2 \\
\hline
\end{tabular}




\begin{tabular}{|c|c|c|c|}
\hline \multicolumn{4}{|c|}{ PERSONAL DE MANTENIMIENTO } \\
\hline SERVICIO & $12 \mathrm{H}$ & $24 \mathrm{H}$ & SUBSIDIO \\
\hline OPERADOR DE CALDERAS & 1 & 2 & 3 \\
\hline PLOMEROS & 0.3 & 0.6 & 1.6 \\
\hline TÉCNICO ELECTROMEDICINA & 1 & 2 & 3 \\
\hline CARPINTERO & 0.5 & 1 & 2 \\
\hline TECNICO REFRIGERACIÓN & 0.3 & 0.6 & 1.6 \\
\hline ELECTRICISTA & 1 & 2 & 3 \\
\hline \multirow[t]{3}{*}{ RESPONSABLE DE ALMACE'N } & 0.1 & 0.2 & 1.2 \\
\hline & & & 15 \\
\hline & & SERVICIO & 8 \\
\hline
\end{tabular}

\begin{tabular}{|c|c|c|}
\hline \multicolumn{3}{|c|}{ PERSONAL DE LAVANDERÍA } \\
\hline SERVICIO & CAMAS & RECURSOS NECCESARIOS \\
\hline LAVADOR & 181 & 4 \\
\hline COSTURERA & 181 & 2 \\
\hline PLANCHADOR & 181 & 3 \\
\hline DESPACHADOR & 181 & 4 \\
\hline JEFE & & 1 \\
\hline & SERVICIO & 13 \\
\hline
\end{tabular}

\begin{tabular}{|r|r|r|r|r|r|}
\hline \multicolumn{7}{|c|}{ PERSONAL DE LIMPIEZA } & SUBSIDIO \\
\hline AREA TOTAL & AREA M2 POR ASEADOR & TURNO 8H & 24H & 146 & 1 \\
\hline 19443 & 49 & 49 & & 94 \\
\hline & & & & 31 \\
\hline
\end{tabular}

\begin{tabular}{|c|c|c|c|c|c|c|c|c|c|}
\hline \multicolumn{10}{|c|}{ HOSPITALIZACIÓN ENFERMERÍA } \\
\hline SERVICIO & CAMAS & HORAS DE ATENCIÓN & $\begin{array}{c}\text { DÍAS DE ATENCIÓN AL } \\
\text { AÑO }\end{array}$ & $\begin{array}{c}\text { HORAS LABORALES AL } \\
\text { AÑO }\end{array}$ & $\begin{array}{l}\text { PERSONAL DE } \\
\text { ENFERMERÍA }\end{array}$ & \multicolumn{2}{|c|}{$\%$ ATC ENF } & \multicolumn{2}{|c|}{ \%ATC AUX ENF } \\
\hline MEDICINA INTERNA & 46 & 3 & 365 & 2920 & 17 & 0.3 & 5 & 0.7 & 12 \\
\hline \begin{tabular}{|l|l|} 
PEDIATRÍA \\
\end{tabular} & 45 & 4 & 365 & 2920 & 23 & 0.4 & 9 & 0.6 & 14 \\
\hline CIRUGÍA & 42 & 4 & 365 & 2920 & 18 & 0.3 & 6 & 0.7 & 13 \\
\hline GINECOLOGÍA & 48 & 3 & 365 & 2920 & 18 & 0.4 & 7 & 0.6 & 11 \\
\hline NEONATOLOGÍA & 8 & 4 & 365 & 2920 & 4 & 0.6 & 2 & 0.4 & 2 \\
\hline \multirow{3}{*}{\begin{tabular}{|l} 
EMERGENCIA \\
\end{tabular}} & 15 & 6 & 365 & 2920 & 11 & 0.6 & 7 & 0.4 & 5 \\
\hline & & & & & & & 36 & & 55 \\
\hline & & & & & & & 37 & & 56 \\
\hline
\end{tabular}

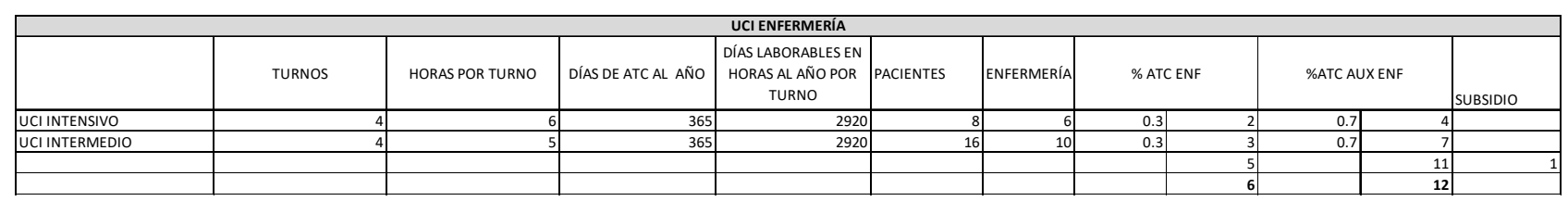

\begin{tabular}{|l|r|}
\hline \multicolumn{2}{|c|}{ RESUMEN DE PERSONAL } \\
\hline PERSONAL MÉDICO & 74 \\
\hline PERSONAL ENFERMERÍA & 43 \\
\hline PERSONAL AUX ENFERMERÍA & 69 \\
\hline PERSONAL TÉCNICO & 30 \\
\hline PERSONAL ADMINISTRATIVO & 27 \\
\hline PERSONAL DE SERVIICIO & 54 \\
\hline
\end{tabular}




\subsection{INFORMACIÓN CUALITATIVA}

\subsubsection{PAQUETES FUNCIONALES}

Tabla 33: Paquetes funcionales

\begin{tabular}{|c|c|c|}
\hline & & SALA DE ESPERA REPARTIDO EN CADA ÁREA DE CONSULTA \\
\hline & & CONTROL INGRESO MEDICO \\
\hline & & COUNTER CAIA \\
\hline & & COUNTER ADMISIÓN, CITAS (INFORMACIÓN) \\
\hline & 竎 & SERVICIO SOCIAL \\
\hline & 产 & MODULO SIS \\
\hline & $\succsim$ & OF. DE REFERENCIA Y CONTRAREFERENCIA \\
\hline & $\underline{0}$ & ARCHIVOS HISTORIAS CLÍNICAS \\
\hline & $\frac{\bar{n}}{5}$ & SH.HOMBRES (5) \\
\hline & & SH.MUJERES (5) \\
\hline & & SH DISCAPACITADOS (2) \\
\hline & & SALA DE JUNTAS MÉDICAS \\
\hline & & JEFATURA DE ENFERMERÍA \\
\hline & & JEFATURA DE CONSULTA EXTERNA \\
\hline & & MEDICINA INTERNA \\
\hline & & PEDIATRÍA \\
\hline & & CIRUGÍA GENERAL \\
\hline & & GINECOLOGÍA Y OBSTETRICIA \\
\hline & & SALA DE ECOGRAFÍA Y MONITOREO FETAL \\
\hline & & MEDICINA FAMILIAR \\
\hline UNIDAD DE CONSULTA & & MEDICINA DE REHABILITACIÓN \\
\hline EXTERNA & & TRAUMATOLOGÍA Y REHABILITACIÓN \\
\hline & & CARDIOLOGÍA \\
\hline & & NEUROLOGÍA \\
\hline & $\underline{\Xi}$ & NEUMOLOGÍA \\
\hline & $\underline{z}$ & GASTROENTEROLOGÍA \\
\hline & s & REUMATOLOGÍA \\
\hline & & PSIQUIATRIA \\
\hline & & OFTALMOLOGÍA \\
\hline & & UROLOGÍA \\
\hline & & OTORRINOLARINGOLOGÍA \\
\hline & & DERMATOLOGÍA \\
\hline & & NUTRICIÓN Y DIETÉTICA \\
\hline & & TÓPICO EN CONSULTA \\
\hline & & CIRUJANO DENTISTA \\
\hline & & PSICOLOGÍA \\
\hline & & ENDOCRINOLOGÍA \\
\hline & & INYECTABLES A INMUNIZACIONES \\
\hline & & CUARTO DE LIMPIEZA \\
\hline & $\underline{\underline{O}}$ & DEPÓSITO DE RESIDUOS SÓLIDOS \\
\hline & $\sum_{x}$ & DEPÓSITO DE MATERIALES \\
\hline & 岁 & SERVICIOS HIGIÉNICOS PARA PERSONAL \\
\hline
\end{tabular}

\begin{tabular}{|c|c|c|}
\hline \multirow{19}{*}{$\begin{array}{l}\text { UNIDAD DE CENTRO } \\
\text { QUIRÚRGICO }\end{array}$} & \multirow{4}{*}{ 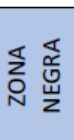 } & ESPERA \\
\hline & & RECEPCIÓN Y CONTROL \\
\hline & & JEFATURA DE PERSONAL (OFICINA DE PERSONAL) \\
\hline & & CAMBIO DE CAMILLA \\
\hline & \multirow{10}{*}{$\begin{array}{l}\frac{N}{\widetilde{N}} \\
\overleftarrow{U} \\
\text { ¿ }\end{array}$} & CONTROL DE OPERACIONES \\
\hline & & RECUPERACIÓN 5 \\
\hline & & ANÉSTESIÓLOGO \\
\hline & & TALLER DE ANESTECIA \\
\hline & & PRE LAVADO DE INSTRUMENTOS \\
\hline & & CUARTO DE LIMPIEZA \\
\hline & & CUARTO SÉPTICO (ROPA SUCIA Y LAVA CHATAS) \\
\hline & & VESTUARIOS DE MÉDICOS Y SERVICIOS HIGIÉNICOS \\
\hline & & VESTUARIOS DE ENFERMERAS Y SERVICIOS HIGIÉNICOS \\
\hline & & CAMBIO DE BOTAS \\
\hline & \multirow{5}{*}{ 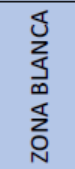 } & LAVABOS DE CIRUJANOS \\
\hline & & SALA DE OPERACIONES 5 \\
\hline & & RAYOS X PORTÁTIL \\
\hline & & DEPÓSITO DE MATERIAL ESTÉRIL \\
\hline & & DEPÓSITO DE EQUIPOS \\
\hline
\end{tabular}




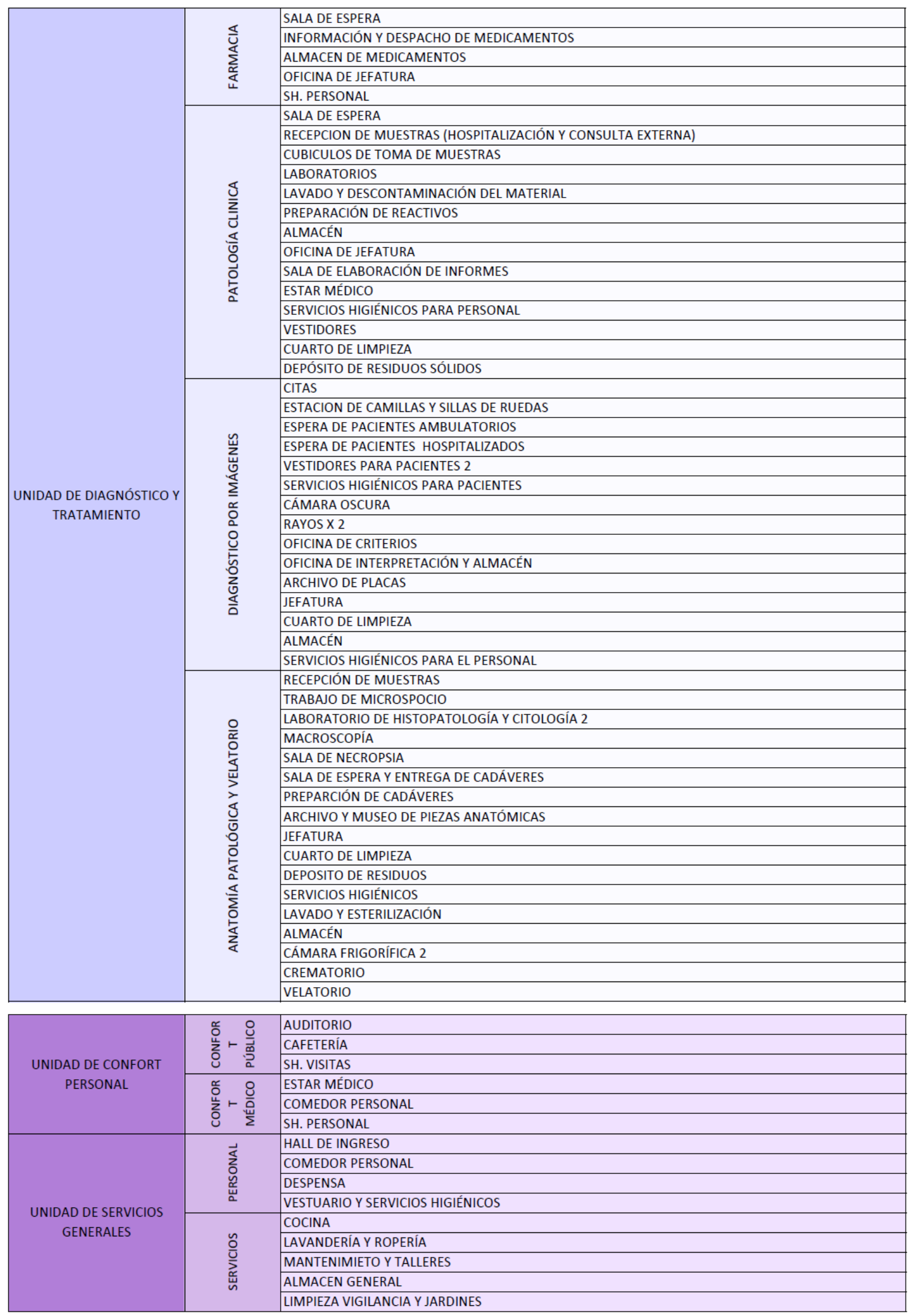




\begin{tabular}{|c|c|c|}
\hline \multirow{21}{*}{$\begin{array}{l}\text { UNIDAD DE CENTRO } \\
\text { OBSTÉTRICO Y } \\
\text { NEONATOLOGÍA }\end{array}$} & \multirow{21}{*}{ 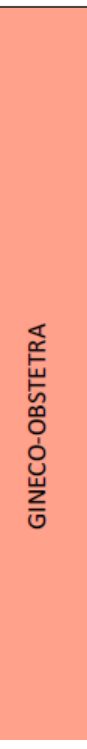 } & RECEPCIÓN Y CONTROL \\
\hline & & ESPERA FAMILIARES \\
\hline & & ESTACION PARA CAAMILLAS Y SILLAS DE RUEDAS \\
\hline & & SALA DE EVALUACION Y PREPARACIÓN DE PACIENTES \\
\hline & & SALA DE DILATACIÓN \\
\hline & & SALA DE EXPULSIÓN (SALA DE PARTO) 2 \\
\hline & & SALA DE CIRUGÍA OBSTÉTRICA \\
\hline & & SALA DE LEGRADO \\
\hline & & SALA DE RECUPERACIÓN POST PARTO 2 CAMAS POR SALA DE EXPULSIÓN \\
\hline & & SALA DE ATENCIÓN AL RECIÉN NACIDO \\
\hline & & DEPÓSITO DE MATERIAL ESTÉRIL \\
\hline & & TRABAJO DE ENFERMERAS \\
\hline & & LIMPIEZA INSTRUMENTAL \\
\hline & & CUARTO DE LIMPIEZAA \\
\hline & & CUARTO SEPTICO LAVA CHATAS \\
\hline & & VESTUARIOS MÉDICOS \\
\hline & & VESTUARIO ACOMPAÑANTE \\
\hline & & SS.HH MEDICOS \\
\hline & & SALA DE JUNNTAS \\
\hline & & ESTACION DE ENFERMERAS \\
\hline & & ROPA LIMPIA \\
\hline \multirow{20}{*}{$\begin{array}{l}\text { UNIDAD DE CUIDADOS } \\
\text { INTENSIVOS }\end{array}$} & \multirow{5}{*}{ 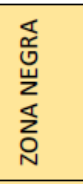 } & ESPERA Y SECRETARIA \\
\hline & & RECEPCIÓN Y CONTROL \\
\hline & & JEFATURA \\
\hline & & SALA DE JUNTAS \\
\hline & & ESTAR DE PERSONAL \\
\hline & \multirow{10}{*}{ 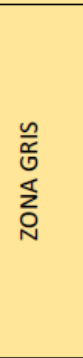 } & VESTUARIO Y SERVICIOS HIGIÉNICOS PARA MÉDICOS \\
\hline & & VESTUARIO Y SERVICIOS HIGIÉNICOS PARA ENFERMERAS \\
\hline & & CUIDADOS INTENSIVOS \\
\hline & & CUIDADOS INTERMEDIOS \\
\hline & & CAMBIO DE BOTAS \\
\hline & & TRANSFER DE CAMILLAS \\
\hline & & REPOSTERO \\
\hline & & LABORATORIO DE GASES \\
\hline & & CUARTO SÉPTICO (ROPA SUCIA Y LAVA CHATAS) \\
\hline & & CUARTO DE LIMPIEZA \\
\hline & \multirow{5}{*}{ 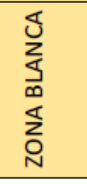 } & ESTACION DE ENFERMERAS (CENTRAL MONITOREO) \\
\hline & & TRABAJO DE ENFERMERAS \\
\hline & & DEPÓSITO DE EQUIPOS \\
\hline & & DEPÓSITO DE MATERIALES \\
\hline & & CUBÍCULO DE TRATAMIENTO \\
\hline \multirow{26}{*}{ UNIDAD DE EMERGENCIA } & \multirow{4}{*}{ 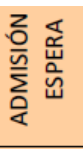 } & ADMISION Y CONTROL,CAJA INFORME \\
\hline & & AMBIENTE PARA POLICÍA NACIONAL \\
\hline & & ESPACIO DE CAMILLAS Y SILLAS DE RUEDAS \\
\hline & & JEFATURA DE PERSONAL ( OFICINA DE PERSONAL \\
\hline & \multirow{12}{*}{ 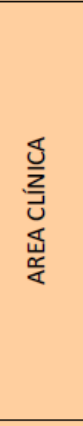 } & TRIAJE (ADULTOS Y NIÑOS) \\
\hline & & CONSULTORIO TÓPICO (ADULTOS Y NIÑOS) 2 \\
\hline & & TRABAJO DE ENFERMERAS \\
\hline & & TRAUMA SHOCK 2 \\
\hline & & \begin{tabular}{|l|} 
CUARTO DE AISLADOS 2 \\
\end{tabular} \\
\hline & & SALAS DE OBSERVACIÓN 9N 3A \\
\hline & & REHIDRATACIÓN PEDIÁTRICA 9 \\
\hline & & BAÑO DE ARTESA \\
\hline & & LABORATORIO DE EMERGENCIA \\
\hline & & RAYOS X PORTÁTIL ESPACIO LIBRE \\
\hline & & CONSULTORIO DE TRAUMATOLOGÍA \\
\hline & & TÓPICO DE YESOS \\
\hline & \multirow{10}{*}{ 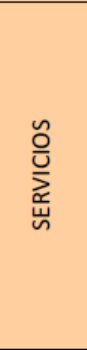 } & ESTAR MÉDICO Y DE ENFERMERAS \\
\hline & & DORMITORIO MÉDICO DE GUARDIA \\
\hline & & ALMACÉN DE EQUIPO Y MEDICAMENTOS \\
\hline & & ROPA LIMPIA \\
\hline & & CUARTO DE LIMPIEZA \\
\hline & & CUARTO ROPA SUCIA \\
\hline & & CUARTO SEPTICO LAVA CHATAS \\
\hline & & SERVICIOS HIGIÉNICOS PARA PERSONAL \\
\hline & & SERVICIOS HIGIÉNICOS PARA PACIENTES 3H, 3M, 1 DSCP \\
\hline & & ESTACIONAMIENTO DE AMBULANCIAS \\
\hline
\end{tabular}




\begin{tabular}{|c|c|c|}
\hline & \multirow{2}{*}{$\overrightarrow{\vec{x}}$} & HALL DE INGRESO \\
\hline \multirow{20}{*}{$\begin{array}{c}\text { UNIDAD DE } \\
\text { ADMINISTRACIÓN }\end{array}$} & & ESPERA Y SECRETARIA \\
\hline & \multirow{4}{*}{ 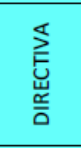 } & DIRECCIÓN CON SS.HH. \\
\hline & & SALA DE REUNIONES \\
\hline & & POOL DE SECRETARIAS \\
\hline & & SUB DIRECCIÓN CON SS.HH. \\
\hline & $\vec{\nwarrow}$ & SALA DE REUNIONES \\
\hline & 妾 & CENTRAL TELEFÓNICA Y BUSCA PERSONAS \\
\hline & 岕 & JEFATURA DE PERSONAL ( OFICINA DE PERSONAL \\
\hline & $\gtreqless$ & OFICINA DE ENFERMERA SUPERVISORA \\
\hline & 必 & OFICINA DE COMPRAS, PRESUPUESTO Y PLANILLA \\
\hline & $\frac{5}{7}$ & OFICINA CONTADOR \\
\hline & $\sum_{n}^{2}$ & OFICINA DE CONTABILIDAD Y CAJA \\
\hline & षे & OFICINA DE RELACIONES PÚBLICAS \\
\hline & 님요 & CENTRAL DE CÓMPUTO Y SERVIDORES \\
\hline & ঝุ” & SALA DE UPS Y TABLEROS ELECTRICOS \\
\hline & $\sum_{i}^{L} \sum_{0}$ & AIRE ACONDICIONADO A PRESIÓN \\
\hline & 岕 品 & ADMINISTADOR DATA CENTER \\
\hline & & DEPÓSITO DE RESIDUOS SÓLIDOS \\
\hline & $\sum_{\bar{w}}^{\infty} n$ & SERVICIOS HIGIENICOS DE PERSONAL \\
\hline & & CUARTO DE LIMPIEZA \\
\hline
\end{tabular}

\begin{tabular}{|c|c|c|}
\hline \multirow{30}{*}{$\begin{array}{l}\text { UNIDAD DE } \\
\text { HOSPITALIZACIÓN }\end{array}$} & \multirow{9}{*}{ 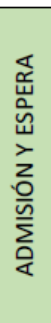 } & ESPERA \\
\hline & & ADMISION HOSPITALARIA \\
\hline & & ESPERA INTERNA PARA ADMISION Y ALTAS \\
\hline & & OFICINA SIS \\
\hline & & OFICINA TRABAJO SOCIAL \\
\hline & & CUBICULO ENTREVISTAS \\
\hline & & JEFATURA DE HOSPITALIZACION \\
\hline & & ESTAR MÉDICO \\
\hline & & SALA DE JUNTAS \\
\hline & \multirow{11}{*}{ 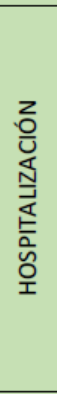 } & ESTAR DE VISITAS Y PACIENTE \\
\hline & & ESTACIÓN DE ENFERMERAS \\
\hline & & TÓPICO \\
\hline & & CAMILLAS Y SILLAS DE RUEDA \\
\hline & & CUBICULO DE PREPARACION DE PACIENTES AMBULATORIOS \\
\hline & & CUBICULO DE CIRUGÍA AMBULATORIA \\
\hline & & CUNERO \\
\hline & & HABITACIONES PEDIÁTRICAS \\
\hline & & HABITACIONES DE CIRUGÍA \\
\hline & & HABITACIONES DE GINECOLOGÍA \\
\hline & & HABITACIONES DE MEDICINA INTERNA \\
\hline & \multirow{10}{*}{ 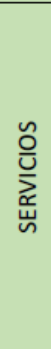 } & REPOSTERO \\
\hline & & TRABAJO DE ENFERMERIA (LIMPIO Y SUCIO) \\
\hline & & ROPA LIMPIA \\
\hline & & CUARTO DE LIMPIEZA \\
\hline & & CUARTO SÉPTICO (ROPA SUCIA Y LAVA CHATAS) \\
\hline & & BAÑO Y VESTIDOR DE PACIENTES \\
\hline & & SERVICIOS HIGIÉNICOS PARA PACIENTE (HOMBRES - MUJERES) COLECTIVO) \\
\hline & & SERVICIOS HIGIÉNICOS PARA PERSONAL (HOMBRES - MUJERES) COLECTIVO) \\
\hline & & SERVICIOS HIGIÉNICOS PARA VISITAS \\
\hline & & DEPÓSITO \\
\hline
\end{tabular}

Fuente: Norma técnica de Salud 110, GERESA, Elaboración propia 


\subsection{DIAGRAMAS ORGANIZACIONALES Y FUNCIONALES}

\subsubsection{ORGANIGRAMA GENERAL INSTITUCIONAL}

Tabla 34: Organigrama genereal

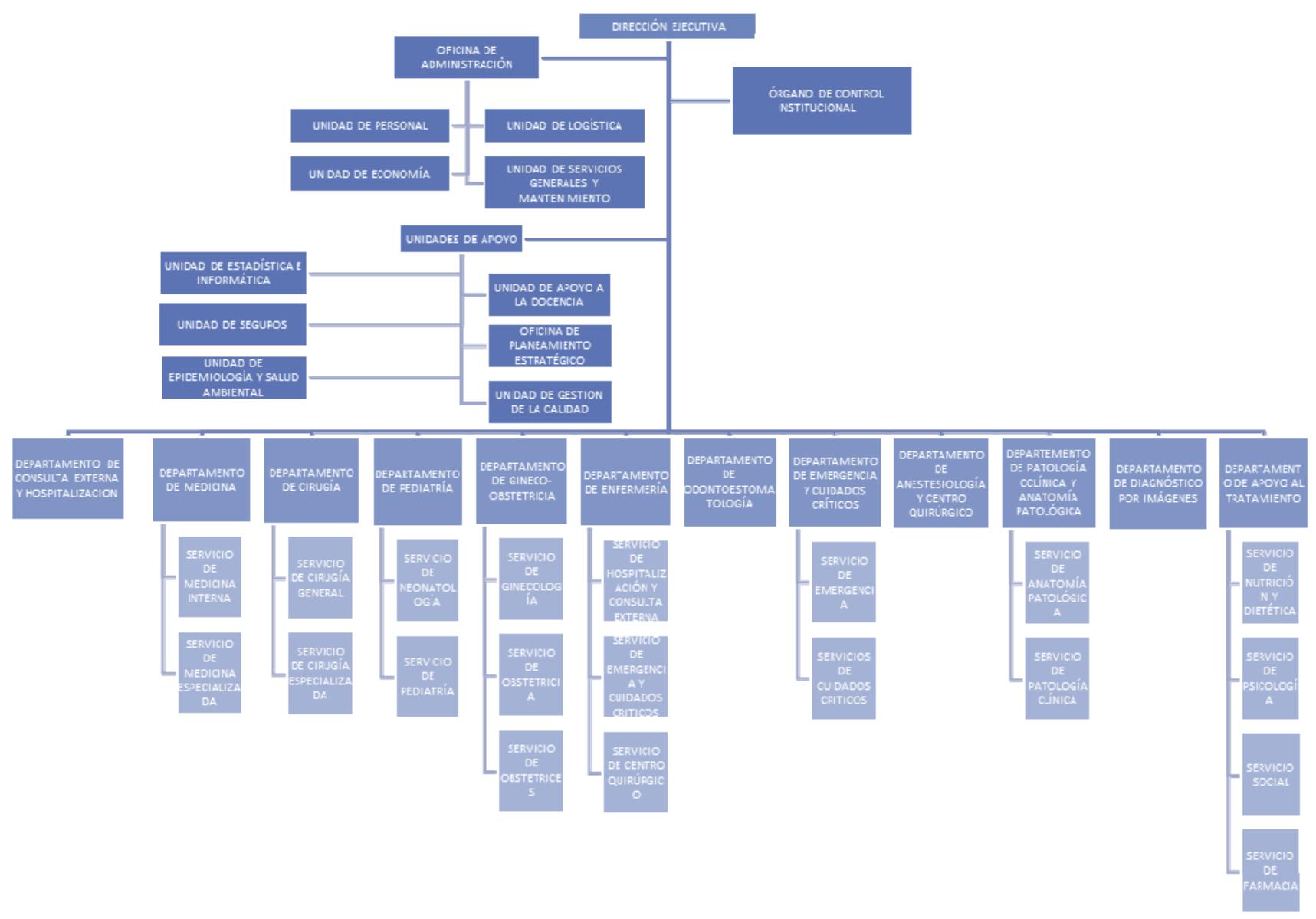

Fuente: Geresa, MINSA Elaboración propia. 


\subsubsection{FLUJOGRAMA GENERAL}

Tabla 35: Flujograma

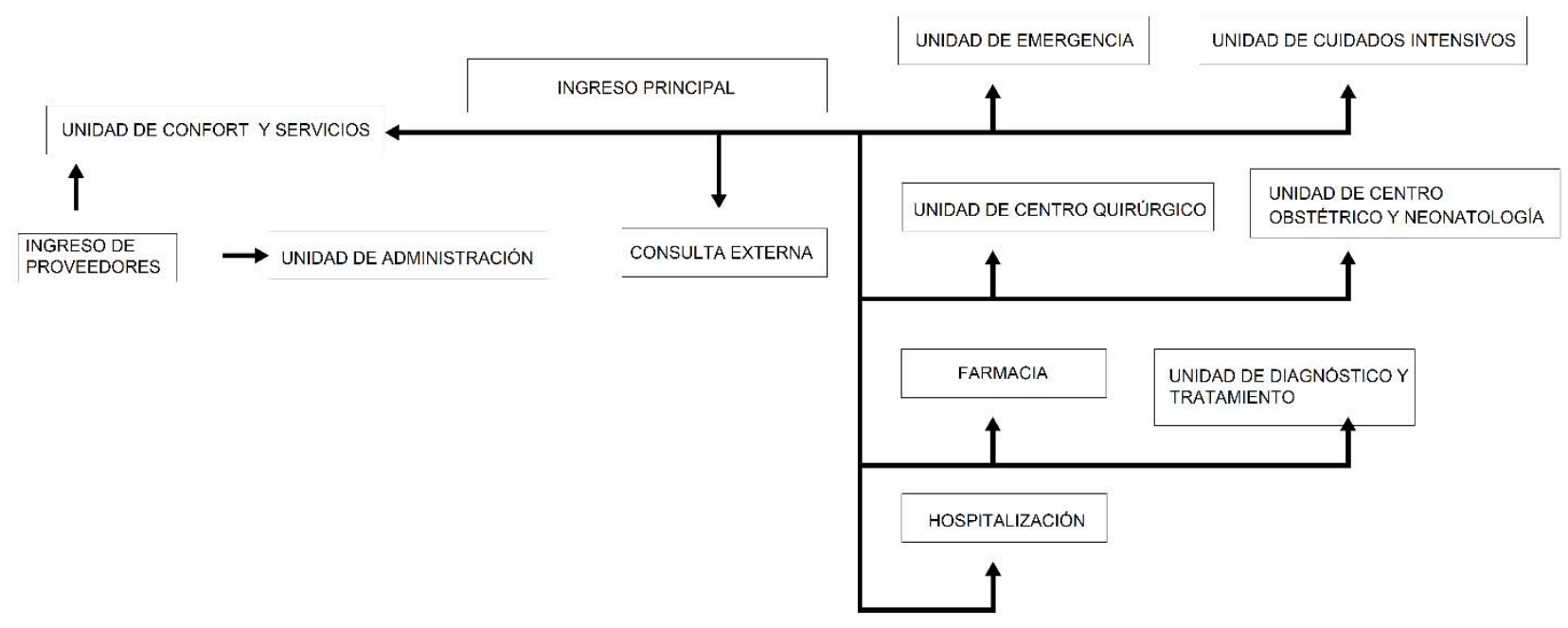

Fuente: MINSA Elaboración propia 


\subsubsection{FLUJOGRAMA POR PAQUETES}

\section{UNIDAD DE CONSULTA EXTERNA}

Tabla 36: Diagrama de flujograma

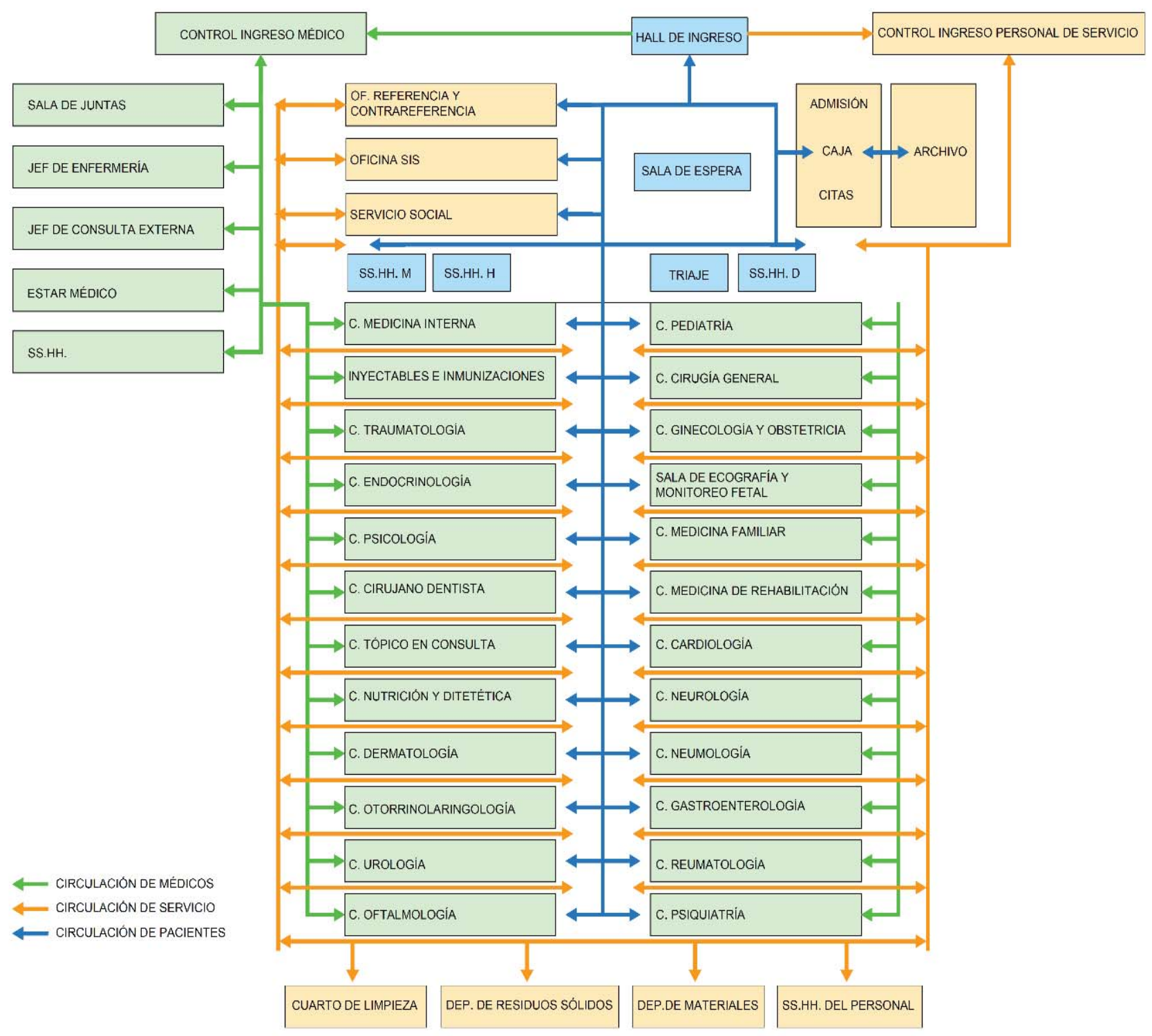

Fuente: Bambarén, MINSA, GERESA. Elaboración propia 


\section{UNIDAD DE DIAGNÓSTICO Y TRATAMIENTO}

PATOLOGÍA CLÍNICA

Tabla 37: Diagrama de Flujograma

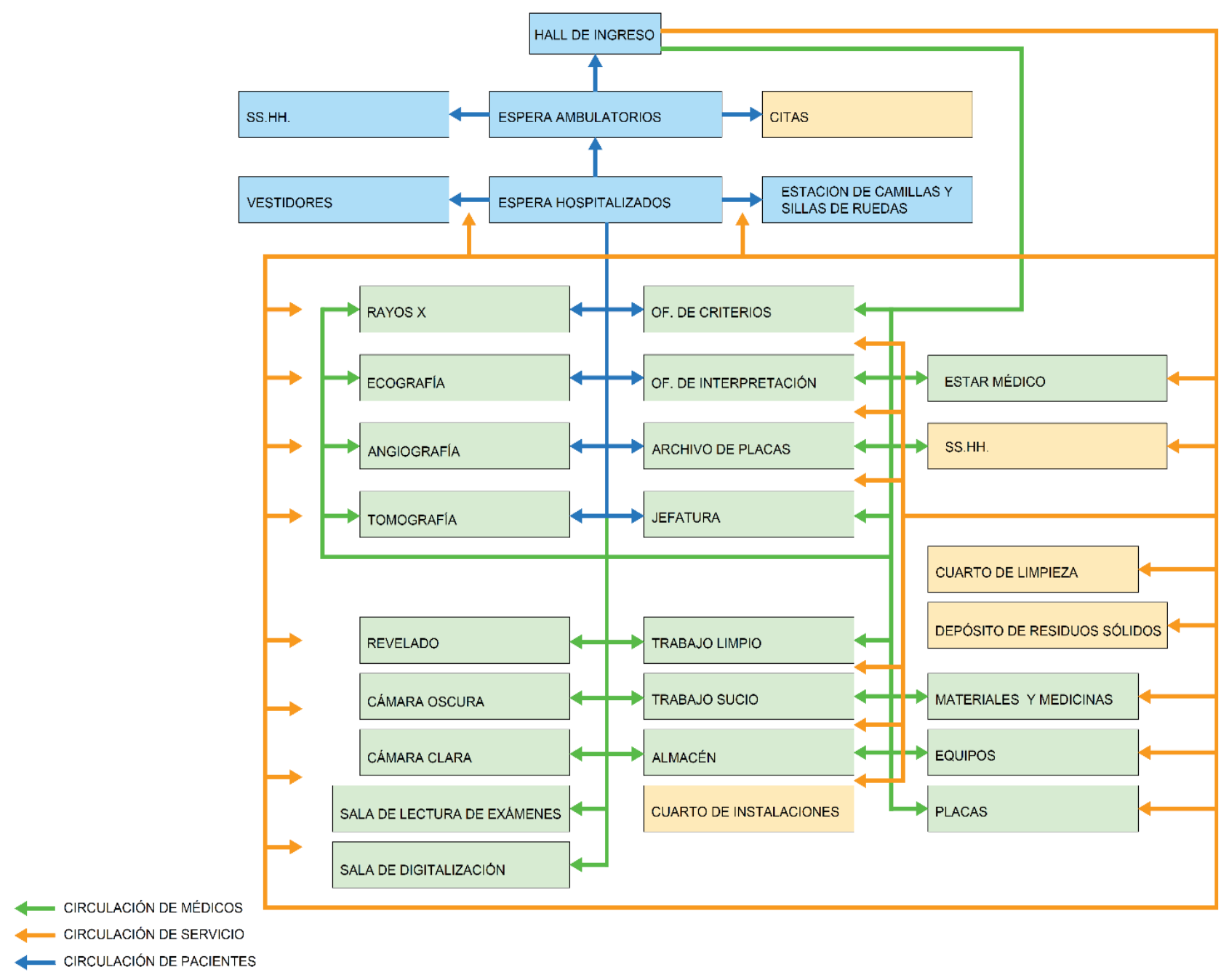

Fuente: Bambarén, MINSA, GERESA. Elaboración propia 


\section{UNIDAD DE ANATOMÍA PATOLÓGICA}

Tabla 38: Diagrama de Flujograma

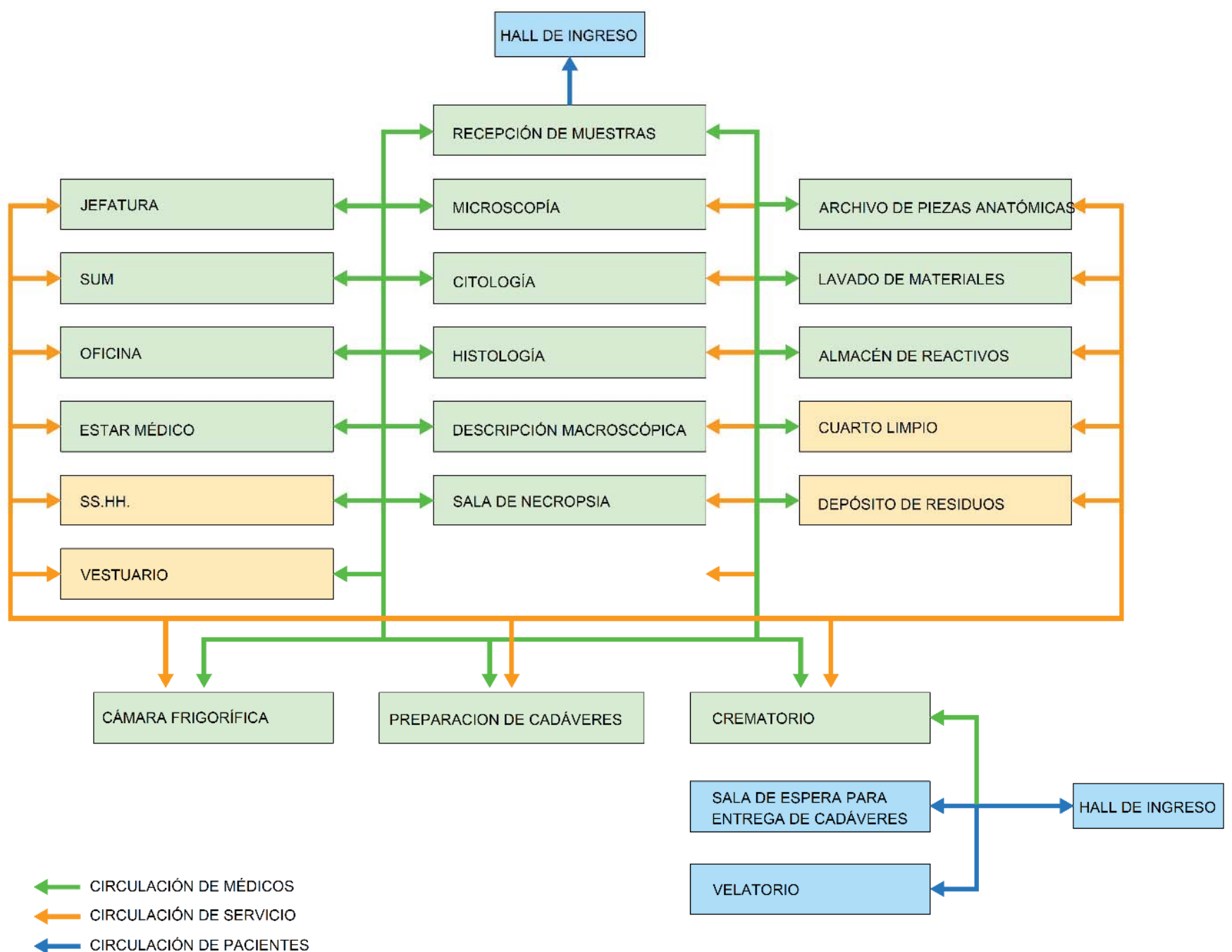

Fuente: Bambarén, MINSA, GERESA. Elaboración propia

Tabla 39: Flujograma de Farmacia

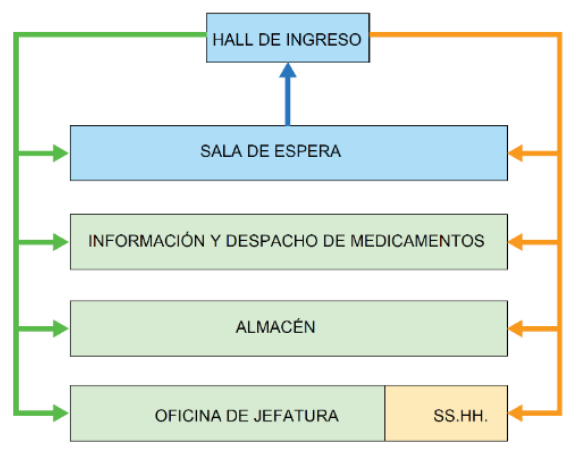

Fuente: Bambarén, MINSA, GERESA. Elaboración propia 


\section{UNIDAD DE EMERGENCIA}

Tabla 40: Diagrama de Flujogrma

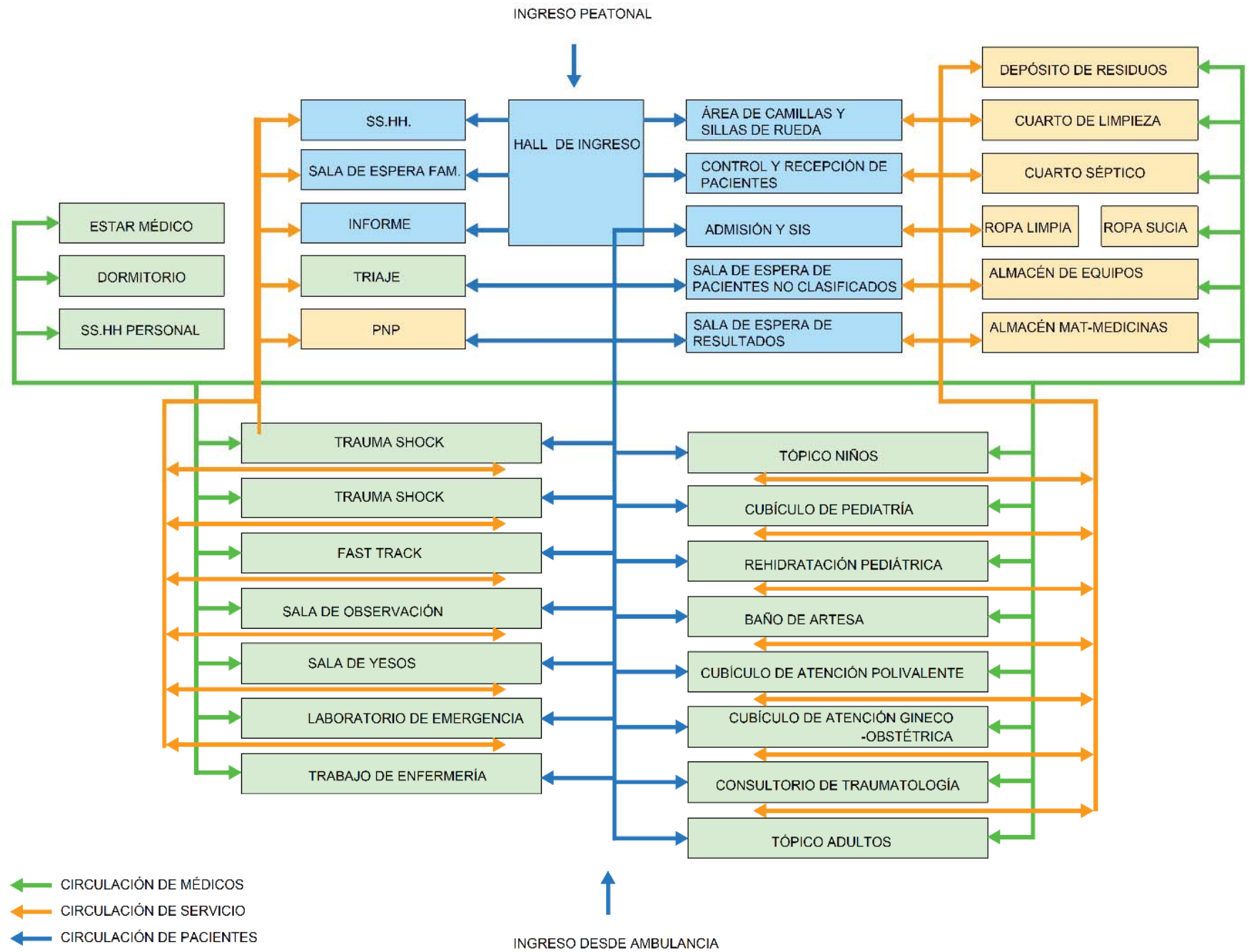

Fuente: Bambarén, MINSA, GERESA. Elaboración propia 


\section{UNIDAD DE CENTRO OBSTÉTRICO Y NEONATOLOGÍA}

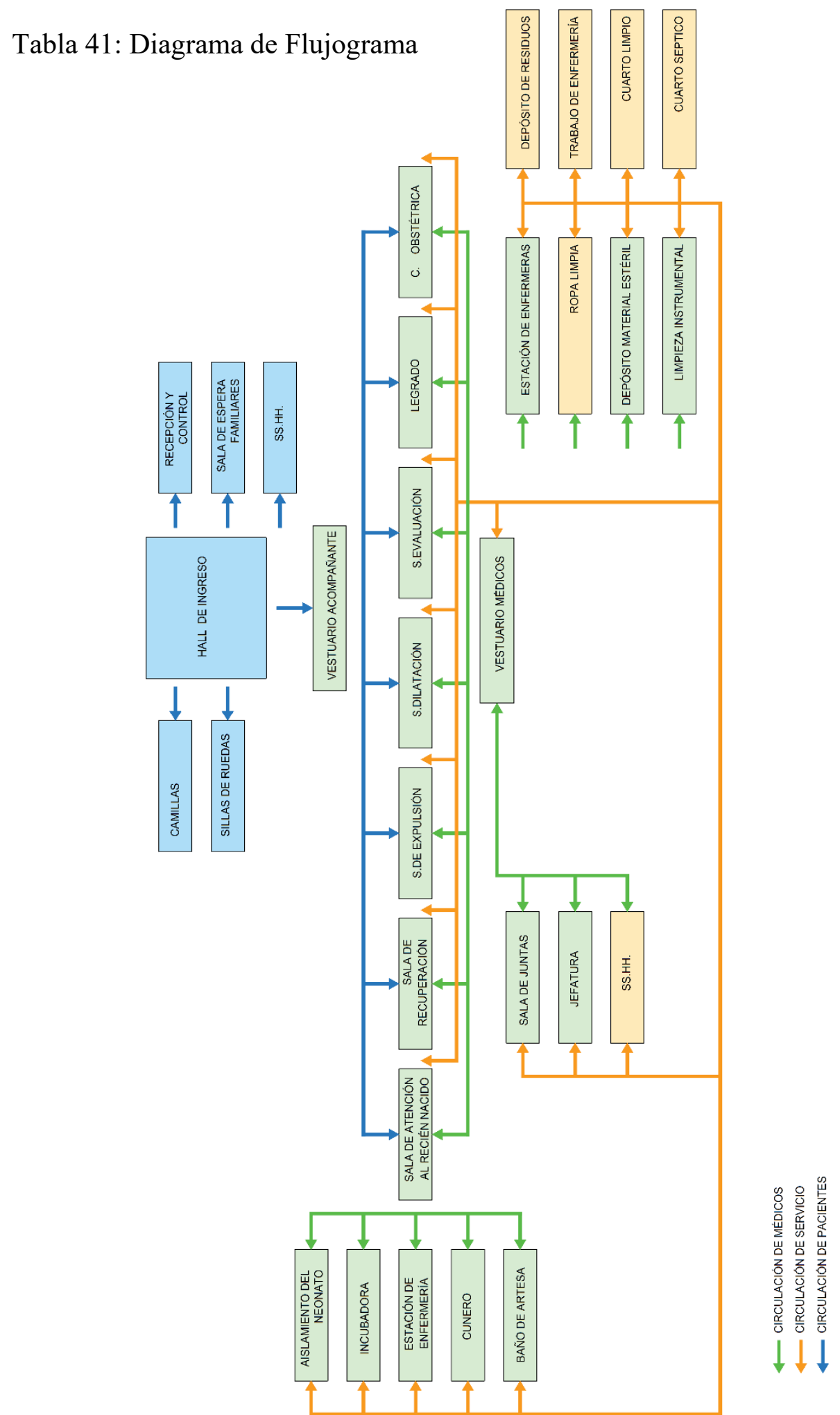

Fuente: Bambarén, MINSA, GERESA. Elaboración propia 


\section{UNIDAD DE CENTRO QUIRÚRGICO}

Tabla 42: Diagrama de flujograma

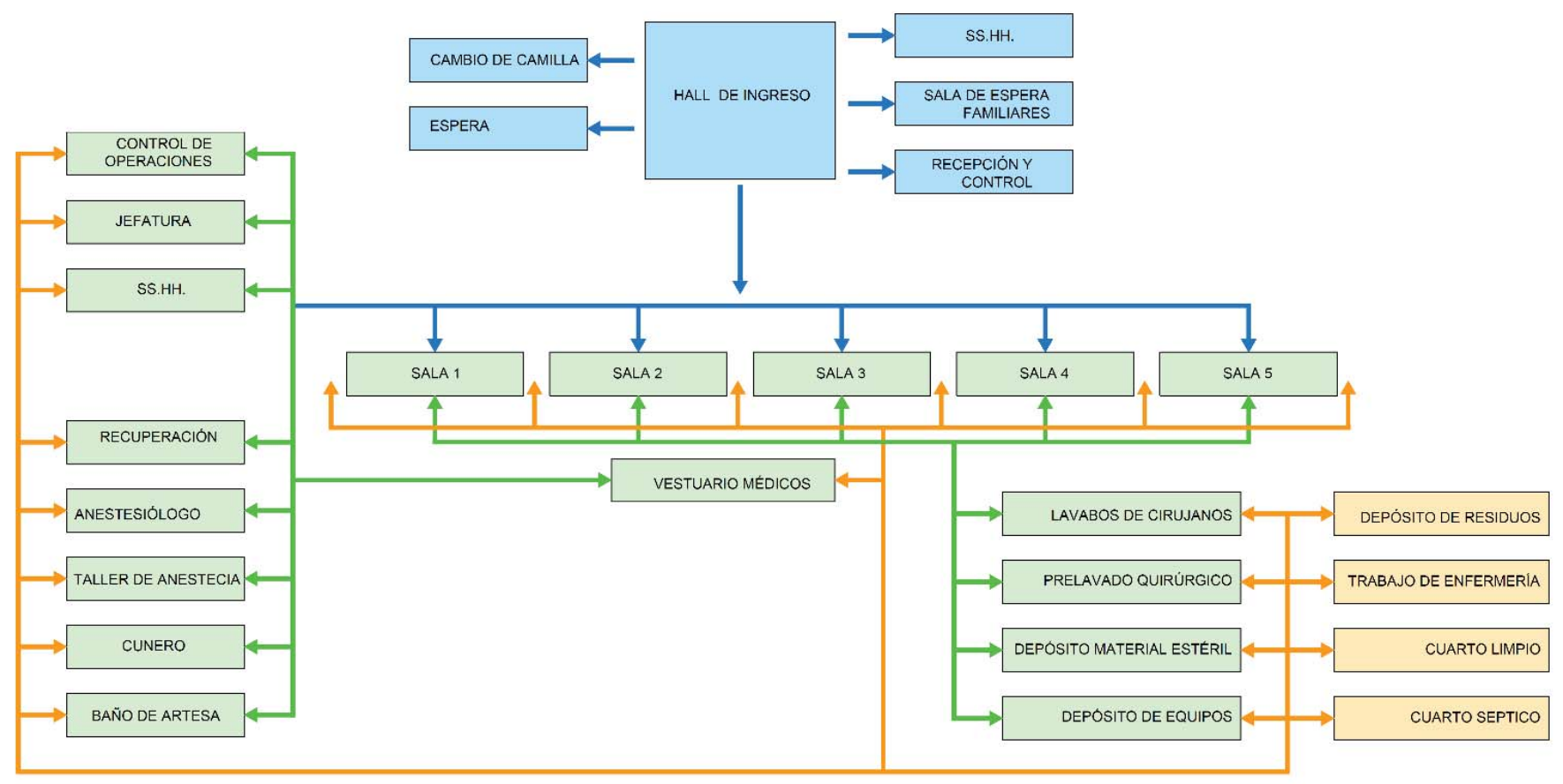

$\longleftarrow$ CIRCULACIÓN DE MÉDICOS

$\longleftarrow$ CIRCULACION DE SERVICIO

_ C.IRCIII ACIONN IF PAC.IFNTFS

Fuente: Bambarén, MINSA, GERESA. Elaboración propia 


\section{UNIDAD DE CUIDADOS INTENSIVOS}

Tabla 43: Diagrama de Flujograma

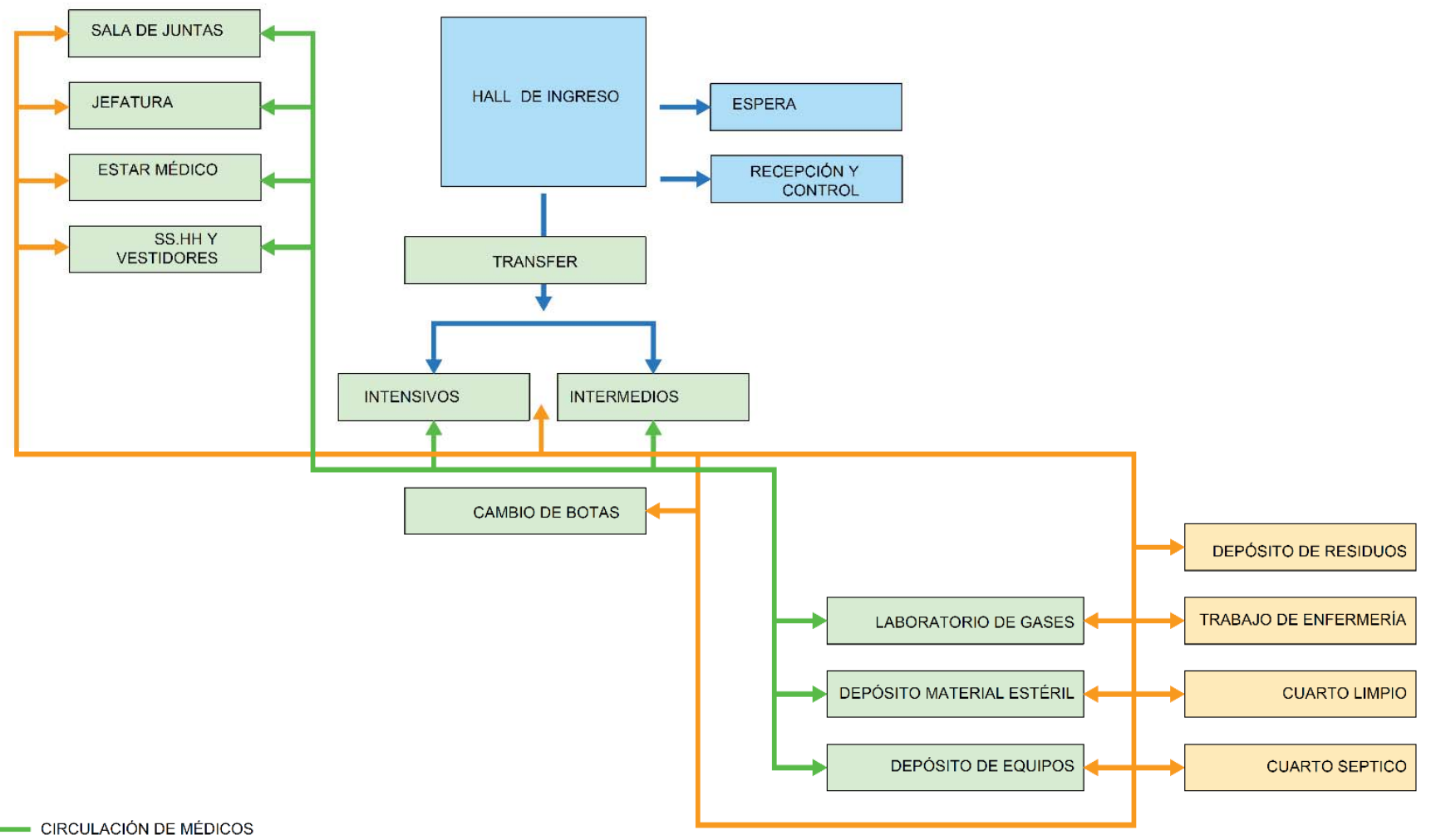


Tabla 44:Diagrama de Fluiograma

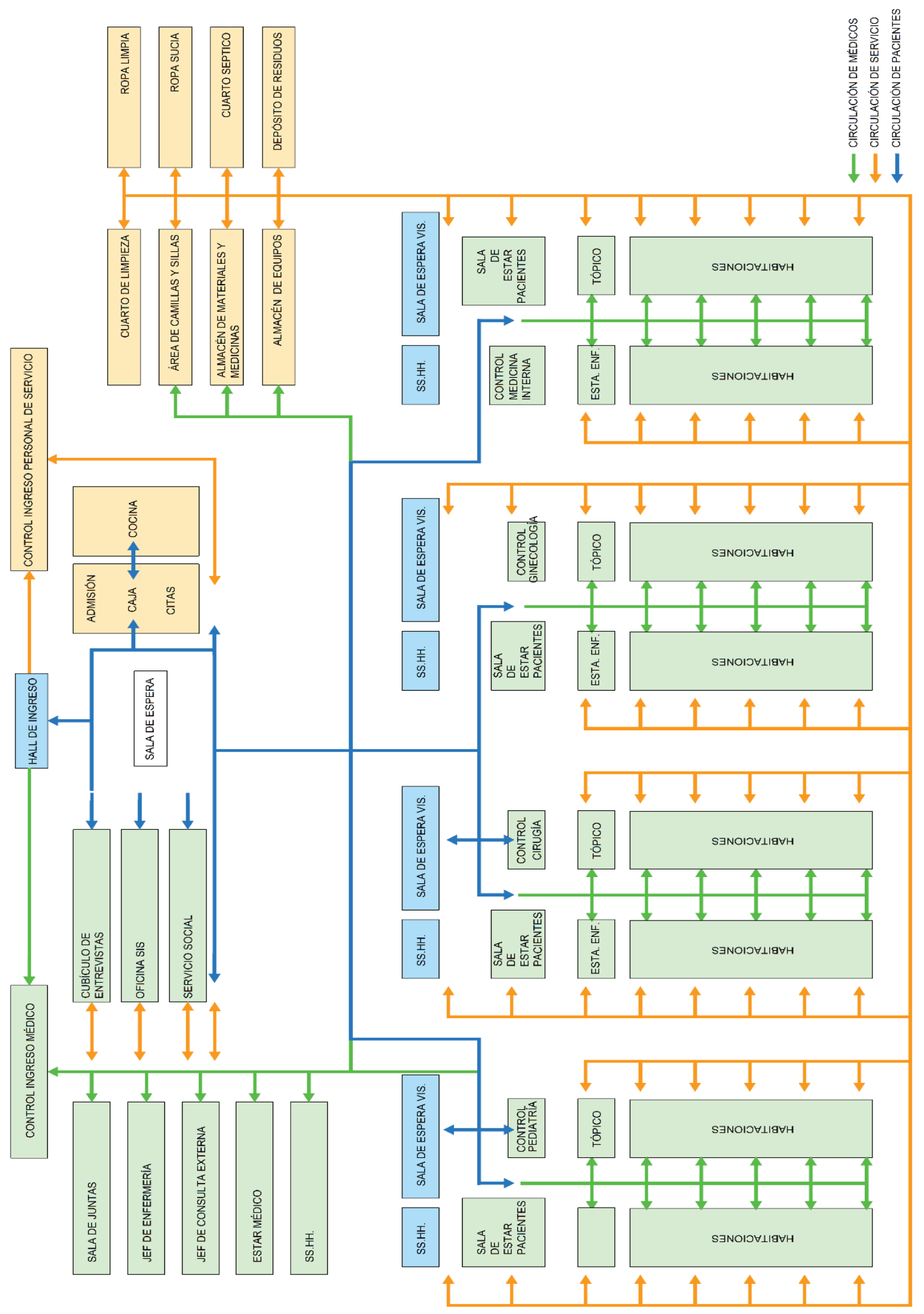

Fuente: Bambarén, MINSA, GERESA. Elaboración propia 


\section{UNIDAD DE CONFORT Y SERVICIOS GENERALES}

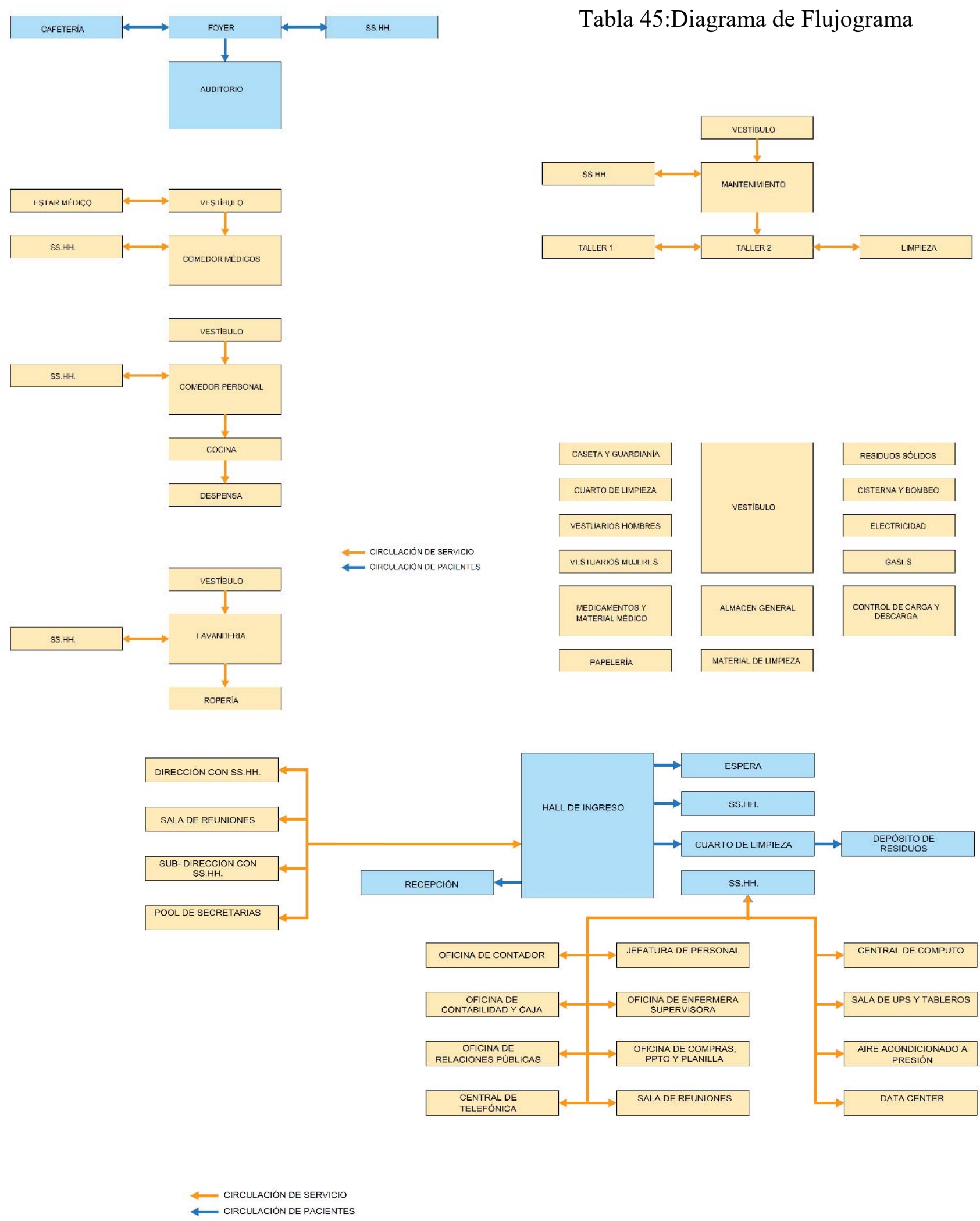

Fuente: Bambarén, MINSA, GERESA. Elaboración propia 


\subsection{DIAGRAMAS DE COMPATIBILIDAD}

Tabla 46: Diagrama de compatibilidad

\begin{tabular}{|c|c|c|c|c|c|c|c|c|c|c|}
\hline $\begin{array}{c}\text { PROXIMIDAD DE } \\
\text { ESPACIOS POR } \\
\text { PAQUETE }\end{array}$ & 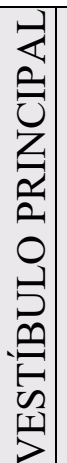 & 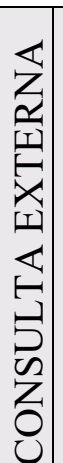 & 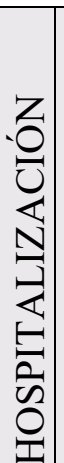 & 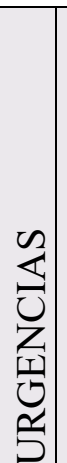 & 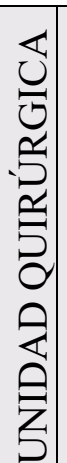 & $\begin{array}{l}\leq \\
0 \\
0 \\
0 \\
0 \\
0 \\
0 \\
0 \\
0\end{array}$ & 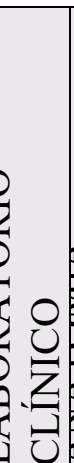 & 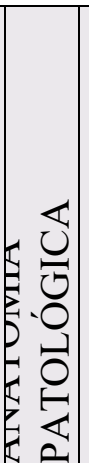 & છِ & 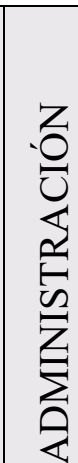 \\
\hline $\begin{array}{l}\text { CONSULTA } \\
\text { EXTERNA }\end{array}$ & & & & & & & & & & \\
\hline HOSPITALIZACIÓN & & & & & & & & & & \\
\hline URGENCIAS & & & & & & & & & & \\
\hline $\begin{array}{l}\text { UNIDAD } \\
\text { QUIRÚRGICA }\end{array}$ & & & & & & & & & & \\
\hline IMAGENOLOGÍA & & & & & & & & & & \\
\hline $\begin{array}{l}\text { LABORATORIO } \\
\text { CLÍNICO }\end{array}$ & & & & & & & & & & \\
\hline $\begin{array}{l}\text { ANATOMÍA } \\
\text { PATOLÓGICA }\end{array}$ & & & & & & & & & & \\
\hline UCI & & & & & & & & & & \\
\hline ADMINISTRACIÓN & & & & & & & & & & \\
\hline $\begin{array}{l}\text { SERVICIOS } \\
\text { GENERALES }\end{array}$ & & & & & & & & & & \\
\hline
\end{tabular}

PROXIMIDAD

DIRECTA

PROXIMIDAD

INDIRECTA

PROXIMIDAD

OCASIONAL

Fuente: Programa arquitectónico para el diseño de hospitales seguros 


\title{
7.6 PROGRAMA
}

\subsubsection{UNIDADES ESPACIO FUNCIONALES (FICHAS)}

\author{
UNIDAD DE ESPACIO FUNCIONAL
}

AMBIENTE: CONSULTORIO GINECOLÓGICO

FUENTE: NORMA TÉCNICA PARA PROYECTOS DE ARQUITECTURSA HOSPITALARIA

ÁREA TOTAL 18M2

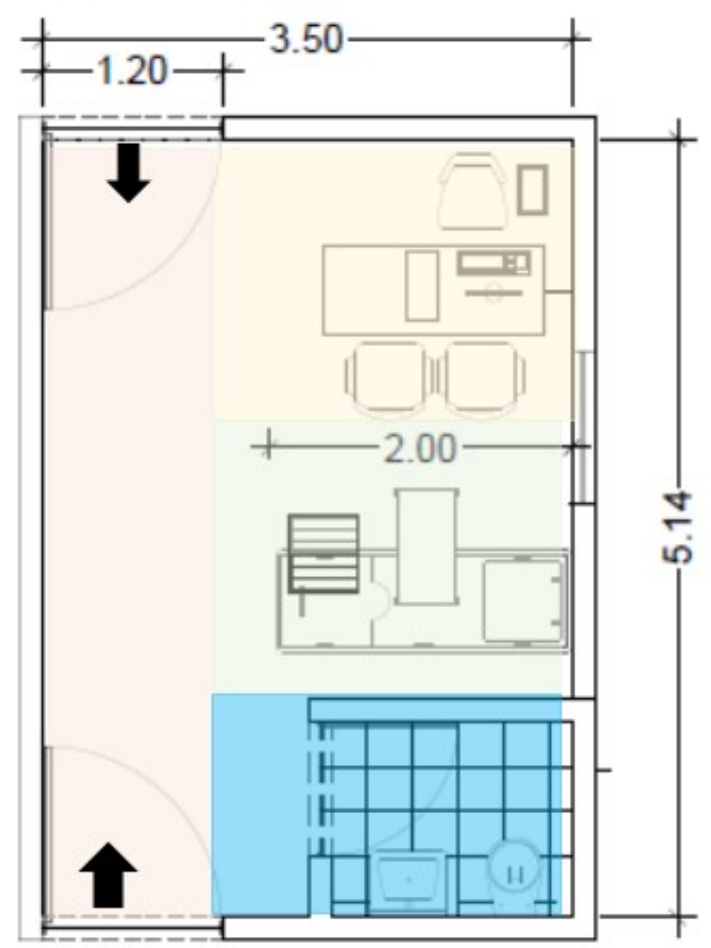

FUENTE: MINSA ELABORACIÓN PROPIA

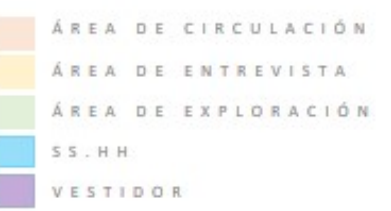

DISTRIBUCIÓN Y FORMAS DEL ESPACIO

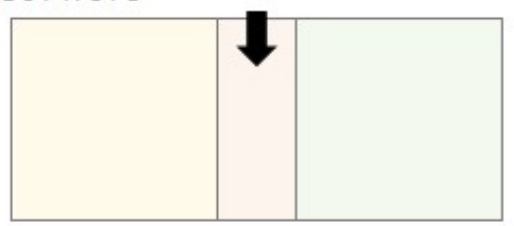

\begin{tabular}{|l|l|}
\hline \multicolumn{2}{|l|}{ RELACIÓN CONSULTA EXTERNA } \\
\hline ADMISIÓN & \\
\hline ESTERILIZACIÓN & \\
\hline IMAGENOLOGÍA & \\
\hline LABORATORIO & \\
\hline REHABILITACIÓN & \\
\hline ANATOMÍA PATOLÓGICA & \\
\hline CIRUGIA AMBULATORIA & \\
\hline FARMACIA & \\
\hline EMERGENCIA & \\
\hline HOSPITALIZACIÓN & \\
\hline
\end{tabular}

FUENTE:PROGRAMA MÉDICO
NÚMERO DE USUARIOS:3

-MÉDICO

-ENFERMERO

-PACIENTE

MOBILIARIO

-COCHE DE CURACIONES

-ESCALINATA DOS PELDAÑOS

-ESCRITORIO

-PC CON RED INTERCONECTADA

-MESA DE EXPLORACIÓN

-LAVAMANOS

IÁMPARA RODABLE

-TELÉFONO

-SILLAS

-TABURETE GIRATORIO

-OTROS (SEGÚN ESPECIALIDAD)

ILUMINACIÓN

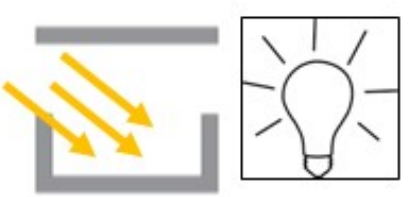

VENTILACIÓN

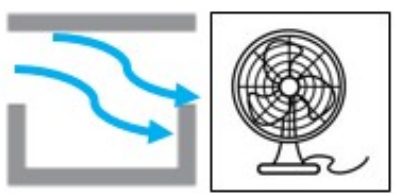

CUADRO DE EQUIPAMIENTO

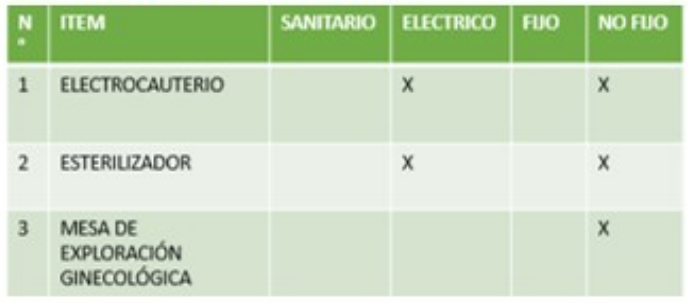

AMBIENTE ANEXO

GABINETES SEGÚN ESPECIALIDAD PUEDEN SER: -ELECTROCARDIOGRAFÍA

-CIRUGÍA MENOR

-RAYOS X

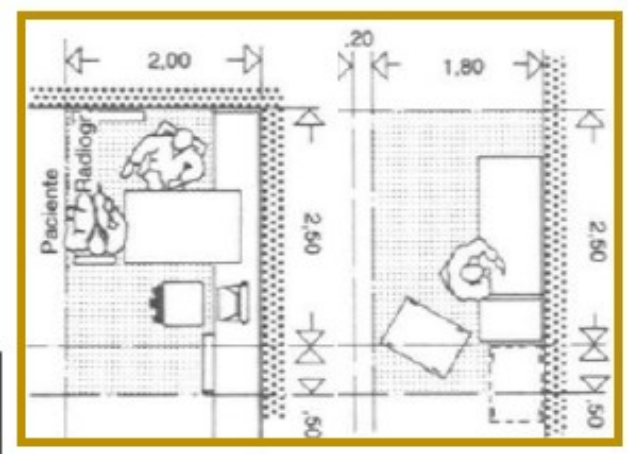

FUENTE: NEUFERT 
UNIDAD DE ESPACIO FUNCIONAL

AMBIENTE: CONSULTORIO GENERAL

FUENTE: NORMA TÉCNICA PARA PROYECTOS DE ARQUITECTURSA HOSPITALARIA

ÁREA TOTAL 15M2

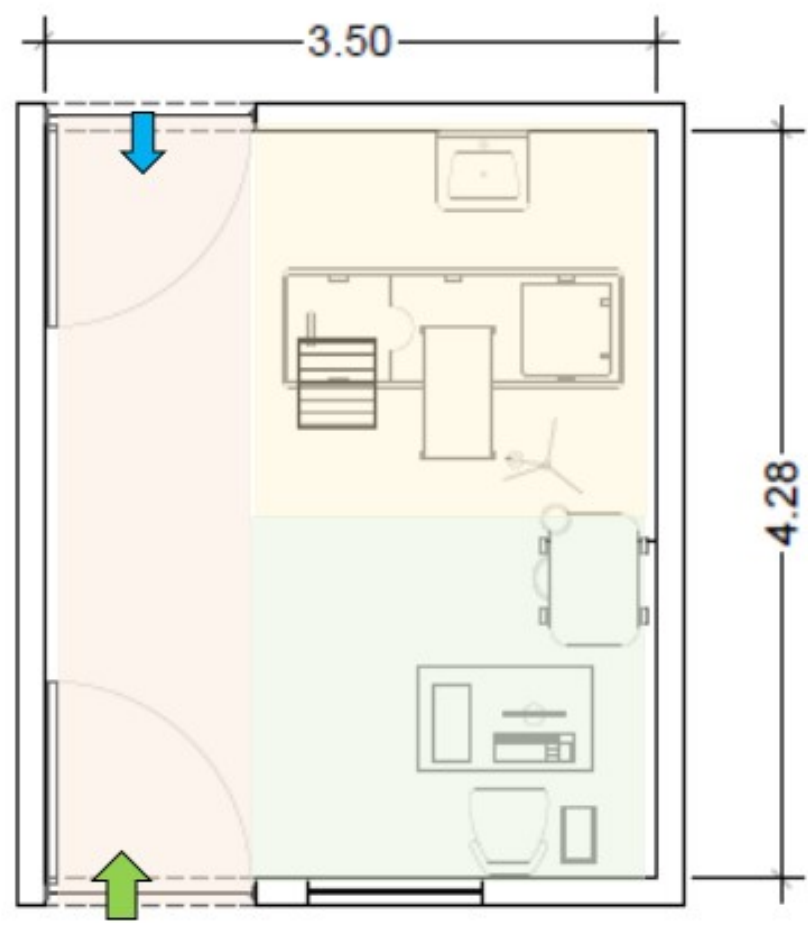

FUENTE: MINSA ELABORACIÓN PROPIA

ÁREA DE CIRCULACIÓN

ÁREA DE ENTREVISTA

ÁREA DE EXPLORACIÓN

DISTRIBUCIÓN Y FORMAS DEL ESPACIO

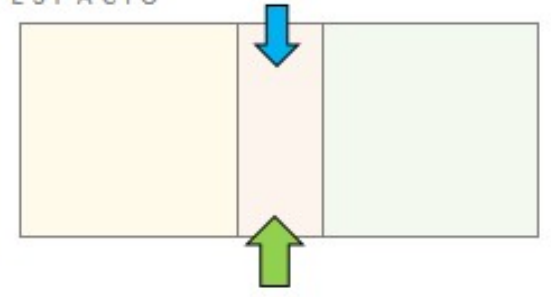

INGRESO PACIENTES

INGRESO MÉDICO
NÚMERO DE USUARIOS:3

-MÉDICO

-ENFERMERO

-PACIENTE

MOBILIARIO

-BALANZA CON TALÍMETRO

-COCHE DE CURACIONES

-ESCALINATA DOS PELDAÑOS

-ESCRITORIO

-PC CON RED INTERCONECTADA

-MESA DE EXPLORACIÓN

-LÁMPARA RODABLE

-MESA DE ACERO

-TELÉFONO

-SILLAS

-TABURETE GIRATORIO

-OTROS (SEGÚN ESPECIALIDAD)

ILUMINACIÓN

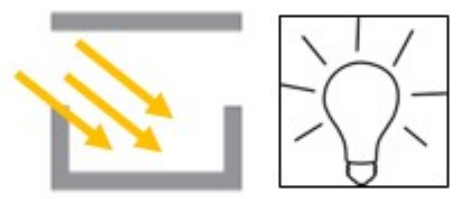

VENTILACIÓN

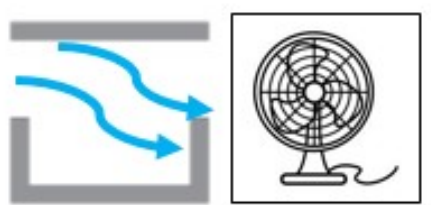

CUADRO DE EQUIPAMIENTO

\begin{tabular}{|c|c|c|c|c|c|}
\hline$\stackrel{N}{N}$ & Irem & SANITARIO & ELECIRICO & Fอ & NOFUO \\
\hline 1 & NEGATOSCOPIO & & $x$ & & $x$ \\
\hline 2 & LAVAMANOS & & $x$ & & $\mathrm{x}$ \\
\hline
\end{tabular}

\begin{tabular}{|l|l|}
\hline \multicolumn{2}{|l|}{ RELACIÓN CONSULTA EXTERNA } \\
\hline ADMISIÓN & \\
\hline ESTERILIZACIÓN & \\
\hline IMAGENOLOGÍA & \\
\hline LABORATORIO & \\
\hline REHABILITACIÓN & \\
\hline ANATOMÍA PATOLÓGICA & \\
\hline CIRUGIA AMBULATORIA & \\
\hline FARMACIA & \\
\hline EMERGENCIA & \\
\hline HOSPITALIZACIÓN & \\
\hline
\end{tabular}

ACCESO INMEDIATO ACCESO DIRECTO ACCESO

FUENTE:PROGRAMA MÉDICO 
UNIDAD DE ESPACIO FUNCIONAL

AMBIENTE: CONSULTORIO PEDIÁTRICO

FUENTE: NORMA TÉCNICA PARA PROYECTOS DE ARQUITECTURSA HOSPITALARIA

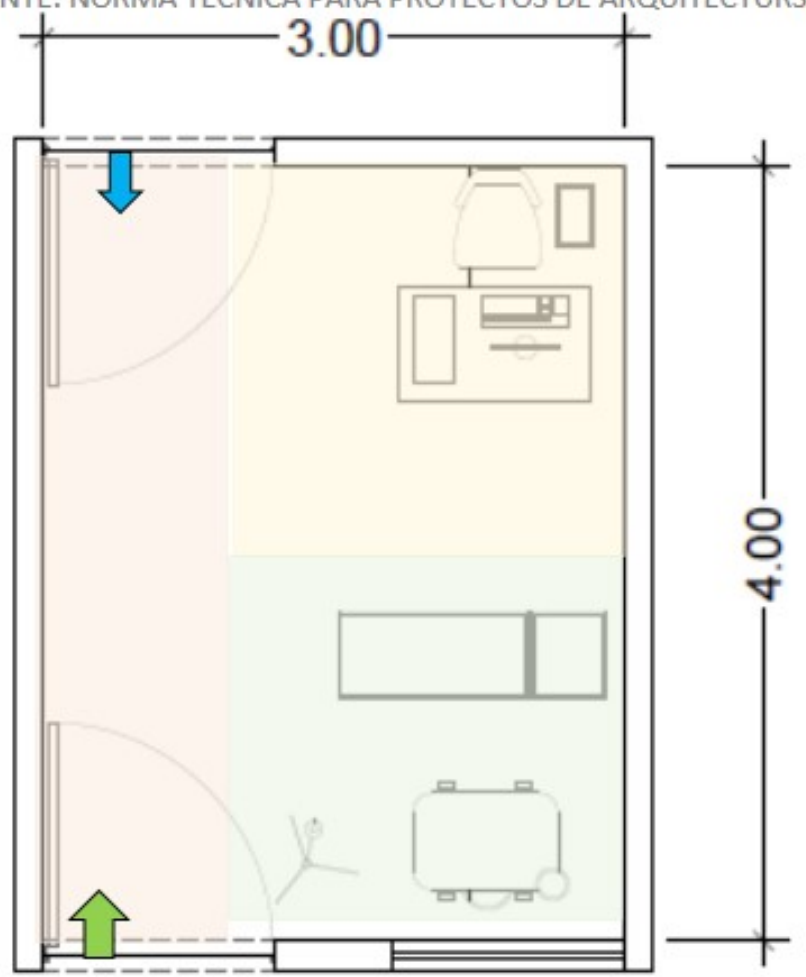

FUENTE: MINSA ELABORACIÓN PROPIA

ÁREA DE CIRCULACIÓN

ÁREA DE ENTREVISTA

ÁREA DE EXPLORACIÓN

DISTRIBUCIÓN Y FORMAS DEL ESPACIO

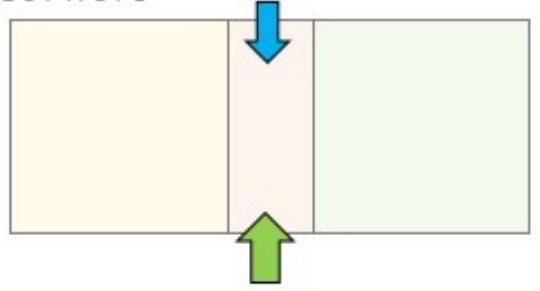

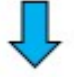

INGRESO PACIENTES

$\triangle$

INGRESO MÉDICO

AMBIENTE ANEXO

BAÑO DE ARTESA 4M2
NÚMERO DE USUARIOS:3

-MÉDICO

-ENFERMERO

-PACIENTE

MOBILIARIO

-BALANZA CON TALÍMETRO

-COCHE DE CURACIONES

-ESCALINATA DOS PELDAÑOS

-ESCRITORIO

-PC CON RED INTERCONECTADA

-MESA DE EXPLORACIÓN

- LÁMPARA RODABLE

-MESA DE ACERO

-TELÉFONO

-SILLAS

-TABURETE GIRATORIO

-OTROS (SEGÚN ESPECIALIDAD)

ILUMINACIÓN

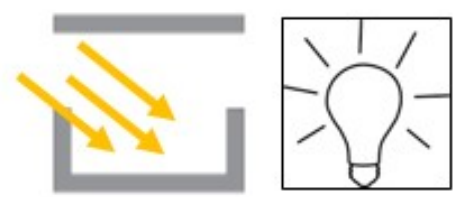

VENTILACIÓN

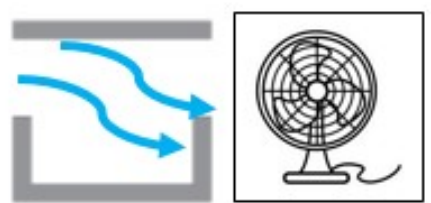

CUADRO DE EQUIPAMIENTO

\begin{tabular}{|c|c|c|c|c|c|}
\hline N & mEM & SANTIARIO & ELecruco & Fo & NOFuO \\
\hline 1 & NEGATOSCOPIO & & $x$ & & $x$ \\
\hline 2 & LAVAMANOS & & $x$ & & $x$ \\
\hline
\end{tabular}

\begin{tabular}{|l|l|}
\hline \multicolumn{2}{|l|}{ RELACIÓN CONSULTA EXTERNA } \\
\hline ADMISIÓN & \\
\hline ESTERILIZACIÓN & \\
\hline IMAGENOLOGÍA & \\
\hline LABORATORIO & \\
\hline REHABILITACIÓN & \\
\hline ANATOMÍA PATOLÓGICA & \\
\hline CIRUGIA AMBULATORIA & \\
\hline FARMACIA & \\
\hline EMERGENCIA & \\
\hline HOSPITALIZACIÓN & \\
\hline
\end{tabular}

ACCESO INMEDIATO ACCESO DIRECTO

ACCESO

FUENTE: NEUFERT 
UNIDAD DE ESPACIO FUNCIONAL

AMBIENTE: SALA DE OPERACIONES

FUENTE: NORMA TÉCNICA PARA PROYECTOS DE ARQUITECTURSA HOSPITALARIA

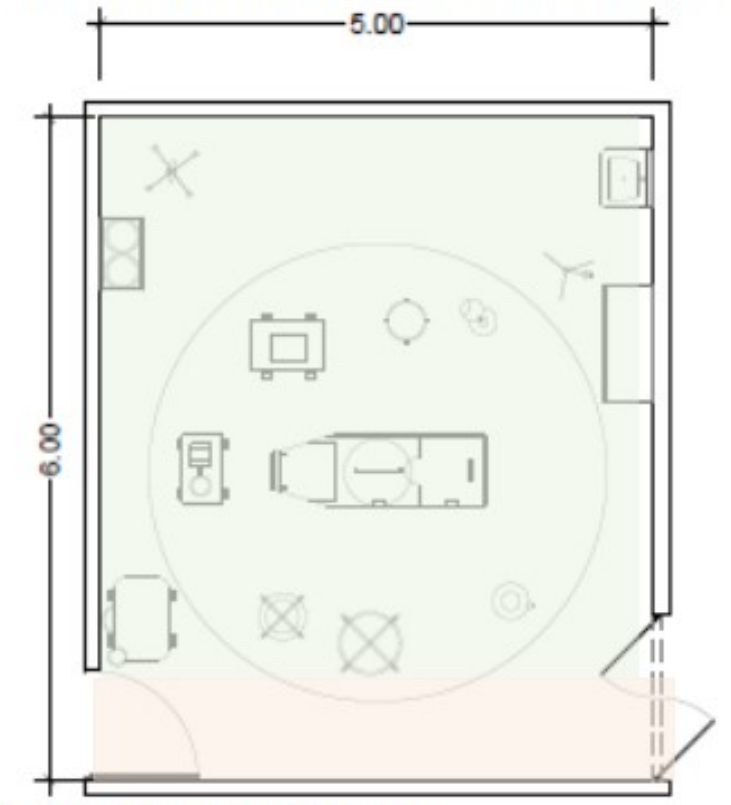

FUENTE: MINSA ELABORACIÓN PROPIA

ÁREA DE CIRCULACIÓN

ÁREA DE OPERACIÓN

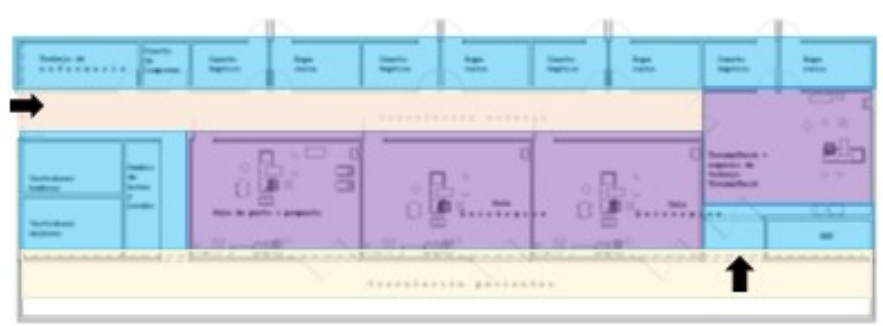

ÁREA DE CIRCULACIÓN MÉDICA ÁREA DE CIRCULACIÓN PACIENTES

ÁREA DE SALAS QUIRÚRGICAS

ÁREAS DE SERVICIO

\begin{tabular}{|c|c|}
\hline EMERGENCIA & \\
\hline ANATOMIA PATOLÓGICCA & \\
\hline BANCO DE SANGRE & \\
\hline DOCUMETACIÓN CLINICA & \\
\hline ESTERILZACIÓN & \\
\hline FARMACIA & \\
\hline HOSPITALIZACIÓN & \\
\hline ONCOLOGIA & \\
\hline CENTRO QUIRÚRGICO & \\
\hline CENTRO EUSENERERIMUNSA & \\
\hline CUIDADEEABGARAGESI PRC & PIA \\
\hline CUIDADOS INTERMEDIOS & \\
\hline HEUPUERTO & \\
\hline IMAGENOLOGIA & \\
\hline LABORATORIO & \\
\hline
\end{tabular}

ÁREA TOTAL 30M2

EL NÚMERO DE USUARIOS ES DE

- el cirujano

- 2 AUXILIARES

- INTRUMENTISTA

- ANESTESIOLOGO

- El MEDICO ESPECIALISTA

- PACIENTE

EQUIPAMIENTO

- MESA DE OPERACIONES

- cARRITO DE INSTRUMENTOS

- escalinata

- EQUIPOS POR ESPECIALIDAD

ÁREA NETA

TRAUMA CORONARIA 24M2

FAST TRACK ROOMS $12 \mathrm{M} 2$

BOX DE ATENCIÓN POLIVALENTE 20M2

BOX DE ATENCIÓN GINECO-OBSTETRA $15 \mathrm{M} 2$

BOX DE ATENCIÓN PEDIÁTRICA 12M2

ILUMINACIÓN
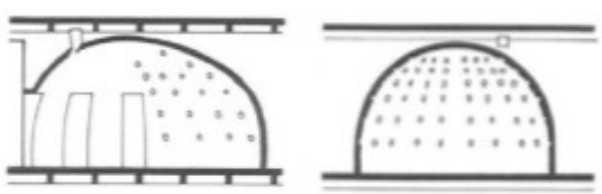

Mecanismo de limpieza de impurezas en salas quirúrgicas consiste en una corriente de expulsión de aire a razón de $0.45 \mathrm{~m} / \mathrm{s}$

Esta corriente arrastra todas las bacterias la superficie que debe mantenerse con aire puro es de $3 \times 3 \mathrm{~m}$. VENTILACION
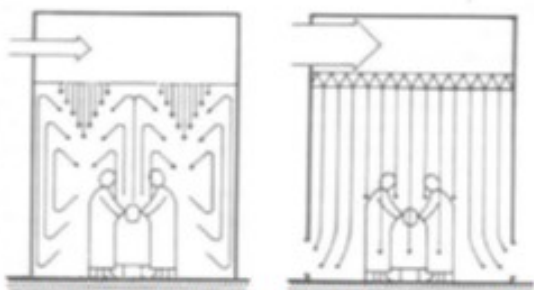

CUADRO DE EQUIPAMIIENTO FUENTE: NEUFERT

\begin{tabular}{|c|c|c|c|c|c|}
\hline$N^{*}$ & ITEM & SANITARIO & ELECTRICO & FUO & NOFUO \\
\hline 1 & LUMINARIA ARTIFICIALL & & $\mathrm{x}$ & $x$ & \\
\hline \multirow[t]{5}{*}{2} & MESA DE OPERACIONES & & & & $\mathrm{x}$ \\
\hline & CALEFACCIONN & & $\mathrm{x}$ & $\mathrm{x}$ & \\
\hline & $\begin{array}{l}\text { BOMEA DE EXTRACCION } \\
\text { ELECTRICA }\end{array}$ & & $x$ & $x$ & \\
\hline & $\begin{array}{l}\text { VITRINA PARA } \\
\text { RADIOGRAFIAS }\end{array}$ & & $x$ & $x$ & \\
\hline & $\begin{array}{l}\text { MES A DE } \\
\text { INSTRUMENTOS }\end{array}$ & & & & $\mathrm{x}$ \\
\hline
\end{tabular}


UNIDAD DE ESPACIO FUNCIONAL

\section{AMBIENTE: MULTIPLE}

FUENTE: NORMA TÉCNICA PARA PROYECTOS DE ARQUITECTURSA HOSPITALARIA

SALA DE DILATACIÓN

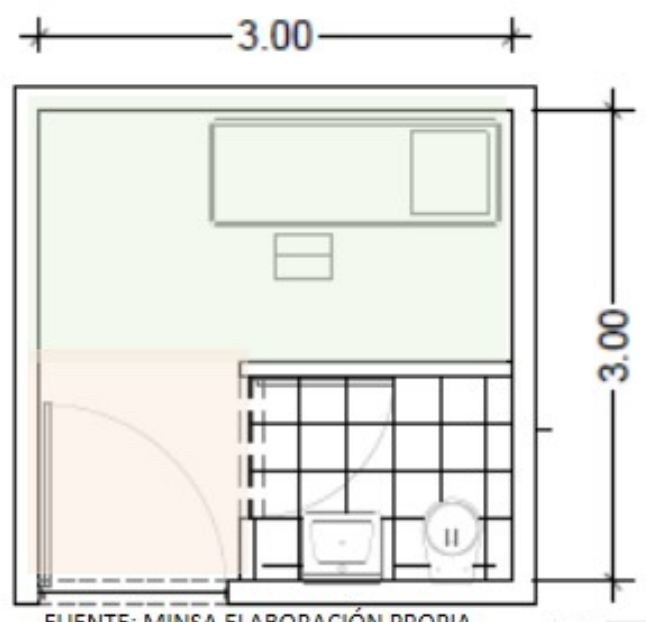

FUENTE: MINSA ELABORACIÓN PROPIA

ÁREA DE CIRCULACIÓN

ÁREA DE TRABAJO
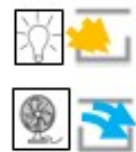

ÁREA TOTAL 9 M2
CUBICULO DE OBSERVACIÓN

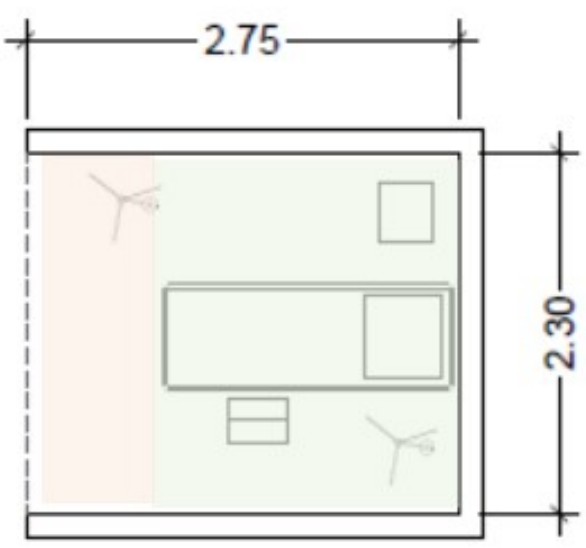

FUENTE: MINSA ELABORACIÓN PROPIA

ÁREA DE CIRCULACIÓN

ÁREA DE TRABAJO
TÓPICO DE EMERGENCIA

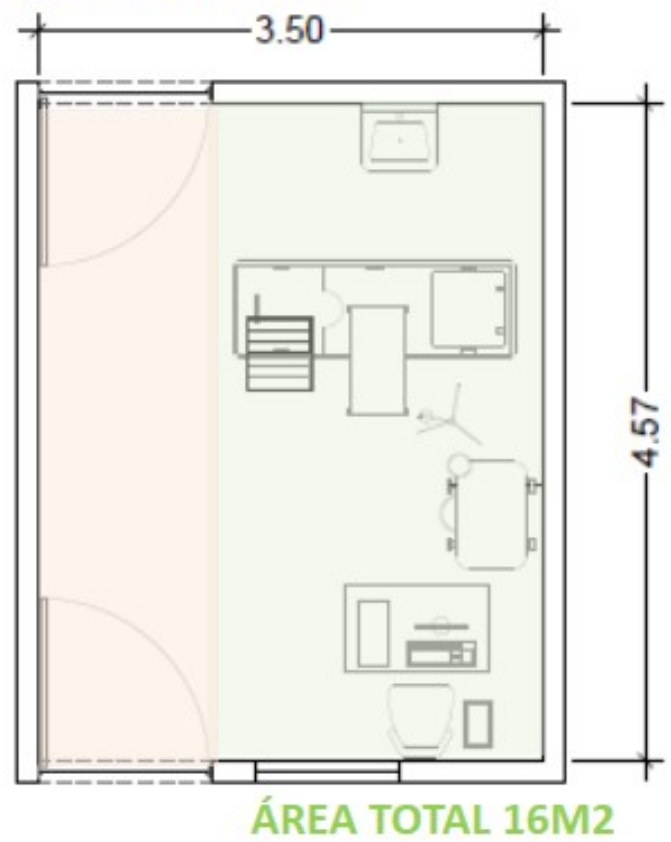

FUENTE: MINSA ELABORACIÓN PROPIA

ÁREA DE CIRCULACIÓN

ÁREA DE TRABAJO

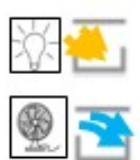

MÓDULO SIS
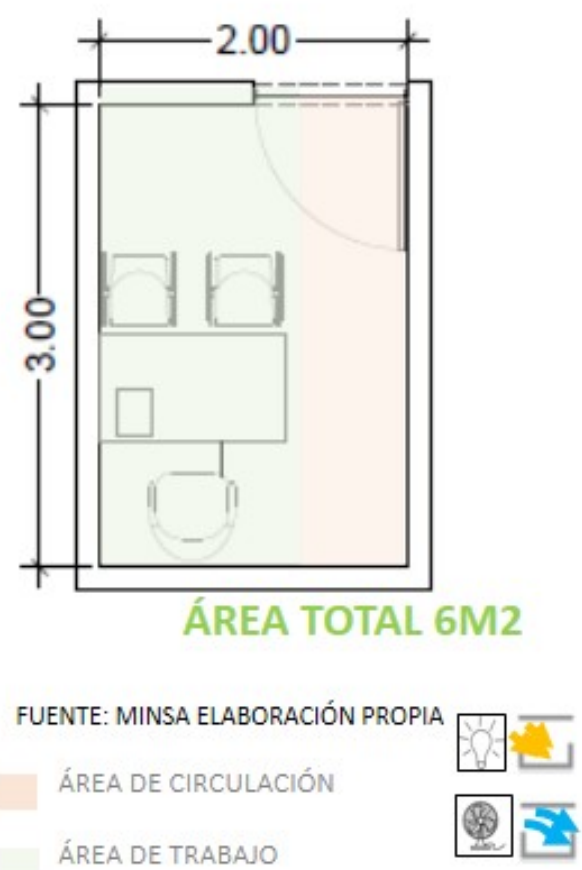


\subsubsection{COMPARATIVO DE PROGRAMA ARQUITECTÓNICO}

Para elaborar el programa arquitectónico del hospital, se cruzó proyectos referenciales de la misma categoría con lo que dicta la norma NTS 110, para corroborar los ambientes que debe tener el nosocomio.

A continuación los cuadros comparativos según unidad prestadora de servicio.

\begin{tabular}{|c|c|c|c|c|c|c|}
\hline \multicolumn{7}{|c|}{ PROGRAMA } \\
\hline PAQUETE & $\begin{array}{c}\text { SUB } \\
\text { PAQUETE }\end{array}$ & ESPACIO & $\begin{array}{c}\text { PROYECTO } \\
\text { REFERENCIAL } 1 \text { Hosp. } \\
\text { Chancay }\end{array}$ & $\begin{array}{c}\text { PROYECTO } \\
\text { REFERENCIAL } 2 \text { Hosp } \\
\text { Sta. Rosa }\end{array}$ & $\begin{array}{c}\text { PROYECTO } \\
\text { REFERENCIAL } 3 \text { Hosp. } \\
\text { San José }\end{array}$ & POR NORMA \\
\hline \multirow{79}{*}{$\begin{array}{l}\text { UNIDAD DE } \\
\text { CONSULTA } \\
\text { EXTERNA }\end{array}$} & \multirow{14}{*}{ 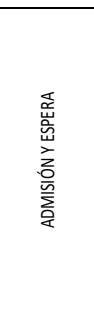 } & SALA DE ESPERA REPARTIDO EN CADA ÁREA DE CONSULTA & & & & \\
\hline & & CONTROL INGRESO MEDICO & & & & \\
\hline & & \begin{tabular}{|l} 
COUNTER CAJA \\
\end{tabular} & & & & \\
\hline & & COUNTER ADMISIÓN, CITAS (INFORMACIÓN) & & & & \\
\hline & & \begin{tabular}{|l} 
SERVICIO SOCIAL \\
\end{tabular} & & & & \\
\hline & & \begin{tabular}{|l|l} 
MERVULO SIS \\
MOL
\end{tabular} & & & & \\
\hline & & OF. DE REFERENCIA Y CONTRAREFERENCIA & & & & \\
\hline & & ARCHIVOS HISTORIAS CLIINICAS & & & & \\
\hline & & SH.HOMBRES (3) & & & & \\
\hline & & SH.MUJERES (3) & & & & \\
\hline & & SH DISCAPACITADOS (2) & & & & \\
\hline & & SALA DE JUNTAS MÉDICAS & & & & \\
\hline & & JEFATURA DE ENFERMERÍA & & & & \\
\hline & & JEFATURA DE CONSULTA EXTERNA & & & & \\
\hline & \multirow{37}{*}{ 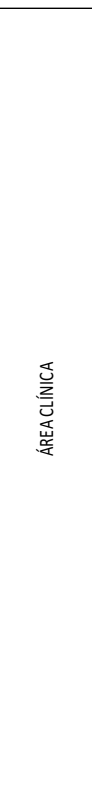 } & MEDICINA INTERNA & & & & \\
\hline & & PEDIATRÍA & & & & \\
\hline & & CIRUGÍA GENERAL & & & & \\
\hline & & GINECOLOGÍA Y OBSTETRICIA & & & & \\
\hline & & MEDICINA FAMILIAR & & & & \\
\hline & & ANESTESIOLOGÍA & & & & \\
\hline & & MEDICINA DE REHABILITACIÓN & & & & \\
\hline & & TRAUMATOLOGÍA Y ORTOPEDIA & & & & \\
\hline & & CARDIOLOGÍA & & & & \\
\hline & & NEUROLOGÍA & & & & \\
\hline & & \begin{tabular}{|l|} 
NEUMOLOGÍA \\
\end{tabular} & & & & \\
\hline & & GASTROENTEROLOGÍA & & & & \\
\hline & & REUMATOLOGÍA & & & & \\
\hline & & \begin{tabular}{|l|} 
PSIQUIATRIA \\
\end{tabular} & & & & \\
\hline & & OFTALMOLOGÍA & & & & \\
\hline & & \begin{tabular}{|l|l|l|l|l|l|l} 
UROLOGÍA \\
\end{tabular} & & & & \\
\hline & & OTORRINOLARINGOLOGÍA & & & & \\
\hline & & \begin{tabular}{|l|} 
ONCOLOGÍA MÉDICA \\
\end{tabular} & & & & \\
\hline & & \begin{tabular}{|l|l|} 
DERMATOLOGÍA \\
\end{tabular} & & & & \\
\hline & & ENDOCRINOLOGÍA & & & & \\
\hline & & ODONTOLOGÍA GENERAL + RADIOLOGIA ORAL & & & & \\
\hline & & CRED & & & & \\
\hline & & \begin{tabular}{|l|} 
INMUNIZACIONES \\
\end{tabular} & & & & \\
\hline & & ESTIMULACIÓN TEMPRANA & & & & \\
\hline & & \begin{tabular}{|l|} 
CONSEJERÍA Y PREVENCIÓN ETS \\
\end{tabular} & & & & \\
\hline & & CONSEJERÍAY PREVENCIÓN TUBERCULOSIS & & & & \\
\hline & & \begin{tabular}{|l|} 
ATENCION ADULTO MAYOR \\
\end{tabular} & & & & \\
\hline & & CONSEJERIA Y PREVENCIÓN ENF. NO TRANSMISORAS & & & & \\
\hline & & CONSEJERÍA Y PREVENCIÓN DEL CANCER & & & & \\
\hline & & CONSEJERÍA EN SALUD MENTAL & & & & \\
\hline & & \begin{tabular}{|l|} 
PSICOLOGÍA \\
\end{tabular} & & & & \\
\hline & & \begin{tabular}{|l|} 
CONTROL PRENATAL \\
\end{tabular} & & & & \\
\hline & & PLANIFICACIÓN FAMILIAR & & & & \\
\hline & & \begin{tabular}{|l|} 
PSICOPROFILAXIS \\
\end{tabular} & & & & \\
\hline & & \begin{tabular}{|l|l|l|l|l|l|l} 
NUTRICIÓN \\
\end{tabular} & & & & \\
\hline & & TÓPICO EN CONSULTA & & & & \\
\hline & & $\begin{array}{ll}\text { INYECTABLES } \\
\end{array}$ & & & & \\
\hline & \multirow{24}{*}{ 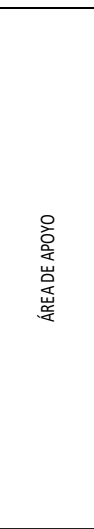 } & SALA DE PROCEDIMIENTOS CIRUGÍA GENERAL & & & & \\
\hline & & SALA DE PROCEDIMIENTOS GINECOLÓGICOS & & & & \\
\hline & & \begin{tabular}{|l|} 
SALA DE COLPOSCOPÍA \\
\end{tabular} & & & & \\
\hline & & SALA DE ECOGRAFÍA OBTÉTRICA & & & & \\
\hline & & SALA DE MONITOREO FETAL & & & & \\
\hline & & SALA DE ENDOSCOPÍA DIGESTIVA ALTA & & & & \\
\hline & & SALA DE ENDOSCOPÍA DIGESTIVA BAJA & & & & \\
\hline & & SALA DE RECUPERACIÓN POST SEDACIÓN & & & & \\
\hline & & \begin{tabular}{|l|} 
SALA DE ELECTROCARDIOGRAFÍA \\
\end{tabular} & & & & \\
\hline & & $\begin{array}{l}\text { SALA DE PRUEBA DE ESFUERZO } \\
\end{array}$ & & & & \\
\hline & & SALA DE HOLTER Y MAPA & & & & \\
\hline & & SALA DE ECOCARDIOGRAFÍA & & & & \\
\hline & & SALA DE BRONCOSCOPÍA & & & & \\
\hline & & SALA DE ESPINOMETRÍA & & & & \\
\hline & & SALA DE ELECTROENCÉFALIOGRAFÍA & & & & \\
\hline & & SALA DE AUDIMETRÍA & & & & \\
\hline & & SALA DE PROCEDIMIENTOS DE OTORRINOLARINGOLOGÍA & & & & \\
\hline & & SALA DE YESOS & & & & \\
\hline & & SALA DE PROCEDIMIENTOS DE OFTALMOLOGÍA & & & & \\
\hline & & SALA DE REFRACCIÓN + ANTESALA & & & & \\
\hline & & SALA DE CAMPIMETRÍA & & & & \\
\hline & & SALA DE CISTOURETROSCOPIA & & & & \\
\hline & & SALA DE PROCEDIMIENTOS DE DERMATOLOGÍA & & & & \\
\hline & & SALA DE DIÁLISIS PERITONEAL & & & & \\
\hline & & CUARTO DE LIMPIEZA & & & & \\
\hline & 은 & DEPÓSITO DE RESIDUOS SÓLIDOS & & & & \\
\hline & $\sum_{\text {站 }}$ & \begin{tabular}{|l|l|} 
DEPÓSITO DE MATERIALES \\
\end{tabular} & & & & \\
\hline & 岕 & SERVICIOS HIGIÉNICOS PARA PERSONAL & & & & \\
\hline
\end{tabular}


Fuente: Indicada en tabla, elaboración propia

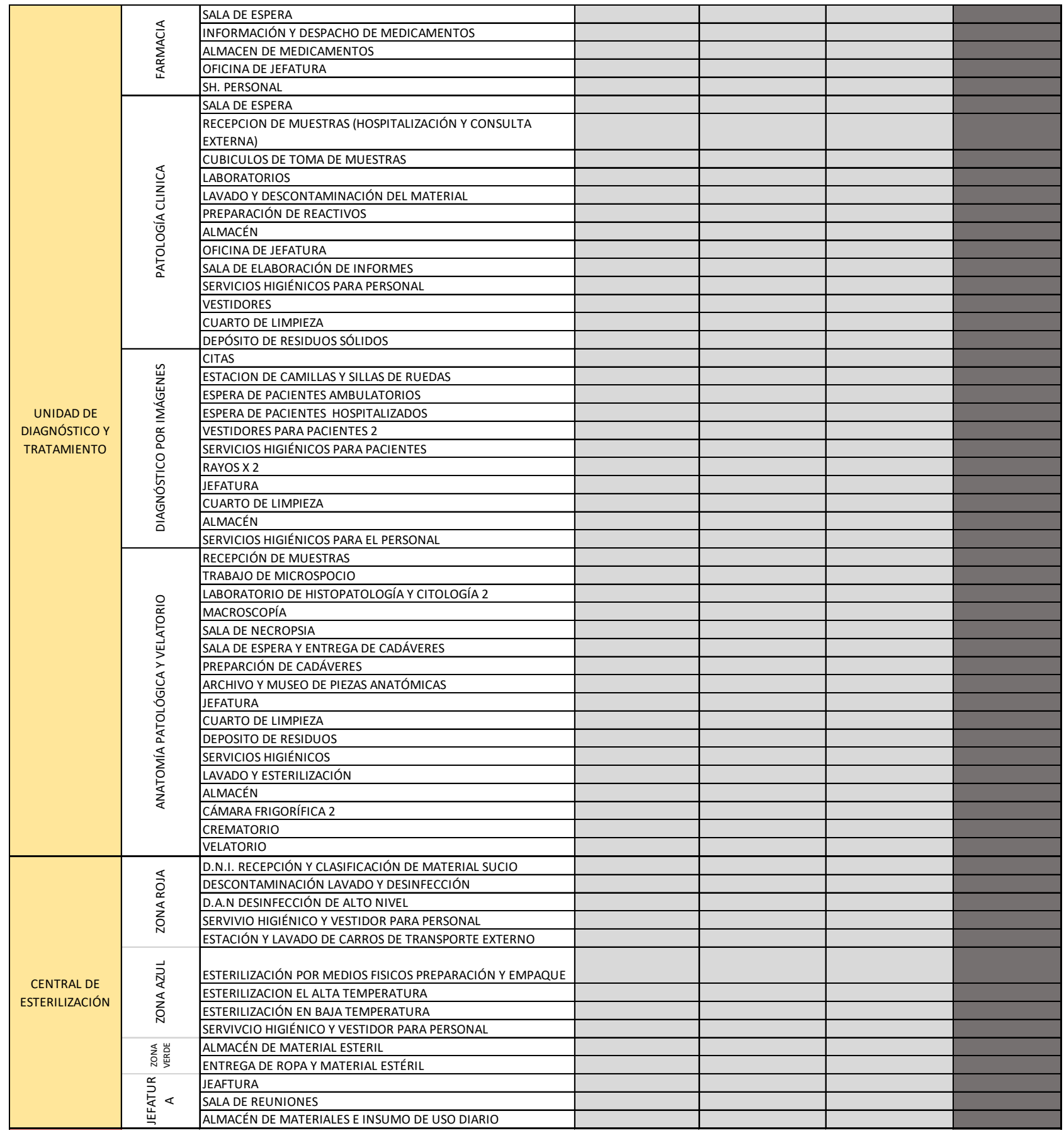

Fuente: Indicada en tabla, elaboración propia 


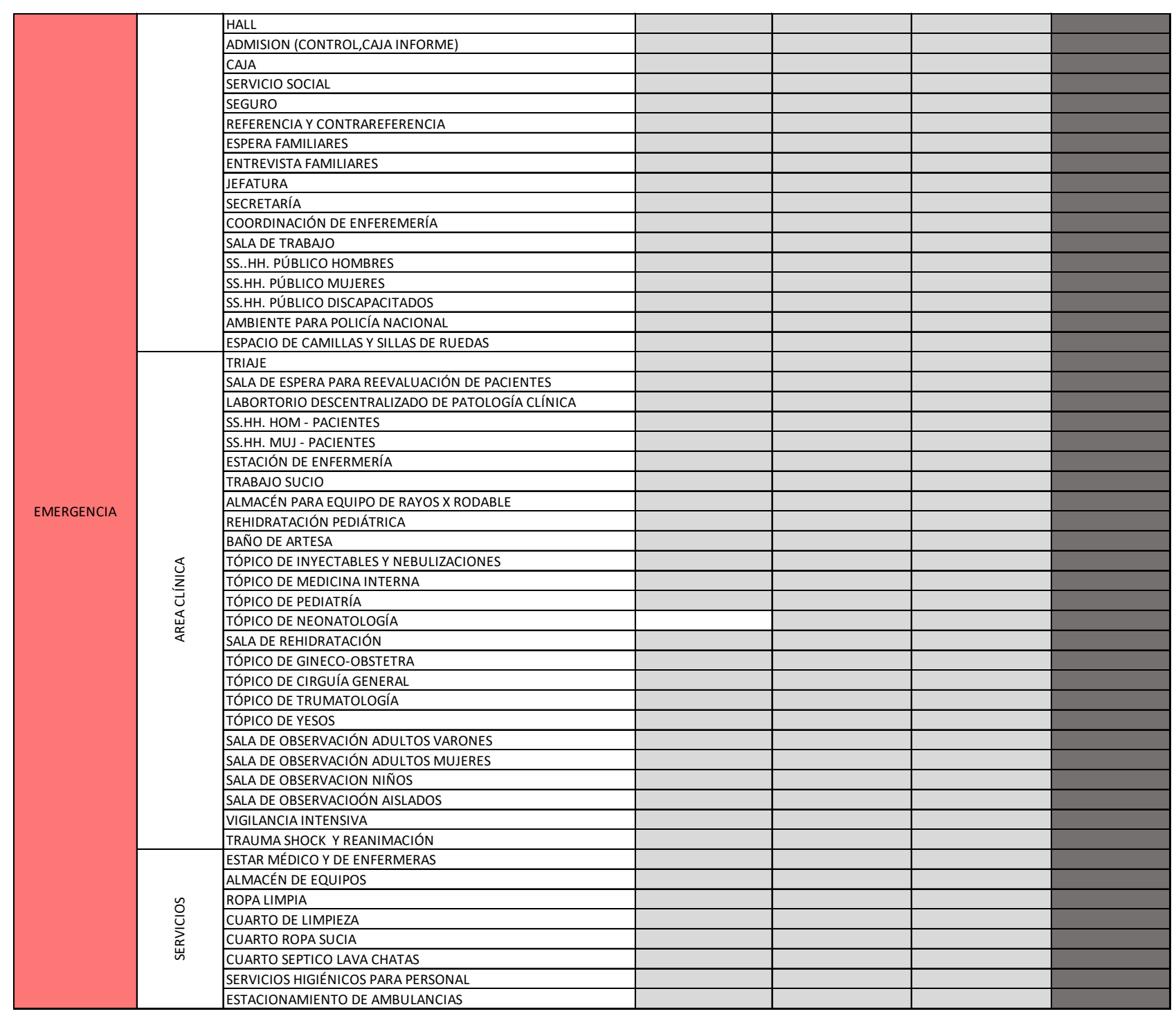

Fuente: Indicada en tabla, elaboración propia 


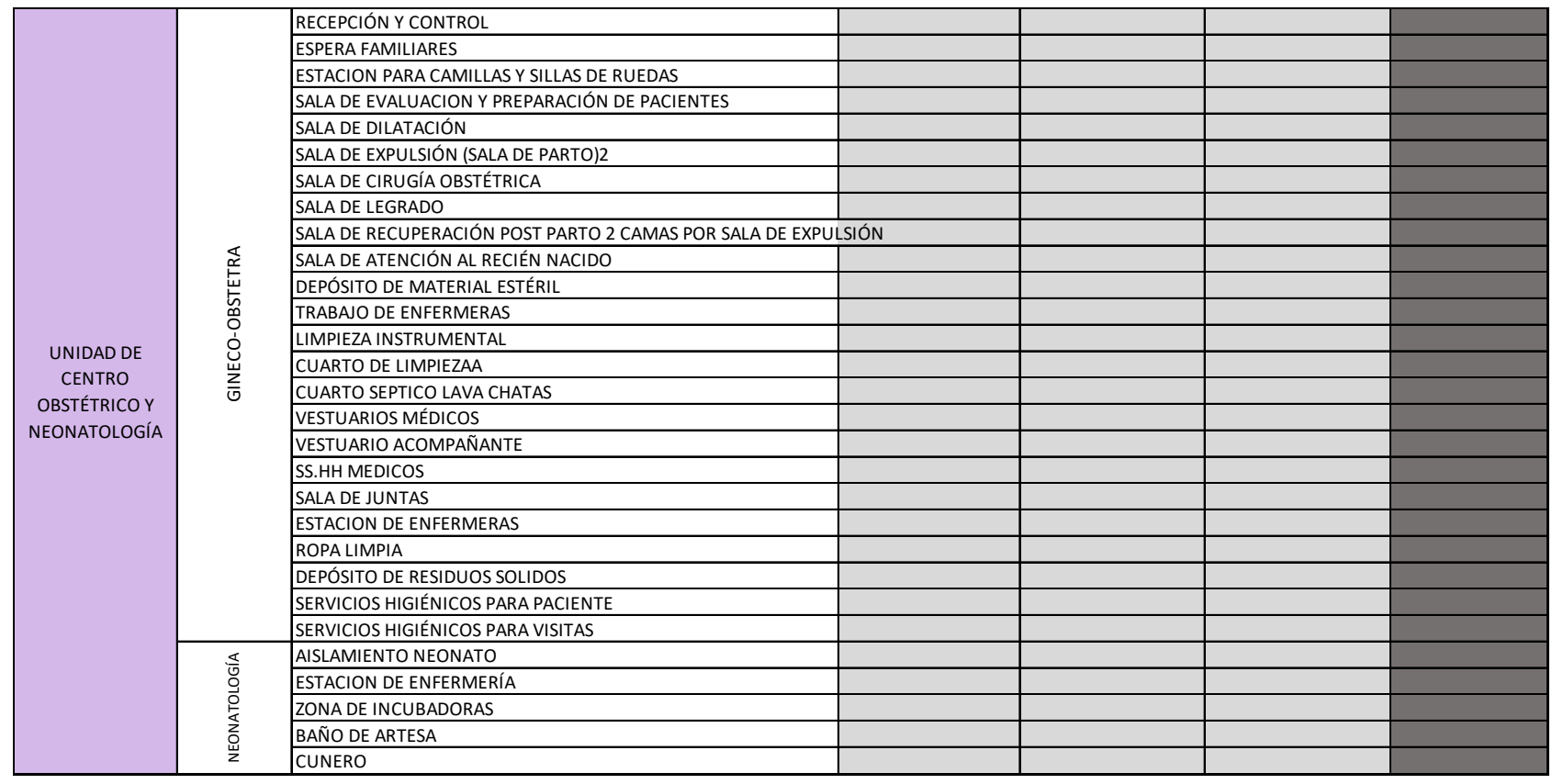

Fuente: Indicada en tabla, elaboración propia

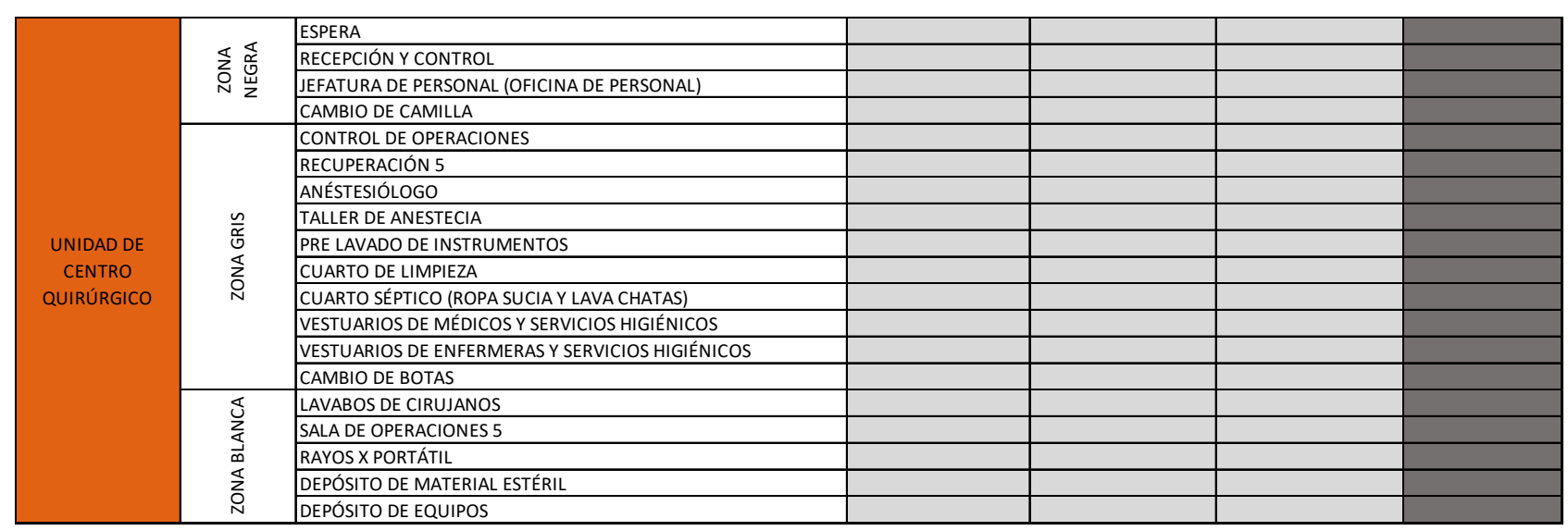

Fuente: Indicada en tabla, elaboración propia 


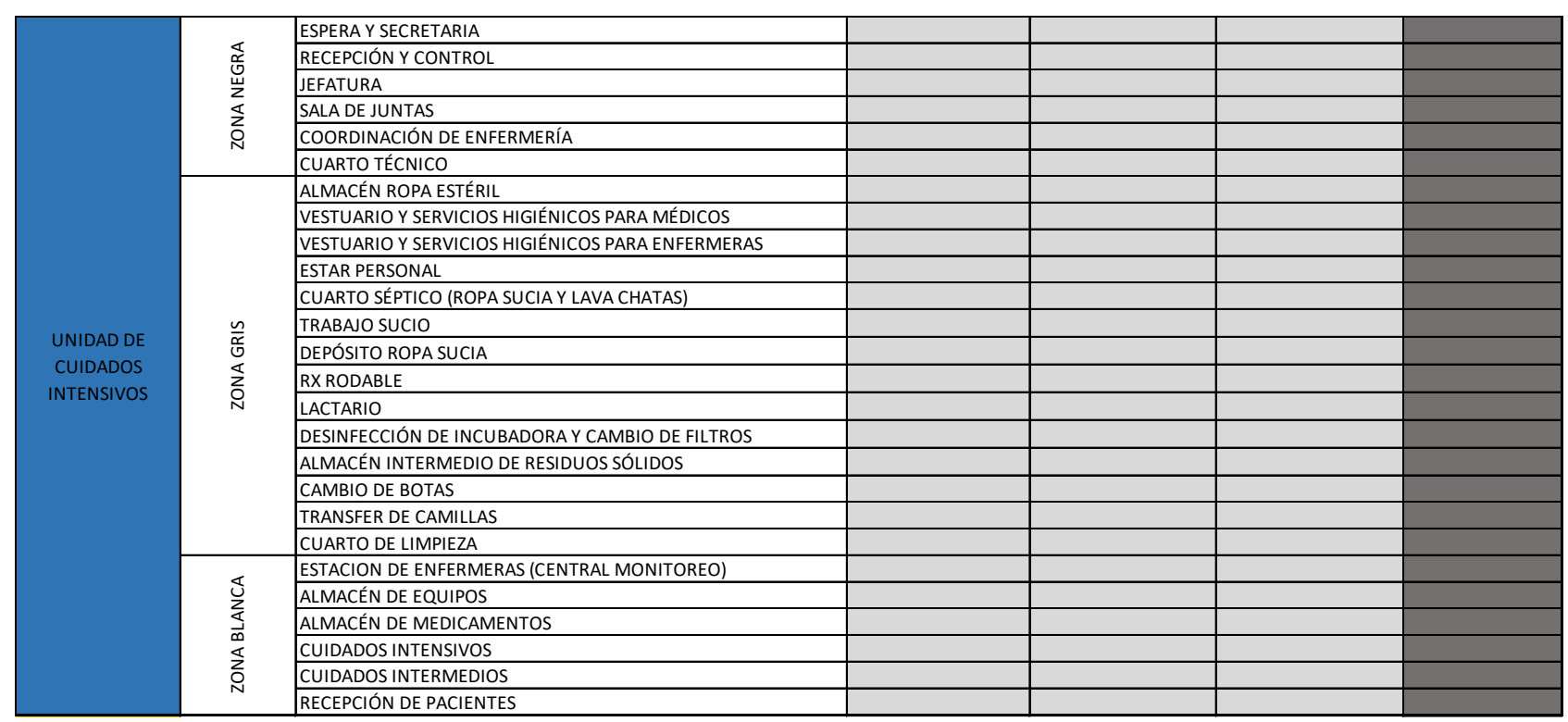

\section{Fuente: Indicada en tabla, elaboración propia}

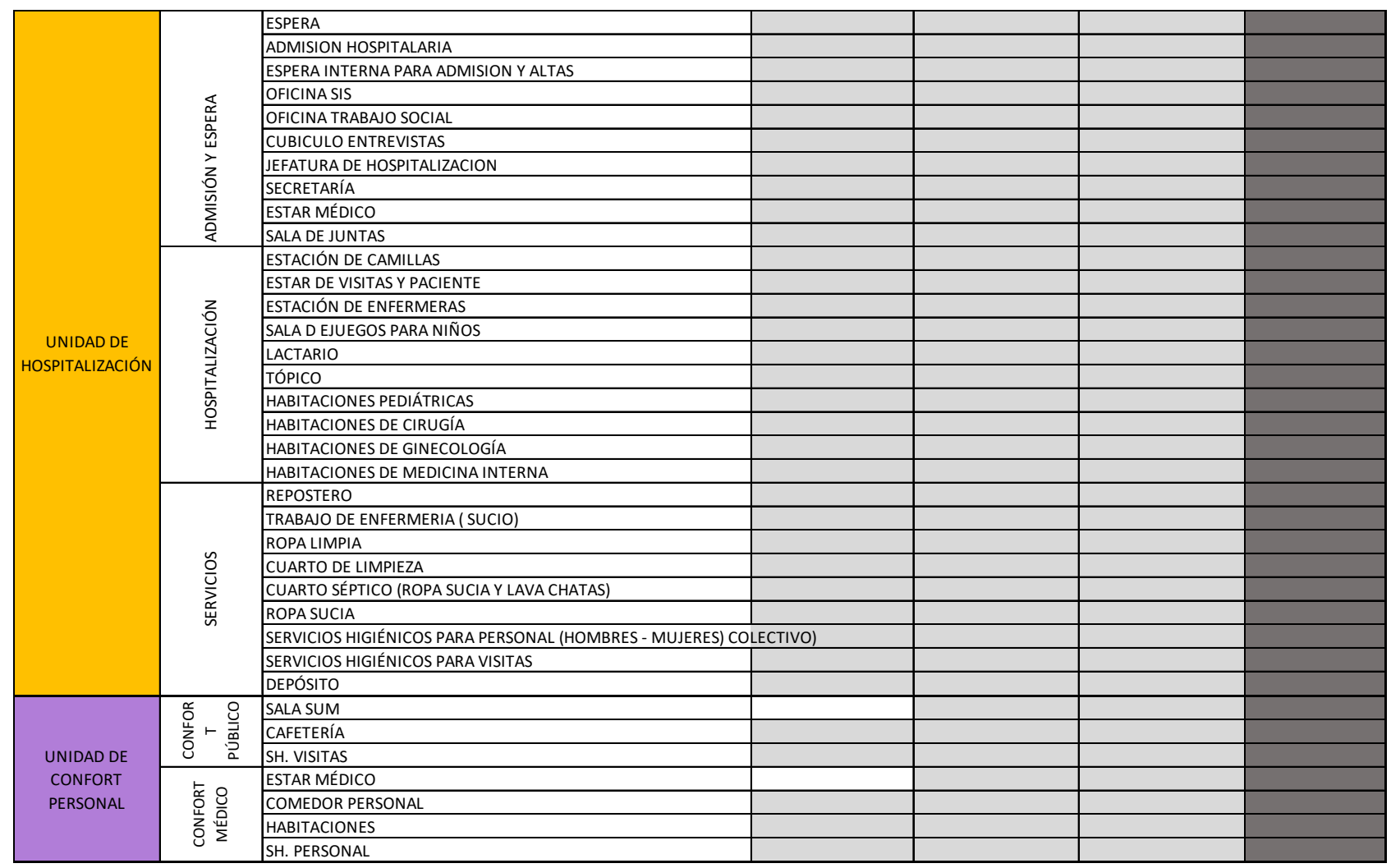

Fuente: Indicada en tabla, elaboración propia 


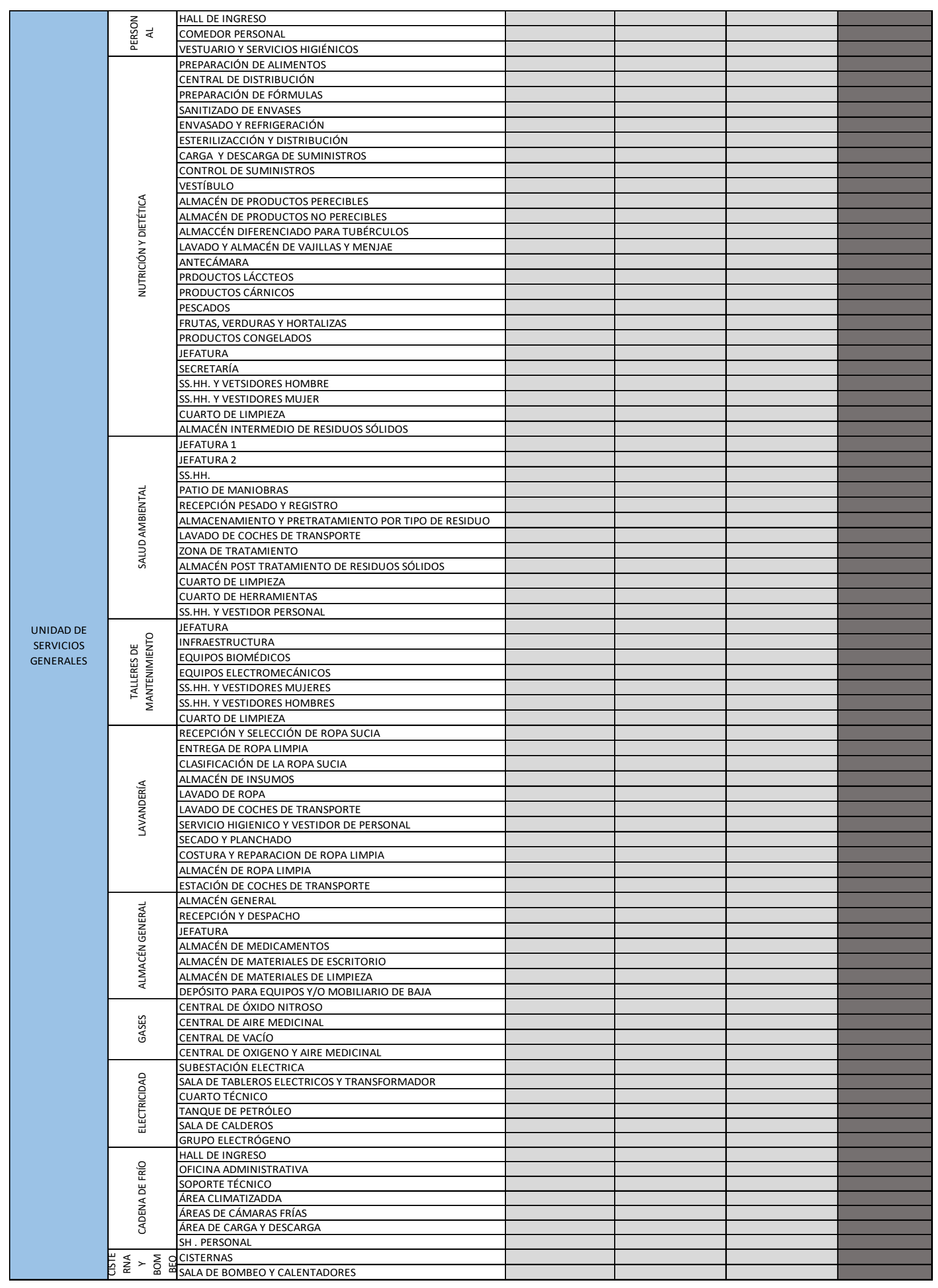

Fuente: Indicada en tabla, elaboración propia 


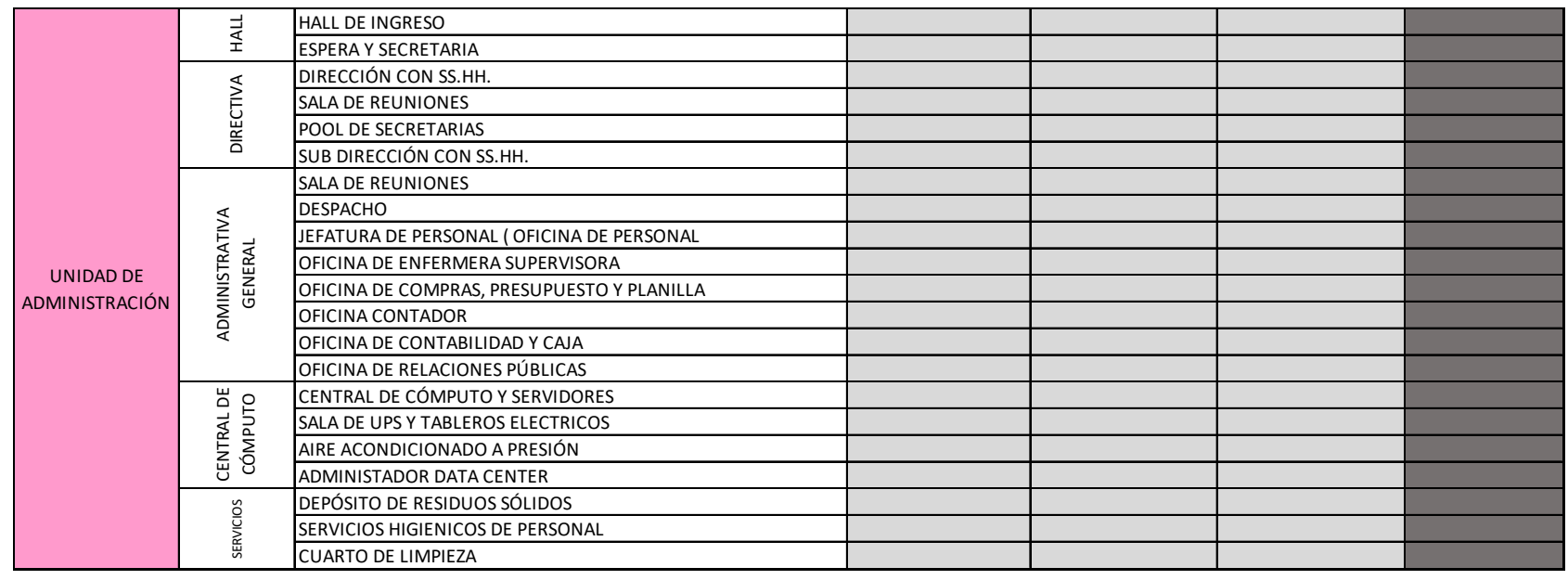

Fuente: Indicada en tabla, elaboración propia 


\subsubsection{PROGRAMACIÓN DE ÁREAS}

Para la elaboración de las áreas mínimas se utilizó la norma NTS 110, el libro de hospitales seguros del Perú, la norma A 120 y los proyectos referenciales nacionales. A continuación el programa con las áreas correspondientes.

\begin{tabular}{|c|c|c|c|c|c|c|c|}
\hline \multicolumn{8}{|c|}{ PROGRAMA } \\
\hline PAQUETE & $\begin{array}{c}\text { SUB } \\
\text { PAQUETE }\end{array}$ & ESPACIO & ÁREA & $\begin{array}{l}\text { CANTI } \\
\text { DAD }\end{array}$ & $\begin{array}{c}\text { AREA POR } \\
\text { ESPACIO }\end{array}$ & SUB TOTAL & TOTAL \\
\hline \multirow{80}{*}{$\begin{array}{l}\text { UNIDAD DE } \\
\text { CONSULTA } \\
\text { EXTERNA }\end{array}$} & \multirow{15}{*}{ 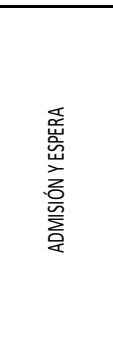 } & SALA DE ESPERA REPARTIDO EN CADA ÁREA DE CONSULTA & 225 & 1 & 225.18 & \multirow{15}{*}{766.56} & \\
\hline & & SALA DE ESPERA INGRESO & 225 & 1 & 225.18 & & \\
\hline & & CONTROL INGRESO MEDICO & 12 & 1 & 12.00 & & \\
\hline & & COUNTER CAJA & $\frac{15}{6}$ & 2 & 12.00 & & \\
\hline & & COUNTER ADMISIÓN, CITAS (INFORMACIÓN) & 6 & 2 & 12.00 & & \\
\hline & & SERVICIO SOCIAL & 12 & 1 & 12.00 & & \\
\hline & & MODULO SIS & 12 & 1 & 12.00 & & \\
\hline & & OF. DE REFERENCIA Y CONTRAREFERENCIA & 12 & 1 & 12.00 & & \\
\hline & & ARCHIVOS HISTORIAS CLÍNICAS & 25 & 1 & 25.00 & & \\
\hline & & SH.HOMBRES (3) & 4.4 & 14 & 61.60 & & \\
\hline & & SH.MUJERES (3) & 4.4 & 14 & 61.60 & & \\
\hline & & SH DISCAPACITADOS (2) & 5 & 12 & 60.00 & & \\
\hline & & SALA DE JUNTAS MÉDICAS & 12 & 1 & 12.00 & & \\
\hline & & \begin{tabular}{|l|} 
JEFATURA DE ENFERMERÍA \\
\end{tabular} & 12 & 1 & 12.00 & & \\
\hline & & JEFATURA DE CONSULTA EXTERNA & $\frac{12}{12}$ & 1 & 12.00 & & \\
\hline & & MEDICINA INTERNA & 13.5 & 1 & 13.50 & & \\
\hline & & \begin{tabular}{|l|} 
PEDIATRÍA \\
\end{tabular} & 13.5 & 1 & 13.50 & & \\
\hline & & CIRUGÍA GENERAL & 13.5 & 1 & 13.50 & & \\
\hline & & GINECOLOGÍA Y OBSTETRICIA & 17 & 1 & 17.00 & & \\
\hline & & \begin{tabular}{|l} 
MEDICINA FAMILIAR \\
\end{tabular} & 13.5 & 1 & 13.50 & & \\
\hline & & ANESTESIOLOGÍA & 13.5 & 1 & 13.50 & & \\
\hline & & MEDICINA DE REHABILITACIÓN & 15 & 1 & 13.50 & & \\
\hline & & TRAUMATOLOGÍA Y ORTOPEDIA & 15 & 1 & 15.00 & & \\
\hline & & \begin{tabular}{|l|} 
CARDIOLOGÍA \\
\end{tabular} & 13.5 & 1 & 15.00 & & \\
\hline & & \begin{tabular}{|l|} 
NEUROLOGÍA \\
\end{tabular} & 13.5 & 1 & 13.50 & & \\
\hline & & NEUMOLOGÍA & 13.5 & 1 & 13.50 & & \\
\hline & & \begin{tabular}{|l|} 
GASTROENTEROLOGÍA \\
\end{tabular} & 17 & 1 & 17.00 & & \\
\hline & & \begin{tabular}{|l|} 
REUMATOLOGÍA \\
\end{tabular} & 15 & 1 & 15.00 & & \\
\hline & & \begin{tabular}{|l|} 
PSIQUIATRIA \\
\end{tabular} & 13.5 & 1 & 13.50 & & \\
\hline & & OFTALMOLOGÍA & 18 & 1 & 18.00 & & \\
\hline & & \begin{tabular}{|l|l} 
UROLOGÍA \\
\end{tabular} & 17 & 1 & 17.00 & & \\
\hline & & OTORRINOLARINGOLOGÍA & 15 & 1 & 15.00 & & \\
\hline & 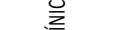 & ONCOLOGÍA MÉDICA & 13.5 & 1 & 13.50 & & \\
\hline & 蒠 & \begin{tabular}{|l|} 
DERMATOLOGÍA \\
\end{tabular} & 13.5 & 1 & 13.50 & & \\
\hline & 妥 & ENDOCRINOLOGÍA & 13.5 & 1 & 13.50 & & \\
\hline & & ODONTOLOGÍA GENERAL + RADIOLOGIA ORAL & 23 & 1 & 23.00 & & \\
\hline & & \begin{tabular}{|ll} 
CRED \\
\end{tabular} & 17 & 1 & 17.00 & & \\
\hline & & INMUNIZACIONES & 15 & 1 & 15.00 & & \\
\hline & & ESTIMULACIÓN TEMPRANA & 24 & 1 & 24.00 & & \\
\hline & & CONSEJERÍA Y PREVENCIÓN ETS & 13.5 & 1 & 13.50 & & \\
\hline & & CONSEJERÍAY PREVENCIÓN TUBERCULOSIS & 13.5 & 1 & 13.50 & & 1809.56 \\
\hline & & ATENCION ADULTO MAYOR & 17 & 1 & 17.00 & & \\
\hline & & CONSEJERIA Y PREVENCIÓN ENF. NO TRANSMISORAS & 13.5 & 1 & 13.50 & & \\
\hline & & CONSEJERÍA Y PREVENCIÓN DEL CANCER & 13.5 & 1 & 13.50 & & \\
\hline & & CONSEJERÍA EN SALUD MENTAL & 13.5 & 1 & 13.50 & & \\
\hline & & PSICOLOGÍA & 15 & 1 & 15.00 & 992.00 & \\
\hline & & CONTROL PRENATAL & 17 & 1 & 17.00 & & \\
\hline & & \begin{tabular}{|l} 
PLANIFICACIÓN FAMILIAR \\
\end{tabular} & 13.5 & 1 & 13.50 & & \\
\hline & & \begin{tabular}{|l|l} 
PSICOPROFILAXIS \\
\end{tabular} & 36 & 1 & 36.00 & & \\
\hline & & NUTRICIÓN & 13.5 & 1 & 13.50 & & \\
\hline & & TÓPICO EN CONSULTA & 16 & 2 & 32.00 & & \\
\hline & & $\begin{array}{l}\text { INYECTABLES } \\
\end{array}$ & 15 & 1 & 15.00 & & \\
\hline & & SALA DE PROCEDIMIENTOS CIRUGÍA GENERAL & 16 & 1 & 16.00 & & \\
\hline & & SALA DE PROCEDIMIENTOS GINECOLÓGICOS & 20 & 1 & 20.00 & & \\
\hline & & SALA DE COLPOSCOPÍA & 20 & 1 & 20.00 & & \\
\hline & & SALA DE ECOGRAFÍA OBTÉTRICA & 17 & 1 & 17.00 & & \\
\hline & & SALA DE MONITOREO FETAL & 20 & 1 & 20.00 & & \\
\hline & & SALA DE ENDOSCOPÍA DIGESTIVA ALTA & 20 & 1 & 20.00 & & \\
\hline & & SALA DE ENDOSCOPÍA DIGESTIVA BAJA & 24 & 1 & 24.00 & & \\
\hline & & SALA DE RECUPERACIÓN POST SEDACIÓN & 10 & 1 & 10.00 & & \\
\hline & & SALA DE ELECTROCARDIOGRAFÍA & 10 & 1 & 10.00 & & \\
\hline & & SALA DE PRUEBA DE ESFUERZO & 20 & 1 & 20.00 & & \\
\hline & & SALA DE HOLTER Y MAPA & 13.5 & 1 & 13.50 & & \\
\hline & 产 & SALA DE ECOCARDIOGRAFÍA & 13.5 & 1 & 13.50 & & \\
\hline & 㟔 & SALA DE BRONCOSCOPÍA & 20 & 1 & 20.00 & & \\
\hline & 岃 & SALA DE ESPINOMETRÍA & 10 & 1 & 10.00 & & \\
\hline & & SALA DE ELECTROENCÉFALI¿¿OGRAFÍA & 13.5 & 1 & 13.50 & & \\
\hline & & SALA DE AUDIMETRÍA & 15 & 1 & 15.00 & & \\
\hline & & SALA DE PROCEDIMIENTOS DE OTORRINOLARINGOLOGÍA & 16 & 1 & 16.00 & & \\
\hline & & $\begin{array}{l}\text { SALA DE YESOS } \\
\end{array}$ & 17 & 1 & 17.00 & & \\
\hline & & SALA DE PROCEDIMIENTOS DE OFTALMOLOGÍA & 20 & 1 & 20.00 & & \\
\hline & & SALA DE REFRACCIÓN + ANTESALA & 26 & 1 & 26.00 & & \\
\hline & & SALA DE CAMPIMETRÍA & 7 & 1 & 7.00 & & \\
\hline & & SALA DE CISTOURETROSCOPIA & 17 & 1 & 17.00 & & \\
\hline & & SALA DE PROCEDIMIENTOS DE DERMATOLOGÍA & 15 & 1 & 15.00 & & \\
\hline & & SALA DE DIÁLISIS PERITONEAL & 15 & 1 & 15.00 & & \\
\hline & $\simeq$ & CUARTO DE LIMPIEZA & 4 & 1 & 4.00 & & \\
\hline & 은 & DEPÓSITO DE RESIDUOS SÓLIDOS & 20 & 1 & 20.00 & & \\
\hline & $\sum_{i}$ & \begin{tabular}{|l|} 
DEPÓSITO DE MATERIALES \\
\end{tabular} & 20 & 1 & 20.00 & 51.00 & \\
\hline & 岕 & SERVICIOS HIGIÉNICOS PARA PERSONAL & 3.5 & 2 & 7.00 & & \\
\hline
\end{tabular}




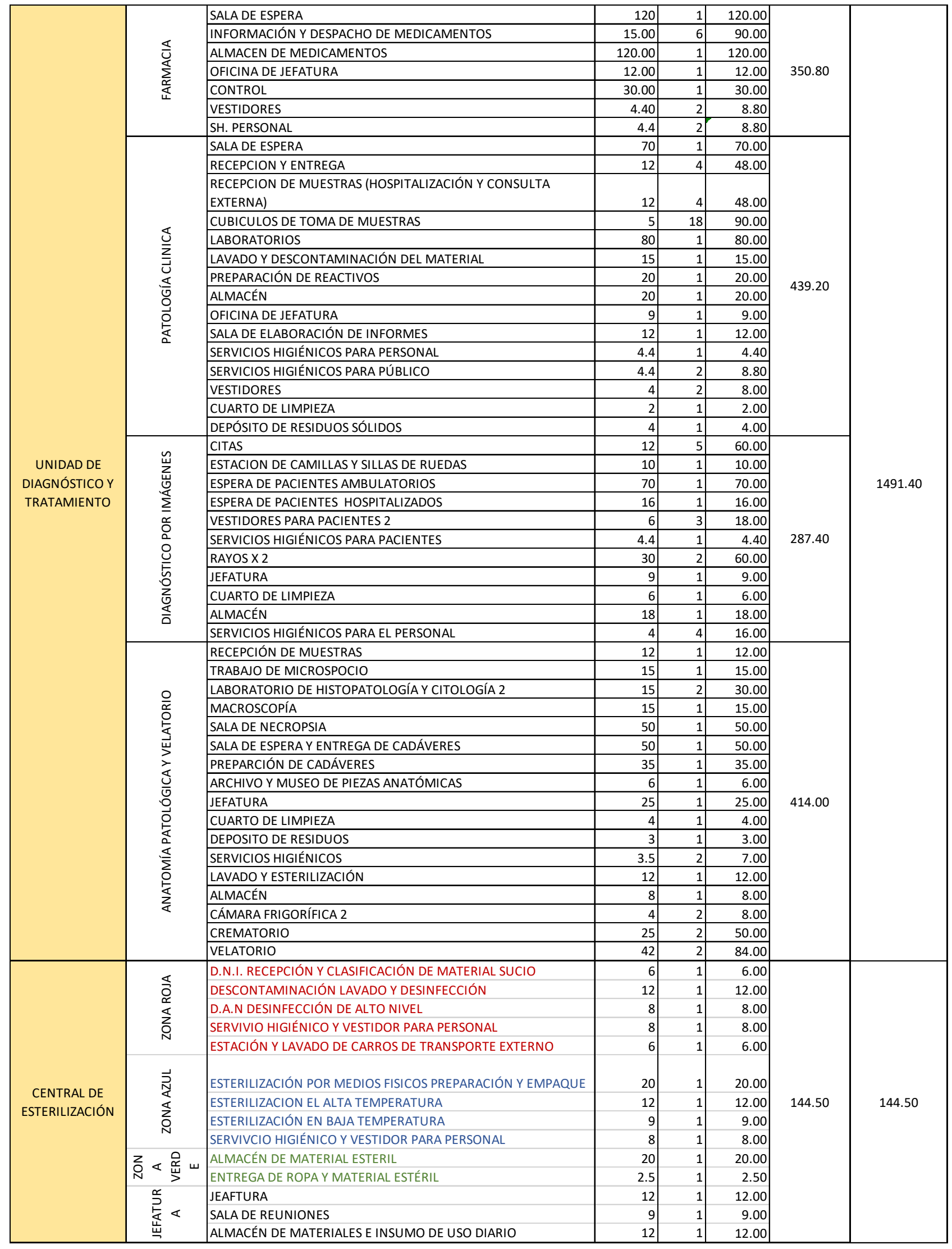




\begin{tabular}{|c|c|c|c|c|c|c|c|}
\hline \multirow{50}{*}{ EMERGENCIA } & & HALL & 30 & 1 & 30.00 & \multirow{17}{*}{171.20} & \multirow{50}{*}{958.20} \\
\hline & & ADMISION (CONTROL,CAJA INFORME) & 4 & 1 & 4.00 & & \\
\hline & & CAJA & 4 & 1 & 4.00 & & \\
\hline & & SERVICIO SOCIAL & 12 & 1 & 12.00 & & \\
\hline & & SEGURO & 12 & 1 & 12.00 & & \\
\hline & & REFERENCIA Y CONTRAREFERENCIA & 12 & 1 & 12.00 & & \\
\hline & & ESPERA FAMILIARES & 90 & & 0.00 & & \\
\hline & & ENTREVISTA FAMILIARES & 12 & 1 & 12.00 & & \\
\hline & & JEFATURA & 12 & 1 & 12.00 & & \\
\hline & & SECRETARÍA & 12 & 1 & 12.00 & & \\
\hline & & COORDINACIÓN DE ENFEREMERÍA & 12 & 1 & 12.00 & & \\
\hline & & SALA DE TRABAJO & 12 & 1 & 12.00 & & \\
\hline & & SS..HH. PÚBLICO HOMBRES & 4.4 & 1 & 4.40 & & \\
\hline & & SS.HH. PÚBLICO MUJERES & 4.4 & 1 & 4.40 & & \\
\hline & & SS.HH. PÚBLICO DISCAPACITADOS & 4.4 & 1 & 4.40 & & \\
\hline & & AMBIENTE PARA POLICÍA NACIONAL & 12 & 1 & 12.00 & & \\
\hline & & ESPACIO DE CAMILLAS Y SILLAS DE RUEDAS & 12 & 1 & 12.00 & & \\
\hline & \multirow{25}{*}{ 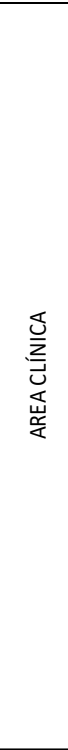 } & TRIAJE & 25 & 3 & 75.00 & \multirow{25}{*}{650.00} & \\
\hline & & SALA DE ESPERA PARA REEVALUACIÓN DE PACIENTES & 70 & 3 & 210.00 & & \\
\hline & & LABORTORIO DESCENTRALIZADO DE PATOLOGÍA CLÍNICA & 20 & 1 & 20.00 & & \\
\hline & & SS.HH. HOM - PACIENTES & 5 & 1 & 5.00 & & \\
\hline & & SS. HH. MUJ - PACIENTES & 5 & 1 & 5.00 & & \\
\hline & & ESTACIÓN DE ENFERMERÍA & 20 & 1 & 20.00 & & \\
\hline & & TRABAJO SUCIO & 8 & 1 & 8.00 & & \\
\hline & & ALMACÉN PARA EQUIPO DE RAYOS X RODABLE & 6 & 1 & 6.00 & & \\
\hline & & REHIDRATACIÓN PEDIÁTRICA & 15 & 1 & 15 & & \\
\hline & & BAÑO DE ARTESA & 4 & 1 & 4.00 & & \\
\hline & & TÓPICO DE INYECTABLES Y NEBULIZACIONES & 18 & 1 & 18.00 & & \\
\hline & & TÓPICO DE MEDICINA INTERNA & 16 & 1 & 16.00 & & \\
\hline & & TÓPICO DE PEDIATRÍA & 16 & 1 & 16.00 & & \\
\hline & & TÓPICO DE NEONATOLOGÍA & 12 & 1 & 12.00 & & \\
\hline & & SALA DE REHIDRATACIÓN & 16 & 1 & 16.00 & & \\
\hline & & TÓPICO DE GINECO-OBSTETRA & 18 & 1 & 18.00 & & \\
\hline & & TÓPICO DE CIRGUÍA GENERAL & 16 & 1 & 16.00 & & \\
\hline & & TÓPICO DE TRUMATOLOGÍA & 22 & 1 & 22.00 & & \\
\hline & & TÓPICO DE YESOS & 16 & 1 & 16.00 & & \\
\hline & & SALA DE OBSERVACIÓN ADULTOS VARONES & 18 & 1 & 18.00 & & \\
\hline & & SALA DE OBSERVACIÓN ADULTOS MUJERES & 18 & 1 & 18.00 & & \\
\hline & & SALA DE OBSERVACION NIÑOS & 16 & 1 & 16.00 & & \\
\hline & & SALA DE OBSERVACIOÓN AISLADOS & 18 & 1 & 18.00 & & \\
\hline & & VIGILANCIA INTENSIVA & 22 & 1 & 22.00 & & \\
\hline & & TRAUMA SHOCK Y REANIMACIÓN & 20 & 2 & 40.00 & & \\
\hline & \multirow{8}{*}{$\frac{\widetilde{O}}{\text { 总 }}$} & ESTAR MÉDICO Y DE ENFERMERAS & 9 & 1 & 9.00 & & \\
\hline & & ALMACÉN DE EQUIPOS & 30 & 1 & 30.00 & & \\
\hline & & ROPA LIMPIA & 8 & 1 & 8.00 & & \\
\hline & & CUARTO DE LIMPIEZA & 4 & 1 & 4.00 & & \\
\hline & & CUARTO ROPA SUCIA & 4 & 1 & 4.00 & 137.00 & \\
\hline & & CUARTO SEPTICO LAVA CHATAS & 8 & 1 & 8.00 & & \\
\hline & & SERVICIOS HIGIÉNICOS PARA PERSONAL & 3.5 & 4 & 14.00 & & \\
\hline & & ESTACIONAMIENTO DE AMBULANCIAS & 15 & 4 & 60.00 & & \\
\hline & & RECEPCIÓN Y CONTROL & 10 & 1 & 10.00 & & \\
\hline & & ESPERA FAMILIARES & 40 & 1 & 40.00 & & \\
\hline & & ESTACION PARA CAMILLAS Y SILLAS DE RUEDAS & 10 & 1 & 10.00 & & \\
\hline & & SALA DE EVALUACION Y PREPARACIÓN DE PACIENTES & 12 & 6 & 72.00 & & \\
\hline & & SALA DE DILATACIÓN & 12 & 6 & 72.00 & & \\
\hline & & SALA DE EXPULSIÓN (SALA DE PARTO)2 & 35 & 1 & 35.00 & & \\
\hline & & SALA DE CIRUGÍA OBSTÉTRICA & 35 & 1 & 35.00 & & \\
\hline & & \begin{tabular}{|l|} 
SALA DE LEGRADO \\
\end{tabular} & 35 & 1 & 35.00 & & \\
\hline & & SALA DE RECUPERACIÓN POST PARTO 2 CAMAS POR SALA DE EXPUI & 15 & 6 & 90.00 & & \\
\hline & 吕 & \begin{tabular}{|l|} 
SALA DE ATENCIÓN AL RECIÉN NACIDO \\
\end{tabular} & 25 & 2 & 50.00 & & \\
\hline & $\stackrel{\mathrm{b}}{\mathrm{n}}$ & DEPÓSITO DE MATERIAL ESTÉRIL & 8 & 3 & 24.00 & & \\
\hline & Ø̋ & TRABAJO DE ENFERMERAS & 7.2 & 1 & 7.20 & & \\
\hline UNIDAD DE & ò่ & LIMPIEZA INSTRUMENTAL & 12 & 1 & 12.00 & 565.50 & \\
\hline CENTRO & 岂 & CUARTO DE LIMPIEZAA & 4 & 1 & 4.00 & & \\
\hline OBSTÉTRICO Y & ভ & CUARTO SEPTICO LAVA CHATAS & 8 & 1 & 8.00 & & $624 . \%$ \\
\hline NEONATOLOGÍA & & VESTUARIOS MÉDICOS & 2 & 6 & 12.00 & & \\
\hline & & \begin{tabular}{|l} 
VESTUARIO ACOMPAÑANTE \\
\end{tabular} & 2 & 1 & 2.00 & & \\
\hline & & SS.HH MEDICOS & 2.2 & 3 & 6.60 & & \\
\hline & & SALA DE JUNTAS & 12 & 1 & 12.00 & & \\
\hline & & ESTACION DE ENFERMERAS & 7.2 & 1 & 7.20 & & \\
\hline & & ROPA LIMPIA & 8 & 1 & 8.00 & & \\
\hline & & DEPÓSITO DE RESIDUOS SOLIDOS & 3 & 1 & 3.00 & & \\
\hline & & SERVICIOS HIGIÉNICOS PARA PACIENTE & 3.5 & 2 & 7.00 & & \\
\hline & & SERVICIOS HIGIÉNICOS PARA VISITAS & 3.5 & 1 & 3.50 & & \\
\hline & & AISLAMIENTO NEONATO & 6 & 4 & 24.00 & & \\
\hline & $\overrightarrow{\frac{o}{2}} \leq$ & ESTACION DE ENFERMERÍA & 7.2 & 1 & 7.20 & 59.20 & \\
\hline & o & BAÑO DE ARTESA & 4 & 1 & 4.00 & 39.20 & \\
\hline & 岁 & CUNERO & 6 & 4 & 24.00 & & \\
\hline
\end{tabular}




\begin{tabular}{|c|c|c|c|c|c|c|c|}
\hline \multirow{19}{*}{$\begin{array}{l}\text { UNIDAD DE } \\
\text { CENTRO } \\
\text { QUIRÚRGICO }\end{array}$} & \multirow{4}{*}{ 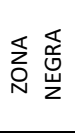 } & ESPERA & 20 & 1 & 20.00 & \multirow{4}{*}{49.40} & \multirow{19}{*}{515.00} \\
\hline & & RECEPCIÓN Y CONTROL & 10 & 1 & 10.00 & & \\
\hline & & JEFATURA DE PERSONAL (OFICINA DE PERSONAL) & 15 & 1 & 15.00 & & \\
\hline & & CAMBIO DE CAMILLA & 4.4 & 1 & 4.40 & & \\
\hline & \multirow{9}{*}{ 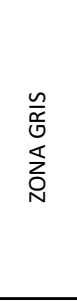 } & CONTROL DE OPERACIONES & 10 & 1 & 10.00 & \multirow{9}{*}{228.60} & \\
\hline & & RECUPERACIÓN 5 & 15 & 6 & 90.00 & & \\
\hline & & TALLER DE ANESTECIA & 15 & 3 & 45.00 & & \\
\hline & & PRE LAVADO DE INSTRUMENTOS & 15 & 1 & 15.00 & & \\
\hline & & CUARTO DE LIMPIEZA & 15 & 1 & 15.00 & & \\
\hline & & CUARTO SÉPTICO (ROPA SUCIA Y LAVA CHATAS) & 8 & 1 & 8.00 & & \\
\hline & & VESTUARIOS DE MÉDICOS Y SERVICIOS HIGIÉNICOS & 4.4 & 3 & 13.20 & & \\
\hline & & VESTUARIOS DE ENFERMERAS Y SERVICIOS HIGIÉNICOS & 4.4 & 6 & 26.40 & & \\
\hline & & CAMBIO DE BOTAS & 2 & 3 & 6.00 & & \\
\hline & \multirow{6}{*}{ 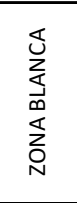 } & LAVABOS DE CIRUJANOS & 2 & 3 & 6.00 & \multirow{6}{*}{237.00} & \\
\hline & & SALA DE OPERACIONES 5 & 40 & 3 & 120.00 & & \\
\hline & & TRANSFER DE CAMILLAS & 15 & 3 & 45.00 & & \\
\hline & & RAYOS X PORTÁTIL & 6 & 3 & 18.00 & & \\
\hline & & DEPÓSITO DE MATERIAL ESTÉRIL & 8 & 3 & 24.00 & & \\
\hline & & DEPÓSITO DE EQUIPOS & 8 & 3 & 24.00 & & \\
\hline \multirow{26}{*}{$\begin{array}{l}\text { UNIDAD DE } \\
\text { CUIDADOS } \\
\text { INTENSIVOS }\end{array}$} & \multirow{6}{*}{ 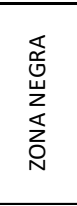 } & ESPERA Y SECRETARIA & 70 & 2 & 140.00 & \multirow{6}{*}{310.00} & \multirow{26}{*}{1511.08} \\
\hline & & RECEPCIÓN Y CONTROL & 10 & 2 & 20.00 & & \\
\hline & & JEFATURA & 20 & 2 & 40.00 & & \\
\hline & & SALA DE JUNTAS & 20 & 2 & 40.00 & & \\
\hline & & COORDINACIÓN DE ENFERMERÍA & 20 & 2 & 40.00 & & \\
\hline & & CUARTO TÉCNICO & 10 & 3 & 30.00 & & \\
\hline & \multirow{14}{*}{ 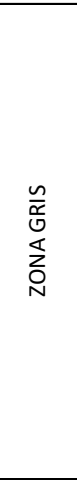 } & ALMACÉN ROPA ESTÉRIL & 20 & 2 & 40.00 & \multirow{14}{*}{288.08} & \\
\hline & & VESTUARIO Y SERVICIOS HIGIÉNICOS PARA MÉDICOS & 4.84 & 8 & 38.72 & & \\
\hline & & VESTUARIO Y SERVICIOS HIGIÉNICOS PARA ENFERMERAS & 4.84 & 4 & 19.36 & & \\
\hline & & ESTAR PERSONAL & 15 & 2 & 30.00 & & \\
\hline & & CUARTO SÉPTICO (ROPA SUCIA Y LAVA CHATAS) & 8 & 2 & 16.00 & & \\
\hline & & TRABAJO SUCIO & 4 & 2 & 8.00 & & \\
\hline & & DEPÓSITO ROPA SUCIA & 4 & 2 & 8.00 & & \\
\hline & & RX RODABLE & 4 & 2 & 8.00 & & \\
\hline & & LACTARIO & 8 & 1 & 8.00 & & \\
\hline & & C. ESTERILIZACIÓN & 40 & 1 & 40.00 & & \\
\hline & & ALMACÉN INTERMEDIO DE RESIDUOS SÓLIDOS & 4 & 2 & 8.00 & & \\
\hline & & CAMBIO DE BOTAS & 4 & 4 & 16.00 & & \\
\hline & & TRANSFER DE CAMILLAS & 20 & 2 & 40.00 & & \\
\hline & & CUARTO DE LIMPIEZA & 4 & 2 & 8.00 & & \\
\hline & \multirow{6}{*}{ 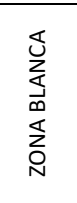 } & ESTACION DE ENFERMERAS (CENTRAL MONITOREO) & 12 & 14 & 168.00 & \multirow{6}{*}{913.00} & \\
\hline & & ALMACÉN DE EQUIPOS & 8 & 2 & 16.00 & & \\
\hline & & ALMACÉN DE MEDICAMENTOS & 8 & 2 & 16.00 & & \\
\hline & & CUIDADOS INTENSIVOS & 16 & 11 & 176.00 & & \\
\hline & & CUIDADOS INTERMEDIOS & 16 & 33 & 528.00 & & \\
\hline & & RECEPCIÓN DE PACIENTES & 9 & 1 & 9.00 & & \\
\hline
\end{tabular}




\begin{tabular}{|c|c|c|c|c|c|c|c|}
\hline \multirow{29}{*}{$\begin{array}{c}\text { UNIDAD DE } \\
\text { HOSPITALIZACIÓN }\end{array}$} & \multirow{10}{*}{ 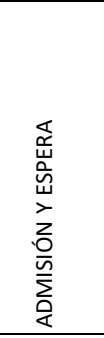 } & ESPERA & 200 & 1 & 200.00 & \multirow{10}{*}{460.00} & \multirow{29}{*}{3724.26} \\
\hline & & ADMISION HOSPITALARIA & 8 & 3 & 24.00 & & \\
\hline & & ESPERA INTERNA PARA ADMISION Y ALTAS & 8 & 1 & 8.00 & & \\
\hline & & OFICINA SIS & 8 & 2 & 16.00 & & \\
\hline & & OFICINA TRABAJO SOCIAL & 8 & 2 & 16.00 & & \\
\hline & & CUBICULO ENTREVISTAS & 8 & 2 & 16.00 & & \\
\hline & & JEFATURA DE HOSPITALIZACION & 12 & 4 & 48.00 & & \\
\hline & & SECRETARÍA & 12 & 1 & 12.00 & & \\
\hline & & ESTAR MÉDICO & 12 & 5 & 60.00 & & \\
\hline & & SALA DE JUNTAS & 15 & 4 & 60.00 & & \\
\hline & \multirow{10}{*}{ 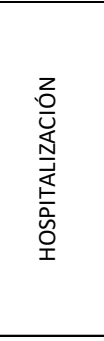 } & ESTACIÓN DE CAMILLAS & 5 & 4 & 20.00 & \multirow{10}{*}{2892.26} & \\
\hline & & ESTAR DE VISITAS Y PACIENTE & 320 & 1 & 320.00 & & \\
\hline & & ESTACIÓN DE ENFERMERAS & 30 & 5 & 150.00 & & \\
\hline & & SALA D EJUEGOS PARA NIÑOS & 200 & 1 & 200.00 & & \\
\hline & & LACTARIO & 6 & 1 & 6.00 & & \\
\hline & & TÓPICO & 30 & 4 & 120.00 & & \\
\hline & & HABITACIONES PEDIÁTRICAS & 480 & 1 & 479.69 & & \\
\hline & & HABITACIONES DE CIRUGÍA & 500 & 1 & 499.61 & & \\
\hline & & HABITACIONES DE GINECOLOGÍA & 543 & 1 & 543.05 & & \\
\hline & & HABITACIONES DE MEDICINA INTERNA & 554 & 1 & 553.91 & & \\
\hline & \multirow{9}{*}{$\frac{\widetilde{O}}{\text { 总 }}$} & REPOSTERO & 8 & 5 & 40.00 & \multirow{9}{*}{372.00} & \\
\hline & & TRABAJO DE ENFERMERIA ( SUCIO) & 4 & 5 & 20.00 & & \\
\hline & & ROPA LIMPIA & 4 & 5 & 20.00 & & \\
\hline & & CUARTO DE LIMPIEZA & 4 & 5 & 20.00 & & \\
\hline & & CUARTO SÉPTICO (ROPA SUCIA Y LAVA CHATAS) & 6 & 5 & 30.00 & & \\
\hline & & ROPA SUCIA & 4 & 5 & 20.00 & & \\
\hline & & SERVICIOS HIGIÉNICOS PARA PERSONAL (HOMBRES - MUJERES) CO & 3.5 & 26 & 91.00 & & \\
\hline & & SERVICIOS HIGIÉNICOS PARA VISITAS & 3.5 & 26 & 91.00 & & \\
\hline & & DEPÓSITO & 8 & 5 & 40.00 & & \\
\hline \multirow{7}{*}{$\begin{array}{l}\text { UNIDAD DE } \\
\text { CONFORT } \\
\text { PERSONAL }\end{array}$} & \multirow{3}{*}{ 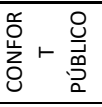 } & SALA SUM & 91 & 1 & 90.51 & \multirow{3}{*}{168.34} & \multirow{7}{*}{513.15} \\
\hline & & CAFETERÍA & 78 & 1 & 77.83 & & \\
\hline & & SH. VISITAS & 3.5 & & 0.00 & & \\
\hline & \multirow{4}{*}{ 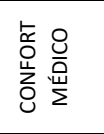 } & ESTAR MÉDICO & 13.3 & 1 & 13.30 & \multirow{4}{*}{344.81} & \\
\hline & & COMEDOR PERSONAL & 271 & 1 & 270.51 & & \\
\hline & & HABITACIONES & 18 & 3 & 54.00 & & \\
\hline & & SH. PERSONAL & 3.5 & 2 & 7.00 & & \\
\hline
\end{tabular}




\begin{tabular}{|c|c|c|c|c|c|c|c|}
\hline & \multirow{3}{*}{$\begin{array}{l}\text { 己. } \\
\text { 岕 } \\
\text { 峞 }\end{array}$} & HALL DE INGRESO & 10 & 1 & 10.00 & \multirow{3}{*}{454.43} & \\
\hline & & COMEDOR PERSONAL & 348.43 & 1 & 348.43 & & \\
\hline & & VESTUARIO Y SERVICIOS HIGIÉNICOS & 8 & 12 & 96.00 & & \\
\hline & \multirow{25}{*}{ 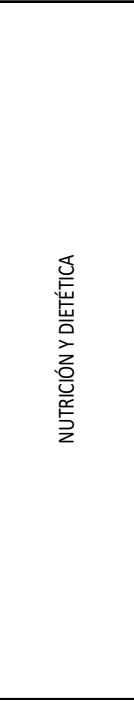 } & PREPARACIÓN DE ALIMENTOS & 24 & 1 & 24.00 & & \\
\hline & & CENTRAL DE DISTRIBUCIÓN & 12 & 1 & 12.00 & & \\
\hline & & PREPARACIÓN DE FÓRMULAS & 15 & 1 & 15.00 & & \\
\hline & & SANITIZADO DE ENVASES & 6 & 1 & 6.00 & & \\
\hline & & ENVASADO Y REFRIGERACIÓN & 6 & 1 & 6.00 & & \\
\hline & & ESTERILIZACCIÓN Y DISTRIBUCIÓN & 9 & 1 & 9.00 & & \\
\hline & & CARGA Y DESCARGA DE SUMINISTROS & 10 & 1 & 10.00 & & \\
\hline & & CONTROL DE SUMINISTROS & 8 & 1 & 8.00 & & \\
\hline & & VESTÍ́BULO & 6 & 1 & 6.00 & & \\
\hline & & ALMACÉN DE PRODUCTOS PERECIBLES & 4 & 1 & 4.00 & & \\
\hline & & ALMACÉN DE PRODUCTOS NO PERECIBLES & 4 & 1 & 4.00 & & \\
\hline & & ALMACCÉN DIFERENCIADO PARA TUBÉRCULOS & 4 & 1 & 4.00 & & \\
\hline & & LAVADO Y ALMACÉN DE VAJILLAS Y MENJAE & 7.5 & 1 & 7.50 & 177.50 & \\
\hline & & ANTECÁMARA & 6 & 1 & 6.00 & & \\
\hline & & PRDOUCTOS LÁCCTEOS & 3 & 1 & 3.00 & & \\
\hline & & PRODUCTOS CÁRNICOS & 3 & 1 & 3.00 & & \\
\hline & & PESCADOS & 3. & 1 & 3.00 & & \\
\hline & & FRUTAS, VERDURAS Y HORTALIZAS & 3 & 1 & 3.00 & & \\
\hline & & PRODUCTOS CONGELADOS & 3. & 1 & 3.00 & & \\
\hline & & JEFATURA & 9 & 1 & 9.00 & & \\
\hline & & SECRETARÍA & 8 & 1 & 8.00 & & \\
\hline & & SS.HH. Y VETSIDORES HOMBRE & 8 & 1 & 8.00 & & \\
\hline & & SS.HH. Y VESTIDORES MUJER & 7 & 1 & 7.00 & & \\
\hline & & CUARTO DE LIMPIEZA & 5 & 1 & 5.00 & & \\
\hline & & ALMACÉN INTERMEDIO DE RESIDUOS SÓLIDOS & 4 & 1 & 4.00 & & \\
\hline & & JEFATURA 1 & 9 & 1 & 9.00 & & \\
\hline & & JEFATURA 2 & 9 & 1 & 9.00 & & \\
\hline & & SS.HH. & 3 & 1 & 3.00 & & \\
\hline & & PATIO DE MANIOBRAS & 30 & 1 & 30.00 & & \\
\hline & 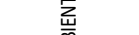 & RECEPCIÓN PESADO Y REGISTRO & 10 & 1 & 10.00 & & \\
\hline & $\overline{\bar{m}}$ & ALMACENAMIENTO Y PRETRATAMIENTO POR TIPO DE RESIDUO & 15 & 1 & 15.00 & 13750 & \\
\hline & 至 & LAVADO DE COCHES DE TRANSPORTE & 5 & 1 & 5.00 & סכ. & \\
\hline & 岂 & ZONA DE TRATAMIENTO & 24 & 1 & 24.00 & & \\
\hline & & ALMACÉN POST TRATAMIENTO DE RESIDUOS SÓLIDOS & 18 & 1 & 18.00 & & \\
\hline & & CUARTO DE LIMPIEZA & 4 & 1 & 4.00 & & \\
\hline & & CUARTO DE HERRAMIENTAS & 3 & 1 & 3.00 & & \\
\hline & & SS.HH. Y VESTIDOR PERSONAL & 7.5 & 1 & 7.50 & & \\
\hline UNIDAD DE & & JEFATURA & 15 & 1 & 15.00 & & \\
\hline SERVICIOS & 崫点 & INFRAESTRUCTURA & 60 & 1 & 60.00 & & 2280.93 \\
\hline GENERALES & 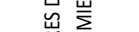 & EQUIPOS BIOMÉDICOS & 100 & 1 & 100.00 & & \\
\hline & 密密 & EQUIPOS ELECTROMECÁNICOS & 60 & 1 & 60.00 & 264.00 & \\
\hline & $\vec{E}$ & SS.HH. Y VESTIDORES MUJERES & 13 & 1 & 13.00 & & \\
\hline & & SS.HH. Y VESTIDORES HOMBRES & 12 & 1 & 12.00 & & \\
\hline & & CUARTO DE LIMPIEZA & 4 & 1 & 4.00 & & \\
\hline & & RECEPCIÓN Y SELECCIÓN DE ROPA SUCIA & 10 & 1 & 10.00 & & \\
\hline & & ENTREGA DE ROPA LIMPIA & 30 & 1 & 30.00 & & \\
\hline & & CLASIFICACIÓN DE LA ROPA SUCIA & 20 & 1 & 20.00 & & \\
\hline & & ALMACÉN DE INSUMOS & 6 & 1 & 6.00 & & \\
\hline & 岦 & LAVADO DE ROPA & 50 & 1 & 50.00 & & \\
\hline & $\sum_{<}$ & LAVADO DE COCHES DE TRANSPORTE & 20 & 1 & 20.00 & 328.00 & \\
\hline & 亲 & SERVICIO HIGIENICO Y VESTIDOR DE PERSONAL & 6 & 2 & 12.00 & & \\
\hline & & SECADO Y PLANCHADO & 90 & 1 & 90.00 & & \\
\hline & & COSTURA Y REPARACION DE ROPA LIMPIA & 20 & 1 & 20.00 & & \\
\hline & & ALMACÉN DE ROPA LIMPIA & 60 & 1 & 60.00 & & \\
\hline & & ESTACIÓN DE COCHES DE TRANSPORTE & 10 & 1 & 10.00 & & \\
\hline & & ALMACÉN GENERAL & 30 & 1 & 30.00 & & \\
\hline & 嵒 & RECEPCIÓN Y DESPACHO & 100 & 1 & 100.00 & & \\
\hline & 岕 & JEFATURA & 12 & 1 & 12.00 & & \\
\hline & $z_{u}$ & ALMACÉN DE MEDICAMENTOS & 45 & 1 & 45.00 & 262.00 & \\
\hline & 岁 & ALMACÉN DE MATERIALES DE ESCRITORIO & 25 & 1 & 25.00 & & \\
\hline & $\sum_{<}$ & ALMACÉN DE MATERIALES DE LIMPIEZA & 25 & 1 & 25.00 & & \\
\hline & & DEPÓSITO PARA EQUIPOS Y/O MOBILIARIO DE BAJA & 25 & 1 & 25.00 & & \\
\hline & & CENTRAL DE OÓXIDO NITROSO & 25 & 1 & 25.00 & & \\
\hline & 岂 & CENTRAL DE AIRE MEDICINAL & 25 & 1 & 25.00 & م010 & \\
\hline & (5) & CENTRAL DE VACÍO & 25 & 1 & 25.00 & 110.00 & \\
\hline & & CENTRAL DE OXIGENO Y AIRE MEDICINAL & 35 & 1 & 35.00 & & \\
\hline & & SUBESTACIÓN ELECTRICA & 20 & 1 & 20.00 & & \\
\hline & & SALA DE TABLEROS ELECTRICOS Y TRANSFORMADOR & 15 & 1 & 15.00 & & \\
\hline & $\frac{\mathrm{U}}{\underline{0}}$ & CUARTO TÉCNICO & 10 & 1 & 10.00 & 185.00 & \\
\hline & 鲁 & TANQUE DE PETRÓLEO & 30 & 1 & 30.00 & 103.00 & \\
\hline & 岂 & SALA DE CALDEROS & 80 & 1 & 80.00 & & \\
\hline & & GRUPO ELECTRÓGENO & 30 & 1 & 30.00 & & \\
\hline & & HALL DE INGRESO & 30 & 1 & 30.00 & & \\
\hline & 음 & OFICINA ADMINISTRATIVA & 15 & 1 & 15.00 & & \\
\hline & 崫 & SOPORTE TÉCNICO & 20 & 1 & 20.00 & & \\
\hline & $\leq$ & ÁREA CLIMATIZADDA & 30 & 1 & 30.00 & 202.50 & \\
\hline & 岁 & ÁREAS DE CÁMARAS FRÍAS & 60 & 1 & 60.00 & & \\
\hline & $\bar{U}$ & ÁREA DE CARGA Y DESCARGA & 45 & 1 & 45.00 & & \\
\hline & & SH. PERSONAL & 2.5 & 1 & 2.50 & & \\
\hline & 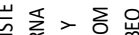 & CISTERNAS & 100 & 1 & 100.00 & & \\
\hline & 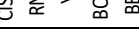 & SALA DE BOMBEO Y CALENTADORES & 60 & 1 & 60.00 & 160.00 & \\
\hline
\end{tabular}




\begin{tabular}{|c|c|c|c|c|c|c|c|}
\hline \multirow{21}{*}{$\begin{array}{c}\text { UNIDAD DE } \\
\text { ADMINISTRACIÓN }\end{array}$} & \multirow{2}{*}{$\underset{\text { 岌 }}{\vec{\Delta}}$} & HALL DE INGRESO & 10.8 & 1 & 10.80 & \multirow{2}{*}{22.80} & \multirow{21}{*}{314.80} \\
\hline & & ESPERA Y SECRETARIA & 12 & 1 & 12.00 & & \\
\hline & \multirow{4}{*}{ 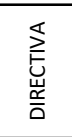 } & DIRECCIÓN CON SS.HH. & 15 & 1 & 15.00 & \multirow{4}{*}{69.00} & \\
\hline & & SALA DE REUNIONES & 15 & 1 & 15.00 & & \\
\hline & & POOL DE SECRETARIAS & 24 & 1 & 24.00 & & \\
\hline & & SUB DIRECCIÓN CON SS.HH. & 15 & 1 & 15.00 & & \\
\hline & \multirow{8}{*}{ 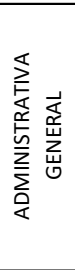 } & SALA DE REUNIONES & 15 & 1 & 15.00 & \multirow{8}{*}{109.00} & \\
\hline & & DESPACHO & 10 & 1 & 10.00 & & \\
\hline & & JEFATURA DE PERSONAL ( OFICINA DE PERSONAL & 12 & 1 & 12.00 & & \\
\hline & & OFICINA DE ENFERMERA SUPERVISORA & 9 & 1 & 9.00 & & \\
\hline & & OFICINA DE COMPRAS, PRESUPUESTO Y PLANILLA & 9 & 3 & 27.00 & & \\
\hline & & OFICINA CONTADOR & 9 & 1 & 9.00 & & \\
\hline & & OFICINA DE CONTABILIDAD Y CAJA & 9 & 2 & 18.00 & & \\
\hline & & OFICINA DE RELACIONES PÚBLICAS & 9 & 1 & 9.00 & & \\
\hline & \multirow{4}{*}{ 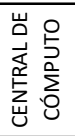 } & CENTRAL DE CÓMPUTO Y SERVIDORES & 25 & 1 & 25.00 & \multirow{4}{*}{100.00} & \\
\hline & & SALA DE UPS Y TABLEROS ELECTRICOS & 25 & 1 & 25.00 & & \\
\hline & & AIRE ACONDICIONADO A PRESIÓN & 25 & 1 & 25.00 & & \\
\hline & & ADMINISTADOR DATA CENTER & 25 & 1 & 25.00 & & \\
\hline & \multirow{3}{*}{ 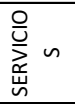 } & DEPÓSITO DE RESIDUOS SÓLIDOS & 3 & 1 & 3.00 & \multirow{3}{*}{14.00} & \\
\hline & & SERVICIOS HIGIENICOS DE PERSONAL & 3.5 & 2 & 7.00 & & \\
\hline & & CUARTO DE LIMPIEZA & 4 & 1 & 4.00 & & \\
\hline & & & & & & & 13887.58 \\
\hline & & & & & \multicolumn{2}{|c|}{$40 \%$ circulación y muros } & 5555.03 \\
\hline & & & & & & & 19442.61 \\
\hline & & ESTACIONAMIENTOS & 35 & 181 & 6335.59 & & 6335.59 \\
\hline & & & & & & & \\
\hline & & & & & ÁREA T & CHADA & 25778.20 \\
\hline
\end{tabular}

\begin{tabular}{|l|r|}
\hline CONSULTA EXTERNA & 1809.56 \\
\hline DIAGNÓSTICO POR IMÁGENES + CENTRO & 1635.90 \\
\hline EMERGENCIA & 958.20 \\
\hline CENTRO OBSTÉTRICO & 624.70 \\
\hline CENTRO QUIRÚRGICO & 515.00 \\
\hline UCI & 1511.08 \\
\hline HOSPITALIZACIÓN & 3724.00 \\
\hline CONFORT & 513.15 \\
\hline SERVICIOS & 2280.93 \\
\hline ADMINISTRACION & 314.80 \\
\hline
\end{tabular}

\begin{tabular}{|l|r|}
\hline SUB TOTAL & 13887.58 \\
\hline CIRCULACIÓN Y MUROS 40\% & 5555.03 \\
\hline ESTACIONAMIENTOS & 6335.59 \\
\hline TOTAL & $\mathbf{2 5 7 7 8 . 2 0}$ \\
\hline
\end{tabular}

\begin{tabular}{|l|r|}
\hline ÁREA DEL TERRENO & 25996.97 \\
\hline ÁREA CONSTRUIDA & 25778.2 \\
\hline ESTACIONAMIENTO TECHADO & 6335.59 \\
\hline ÁREA LIBRE & 7799 \\
\hline ÁREA DE EXPANSIÓN & 5199 \\
\hline ÁREA TECHADA PRIMER PISO & 12998.97 \\
\hline
\end{tabular}


CAPÍTULO 8 - EL PROYECTO 


\subsection{CRITERIOS DE INTERVENCIÓN}

Los criterios de intervención van desde la ubicación de los ingresos según la importancia de las vías que encierran el terreno, el asoleamiento, dirección de vientos, mitigación de ruidos, escala urbana actual y a futuro y como punto de partida la correcta ubicación de los paquetes funcionales según conectividad.

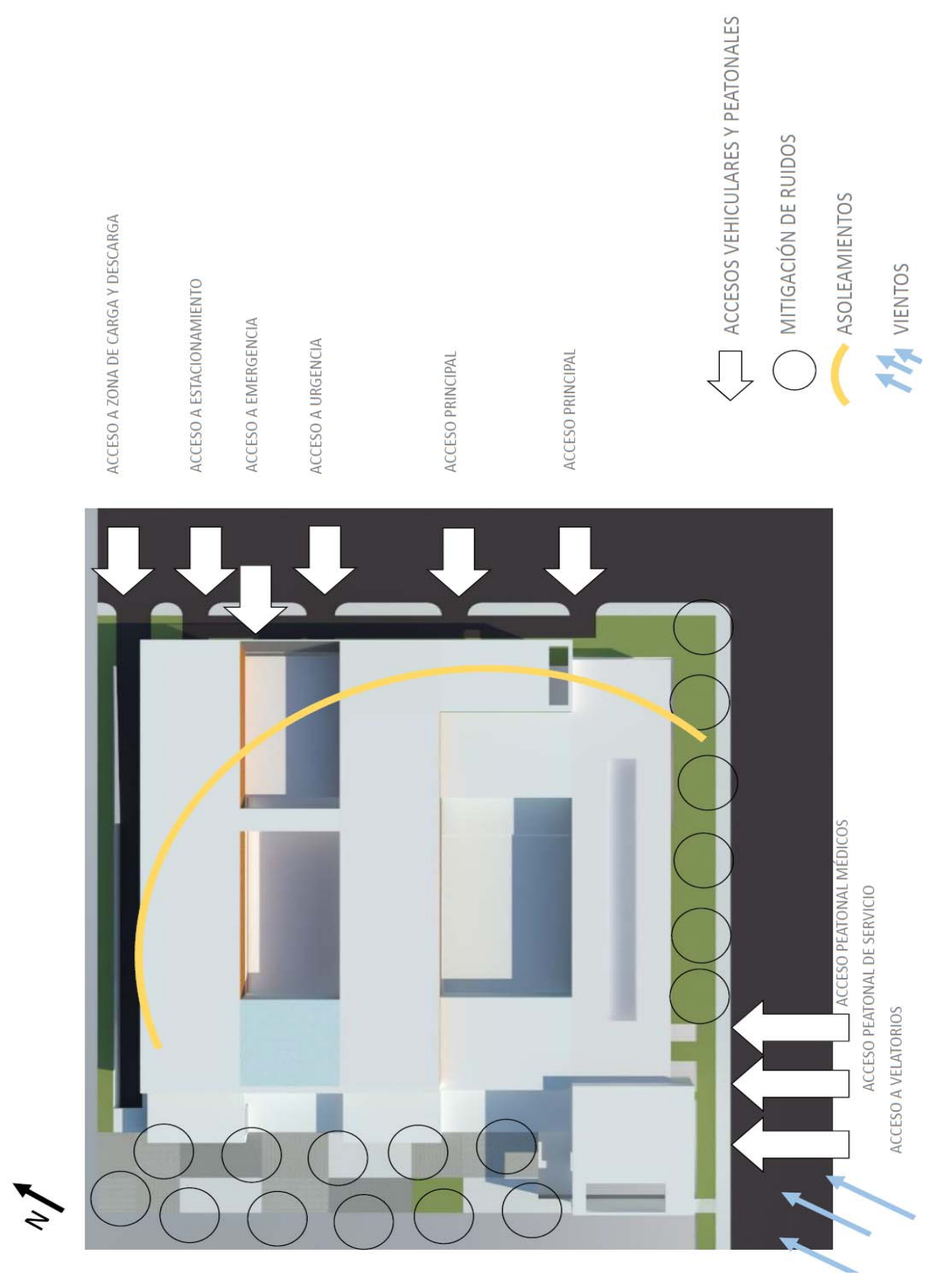




\subsection{EMPLAZAMIENTO DE PLATAFORMAS}
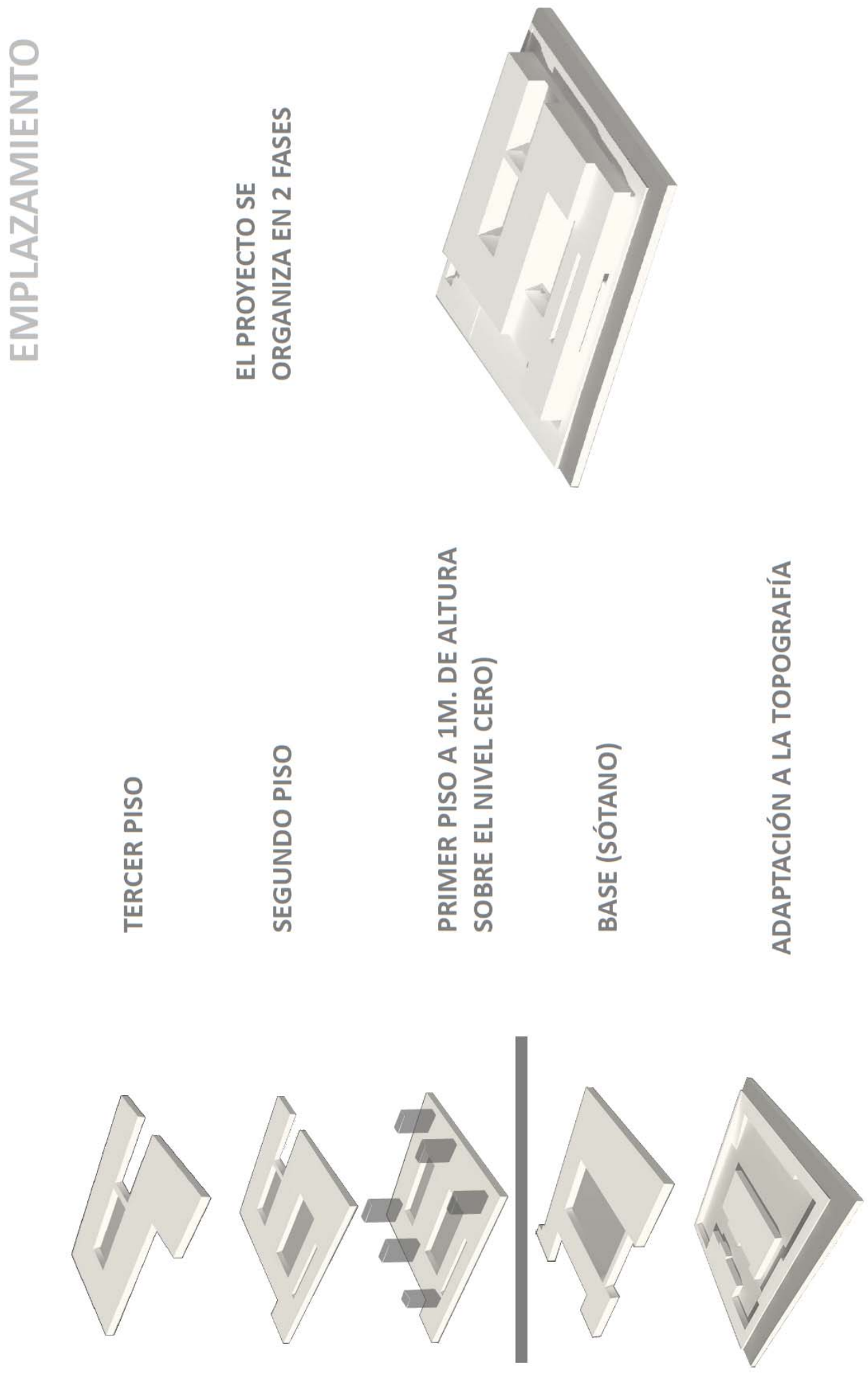


\subsection{EMPLAZAMIENTO DE PAQUETES FUNCIONALES}

Los paquetes funcionales se ubican según la necesidad de la proximidad hacia otro paquete funcional, en este caso le presento un diagrama que muestra la relación entre paquetes mediante circulaciones.

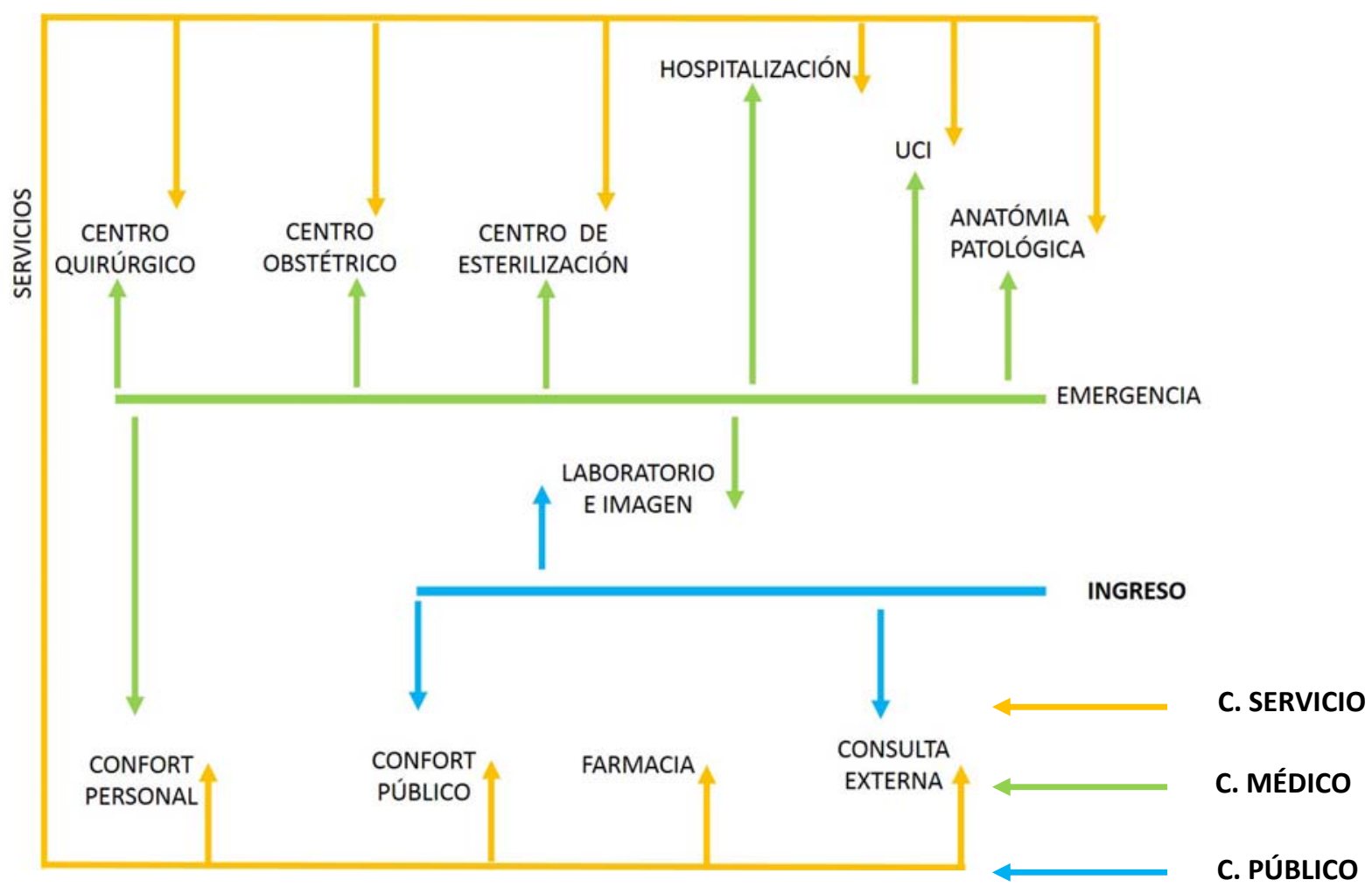

Sin embargo al plasmarlo en el terreno hay que tener en cuenta la topografía del terreno que va de $-1.00 \mathrm{a}+1.00$, con lo cual favorece a tener un primer piso $a+1.00$ el cual es una recomendación de la norma NTS 110.

La accesibilidad peatonal y vehicular es la base para poder ubicar los estacionamientos y zonas de servicios, al contar con dos avenidas como la Av. Circunvalación que es una via interprovincial y la Av. Las Flores que es una vía interdistrital.

La escala y forma responden a una relación con el contexto inmediato que son una amplia zona agrícola, vivienda y una zona de múltiples usos destinada a Universidad, Centro comercial, vivienda multifamiliar, Centro deportivo y Centro recreacional que serán edificadas a futuro.

A continuación la ubicación de los paquetes en el terreno. 


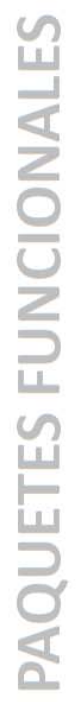

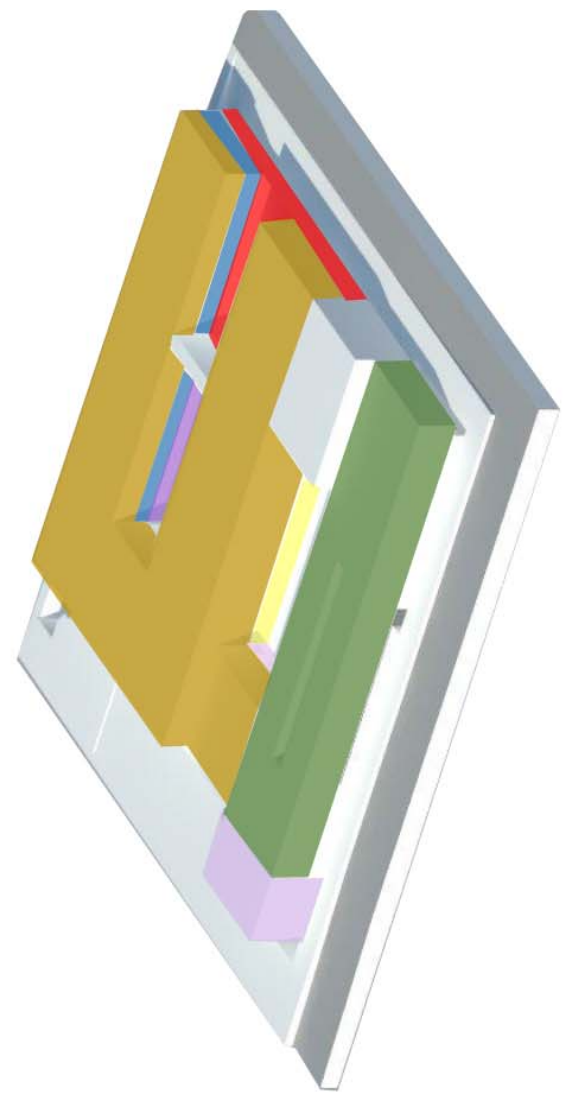

状

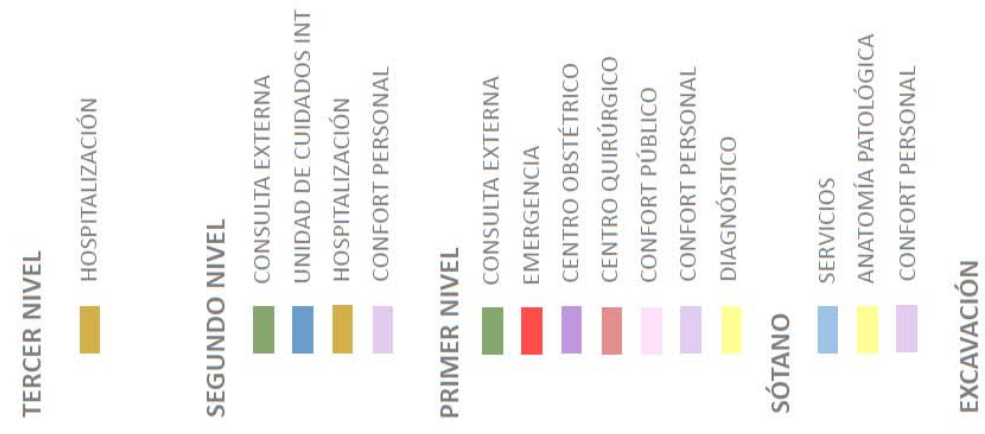

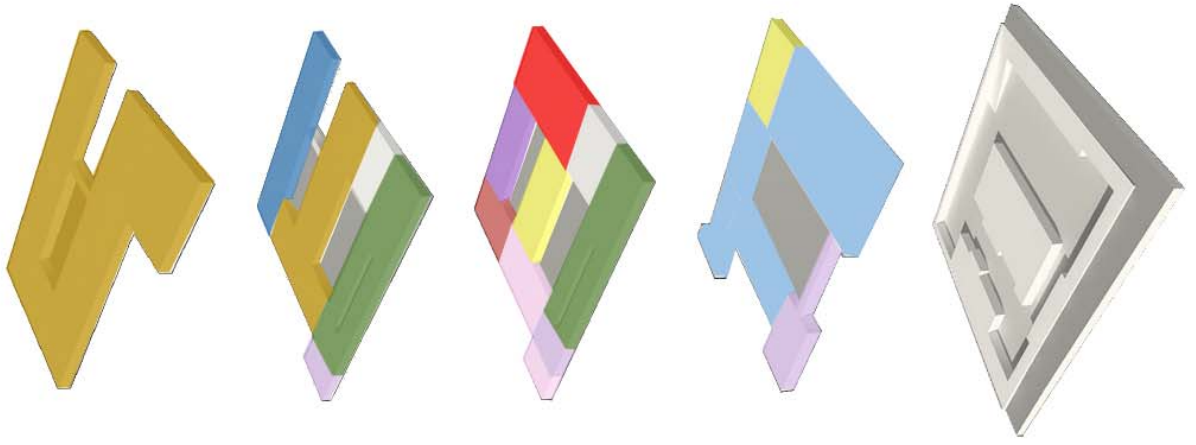




\subsection{CIRCULACIONES HORIZONTALES Y VERTICALES}

鄫
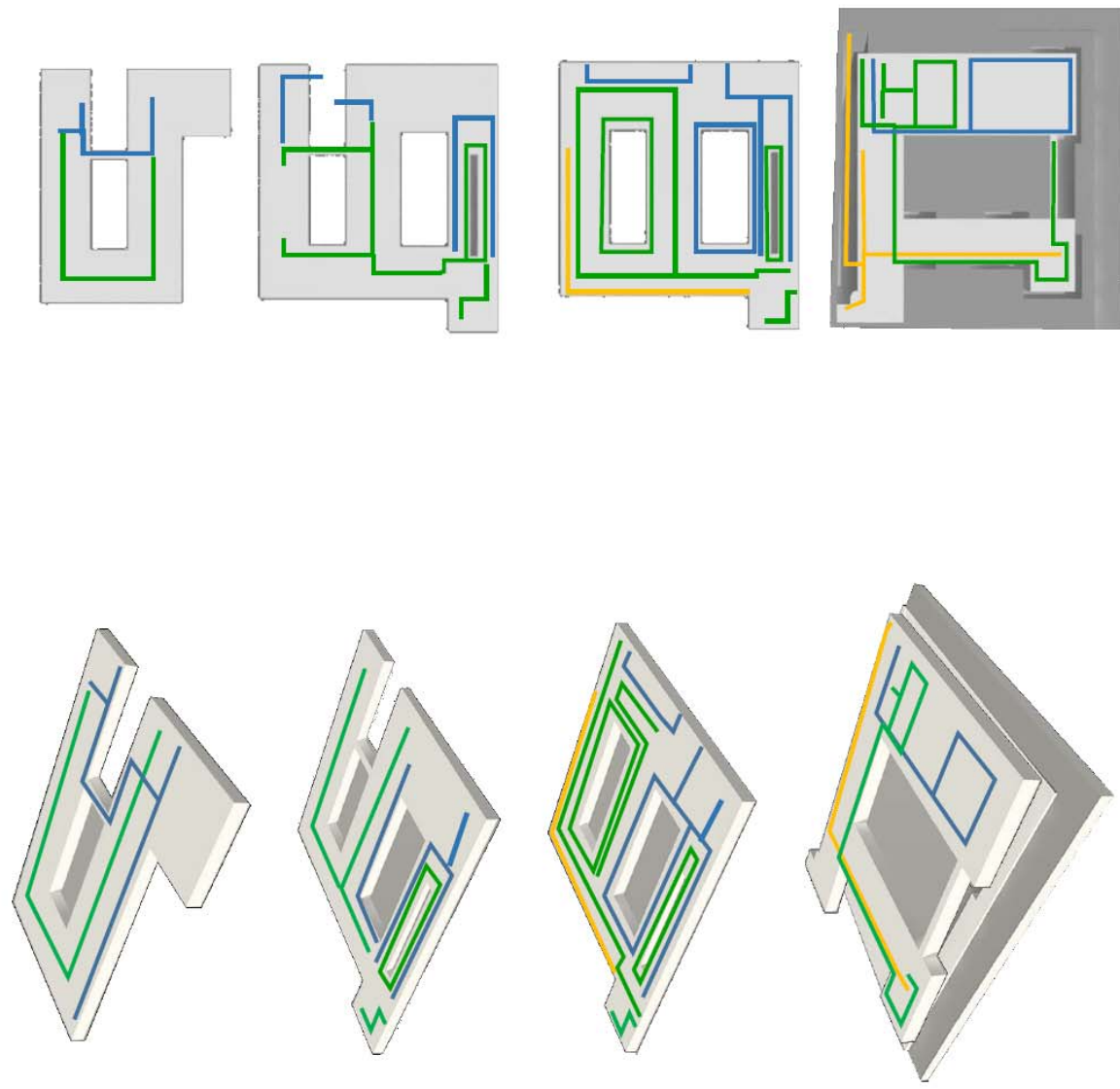

얼

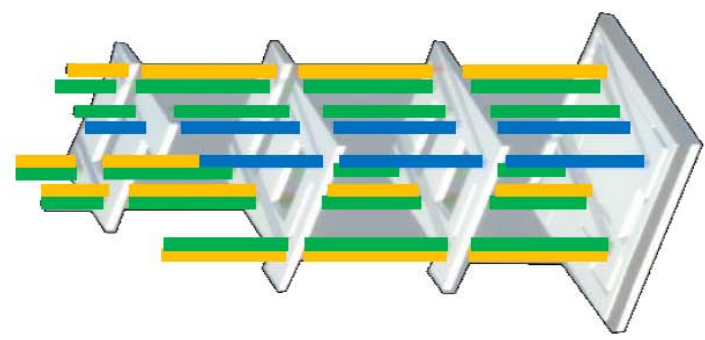




\subsection{CRITERIOS ESPACIALES}
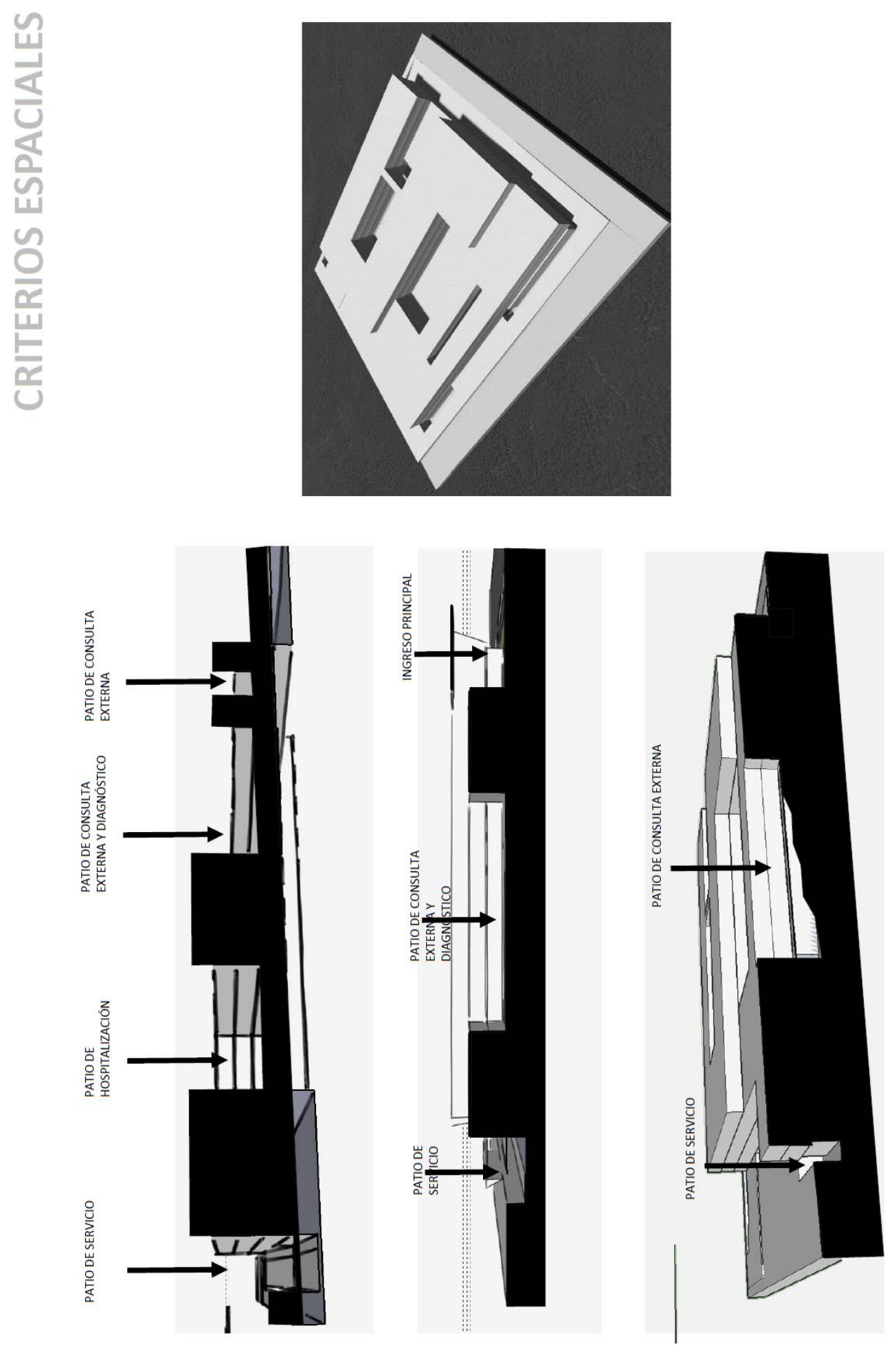


\subsection{CRITERIOS DE SELECCIÓN ESTRUCTURAL}

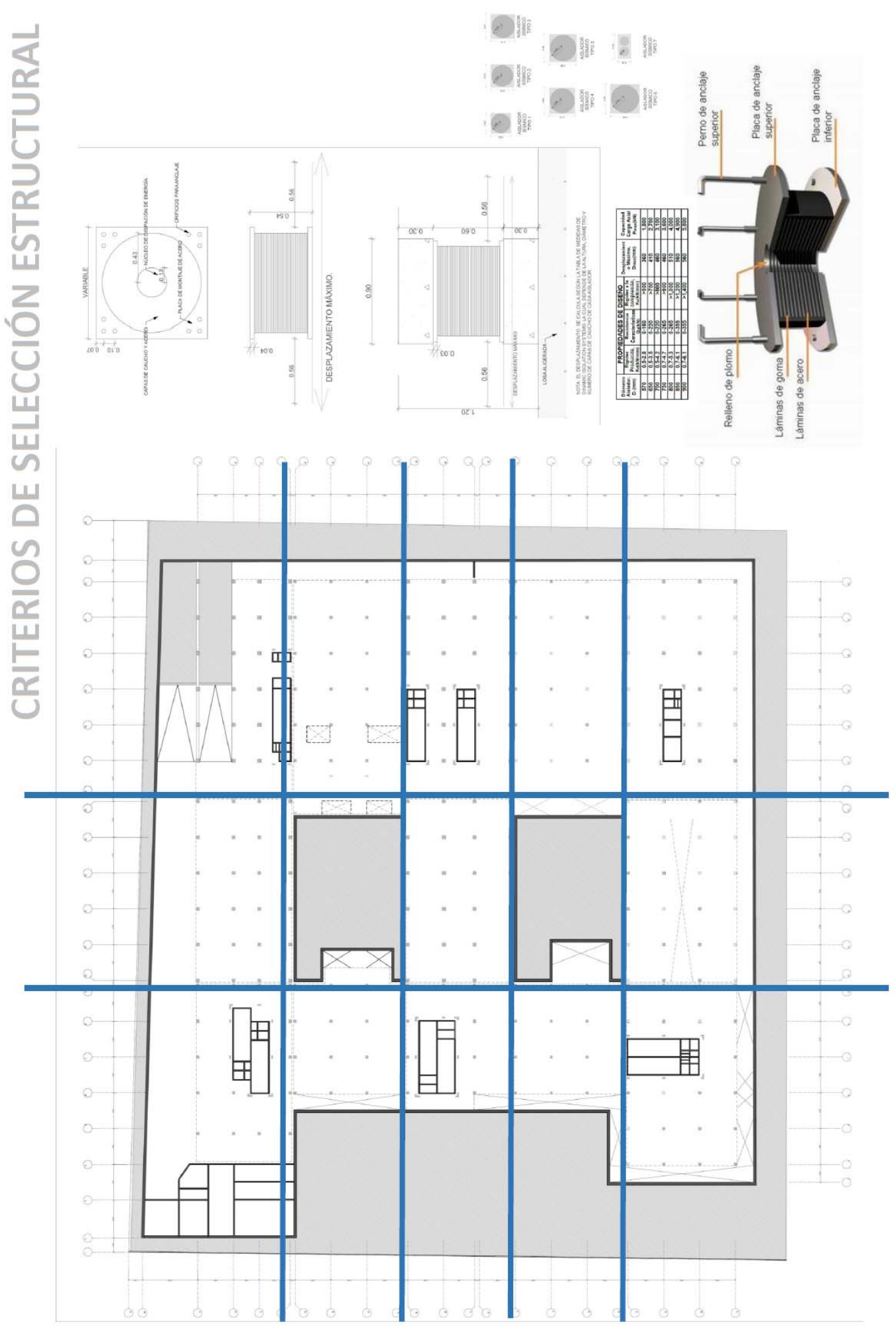




\subsection{PLANOS}

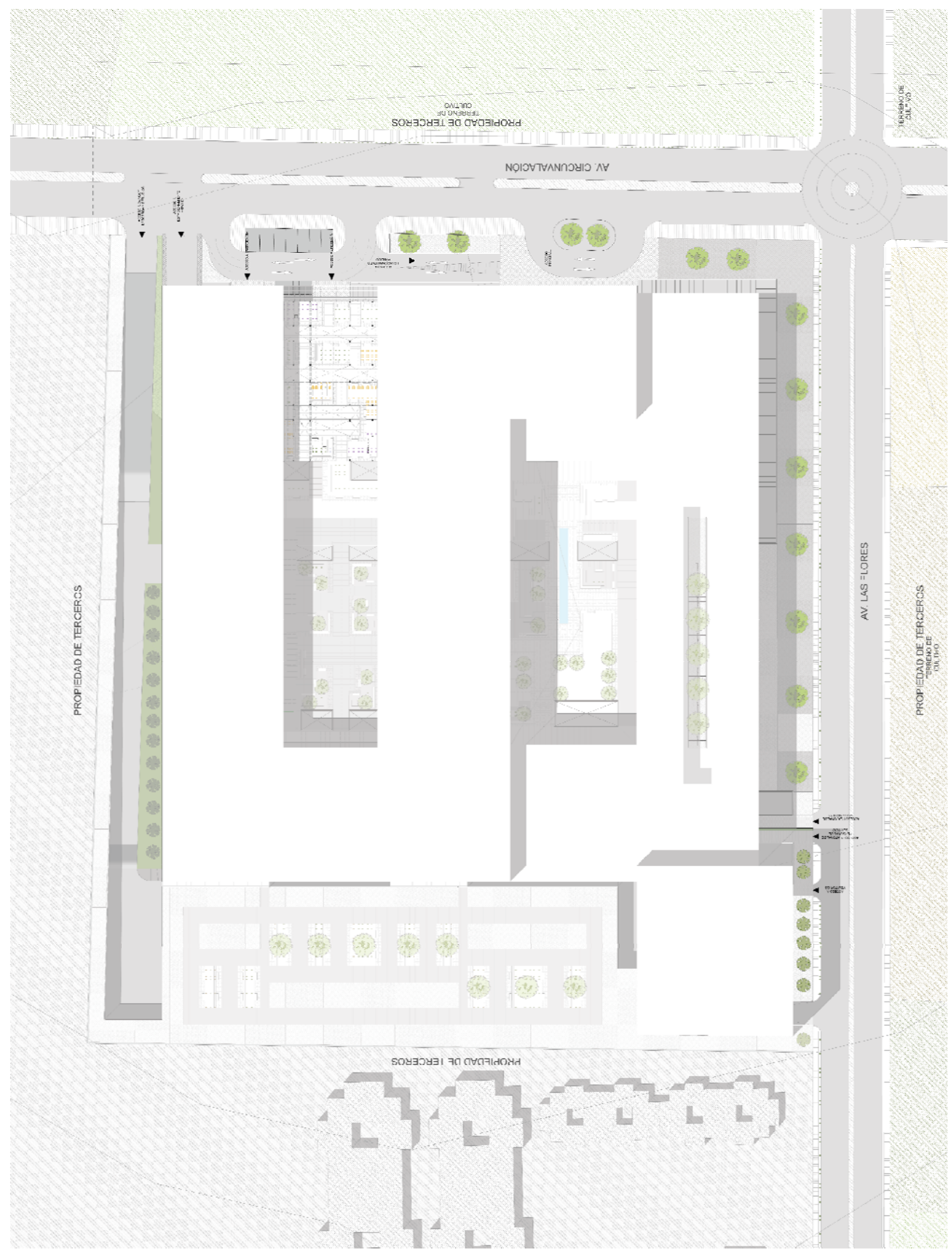




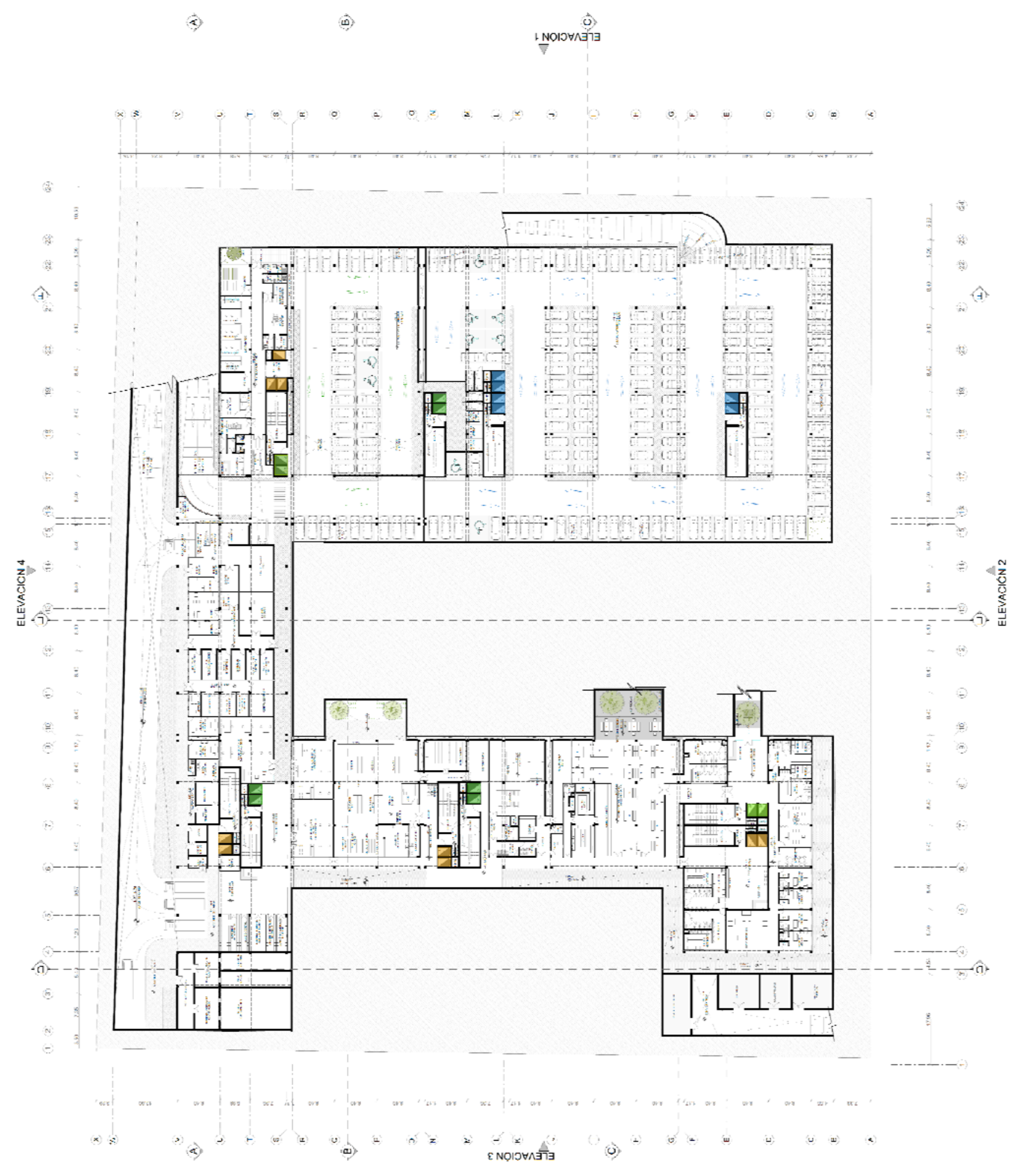




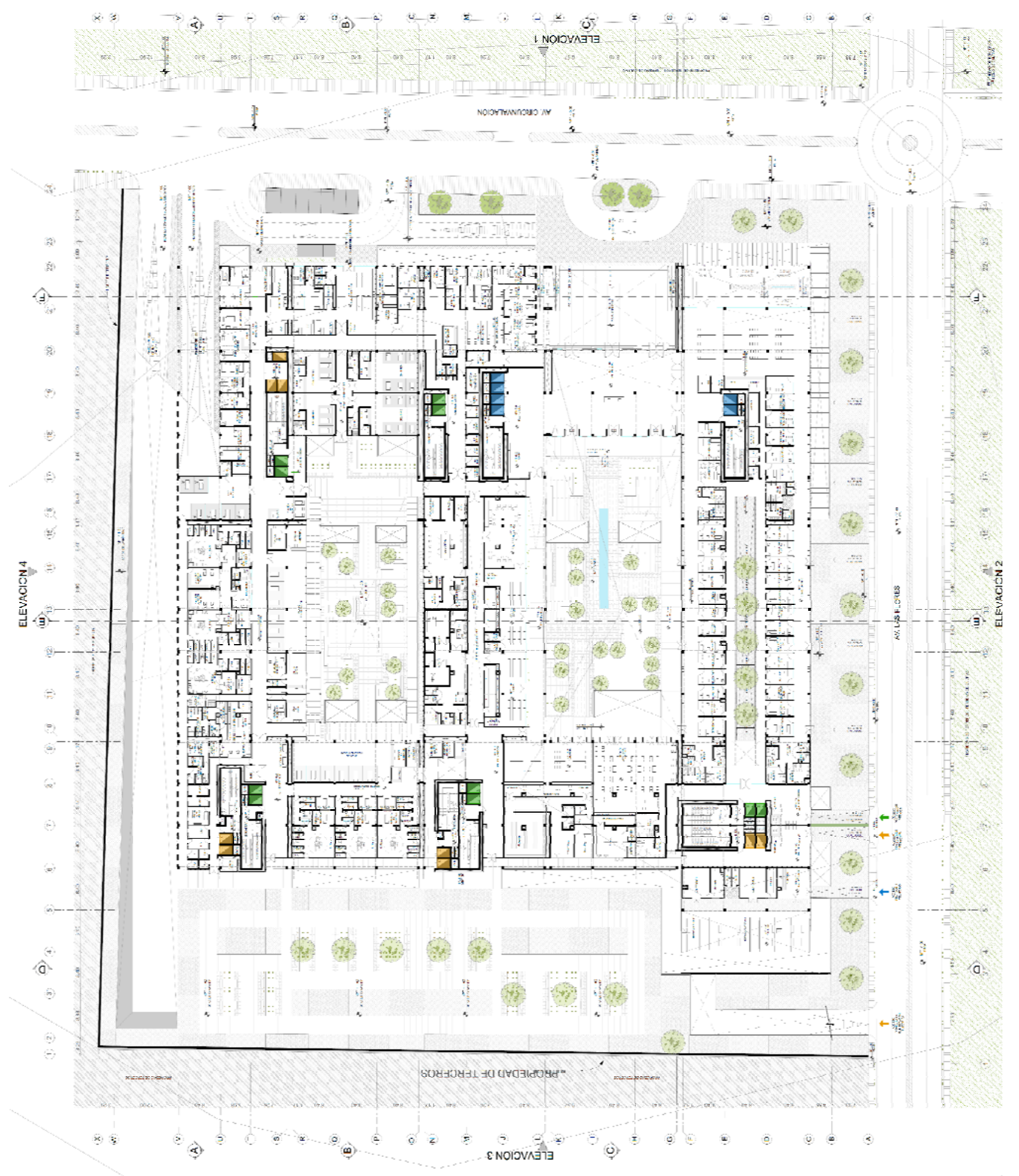




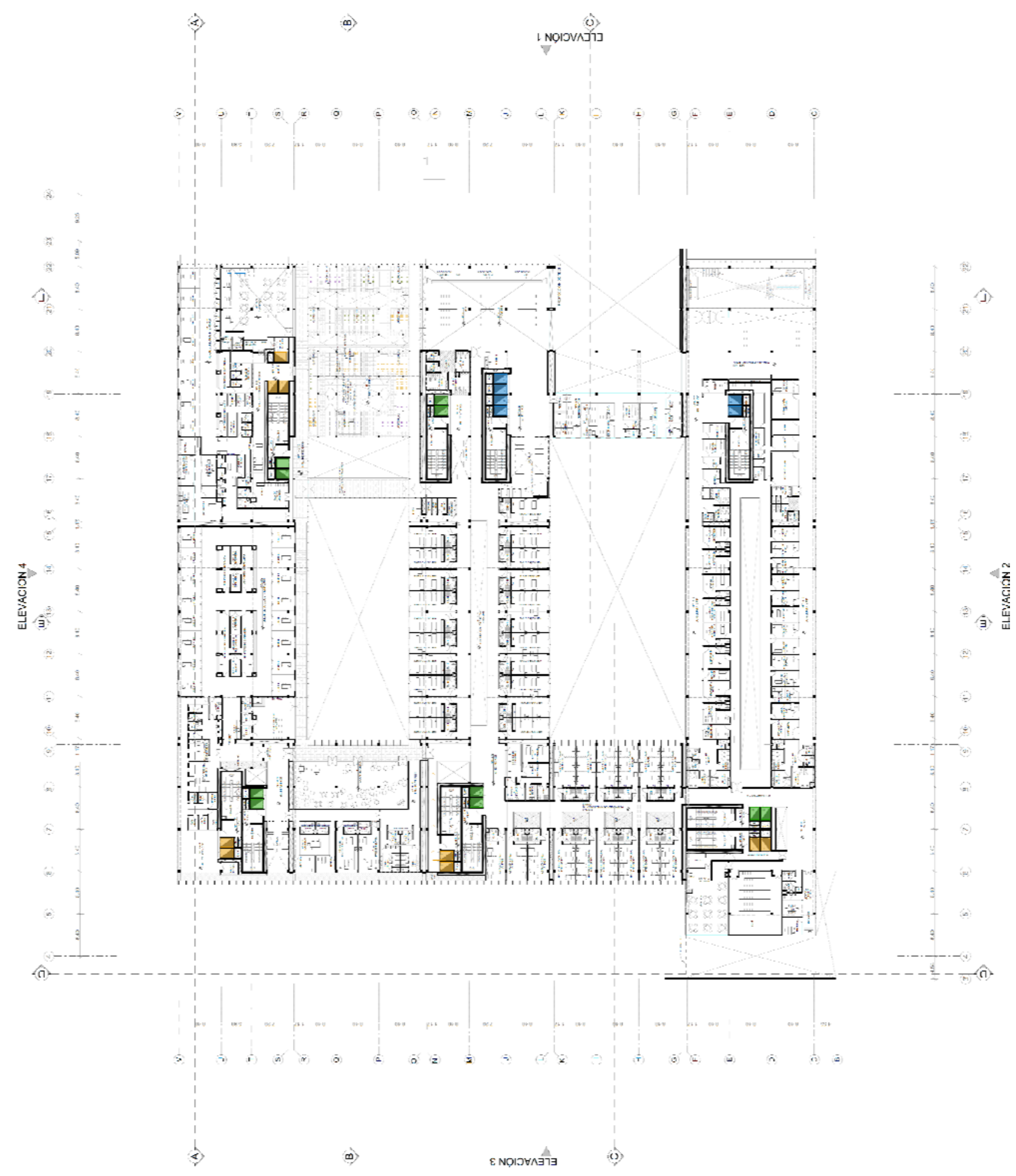




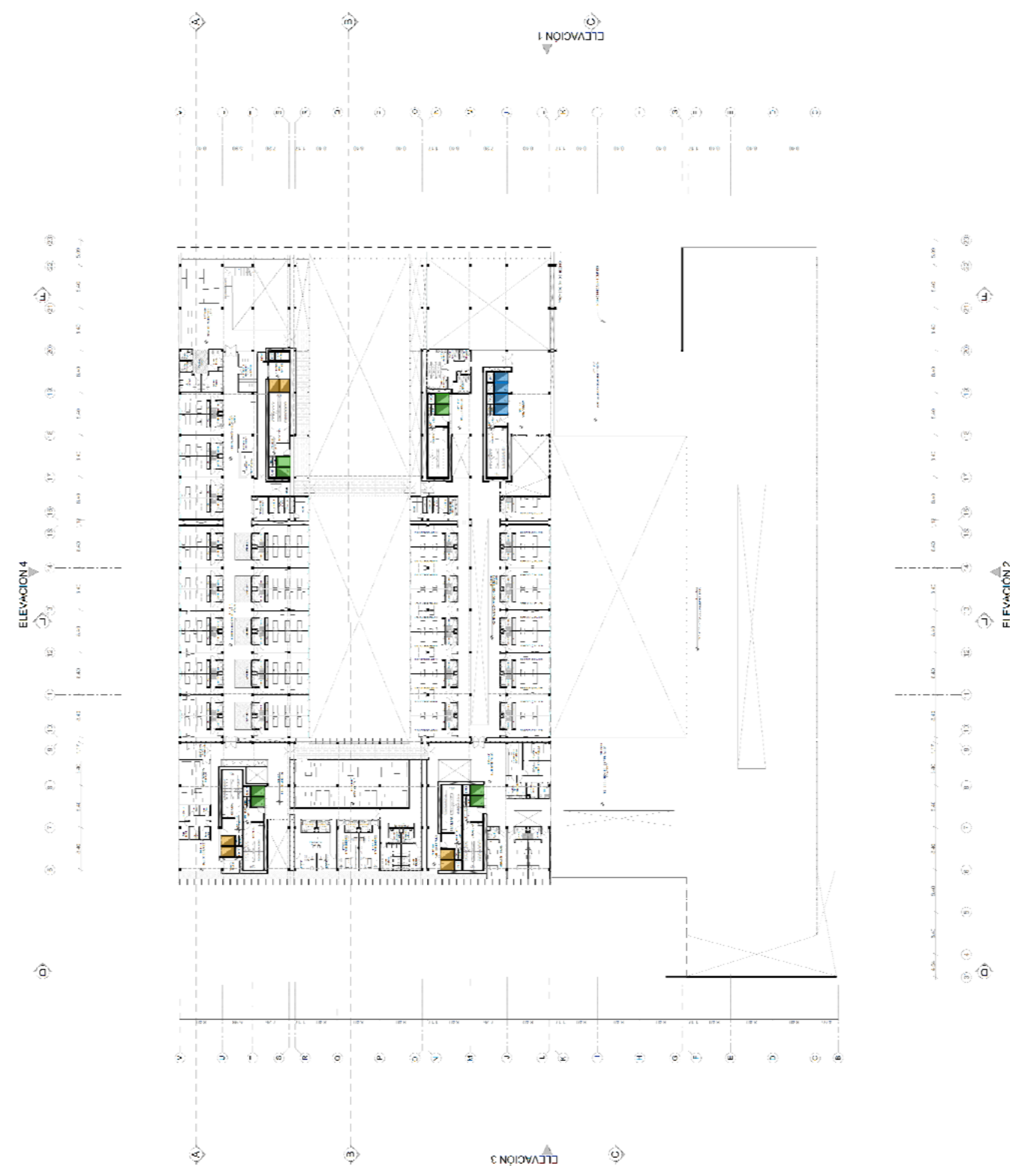



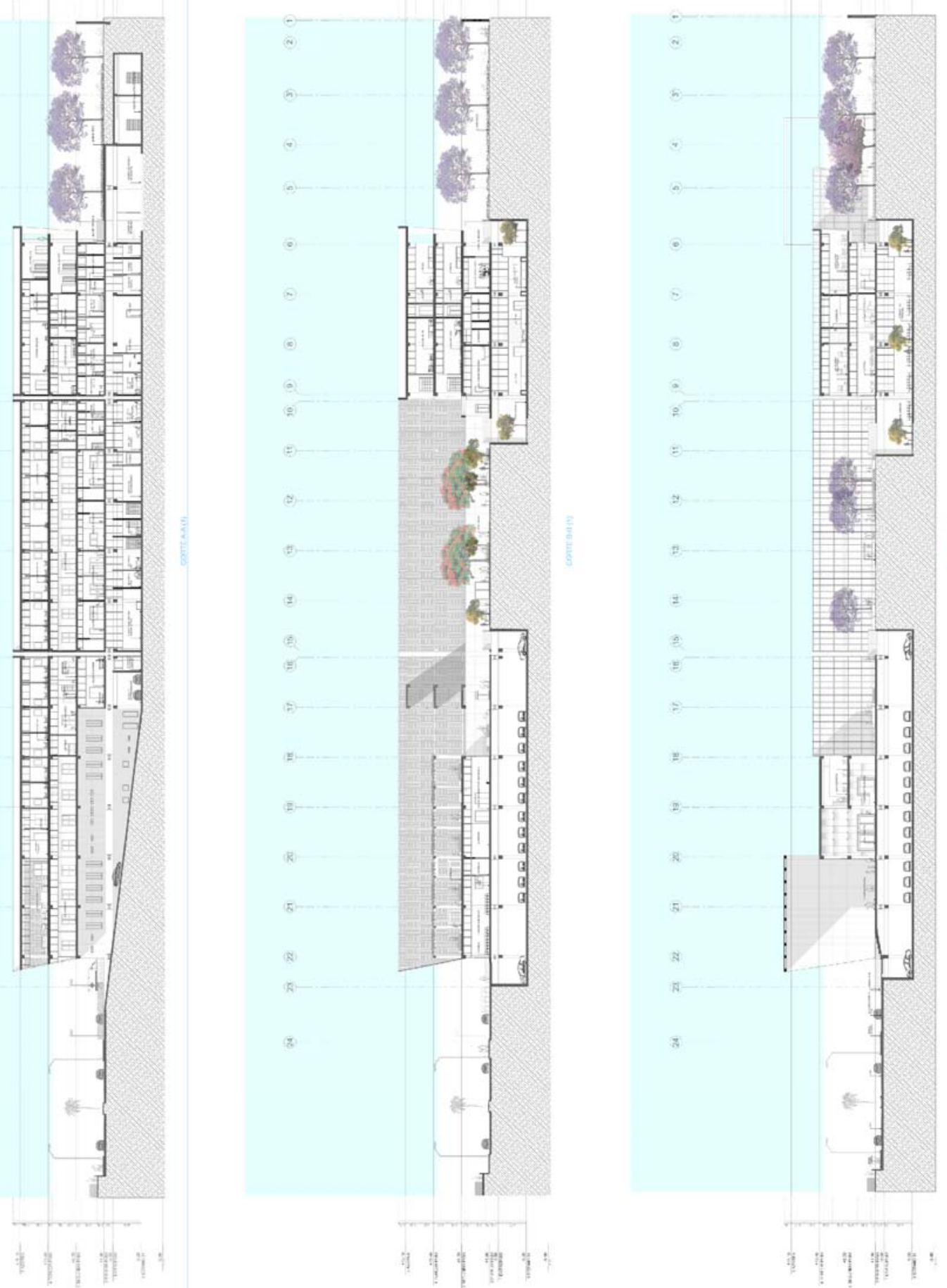
144

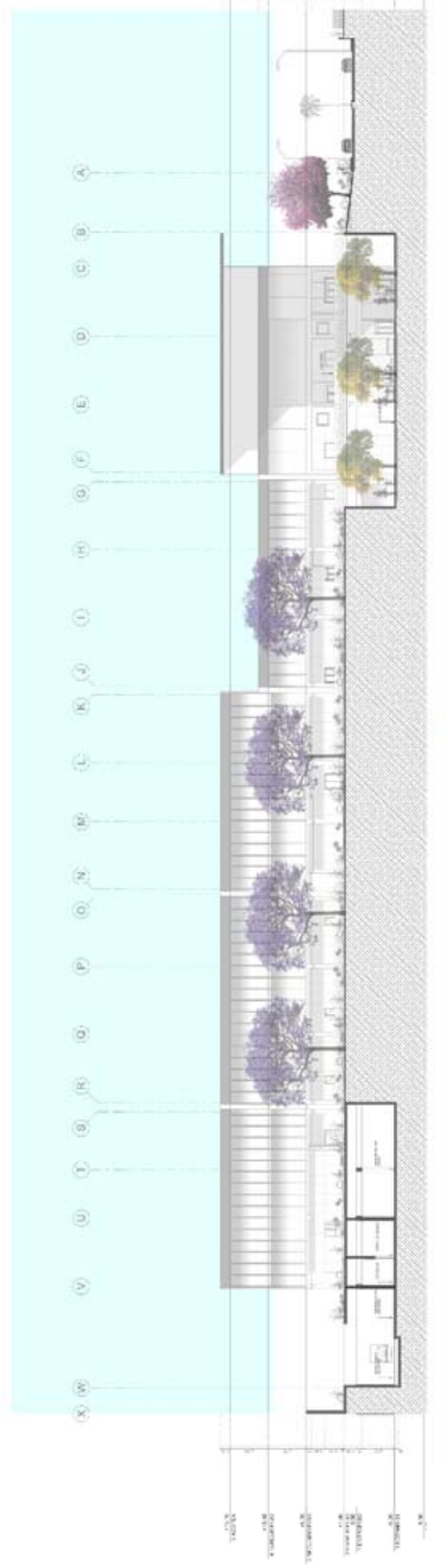

HI In

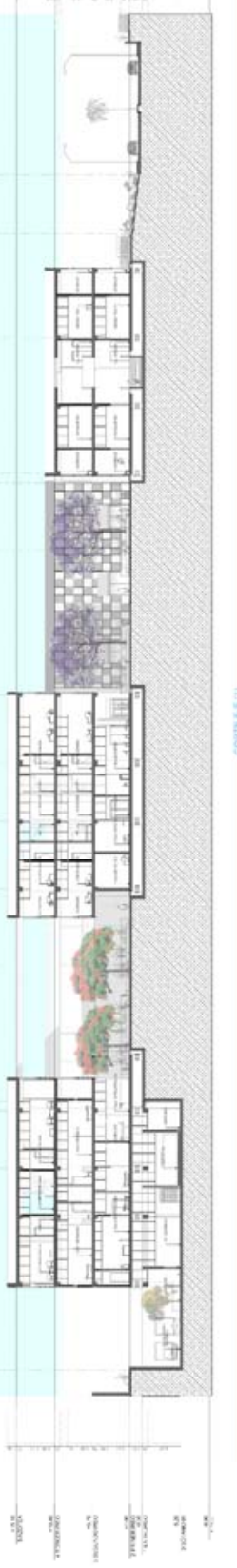

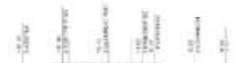

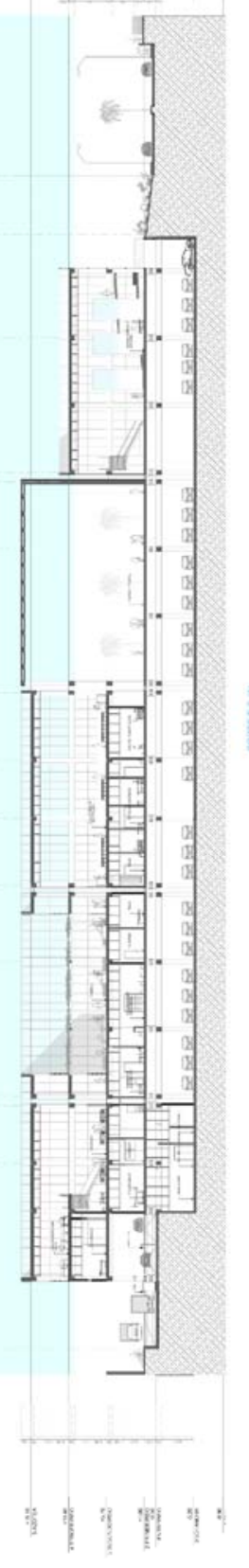


111

$$
144
$$
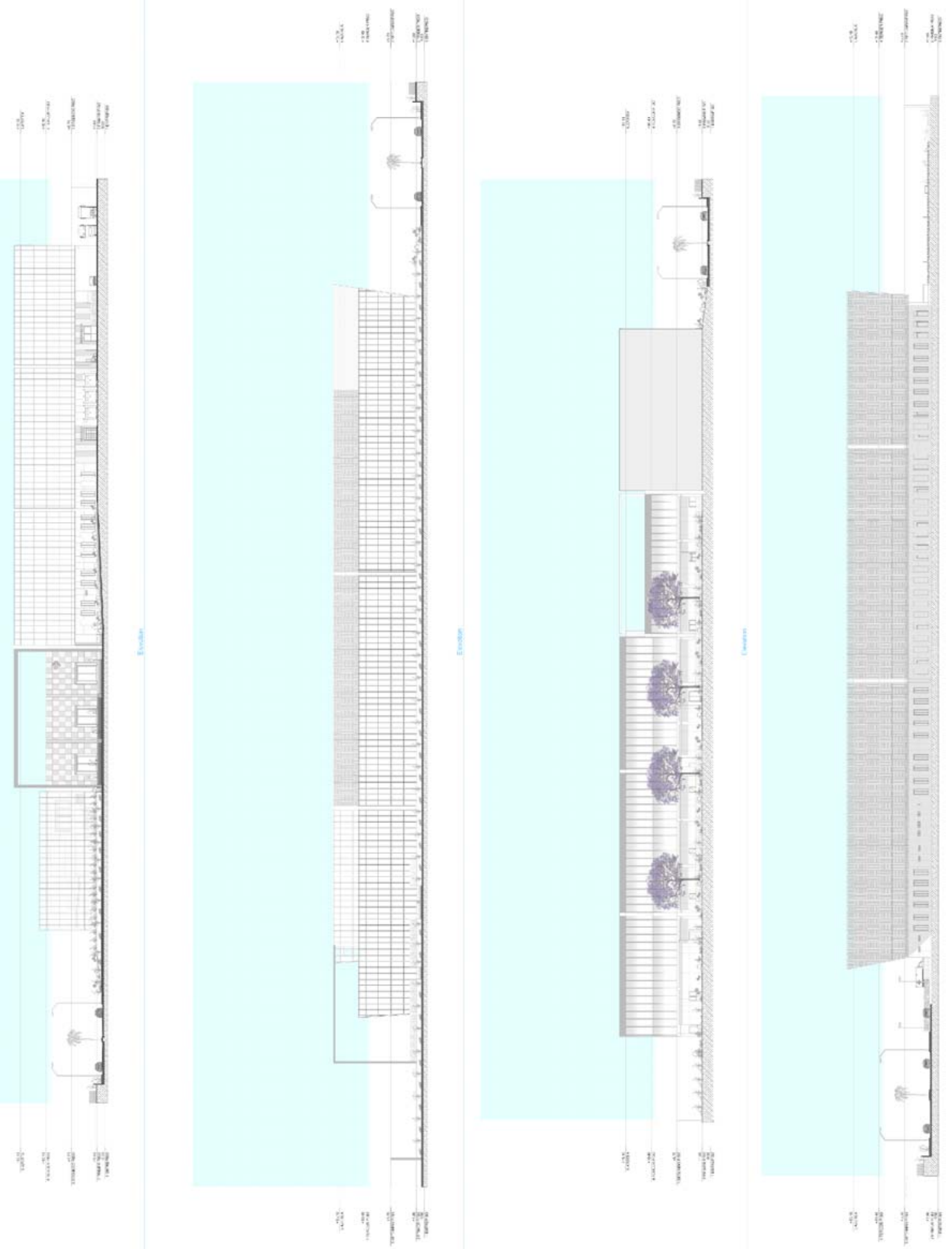

19 19

$$
\text { 4 } 17
$$



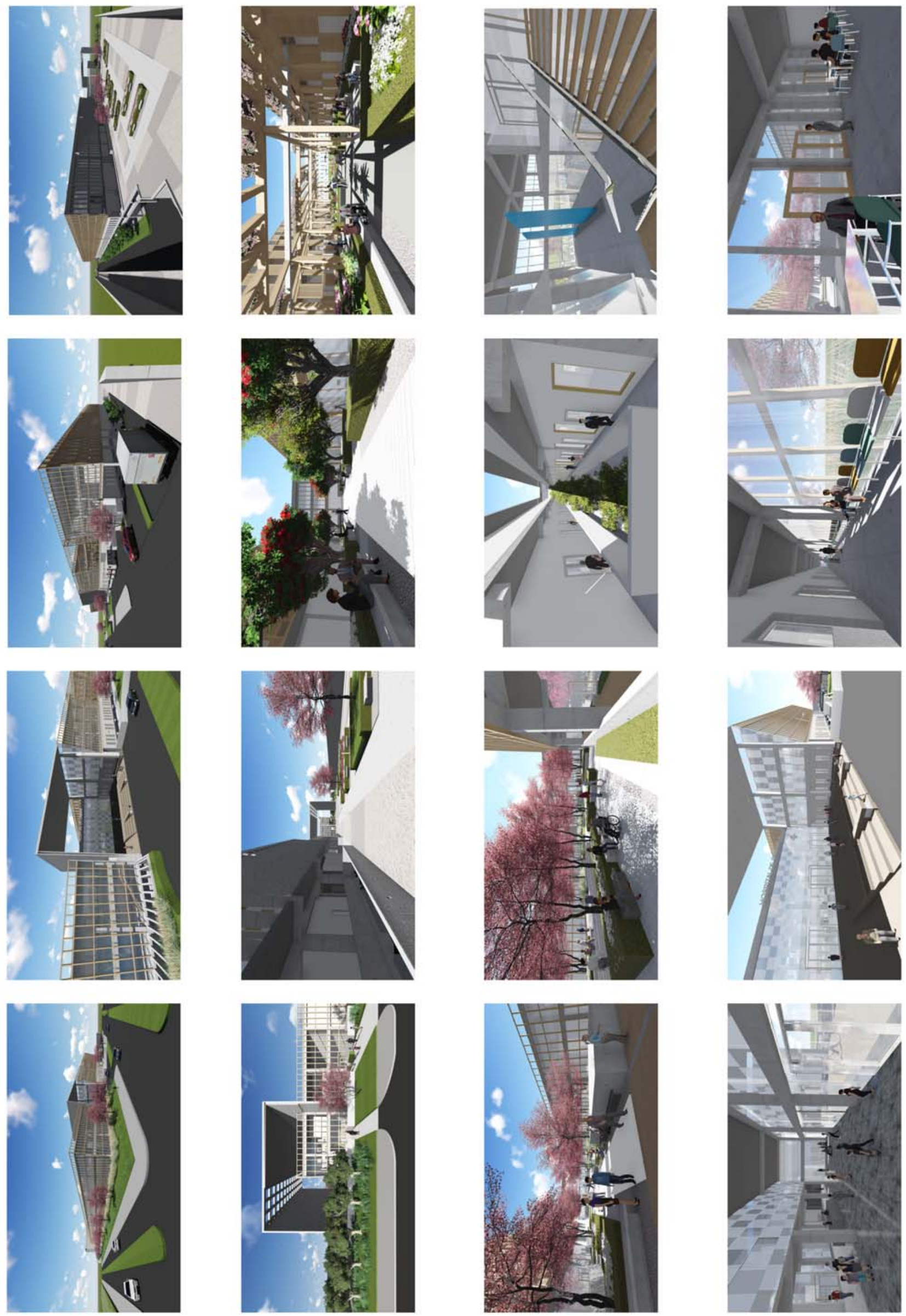
Bibliografía

(s.f.).

Bambarén Alatrista, C. y. (2008). Programa Médico Arquitectónico para el Diseño de Hospitales Seguros. Lima: SINCO.

Feldman, R. (1999). Psicología. México D.F.: Mc Graw Hill.

FERNANDEZ CASTILLO, A., \& LÓPEZ NARANJO, I. (02 de 09 de 2015). Transmisión de emociones, miedo y estrés infantil por hospitalización. Obtenido de http://www.redalyc.org/articulo.oa?id=33760308

HOSPITAL DE CHANCAY. (12 de 11 de 2015). http://www.hospitaldechancay.gob.pe/. Obtenido de http://www.hospitaldechancay.gob.pe/

HOSPITAL SAN JOSÉ DEL CALLAO. (12 de 11 de 2015). http://www.hsj.gob.pe. Obtenido de http://www.hsj.gob.pe/conociendonos.html\#or

http://.hksinc.com. (28 de 01 de 2016). Obtenido de http://.hksinc.com/places/dm-healtcare-astermedcity/

http://diariocorreo.pe. (03 de 11 de 2015). Obtenido de http://diariocorreo.pe/edicion/arequipa/hospital-de-camana-se-queda-sin-director-ymedicos-renuncian-615520/

http://elcomercio.pe. (17 de 10 de 2015). Obtenido de DIARIO EL COMERCIO: http://elcomercio.pe/peru/lima/agarrense-no-tenemos-frenos-advirtio-chofer-bus-antesaccidente-arequipa-noticia-1548512

http://issuu.com. (01 de 02 de 2016). Obtenido de http://issuu.com/ncmpublicidad/docs/heca http://issuu.com. (01 de 02 de 2016). Obtenido de http://issuu.com/tmkarchitekten/docs/projektbrosch_re_schwarzwald-baarhttp://larepublica.pe. (s.f.). Obtenido de DIARIO LA REPÚBLICA: http://larepublica.pe/14-012015/hospital-de-camana-agoniza-por-carencias-y-grave-hacinamiento

http://www.hospitalaria.cl. (01 de 02 de 2016). Obtenido de http://www.hospitalaria.cl/portada/proyectos/244-hospital-can-misses,-ibiza.html http://www.indexmundi.com. (15 de 11 de 2015). Obtenido de http://www.indexmundi.com/map/?v=2227\&l=es 
http://www.isg.org.ar. (15 de 11 de 2015). Obtenido de http://www.isg.org.ar/wpcontent/uploads/2011/12/Gestion-camas-hospitalarias-ISG.pdf

http://www.nightingaledeclaration.net/. (17 de 10 de 2015). Obtenido de http://www.nightingaledeclaration.net/

http://www.tablademareas.com/pe. (10 de 11 de 2015). Obtenido de http://www.tablademareas.com/pe/arequipa/camana

https://www.healthdesign.org. (17 de 10 de 2015). Obtenido de https://www.healthdesign.org/clinic-design

Huisman, Morales, Van Hoof y Kort. (17 de 10 de 2015). http://www.sciencedirect.com. Obtenido de http://www.sciencedirect.com/science/article/pii/s0360132312001758

LUNGER, C., SCHIRMER, C., GUTMANN, D., NICKEL, H., DIRK RAUH, W., STAUDT, J., . . . LABRYGA, F. (2012). HOSPITALS AND HEALTH CENTRES, CONSTRUCTION AND DESIGN AMNUAL. ALEMANIA: PHILIPP MEUSER Ed.

MATLIN , M., \& FOLEY, H. (1996). Sensación y Percepción. México D.F.: Prentice hall.

Ministerio de Salud. (08 de 11 de 2015). http://www.minsa.gob.pe. Obtenido de http://www.minsa.gob.pe/estadisticas/estadisticas/poblacion/poblacionmarcos.asp?04

OMS. (17 de 10 de 2015). http://www.who.int/en/. Obtenido de http://www.who.int/topics/hospitals/es/

Plazola Cisneros, A. (1995-2001). Enciclopedia de Arquitectura (Vol. 4). México: Plazola Editores S.A.

RAE. (17 de 10 de 2015). http://www.rae.es/x. Obtenido de $\mathrm{http} / /$ dle.rae.es/?w$=$ hospital $\& \mathrm{~m}=$ form $\& \mathrm{o}=\mathrm{h}$

Roses, R. E. (04 de 11 de 2015). http://www.arquitectura.com. Obtenido de http://www.arquitectura.com/arquitectura/monografias/arqhosp/roses.asp

Sacristán de Lama, M. (02 de 09 de 2015). Arquitectura Hospitalaria. Obtenido de http://www.sefh.es/bibliotecavirtual/auxiliares/area1.pdf

salud, O. p. (01 de 09 de 2015). Evolución y tendencias futuras del hospital . Obtenido de www.paho.org/hq/index.php?option=com_docman\&task...

Ulrich, R.S.; Simons, R.F.;Losito,B.D.; Fiorito,E.; Miles, M.A. Y Zelson, M. . (1991). Stress recovery during exposure to natural and urban enviroments, journal of enviromental psychology. Dinamarca: Elsevier Ltd. 
V.Blomkvist, C.A. Eriksen, T. Theorell, R.S. Ulrich, G. Rasmanis. (2005). Acoustics and psychosocial enviroment in coronary intensive care. Upsala - Suecia: BMJ Group.

Zborowsky, Terri. (17 de 10 de 2015). http://www.minnesotamedicine.com. Obtenido de HTTP://WWW.MINNESOTAMEDICINE.COM/PAST-ISSUES/PAST-ISSUES2008/MARCH-2008/CLINICAL-ZBOROWSKY 